\title{
NBSIR 81-2235
}

\section{Annual Report: Technical Contributions to the Development of Incipient Fault Detection/ Location Instrumentation}

W. E. Anderson and J. D. Ramboz

Electrosystems Division

U.S. Department of Commerce

Nationa! Bureau of Standards

Washington, DC 20234

January 1981

issued Niarch 1981 

1980 ANNUAL REPORT: TECHNICAL CONTRIBUTIONS TO THE DEVELOPMENT OF INCIPIENT FAULT DETECTION/ LOCATION INSTRUMENTATION

W. E. Anderson and J. D. Ramboz

Electrosystems Division

U.S. Department of Commerce National Bureau of Standards

Washington, DC 20234

January 1981

Issued March 1981

Sponsored by:

Office of Electric Energy Systems

Department of Energy

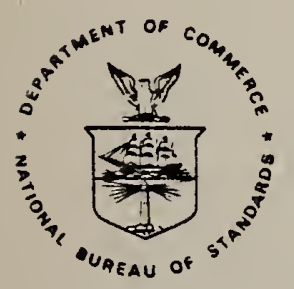

U.S. DEPARTMENT OF COMMERCE, Malcolm Baldrige, Secretary NATIONAL BUREAU OF STANDARDS, Ernest Ambler, Director 



\section{TABLE OF CONTENTS}

Summary . . . . . . . . . . . . . . . . . . . . . . . i Abstract...................... . . $i j i$

I. Introduction.................... . . 1

II. Technical progress... . . . . . . . . . . . . 3

II.1 Measurement System . . . . . . . . . . . 3

II.2 Experimental Results . . . . . . . . . . . . . . 7

II.3 Software Development... . . . . . . . . 39

III. Conclusion................. . . . 46

IV. References . . . . . . . . . . . . . . . 47

Appendix A..................... . . 49

Appendix B................... . . 59

Appendix C.................... 68

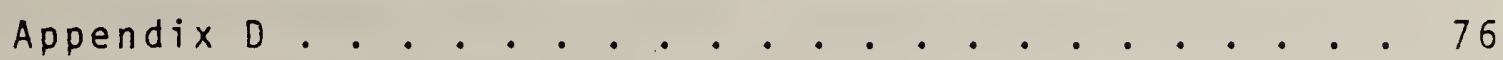

Appendix E. . . . . . . . . . . . . . . 84 


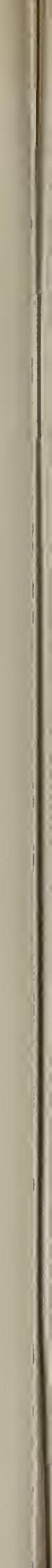


Summary

The objective of this NBS program is to identify and, insofar as practical, remove technical barriers to the development of instrumentation for use in detecting and locating incipient faults in underground power transmission systems.

Underground transmission of electrical energy has econcmic and environmental advantages compared to overhead transmission. A major concern, however, is reliability. Failures are more costly to locate and repair.

The Department of Energy has a program to develop instrumentation for the detection and location of incipient faults (the condition within a cable $\mathrm{n}$ which insulation degradation is occurring at a significantly higher than normal rate which, if not corrected, will cause the cable to fail prematurely). If this program is successful, cables about to fail can be repaired during scheduled outages minimizing perturbation to the transmission system.

Three contracts were awarded by DoE to develop such instrumentation. Besides monitoring the technical progress under these contracts, NBS has provided technical support where needed. Technical barriers include lack of knowledge of (1) the physical, chemical, and electromagnetic behavior of cable insu'ation immediately preceding breakdown; (2) the manner in which characteristic information concerning this behavior is propagated throuah the power system; and (3) appropriate methods of coupling detection systems to operating transmission cables.

A measurement system has been developed at NBS to enable studies of the rf properties of cables, and of the spectral content of discharges at incipient fault sites, and to perform time ard frequency domain reflectometry and other ralated measurements. 
Preliminary measurements were aimed at determining the sensitivity of cable sounding techniques (frequency or time domain) in detecting impedance changes in the cable. Changes of the order of a few parts per million (ppm) were detectable in some cases. A sharp needle was inserted into the cable dielectric and voltage applied. After several breakdowns the resulting breakdown channels were not detectable. The high frequency signals necessary to interact with small damage sites were apparently not reaching the breakdown region. Substantia effort was applied to improving the coupling between the TDR (Time Doma in Reflectometry) unit and the cable under test. While this improved matters, the intrinsic attenuation in the dielectric was shown to rule out sounding approaches in the cable selected for these measurements. Such techniques might still be useful in other types of cables and for fault location in general.

Future measurements will characterize the rf properties of underground transmission cables. Extensive software has been developed to permit these measurements in the time domain and analysis in the frequency domain. 


\section{Abstract}

Technical barriers exist in the development of instrumentation to detect and locate incipient faults in underground transmission cables. Knowledge is required of the physical, chemical, and electromagnetic properties of cables which precede breakdown, of the manner in which characteristic rf signals propagate in cables, and of appropriate methods of coupling detection systems to operating transmission cables. A measurement program has been initiated that will provide data on the rf properties of cables and on the characteristics of some forms of incipient faults. Preliminary measurements demonstrate the limitations of frequency- and time-domain-reflectometry techniques in the detection of incipient faults. Software is presented which permits the Fourier transform of step-like waveforms. 



\section{Introduction}

The objective of this NBS program is to identify and, insofar as practical, remove technical barriers to the development of instrumentation for use in detecting and locating incipient faults in underground power transmission systems.

In many situations underground power transmission cables have economic (and environmental) advantages over overhead transmission lines resulting in an increase in underground installations. Underground transmission does have a major disadvantage in the area of reliability. Faults can be extremely difficult to locate accurately and repair with the results that either long unscheduled outages or extensive redundant cables are necessary.

To alleviate this problem, the Department of Energy has a program area entitled "Research and Development of Fault Detection/Location Techniques and/or Equipment for Underground Power Transmission Cable Systems." The output of this program is expected to be instrumentation and techniques for the detection and location of incipient faults in different types of underground cables; viz. pipe-type (high or medium pressure oil or gas impregnated), extruded solid dielectric, compressed gas, and possibly cryogenic. An "incipient fault" is defined to be the condition with in a cable system in which local insulation degradation is occurring at a significantly higher than normal rate which, if not corrected, will cause the cable system to fail prematurely. A reliable incipient fault detector/locator would allow the defective area to be repaired during a scheduled outage, minimizing the perturbation to the transmission system. 
The Department of Energy in the summer of 1978 awarded contracts to Purdue University, SRI International, and Westinghouse Corporation to develop (or determine the feasibility of) instrumentation for the detection/ location of incipient faults. The School of Electrical Engineering, Purdue University proposed to develop instrumentation that would correlate, using variable time delay, the noise signal received at both ends of the cable emanating from partial discharges at incipient fault sites. The Remote Measurements Laboratory of SRI International proposed instrumentation based on swept-frequency reflectometry. A two-frequency mixing (resulting from the nonlinear incipient fault region) approach was proposed by the Electromagnetics Sciences Laboratory of SRI International. The Chemical Sciences Division of the Westinchouse R\&D Center proposed to do a feasibility study on the use of acoustic waveguides for sensing incipient faults. As their work evolved this also included acousto-optic techniques using fiber optics.

The NBS contribution to this program, besides monitoring the technical progress of the three contractors for DoE, was to provide technical support to the research, development, and testing of incipient fault detection/location instrumentation. In general, the NBS research program was directed towards providing knowledge of the physical, chemical, and electromagnetic behavior which immediately precede breakdown of cables, of the manner in which characteristic information concerning these events is propagated through the power system, and of appropriate methods of coupling detection systems to operating transmission cables. 


\section{Technical Progress}

\section{II.1 Measurement System}

During this year a measurement system has been developed at NBS to enable studies of the $r f$ properties of cables and of the spectral content of discharges at incipient fault sites, to perform time- and frequency-doma in reflectometry and to conduct other related measurements. Time-domainreflectometry (TDR) measurements were performed on cables with induced defects to determine the sensitivity of TDR techniques for incipient fault detection. Software was developed that will permit the determination of the velocity and attenuation of $r f$ signals in cables as a function of frequency (or equivalently the transfer function) in the time domain.

Figure 1 shows a block diagram of the measurement system for generating signals, capturing sigrals, and providing signal analysis capabilities in both the time and frequency domains. 1 The heart of the system is the Tektronix 4051 intelligent terminal with its peripherals. The intelligent terminal is connected to both the RS-232 and general purpose interface bus (GPIB). This provided direct communication between other system components shown. Also through the modem the terminal can communicate with other intelligent sources such as the NBS Univac 1108 computer or with a minicomputer at relatively high data transfer rates. The terminal outputs can go to the Univac ${ }^{1} 1108$, via the RS-232 bus, the printer via the RS-232 bus, the plotter via the GPIB bus, or to a hard copy unit. Directly attached to this system is the floppy disc file manager system capable of storing approximately 1900 kilobytes of information for direct access. Both data files and programs can be accessed rapidly. The ROM (read-only-memory) 


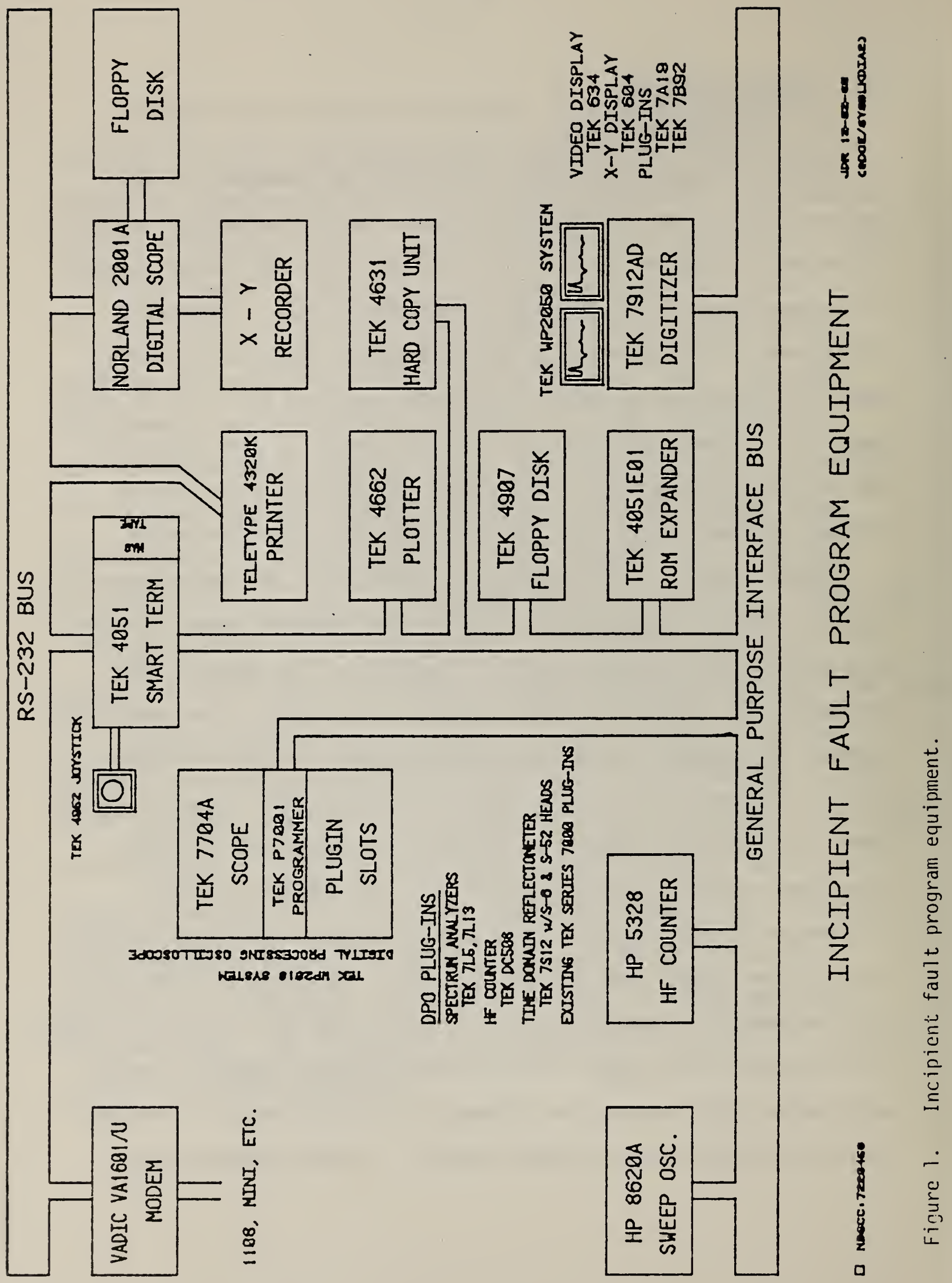


expander provides eight slots for specially designed and programmed "ROM packs" for editing, matrix functions, binary conversions and loading, special signal processing routines, etc. This adds a quick utility to the system without using memory overhead or requiring additional programing time. Having 32 kilobytes of memory, the 4051 system possesses substantial "stand alone" analysis and processing power. Large jobs are more efficiently managed by batch processing by the Univac 1108 or other large system. A Tektronix ${ }^{1} 4054$ intelligent terminal is also available which is an order of magnitude faster than the 4051 .

The Norland ${ }^{1} 2001$ A digital oscilloscope is a digitizing oscilloscope with sample times as short as $2 \mu \mathrm{s} /$ point for a 10-bit word to $1 \mu \mathrm{s} /$ point for an 8-bit word. It can digitize simultaneously up to 4 input channels each of 1024 points, 2 simultaneous channels of 2048 points each, or 1 large continuous array of 4096 points. It has signal processing intelligence that can do, among other things, FFT (fast Fourier transform) and correlations with single keystroke commands. Programs and data can be stored and retrieved from its floppy disc system. It currently communicates with the remaining system over the RS-232 bus but can be adapted to use the GPIB structure through an interface.

The Tektronix ${ }^{1} 7704 \mathrm{~A}_{\text {oscilloscope coupled with the Tektronix }}{ }^{1}$ P7001 Programmer forms a versatile digital processing oscilloscope (DPO) which can accept spectrum analyzer plug-ins, time-doma in reflectometer plug-ins as well as numerous Tektronix ${ }^{1}$ series 7000 plug-ins. Using on-hand spectrum analyzers, capability exists for spectral analysis over a frequency range 
from $20 \mathrm{~Hz}$ to $1.8 \mathrm{GHz}$. Because the DPO is interfaced onto the FPIB structure, the digitized output from any of the plug-ins can be "captured" and processed by the intelligent terminal. The digitized waveform consist of 512 10-bit words. A high-speed-average option is included which permits up to 4096 different waveform samples to be averaged before transmission to the intelligent terminal. In principle these 4096 waveforms could be transmitted sequentially to the terminal which could do the averaging, but because the transfer time is relatively long, the latter method is not normally practical.

The Tektronix ${ }^{\top} 7912 A D$ is a very high speed state-of-the-art digitizer capable of digitizina rates up to $1 \mathrm{GHz}$. Fast transients can be sampled every nanosecond for an array of 512 points and with a resolution of 9-bits. Using a special direct access plug-in, rise-times as fast as $350 \mathrm{ps}$ can he digitized. Data can be output over the GPIB to the intelligent terminal.

The time-domain reflectometry equipment consists of the Tektronix ${ }^{1} 7 S 12$ plug-in and associated sampling, pulse generator, and trigger recognizer heads. Used for TDR, the $7 S 12$ can measure reflection coefficients, $\rho$, from $2 \times 10^{-3} /$ division to $500 \times 10^{-3} /$ division. (When $\rho= \pm 1$, there is total reflection, when $\rho=0$, there is no reflection). Used as a general-purpose sampler, repetitive waveforms up to $18 \mathrm{GHz}$ can be displayed. This TDR/sampler can be used as a plug-in in the DPO permitting digitizing and transmitting of waveforms to the intelligent terminal.

Three spectrum analyzers are available. Two of them (Tektronix $7 L 5$ and $7 L 13)$ can be used in the DPO. The $7 L 5$ has a frequency range of $20 \mathrm{~Hz}$ to 
$5 \mathrm{MHz}$ and the $7 \mathrm{LI} 3$ has a $1 \mathrm{kHz}$ to $1.8 \mathrm{GHz}$ range. A third spectrum analyzer (Tektronix ${ }^{1} 5 L 4 N$ ) is available for low frequency measurements $(20 \mathrm{~Hz}$ to $100 \mathrm{kHz}$ ).

Besides the above-described instrumentation the measurement system consists of various pulse generators, counters, and sweep-frequency oscillators most of which can communicate with the intelligent terminal over the GPIB.

\section{II.2 Experimental Results}

Time-domain-reflectometry measurements were made on cable samples containing known defects in order to determine the limitations of TDR methods for incipient fault detection. The TDR unit was used as a plug-in in the digital processing oscilloscope permitting communication with the intelligent termina 1. Software (see Appendix A) was written to process this data. The software permits automatic acquisition of waveforms, high-speed averaging, proper scaling, plotting, and filtering. Portions of the waveforms can even be enlarged for more detailed plots.

A series of TDR measurements was performed on a short length of distribution cable. The cable studied was a $6.2 \mathrm{~m}$ long, $2 \mathrm{~cm}$ diameter, 15-kV, extrudedpolyethelene distribution cable with semiconducting screen layers. The cable had three skid wires helically wound around the outer surface of the dielectric. Preliminary measurements indicated that the cable could not be treated as a coaxial cable with the skid wires serving as the return conductor. The calculated characteristic impedance of a coaxial cable, of the same dimensions is about 40 ohms. The measured impedance varied between 50 and 75 ohms. The reduced capacitance. between the skid wires (as opposed to a solid coaxial sheath) and the center conductor results in a higher characteristic impedance, $Z_{0}$, since

$$
z_{0}=\sqrt{L / C}
$$


Another indication of the non-coaxial cable behavior was the unstable TDR results obtained on measurements of the coiled cable. The skid wires did not provide adequate shielding between adjacent loops of the cable. In order to overcome these problems an improved outer conductor was needed and a copper braid sheath was used. With the improved coaxial-like behavior, the characteristic impedance was measured to be about 37 ohms -near the predicted value of 40 ohms.

In a TDR measurement a pulse with a fast risetime is sent down a cable and is reflected back by variations in the cable impedance. The output of a TDR measurement is the reflection coefficient, $\rho$. A positive reflection referenced from the peak of the incident pulse indicates the impedance is greater than the TDR output impedance. The reflection coefficient varies from -1 to 1 . The reflection coefficient is related to the load impedance $\left(R_{L}\right)$ by the equation

$$
R_{L}=Z_{0}(1+0) /(1-0)
$$

This relation with $z_{0}$ equal to 50 ohms is used in the following discussion in order to permit the approximate calculation of the impedance along the cable length from the TDR response.

Figure 2 shows the measured impedance (average over 50 runs) along the entire cable length. The response over the first 17 ns shows an impedance of 50 ohms. This represents the impedance of the connector and $R G-58 / U$ cable from the TDR output to the distribution cable input. The response from about 17 ns to 80 ns shows the impedance of the distribution cable. Since the cable 


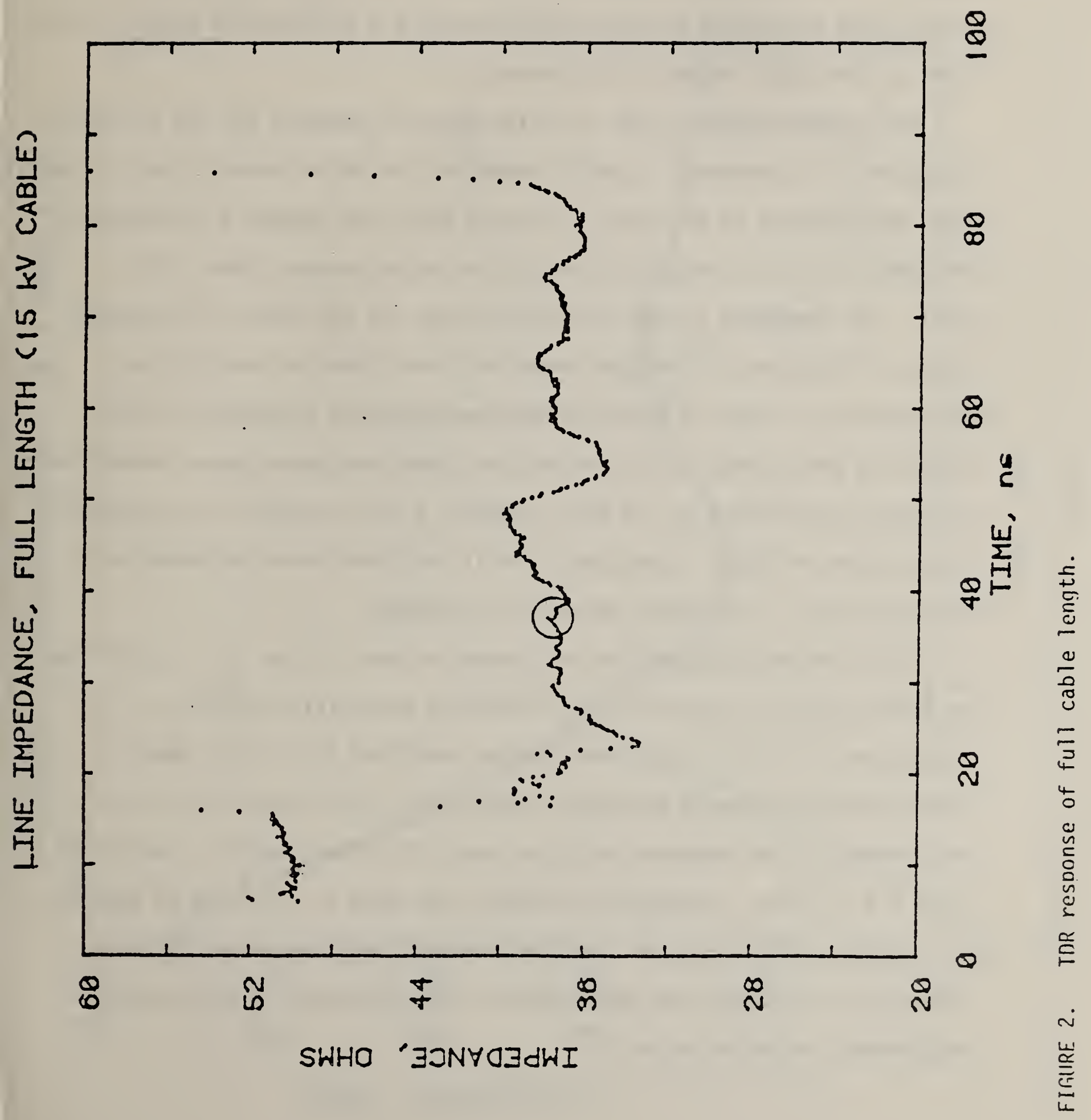


was unterminated, the impedance rapidly increases at the cable end. The times shown are times for the signal to reach a point and return. Therefore, the time for the TDR signal to propagate the length of the cable is actually about 31.5 ns. Assuming a dielectric constant of 2.26 , the length of the cable can be calculated to be $\left(3 \times 10^{8} \mathrm{~m} / \mathrm{s}\right)\left(31.5 \times 10^{-9} \mathrm{~s}\right) / \sqrt{2.26}$ or 6.3 meters, close to the actual length of 6.2 meters.

The circled region of Fig. 2 is the point of interest for the following discussion. It represents a small segment of the cable located about 1.9 meters from the input end of the cable. Figure 3 shows the impedance (average over 200 runs) of a $0.5 \mathrm{~m}$ length $(2.5 \mathrm{~ns})$ of the cable centered about this point. The impedance is seen to vary by about 0.1 ohm along this distance. A mass of 120 grams ( 1.2 newton force) had been placed on the cable at this location. Figure 4 shows the measured impedance (average over 200 runs) with and without this force applied (lower and upper trace, respectively). Apparently application of the force produces a net decrease in the separation of the outer and inner conductors, a localized capacitance increase, and a consequent (Eq. 1) localized decrease in impedance.

The difference between the two traces is shown in Fig. 5. The difference has been scaled by a factor of 10 to show the sensitivity available. The circled region in Fig. 5 has been further amplified (Fig. 6) in order to demonstrate the ultimate meaningful sensitivity of this particular set of measurements. The impedance variation over this $10 \mathrm{~cm}$ length is seen to be about $3 \times 10^{-3} \mathrm{ohm}$. Impedance variations less than $2 \times 10^{-4} \mathrm{ohm}(5 \mathrm{ppm})$ can be resolved. With increased sampling frequency and improved experimental techniques an ultimate TDR resolution of $1 \mathrm{ppm}$ or better in such impedance measurements may be expected. 


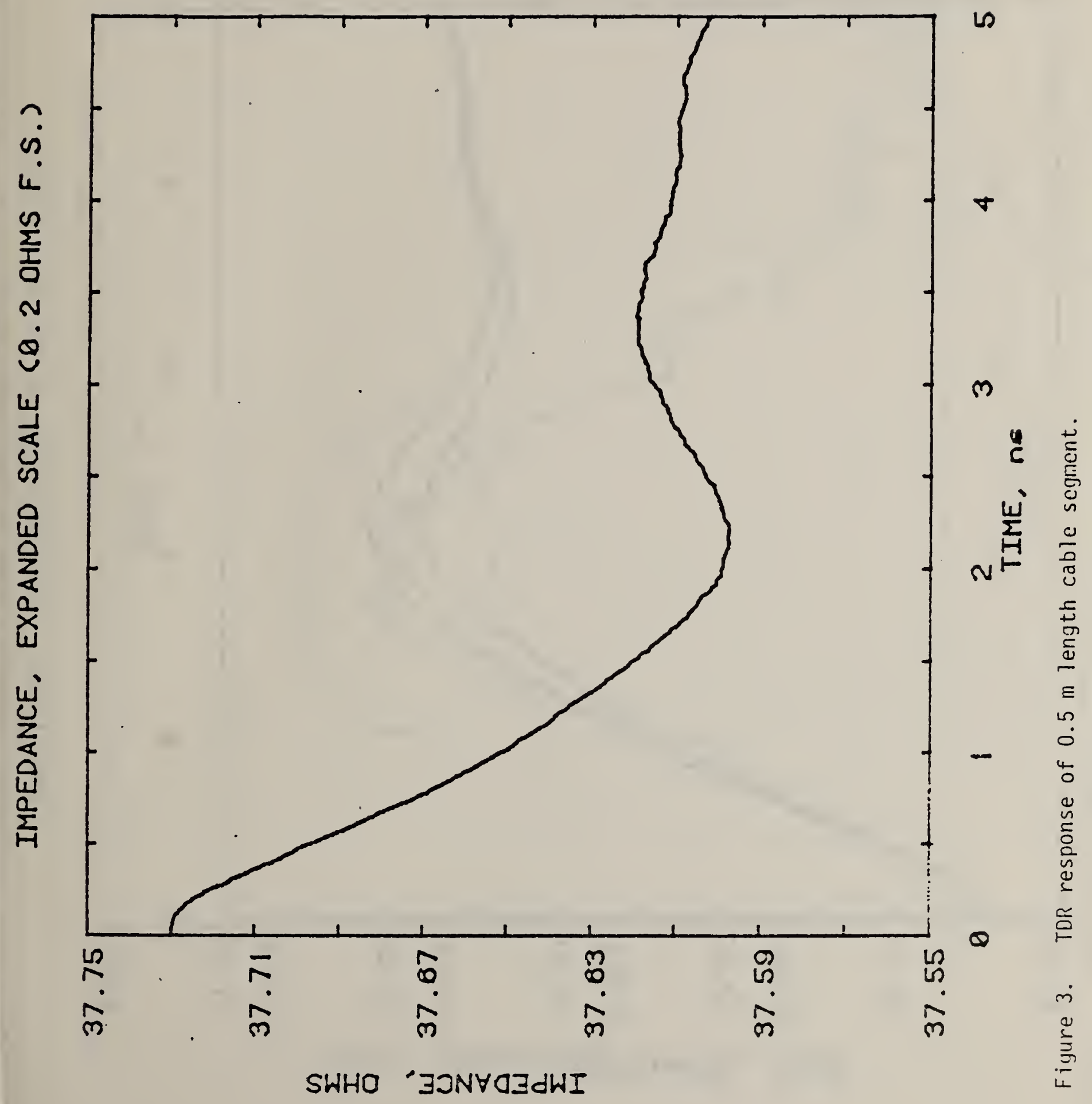




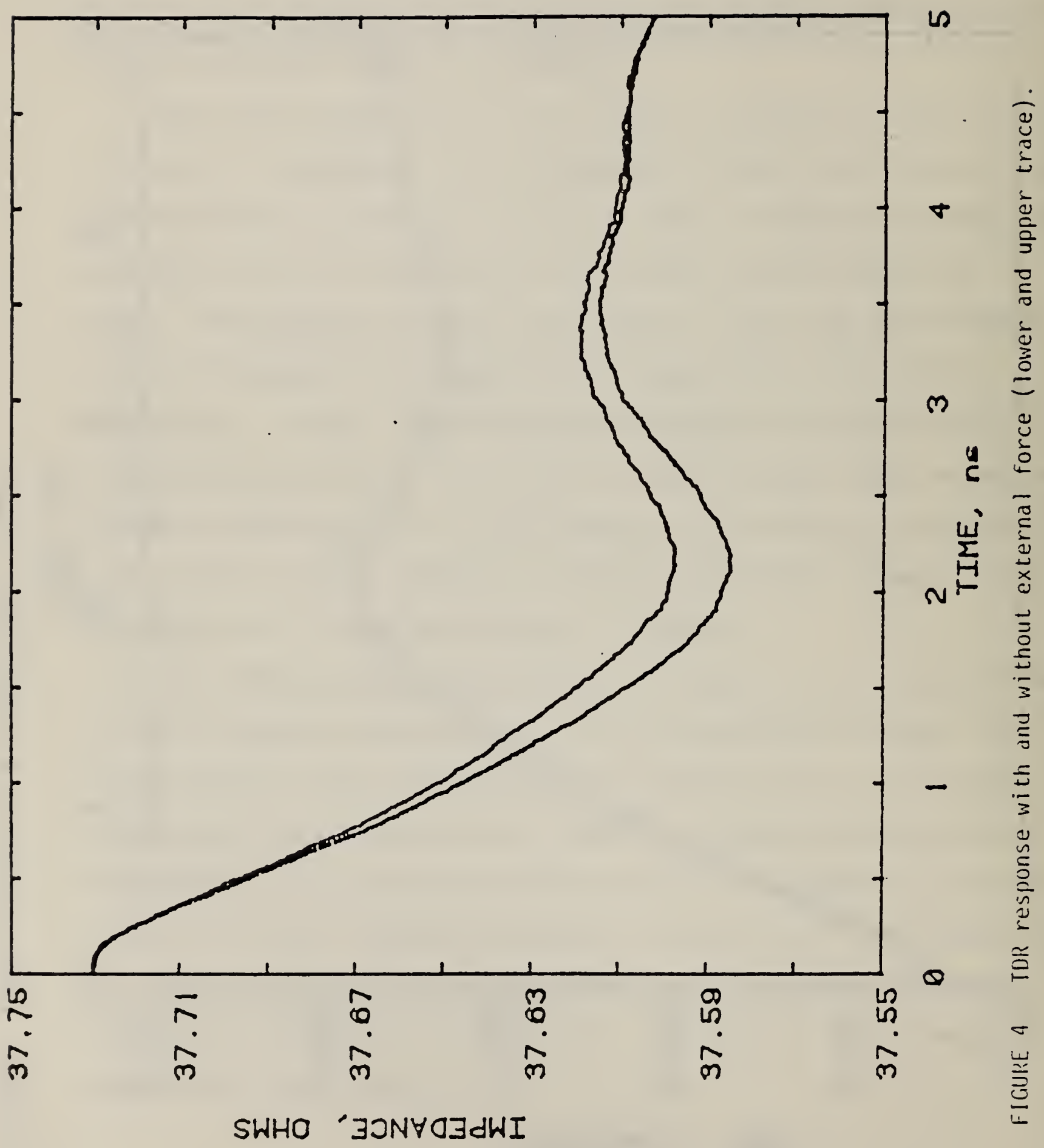




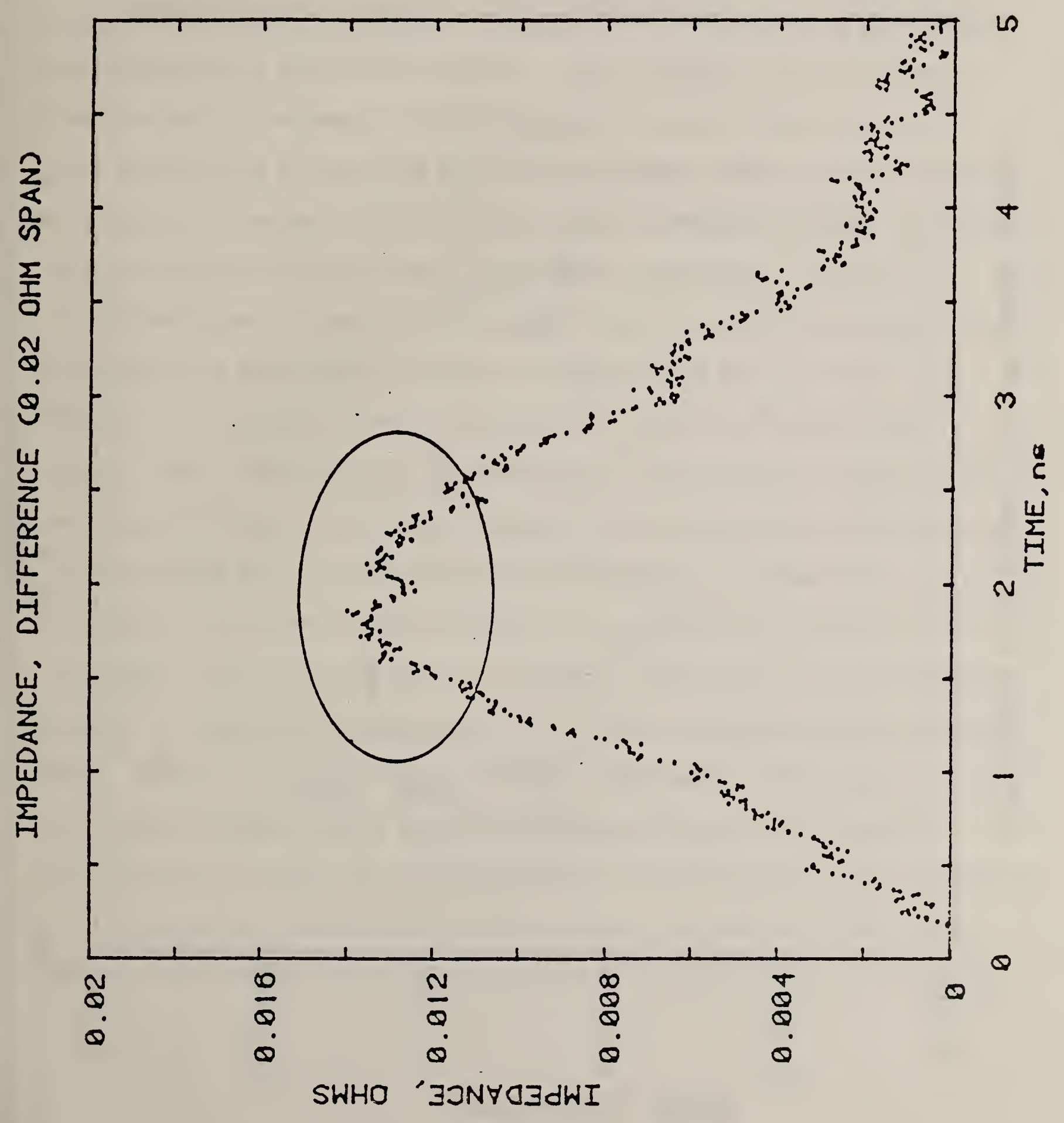




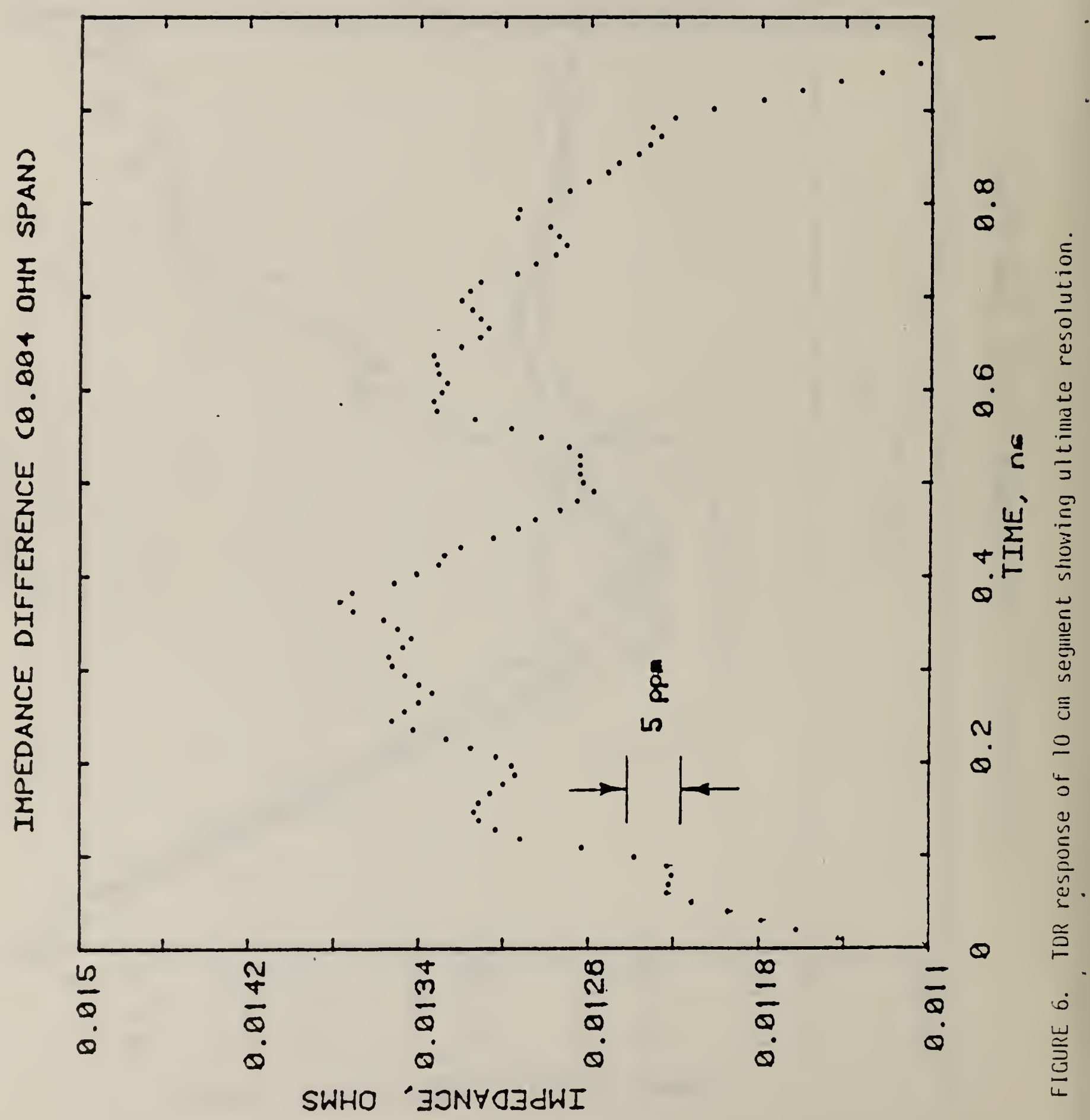


This series of measurements suggests that if the dielectric constant changes by a part per million over a few millimeters length, the TDR technique should resolve it.

The cable dielectric was purposely altered in order to see if such changes were indeed detectable. A hole was drilled through the cable sheath and dielectric to the center conductor. The resulting hole was $2.3 \mathrm{~mm}$ in diameter and $4.6 \mathrm{~mm}$ deep. The TDR response of the cable with the empty hole was obtained and then the hole was filled with either isopropyl alcohol (2-propanol) or water. Figures 7 and 8 show the impedance change resulting from filling the hole with water and alcohol respectively. In Fig. 9 the TDR response of a portion of the cable with the empty hole (upper-trace), alcohol-filled hole (middle-trace), and water-filled hole is shown. The length of cable shown in Figs. $7-9$ is $\left(5 \times 10^{-9} \mathrm{~s}\right)\left(3 \times 10^{8} \mathrm{~m} / \mathrm{s}\right) / \sqrt{2.26}$ or about 1 meter. The volume of the dielectric in this cable is about $240 \mathrm{~cm}^{3}$ per meter of length. The volume of the hole drilled through the dielectric is about $0.020 \mathrm{~cm}^{3}$. The resulting defect represents a change in the dielectric volume in a length of 1 meter of $80 \mathrm{ppm}$. The dielectric properties of the hole are a function of the fluid it contains. Water has a static dielectric constant of about 80 and 2-propanol, 18. This is consistent with the trend shown in Fig. 9. One difficulty with this experiment is that the purity of the liquids is questionable within this hole drilled in the dielectric. Particularly of concern is the resistivity of the fluid under these conditions.

This series of measurements seems to impiy that TDR techniques would be effective in detecting at least one type of incipient fault. In extruded 


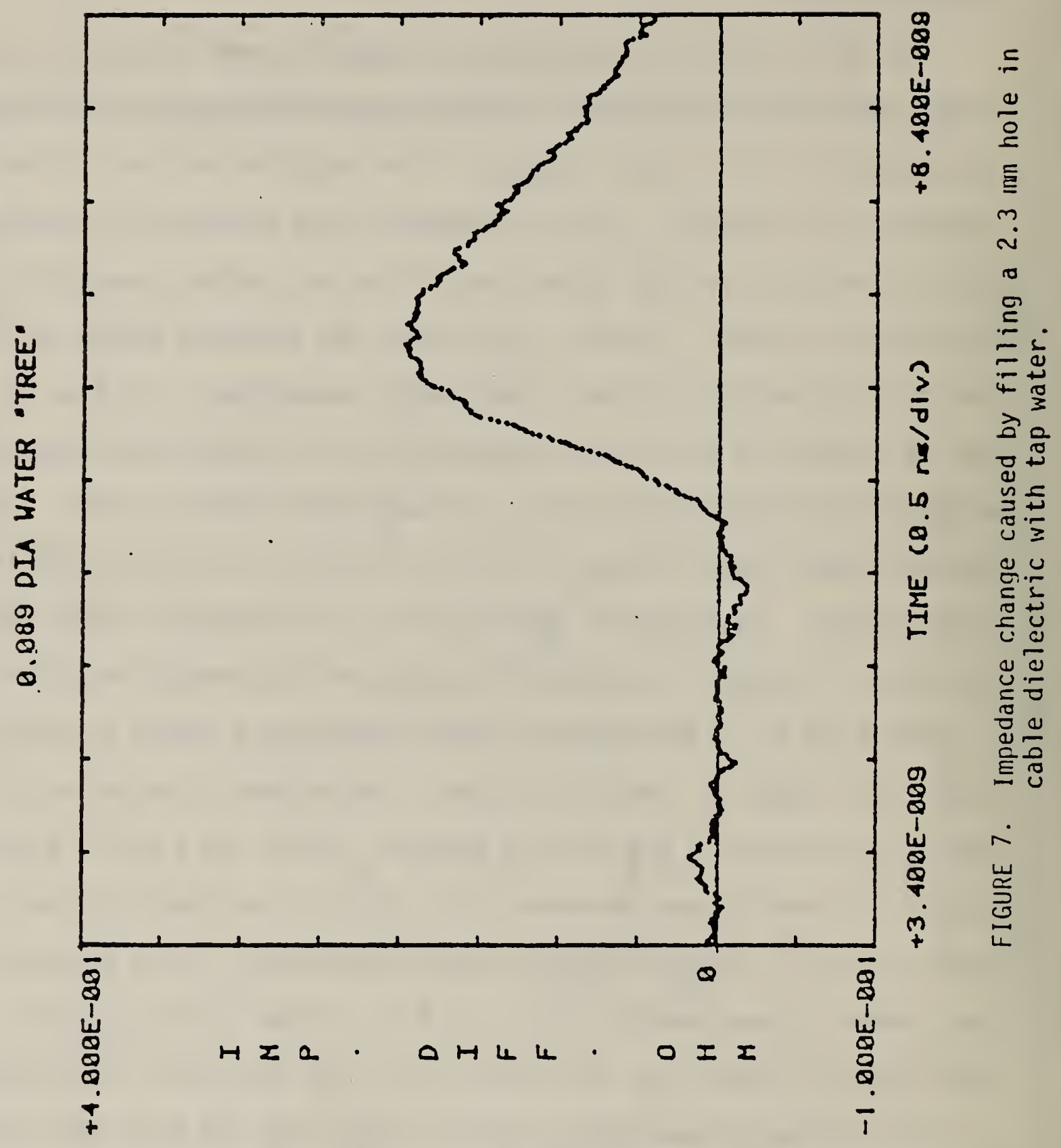




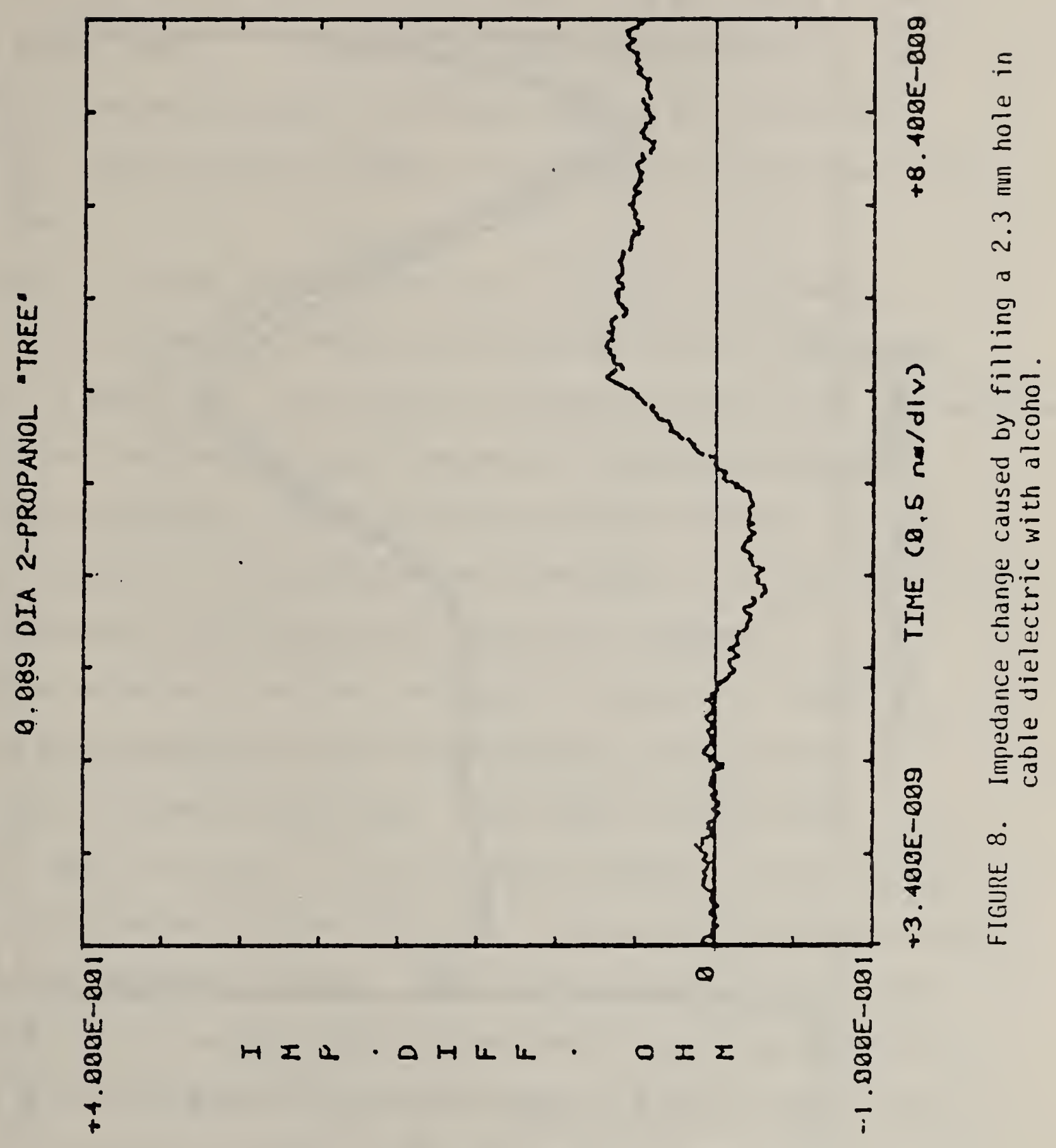




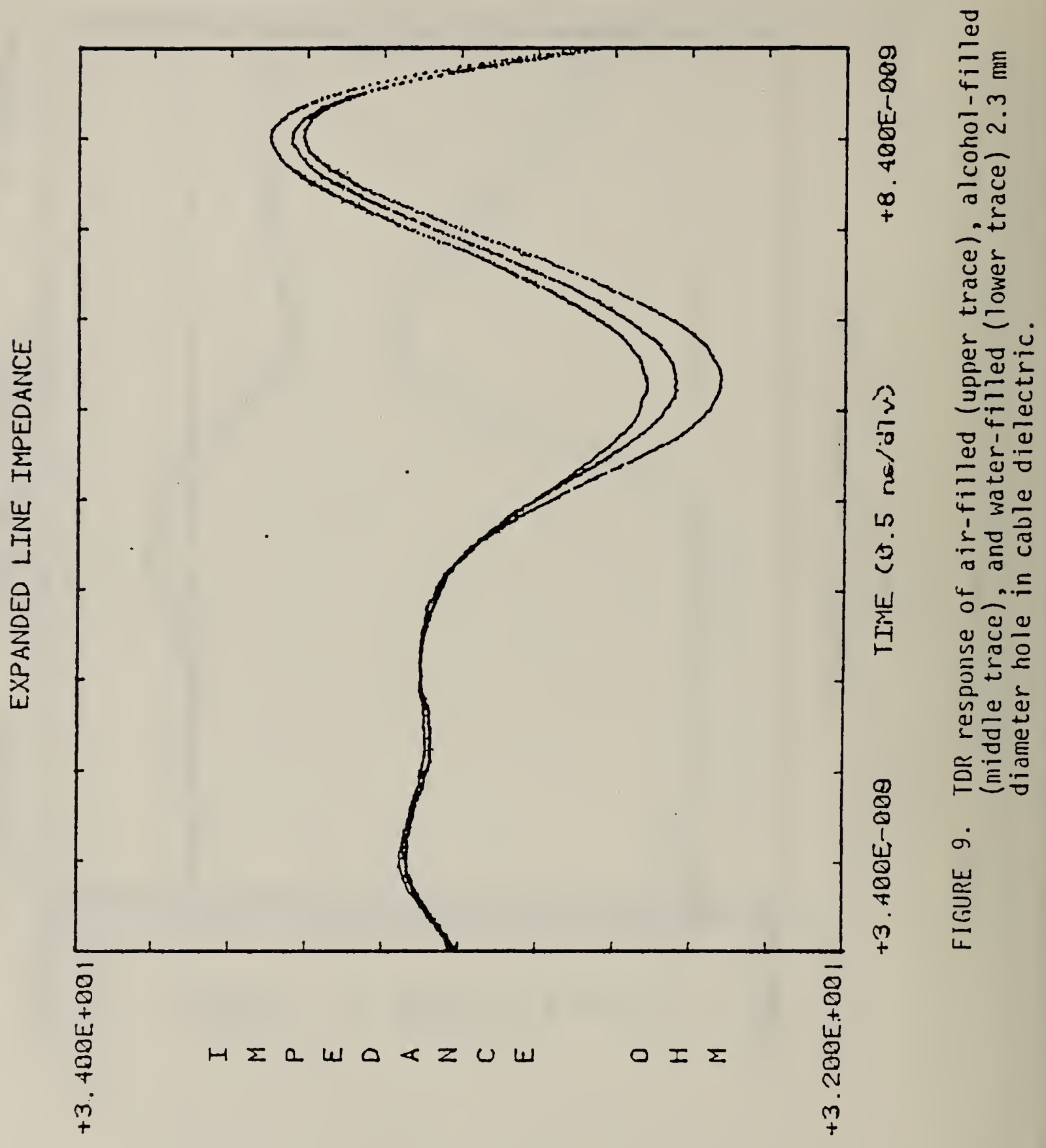


polyethylene cables partial discharge activity promotes the growth of hollow channels in the dielectric. These channels branch out forming a tree-like structure. Cables in service for several years have been found to contain many of these "trees". 3 If these "trees" extend from the inner to outer conductor, breakdown does occur. The inner walls of the "trees" are conductive ${ }^{4}$ suggesting from the above experiment that TDR techniques could detect them.

There is a further difficulty with this series of measurements. It appears in Fig. 9 that the length of the disturbed area is 2 nanoseconds or about 0.4 meter long. The actual hole diameter is only $2.3 \mathrm{~mm}$. The water and alcohol either must be diffusing a considerable distance outside the constraints of the hole, probably along the stranded wires that constitute the inner conductor, or the high-frequency components of the TDR signal are being attenuated so much that spatial resolution is hampered.

Further experiments were next initiated to determine if "trees" or localized sites damaged by partial discharges would be discernible by time-domain reflectometry techniques. Measurements were performed on the same cable described above. A fine steel sewing needle $1.3 \mathrm{~mm}$ in diameter was carefully inserted into the dielectric of the cable to within about one millimeter of the center conductor. (The outer semiconducting layer was previously removed from the vicinity of the needle site). Nenative pulses having a duration of $500 \mu \mathrm{s}$ were applied between the needle and the center conductor. At first, 10 pulses of 500 volts amplitude were applied and the TDR response obtained. Then the voltage was increased in 500 volt increments and more data were obtained. The maximum voltage applied (the limit of the power supply) was 2500 volts. The field at the tip of the needle under these 
conditions is estimated to be of order $500 \mathrm{kV} / \mathrm{mm}$. That is certainly high enough to cause damage to the dielectric. However, after applying these impulses even at the maximum voltage level, no change was seen in the TDR response.

While the voltage levels appeared to be high enough to cause some damage, the lack of change in the TDR response suggested that the dielectric was not being significantly altered. In order to test that hypothesis, dc voltage was applied to the needle. At $7 \mathrm{kV}$ a breakdown was observed. The TDR response showed no change. After an additional 10 breakdowns another TDR response was taken. The results are shown in Fig. 1n. The portion of cable over which the impedence is being measured is $\left(3 \times 10^{10} \mathrm{~cm} / \mathrm{s}\right) \times$ $\left(2 \times 10^{-9} s / 2\right) / \sqrt{2.26}$ or about 20 centimeters long. The reflection coefficient is negative because of the cable's impedance of 37 ohms compared to the output impedance of the TDR unit of 50 ohms. The data shown in Fig. 10 are the average of 512 runs. Any change in the TDR response is lost in the noise.

The result was initially surprising. Previous work had shown this technique to be quite sensitive. He assumed that the partially conducting surfaces of the breakdown channels or "trees" would be readily discernible using TDR. To further test the system, a hole $1.5 \mathrm{~mm}$ in diameter was drilled in the cable dielectric to the center conductor. The hole was then filled with graphite (pencil lead). The results are shown in Fig. 11. The TDR technique can readily detect the change in impedance. The graphite effectively is forming a resistive shunt between the outer and inner conductors. This is similar to the case of a "tree" extending across the dielectric. 
TOR REIPONSE OF CAOLE DEFORE DREAKDOWN

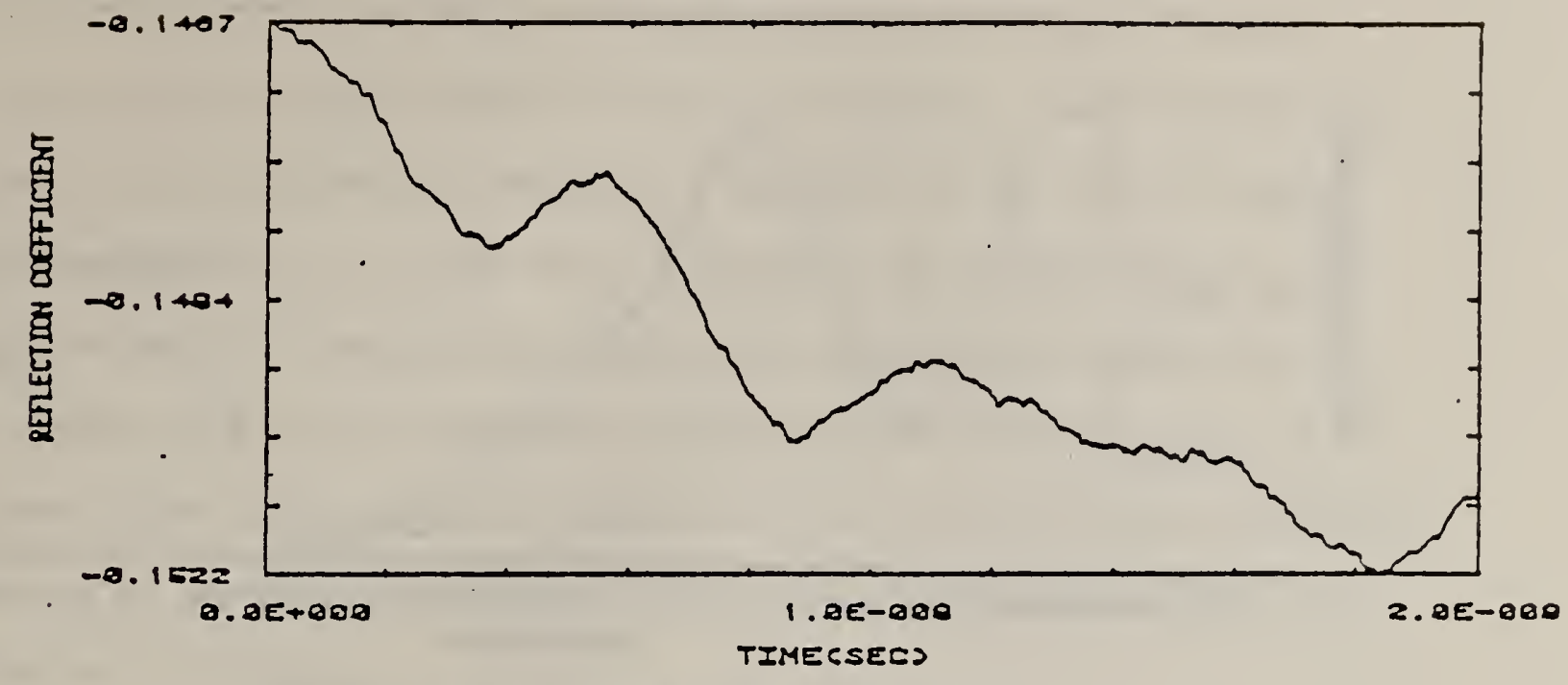

AFTER II BREAKDOWNS
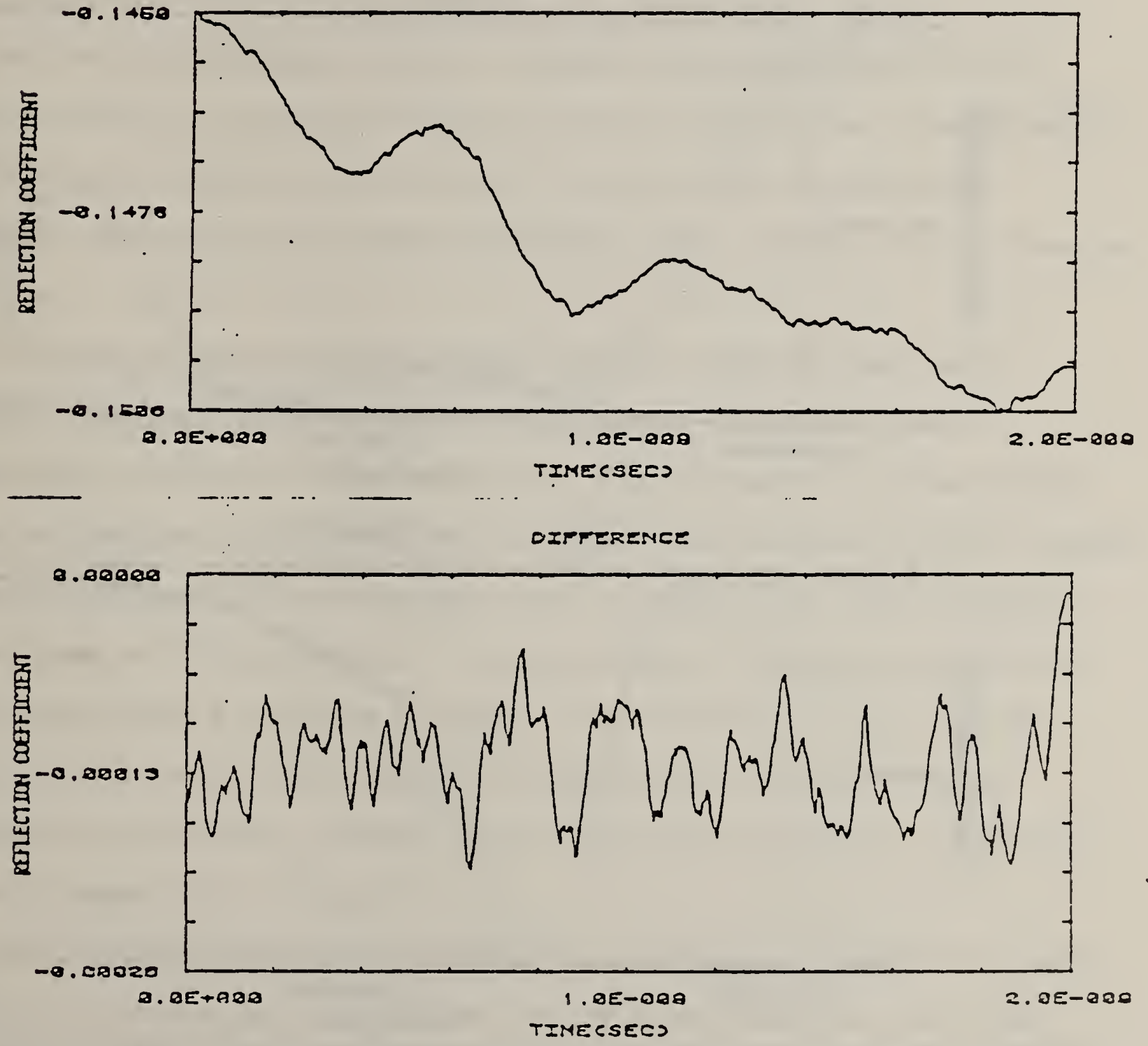

FIGURE 10. Change in TOR response of cable resulting from 11 breakdowns at $7 \mathrm{kV} \mathrm{dc}$. Breakdown channel is estimated. to be $1 \mathrm{~mm}$ long and is undetectable in the noise. 
TOR RESPONSE OF CABLE WITH DRILLEO MOLE

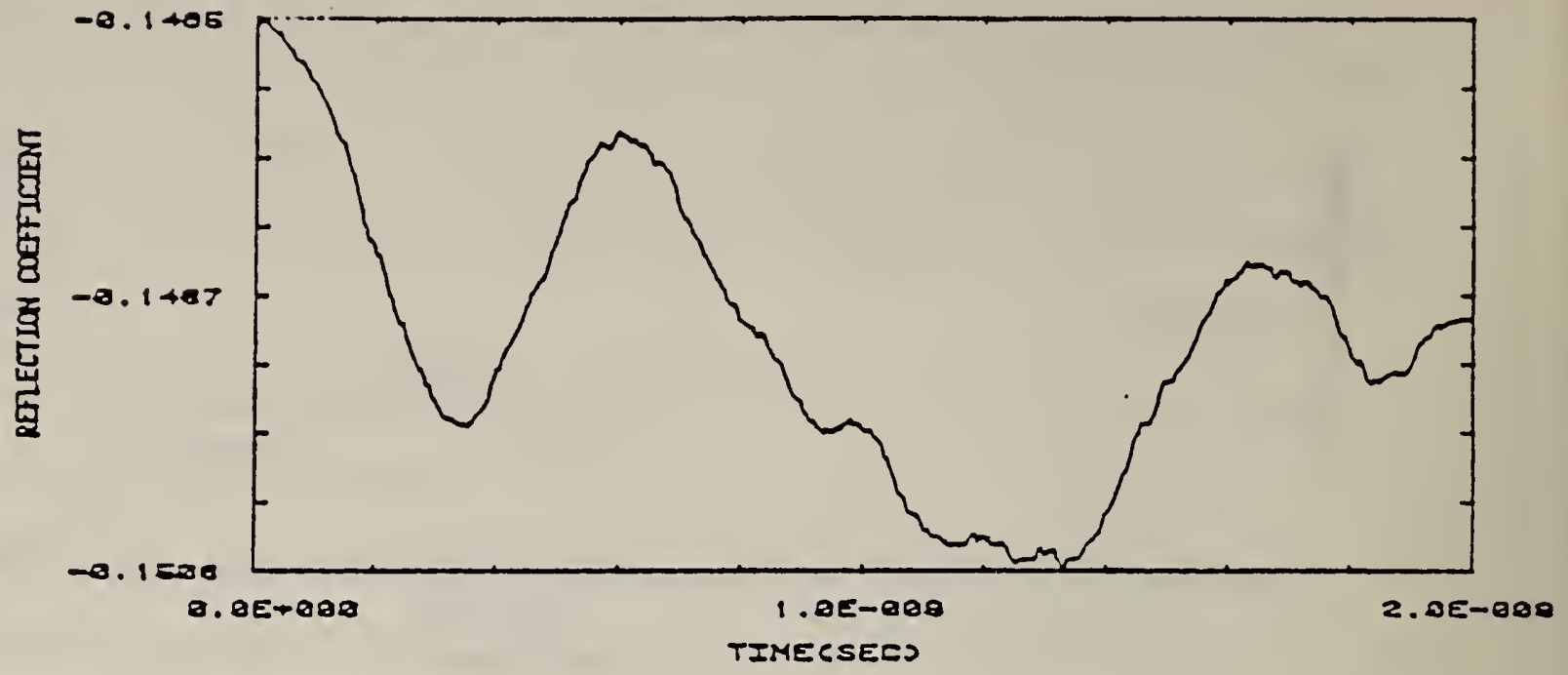

HOLE FILLED WITH GRAPHITE
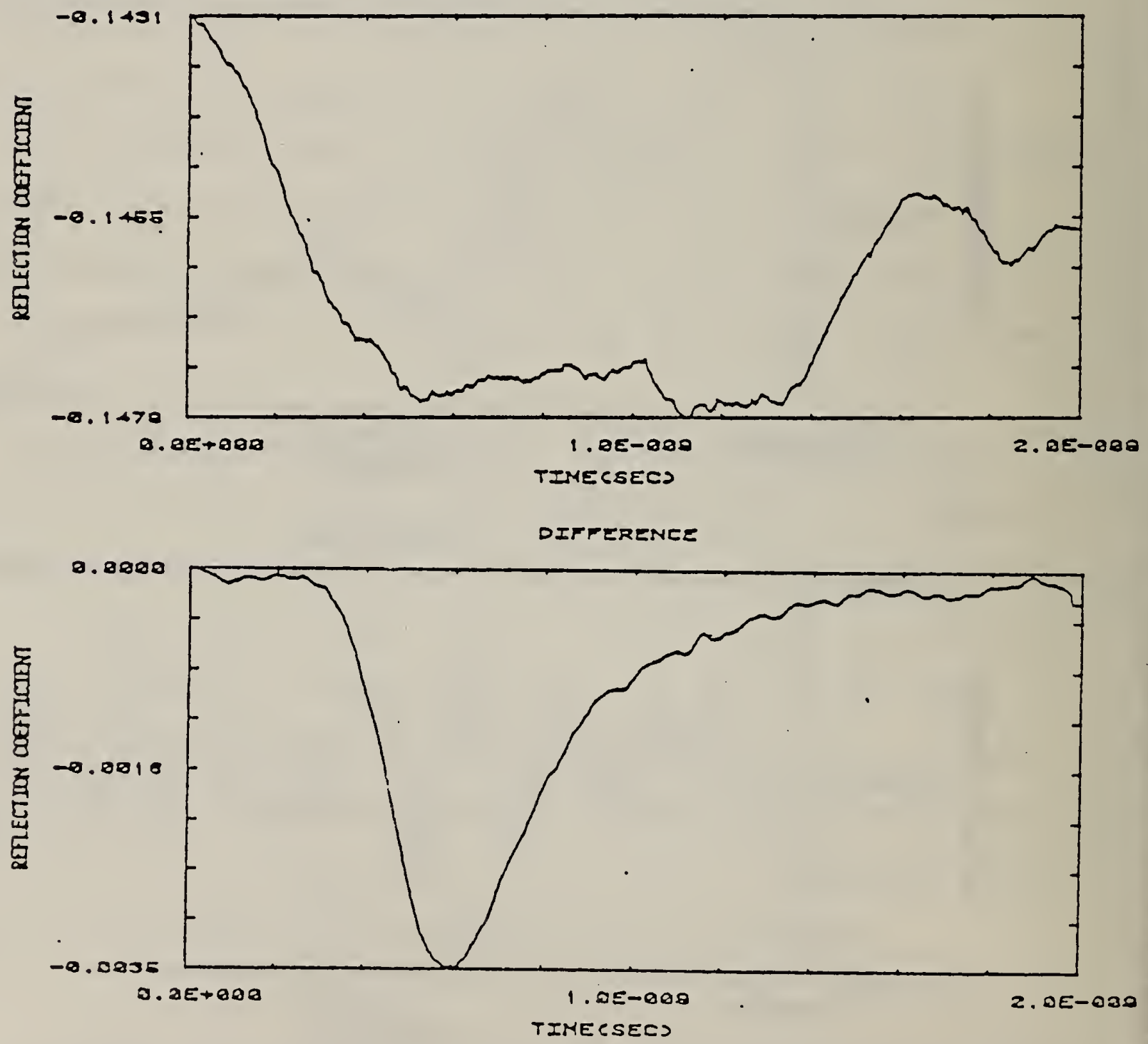

FIGURE 11. Change in TOR response of cable resulting from filling a drilled hole in the cable with graphite. The hole is $1.5 \mathrm{~mm}$ in diameter and $4 \mathrm{~mm}$ deep. 
The negative results shown in Fig. 10 prompted a study to determine whether they arise from a fundamental limitation of the TDR or sweptfrequency approach. In order for a reflection (or interaction) to occur from a region of inhomogeniety within a dielectric, the minimum size of that region must be the same order of magnitude as the wavelength of the incident signal (e.g., an electromagnetic signal with a minimum wavelength component of one meter would have little interaction with a defect one millimeter in length).

In the case of our TDR measurements, the incident pulse has a risetime of less than 30 picoseconds implying a maximum frequency component of the order of $30 \mathrm{GHz}$ or a wavelength in the dielectric of about $6 \mathrm{~mm}$. The estimated length of the breakdown channel in Fig. 10 is $1 \mathrm{~mm}$. Assuming the high frequency components actually get to the damage site, detection should indeed be possible.

In order to determine if the higher frequency components were being severely attenuated making detection of small sites impossible, further measurements were made. Figure 12 shows the TDR response of a shorted RG-58/U cable and the power cable shorted at the damage site previously studied. Whereas the effect of the short in the RG-58/U cable is evident over a time interval of the order of $100 \mathrm{ps}$ (length of $1 \mathrm{~cm}$ ), the effect of the short in the power cable extends over $2 \mathrm{~ns}(20 \mathrm{~cm}$ in length). The difficulty in resolving the location of the short in the power cable demonstrates that high frequency attenuation is occurring. Without these high frequency components, resolution of small damage sites is impossible.

Two solutions to this problem have been considered: (1) better impedance matching to increase the high frequency content within the power cable; and 
TDR RESPONSE OF SHCRTED RG 58 CABLE
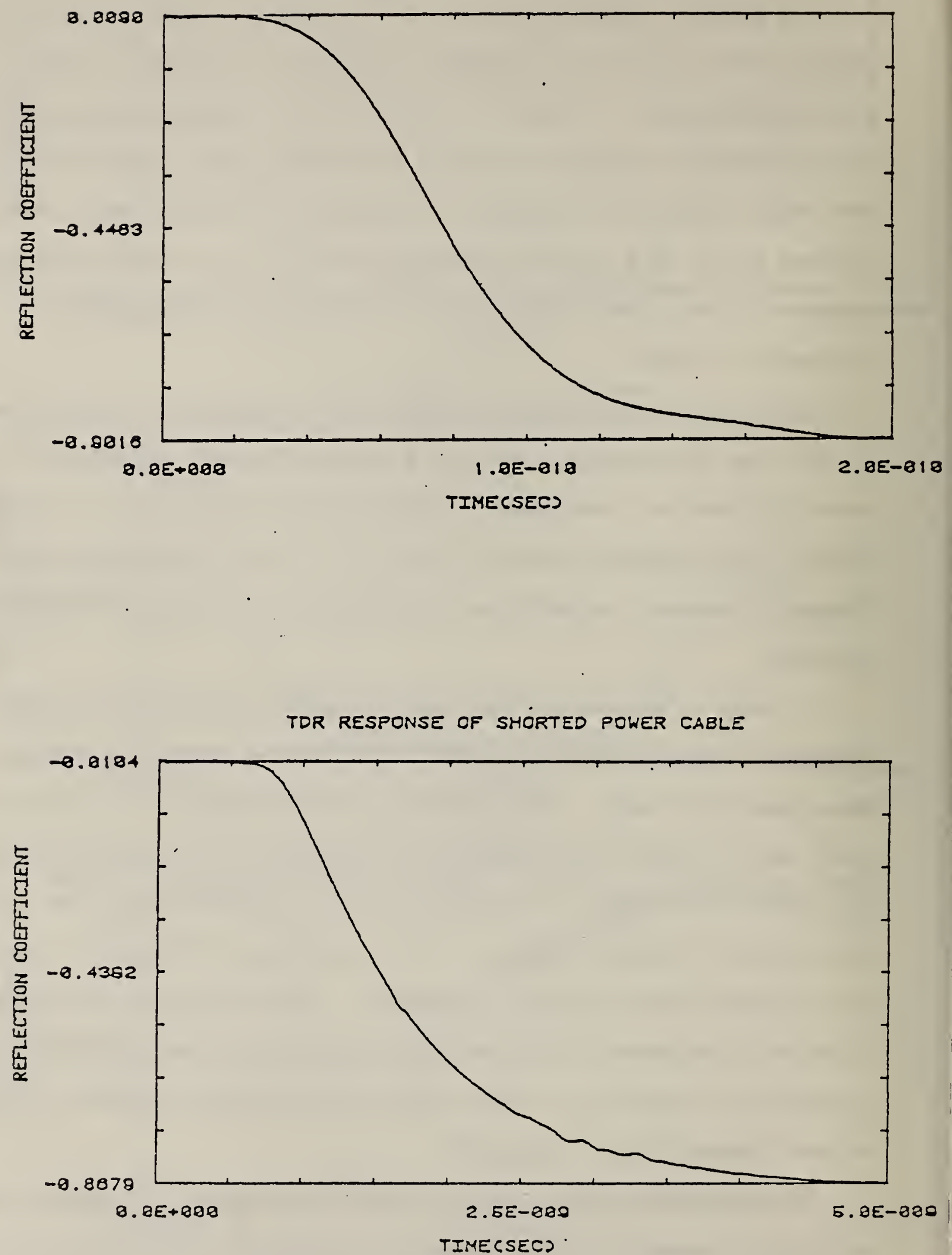

FIGURE 12. TOR response of $R G-58 / U$ cable and power terminated by zero impedance. 
(2) after careful measurements, compensation for the attenuation in software.

As seen in Fig. 12 and discussed above, there is a serious attenuation of the high frequency components of the step input. A large fraction of this "loss" may be the result of the impedance mismatch between the $50 \mathrm{ohm}$ TDR system and the 37 ohm high voltage cable. Additionally at or near the connection to the cable other mismatches are evident from the reflections present in that region. These results suggested the need for an impedance matching device to improve coupling of the high frequency components into the high voltage cable.

Impedance transforming baluns were considered, but the idea discarded since pulse risetimes of 25 ns or shorter are being considered. An investigation into other impedance matching schemes led to the use of tapered sections of coaxial transmission lines to achieve an impedance transformation. A design having minimal reflections over a wide bandwidth employing a aradual exponential taper was examined. A linear conical tapered line was also investigated. Although the exponential taper is theoretically better, the difference is so little so as to make the difficult exponential taper not worth the extra machine time and costs. ${ }^{5}$ This is especially true if the taper is long and gradual in comparison to the wavelength of the lowest frequency of interest. The tapered section will act as a high pass filter so long as the phase constant does not contain an imaginary term. At lower frequencies the phase constant is complex and the signal is attenuated. Practically, impedance changes of 2 to 1 can be made if the tapered section is one wavelength long or longer. A good impedance match will result for higher frequencies. 
Figure 13 shows details of the tapered line. The outer conductor of the line is made from a thick-walled section of brass tubing which clamps over the braided shield of the high voltage cable. In the right end of the "tube", a machined adaptor is inserted. This couples to a General Radio ${ }^{1}$ type 874-BP58A flanged panel connector. This type of connector is known to have a constant 50-ohm impedance throughout its length and to provide for a good electrical connection with low series and shunt losses. The stepped portion of the center conductor shown in Fig. 13 fits inside the adaptor. The dimensions have been selected to maintain a 50-ohm characteristic impedance throughout its entire length. The susceptances at each "step" should be low enough even at the highest frequencies to provide a constant 50-ohm match in this region of the line.

The center conductor of the line is tapered. The tapered length is $30.18 \mathrm{~cm}$ which is one wavelength at a frequency of $993 \mathrm{MHz}$. It would be desirable to have a longer line so the lower cutoff frequency would be less, but this becomes mechanically difficult and cumbersome.

The left end of the tapered center conductor fits directly over the center conductor of the high voltage cable. Because of possible end effects of the tapered section and the abrupt discontinuity of the polyethylene dielectric at the end of the cable, impedance mismatch reflections can be expected. The influence of these remaining reflections has been experimentally determined. 


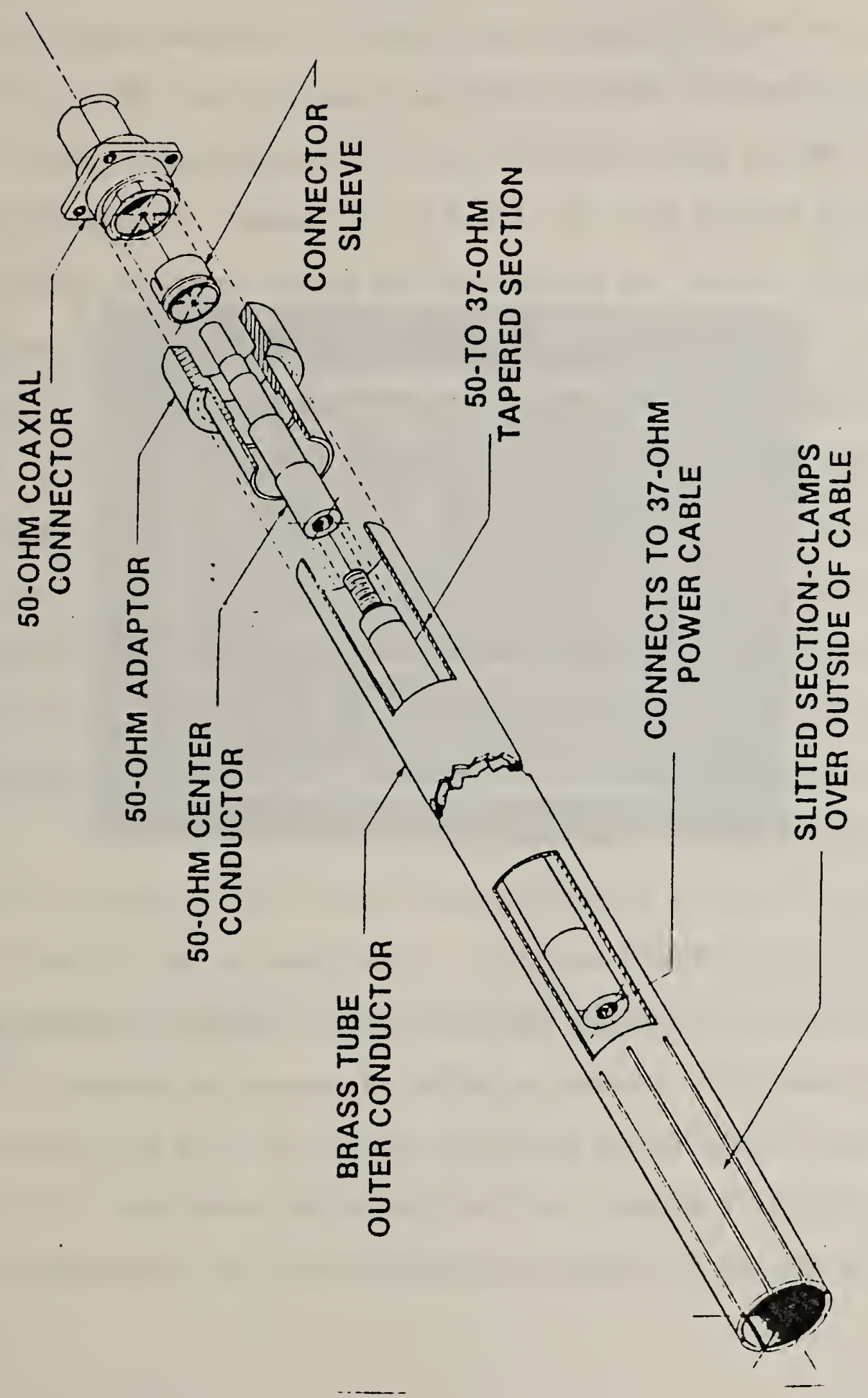

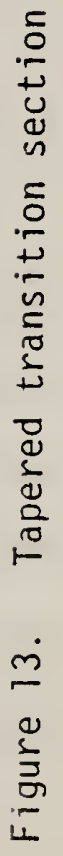


The performance of the transition section is shown in Figs. 14 to 17. Figure 14 shows the TDR response at the end of the 50-ohm coaxial cable and at the beginning of the 37-ohm distribution cable without the transition section. The output of the TDR analyzer was adapted to BNC-type coaxial connectors. A one meter length of $R G-58 / \mathrm{U}$ cable was connected to a $G R^{\top}$ type 874 BNC-to-GR adaptor. The six outer strands of the distribution cable center conductor were removed leaving only one strand at the center. The female portion of the BNC-to-GR adaptor was placed over the single remaining center strand of the cable's inner conductor. The braided sheath of the cable was then dressed over the adaptor and the whole assemblage taped into place. Using this arrangement, two major impedance mismatches occurred. The first was due to the short length of small diameter single-strand center conductor. This length was about $9 \mathrm{~mm}$ and caused the impedance to increase to about 90 ohms, the first major peak in Fig. 14. The second mismatch is due to the lower characteristic impedance of the distribution cable. (The small variations of impedance seen in the 37-ohm portion of the cable are caused principally by the unevenness of the braided sheath).

Figure 15 shows a cross-sectional view of the 50-ohm end of the transition. (The GR874BP connector is not shown on the left end). The steps of the center conductor were designed to coincide with the steps of the outer conductor. However, an error on the design drawing of $0.2 \mathrm{~cm}$ shifted the two larger diameters on the right towards the left end resulting in a lack of coincidence between the inner and outer conductors. This was discovered after the piece was fabricated and assembled and the TDR response obtained. 


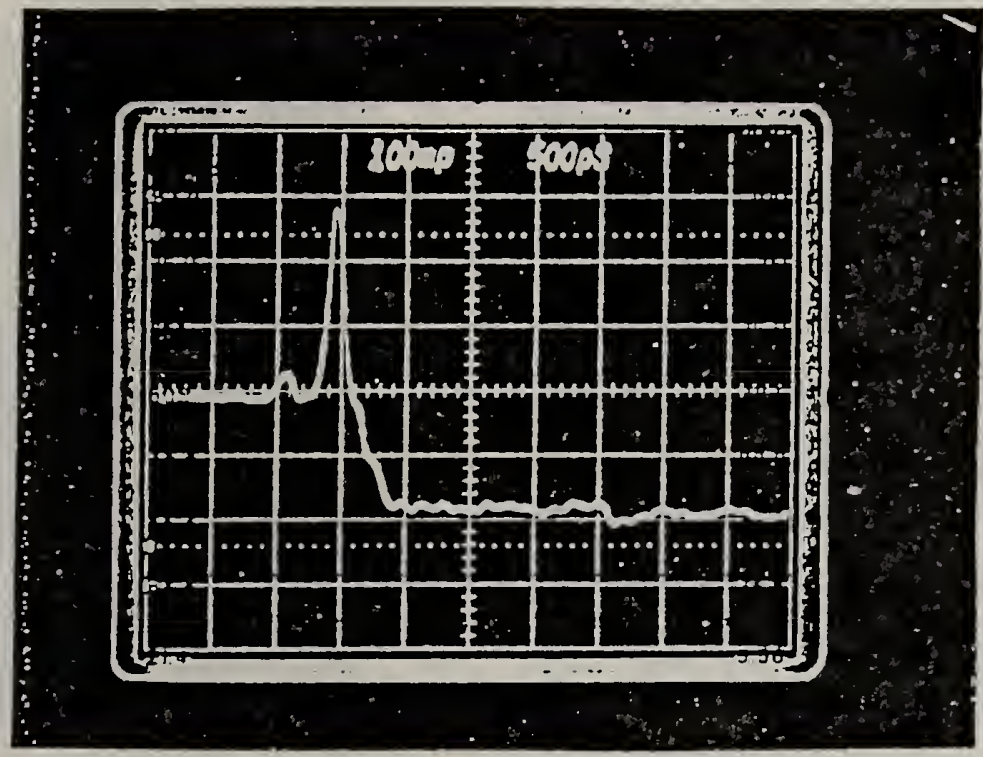

gure 14. TDR response of $R G-58 / U$ cable connection onto 37-ohm distribution cable. 


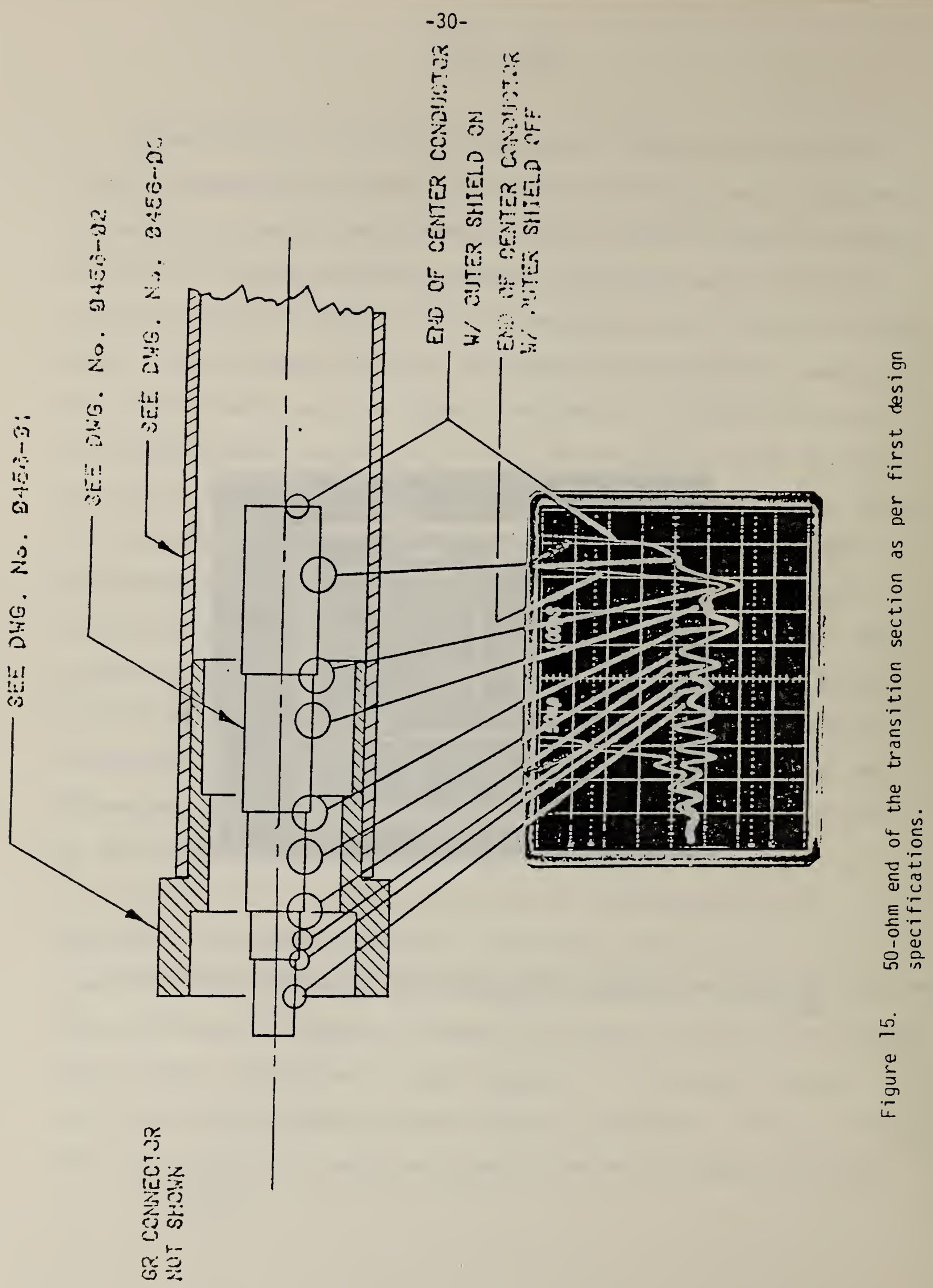


The TDR response is keyed to the stepped center conductor as shown in Fig. 15. (Vertical sensitivity is about 5 ohms per division). Several problems were evident upon examination of this response. First the impedance variations were greater than expected and second, the impedance of the fourth step was lower than design specifications. From the latter, a second drawing error was discovered: the inside diameter of the outer conductor was too small by $0.09 \mathrm{~cm}$.

It was obvious that even though the steps in diameter were each only $0.12 \mathrm{~cm}$, a 3-to 5-ohm impedance change occurred at each step. Because the impedance decreased in the vicinity of each step, this indicated that the shunt susceptance at the steps was too great. In order to compensate for and to reduce this susceptance, each of the steps of the center conductor piece was shifted to the right by an amount equal to $D / 8$ where $D$ is the inside diameter of the outer conductor. Also the inside diameter of the last step of the outer conductor was increased by $0.09 \mathrm{~cm}$ to increase the impedance in that region of the transition section. The TDR response in Fig. 16 shows a significant improvement over that of Fig. 15. The impedance does not vary by more than two ohms.

Fiqure 17 shows the TDR response for the entire length of the tapered transition section. At the left is the 50-ohm TDR system impedance; in the center is the tapered line; and on the right is the $37-0 \mathrm{hm}$ high voltage distribution cable. As can be seen at the right end of the tapered section, impedance variatiations are apparent. These are caused by the end effects of the tapered line attaching to the distribution cable center conductor and 


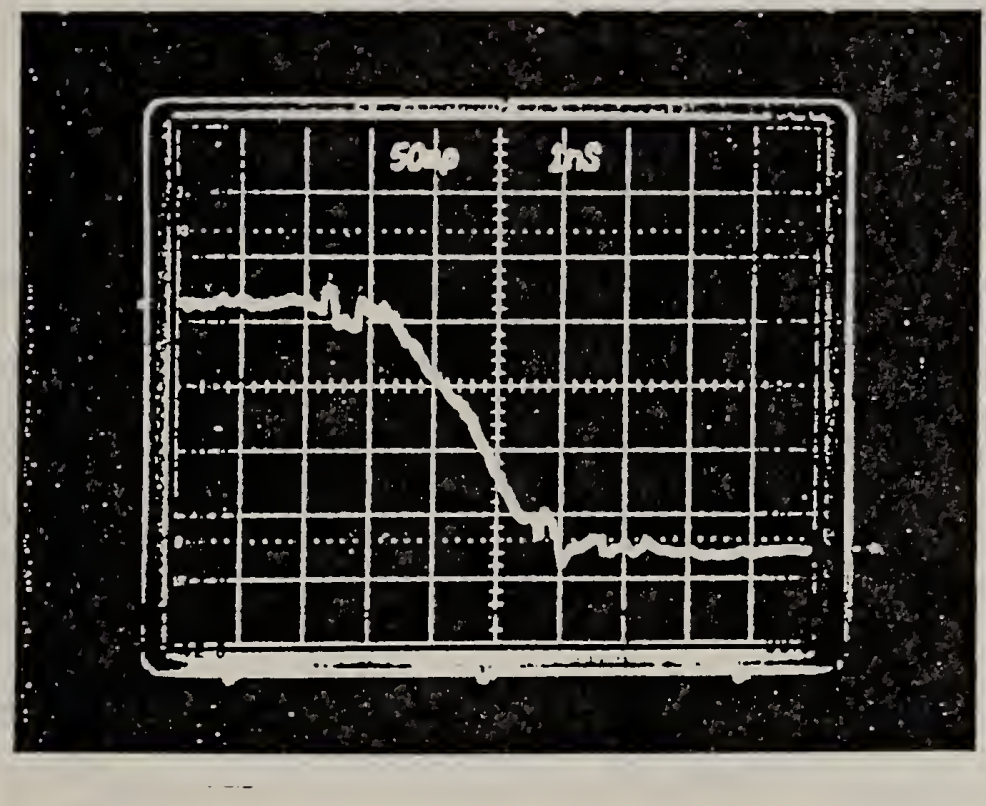

Figure 17. TDR response of tapered line transition section. 
imperfections in the shield geometry at and near the beginning of the distribution cable.

Comparing Figs. 14 and 17 we see that the transition section has fulfilled its intended purpose -- a smooth impedance transition from the 50-ohm output impedance of the TDR analyzer to the 37-ohm characteristic impedance of the cable. The next step was to determine if this transition section permitted significantly more high frequency signal to enter the cable and, if so, would this enable resolution of incipient faults or would attenuation within the cable still be a probiem.

With the transition section in place the outer and inner conductors were shorted together at a distance of $61 \mathrm{~cm}$ from the cable end (and the TDR analyzer). The TDR display was averaged 512 times and sent to the intelligent terminal for display. The results are shown in Fig. 18. The ordinate has not been normalized as on the previous figures (i.e., a constant has not been added to the reflection coefficient in order to force it to be zero for the power cable's characteristic impedance of 37 ohms). The important parameter, reflection coefficient variation, is not affected. The upper graph is from Fig. 12 and is taken without benefit of the transition section. The lower graph demonstrates the effect of the transition section. For the sake of simplicity we will define the decay time as the time it takes the signal to decrease from $7 / 8$ to $1 / 8$ of the difference of the average maximum and minimum values. The decay time, thus defined, is 1750 ps without and 800 ps with the transition section. This means the additional hiah frequency components entering the cable with the transition section have permitted better spatial resolution of the short. The 800 ps decay time corresponds to a length of $8 \mathrm{~cm}$ which is much longer than the shorted hole's 
SHORTED POHER CABLE (NO TRANSITION SECTION), LENGTH $81 \mathrm{~cm}$

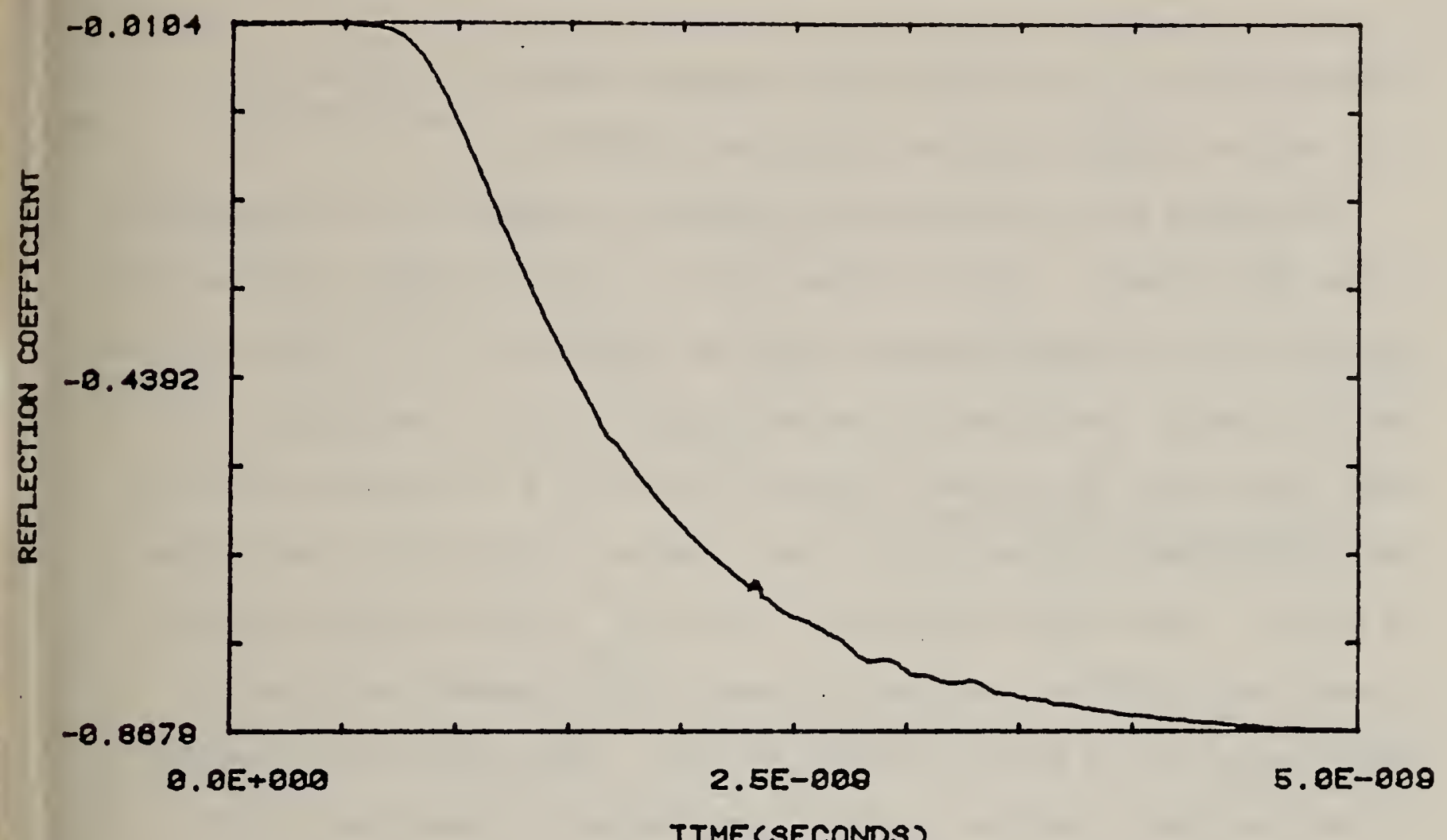

TIME(SECONDS)

SHORTED POHER CABLE, LENGTH $61 \mathrm{~cm}$

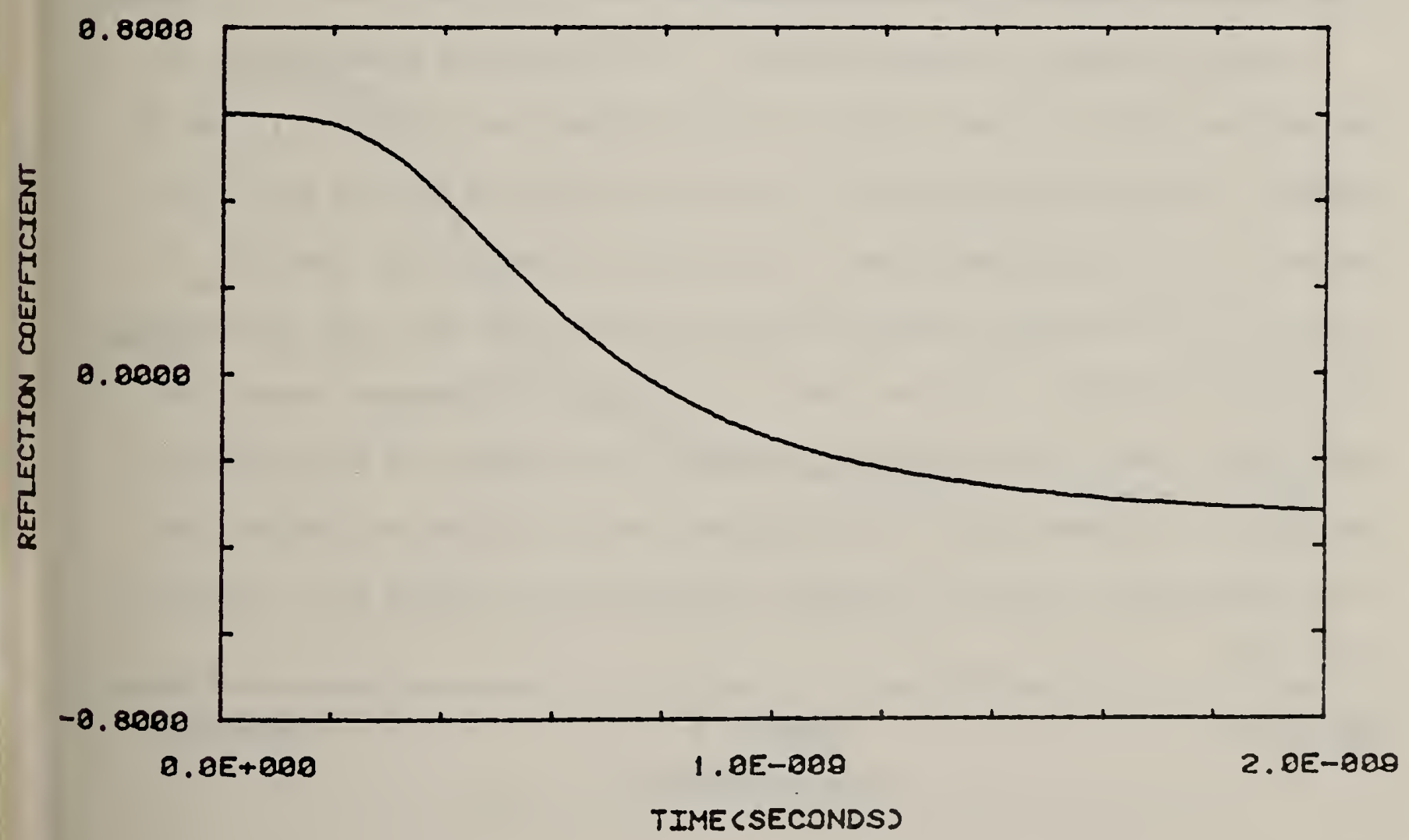

Figure 18. TOR response of power cable terminated by zero impedance with and without transition section. 
diameter $(0.13 \mathrm{~cm})$. Sufficient high frequency content, therefore, is still not available to resolve this region adequately.

The second factor affecting high frequency propagation is the attenuation in the cable itself. Figure 19 shows results, taken as before, with the short located at two different distances from the TDR analyzer. The figure indicates that the greater the distance of propagation in the cable the greater the decay time of the TDR response. A short located at $4 \mathrm{~cm}$ from the cable end has a decay time of 340 ps while a short located at $163 \mathrm{~cm}$ has a decay time of 1050 ps. From above we found that a short $61 \mathrm{~cm}$ from the cable end has a decay time of 800 ps. At $4 \mathrm{~cm}$ the decay time corresponds to a spatial resolution of $3.4 \mathrm{~cm}$ and at $163 \mathrm{~cm}$ to $10.5 \mathrm{~cm}$. These results are troubling in that they imply that the intrinsic high frequency attenuation in this type of cable makes the detection at large distances of small-size damage sites very difficult, if not impossible.

Figure 20 shows this quite clearly. In the previous measurements, we had not been able to detect a hole drilled through the dielectric $1.3 \mathrm{~mm}$ in diameter. We again attempted this with holes drilled $4 \mathrm{~cm}$ from the cable end and $61 \mathrm{~cm}$ from the cable end. At $61 \mathrm{~cm}$ the response with the hole (light trace) and without (heavy trace) are nearly the same, any differences not being repeatable. At $4 \mathrm{~cm}$, there is a definite difference between the two traces. New minima and maxima have been introduced with the drilling of the hole. From these data, it is inferred that, at distances greater than a few centimeters, the high frequency attenuation has caused this information to be lost. 
SHORTED POWER CABLE, LENGTH $4 \mathrm{~cm}$
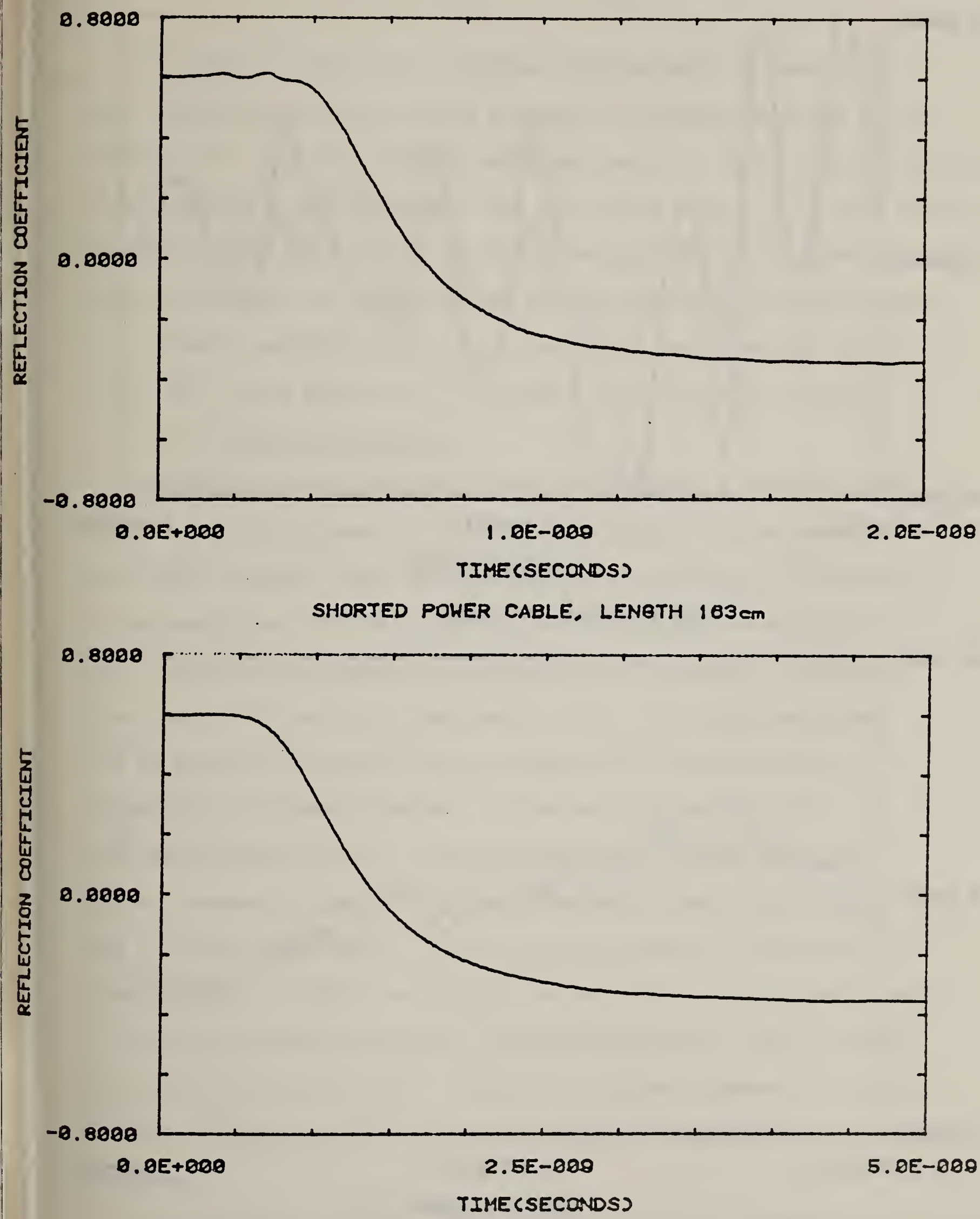

Figure 19. TDR iceoonse of power cable terminaled by zein impedame; the location of short is $4 \mathrm{~cm}$ and $163 \mathrm{~cm}$ from cable end; measurements made using transition section. 
TDR RESPONSE OF CABLE AT $4 \mathrm{~cm}$

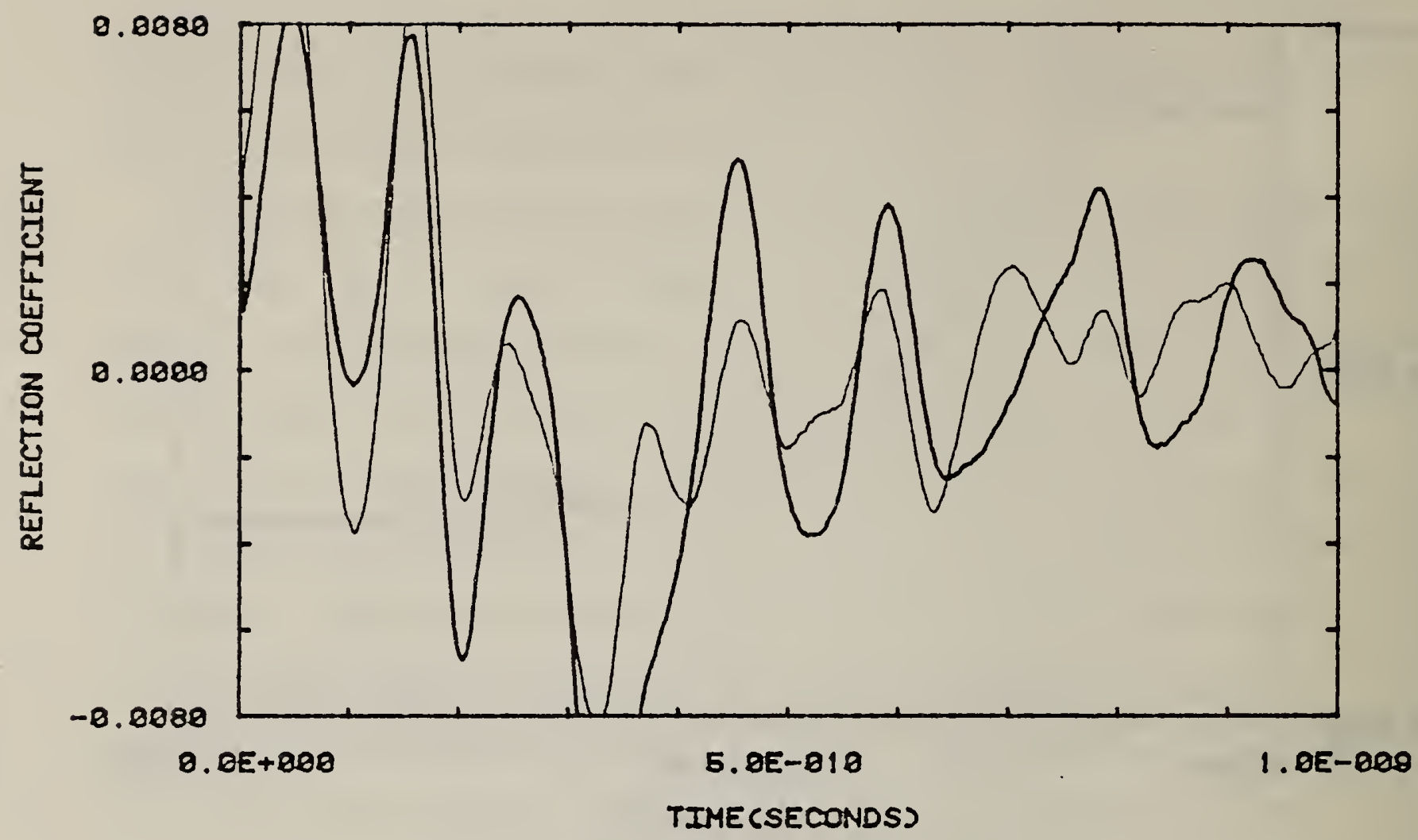

TDR RESPONSE OF CABLE AT $81 \mathrm{~cm}$

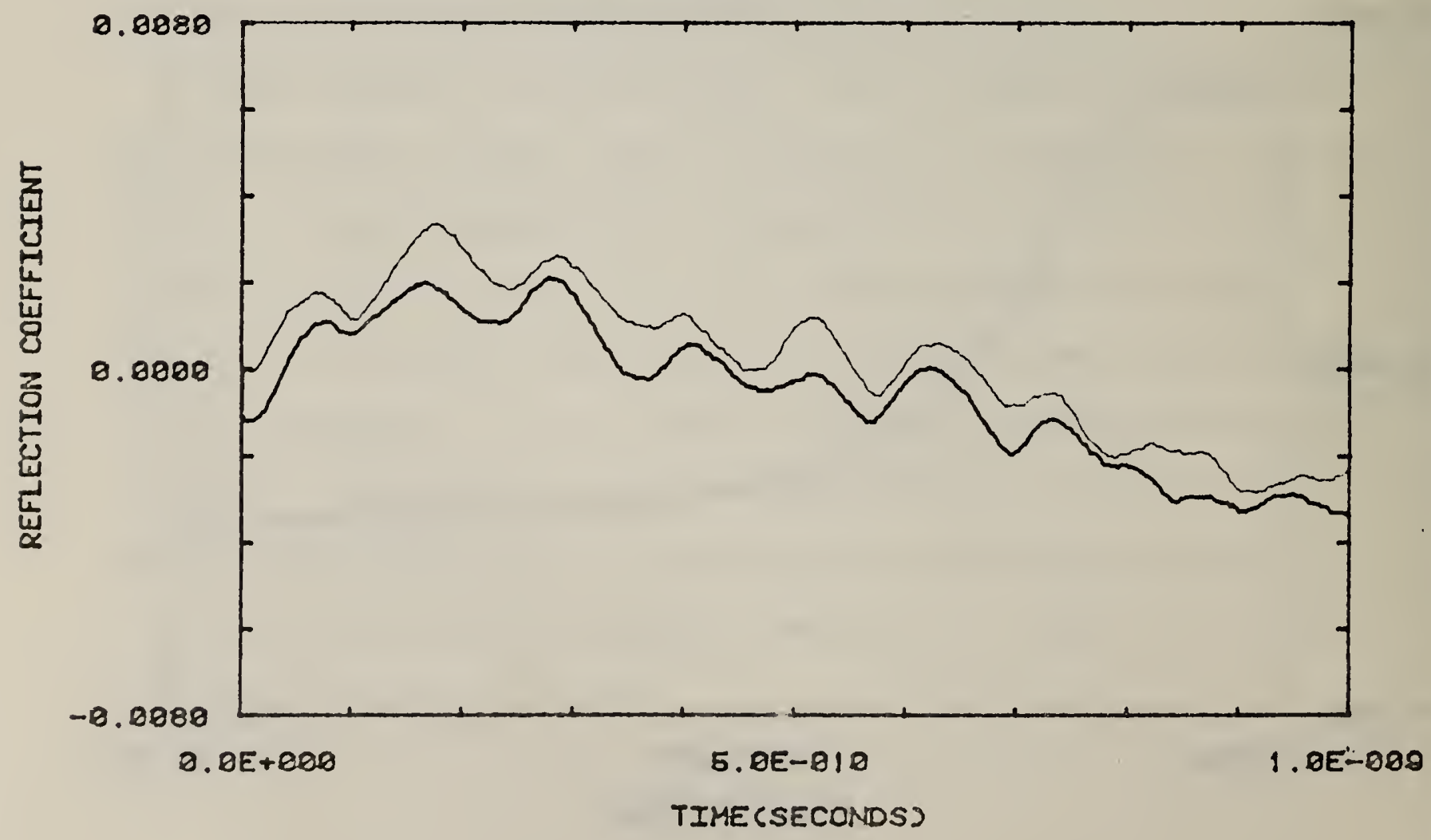

Figure 20. TOP response of power cable (using transition section) with (lighter) and without (darker) a hole drilled through dielectric. Distance of $1.3 \mathrm{~mm}$ diameter hole from cable end is $4 \mathrm{~cm}$ (upper) and $61 \mathrm{~cm}$ (lower). 
The results indicate that incipient fault detection schemes based on high frequency sounding may not be practical for plastic-insulated cables although it is possible that such techniques may be of value for compressed-gas (spacer failure), superconducting, and other cable types. It is also possible that our results obtained on a $15 \mathrm{kV}$ extruded polyethylene distribution cable may not fully apply to higher voltage transmission cables of similar design. High frequency sounding could still be useful for fault location and, if a sufficiently large damage site is available, incipient fault location.

\section{II.3 Software Development}

In addition to the software presented in Appendix $A$ which was developed for data transfer between the digital processing oscilloscope and the intelligent terminal, other software needed to be developed. Experiments in the coming year will be initiated with the objective of determining the signal velocity and attenuation in cables at $\mathrm{rf}$ frequencies. Initial measurements will be in the time-domain. Step-like voltage waveforms will be applied to the cable and the output waveform digitized and transmitted to the smart terminal. A Fourier transform will then yield the transfer function in the frequency domain. Problems arise, however, because instead of a Fourier transform of continuous data we have a Fourier transform of discretely sampled data or a discrete Fourier transform (DFT). A DFT of an impulse-like waveform (a waveform which ends at the same amplitude it begins) is straightforward and a fast algorithm exists for its solution (FFT). ${ }^{6}$ Step-like waveforms, however, will produce a serious truncation error ${ }^{7}$ if they are treated by conventional DFT (and FFT) techniques.

We have found two different (but related) methods to overcome this problem. The first is the $\sin x / x$ expansion presented by Samulon. ${ }^{8}$ 
The measured curve is sampled at time intervals, $\tau$, such that:

$$
\tau \leq 1 / 2 f_{C},
$$

where $f_{C}$ is the highest frequency component present. This restraint is necessary to avoid "aliasing" problems ${ }^{7,9}$. Using a $\sin x / x$ expansion the given time function, $F(t)$, can be expressed

$$
F(t)=\sum_{n=0}^{\infty} \frac{A_{n} \sin f_{c}(t-n \tau) 2 \pi}{f_{c}(t-n \tau) 2 \pi}
$$

where $A_{n}$ is the amplitude of the nth sampled point. The Fourier transform of the nth term of Eq. (4) is given by

$$
\phi_{n}(\omega)=\int_{-\infty}^{\infty} \frac{A_{n} \sin \left[2 \pi f_{c}(t-n \tau)\right]}{2 \pi f_{c}(t-n \tau)} e^{-j \omega t} d t,
$$

or

$$
\phi_{n}(\omega)=\frac{A_{n}}{2 \pi f} \int_{c}^{\infty} \frac{\sin \left[2 \pi f_{c}(t-n \tau)\right]}{t-n \tau}\{\cos \omega t-j \sin \omega t\} d t .
$$

Subsituting $t^{\prime}$ for $t-n \tau$ and using

$$
\int_{-\infty}^{\infty} \frac{\sin m x \cos n x}{x} d x=\pi \text { for } m>n \geq 0
$$


We obtain

$$
\phi_{n}(\omega)=\frac{A_{n} e^{-j n \omega \tau}}{2 f_{c}},
$$

or

$$
\Phi(\omega)=\sum_{n=0}^{\infty} \frac{A_{n} e^{-j n \omega \tau}}{2 f_{c}} ; \tau \leq 1 / 2 f_{c} .
$$

Software based ori Eq. (9) has been written and is incorporated in Appendix B. However, this is not the most useful form of the $\sin x / x$ expansion. If $A_{n}$ does not equal zero for some $n$ greater than an arbitrary $m$, Eq. (9) does not converge and cannot be used. If $A_{n}$ does not converge and the summation is arbitrarily terminated at some point, ripples will occur obscuring the results.

A modified form of Eq. (9) can be used which does not have such limitations. Let $B_{n} \equiv A_{n}-A_{n-1}$ and replace the sequence $\left\{A_{0}, A_{1}, A_{2} \ldots\right\}$ by $\left\{A_{0}, A_{1} e^{-\tau / \delta}\right.$, $\left.A_{2} e^{-2 \tau / \delta}, \ldots\right\}$. The value of $\delta$ can be made arbitrarily large so as not to affect our transient unless $\tau$ is very large or in the frequency domain $\omega$ is very small. Using the relation

$$
A_{n}=\sum_{m=0}^{n} B_{m}
$$

Eq. (9) becomes 


$$
\Phi(\omega)=\frac{1}{2 f_{c}} \sum_{n=0}^{\infty}\left(\sum_{m=0}^{n} B_{m}\right) e^{-j n \omega \tau-n \tau / \delta} .
$$

If we let $n \varepsilon=j n \omega \tau+n \tau / \delta$, we obtain

$$
2 f_{c} \Phi(\omega)=\sum_{n=0}^{\infty}\left(\sum_{m=0}^{n} B_{m}\right) e^{-n \varepsilon},
$$

or equivalently

$$
2 f_{C} \Phi(\omega)=\left(\sum_{n=0}^{\infty} e^{-n \varepsilon}\right)\left(\sum_{m=0}^{\infty} B_{m} e^{-m \varepsilon}\right) .
$$

The series $\sum e^{-n \varepsilon}$ is absolutely convergent if

$$
\sum_{0}^{\infty}\left|e^{-j n \omega t}-n \omega / \delta\right|
$$

converges. But

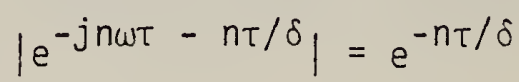

and (14) is seen to be a geometric progression, convergent for $e^{-\tau / \delta}<1$. Using the formula for the surn of an infinite geometric progression:

$$
\sum_{n=0}^{\infty} e^{-n_{\varepsilon}}=1 /\left(1-e^{-\varepsilon}\right),
$$


or

$$
\sum_{n=0}^{\infty} e^{-n \varepsilon}=1 /\left(1-e^{-\tau / \delta} e^{-j \omega \tau}\right) .
$$

The factor $e^{-\tau / \delta}$ can be made arbitrarily close to unity yielding

$$
\sum_{n=0}^{\infty} e^{-n \varepsilon}=1 /\left(1-e^{-j \omega \tau}\right)
$$

From Eq. (13), we obtain

$$
\Phi(\omega)=\left[1 /\left(2 f_{c}\left(1-e^{-j \omega \tau}\right)\right] \sum_{n=0}^{\infty} B_{n} e^{-j n \omega \tau} .\right.
$$

Appendix C contains the software utilizing En. (19). This program is nood for waveforms of arbitrary shape and can always be used assuming $\tau \leq 1 / 2 f_{c}$ and that, for $n$ greater than some $m, B_{n}$ approaches some constant (not necessarily zero). The only difficulty with En. (19) is that the processing can take several seconds per frequency point making it impractical for some experiments.

The second method used a modified FFT. As mentioned above a conventional FFT yields incorrect results due to truncation error. A modified FFT has recently been presented ${ }^{10}$ which overcomes this problem.

From Eq. (19) and the definition of $B_{n}$ we obtain

$$
\Phi(\omega)=\left[1 /\left(2 f_{c}\left(1-e^{-j \omega \tau}\right)\right)\right] \sum_{n=0}^{\infty}\left(A_{n}-A_{n-1}\right) e^{-j n_{\omega \tau}} .
$$

We assume the waveform becomes a constant at $T=N \tau$ ( $i . e ., A_{i}=A_{i-1}$ for $i \geq 1$ ). It is further assumed that $A_{0}$ is equal to zero (i.e., the dc offset of the waveform is zero. $A_{-1}$ is defined to be zero. Substituting $v_{r}$ for $v$ 
$(\nu=\omega / 2 n)$ such that

$$
v_{k}=k v_{0}=k(1 / T)=k / N \tau, k=1,2, \cdots, N-1 .
$$

Eq. (20) becomes

$$
\bar{\Phi}_{K}=\left[\tau /\left(1-e^{-j k 2 \pi / N}\right)\right] \sum_{n=0}^{N-1}\left(A_{n}-A_{n-1}\right) e^{-j n k 2 \pi / N} .
$$

In Eq. (22), $\tau$ has been set equal to $1 / 2 f_{c}$ satisfying the sampling theorem. In order to be consistent with FFT conventional formalism the factor $\tau$ will be removed from Eq. (22). Separating the sum into two parts, we obtain

$$
\Phi_{\kappa}=1 /\left(1-e^{-j k 2 \pi / N}\right) \quad\left\{\sum_{n=0}^{N-1} A_{n} e^{-j n \kappa 2 \pi / N}-\sum_{n=0}^{N-1} A_{n-1} e^{-j n k 2 \pi / N}\right\}
$$

Defining $S_{K}$,

$$
S_{K}=\sum_{n=0}^{N-1} A_{n} e^{-j n k 2 \pi / N}
$$

to be the FFT acting on the data set $\left\{A_{n}\right\}, E q .(23)$ becomes

$$
\oint_{k}=1 /\left(1-e^{-j k 2 \pi / N}\right)\left\{S_{K}-\sum_{n=0}^{N-1} A_{n-1} e^{-j n k 2 \pi / N}\right\} \text {, }
$$

or

$$
\omega_{k}=\left(1-e^{-j k 2 \pi / N}\right)^{-1}\left\{S_{k}-e^{-j k 2 \pi / N} \sum_{\ell=0}^{N-2} A_{l} e^{-j 2, k 2 \pi / N}\right\} .
$$


This is equivalent to

$$
\Phi_{K}=\left(1-e^{-j k 2 \pi / N}\right)^{-1}\left\{S_{K}-e^{-j k 2 \pi / N}\left\{S_{K}-A_{N-1} e^{-j(N-1) K 2 \pi / N}\right)\right\}
$$

and, since $e^{-j k 2 \pi}=1$,

$$
\Phi_{K}=S_{K}+A_{N-1} /\left(1-e^{-j k 2 \pi / N}\right) k=1, \ldots, N-1 .
$$

This is a very important result in that it permits considerable saving in computational time. Using an FFT read-only-memory pack our intelligent terminal can compute for 256 frequency points, $\Phi_{K}$ in under a minute compared to over an hour if Eq. (19) were used. Appendix $D$ contains the software utilizing Eq. (28). Appendix $E$ contains the results of using the $\sin x / x$ approach Eq. (19) and the modified FFT approach Eq. (28) on the same data. The results are identical.

Both approaches are sensitive to dc offset. Assuming the zero frequency result is not of interest the waveform should be shifted so as to make the amplitude zero at time equal to zero. Equivalently, using Eq. (19), $B_{0}$ can be set to zero in software or using the modified FFT approach replacing Eq. (28) by

$$
\Phi_{K}=S_{K}+\left(A_{N-1}-A_{0}\right) /\left(1-e^{-j k 2 \pi / N}\right), k=1, \ldots, N-1 .
$$


If the software is modified in such a way both methods are insensitive, as they should be, to dc offset.

The software development will be invaluable in future measurements. The $\sin x / x$ approach has the advantage of allowing the user to choose the points to be calculated. The modified FFT approach is considerably faster.

\section{Conclusion}

A measurement program has been initiated at NBS that will contribute to the development, testing, and utilization of incipient fault detection/ location instrumentation. The measurement system, centered on an intelligent terminal, permits the digitizing of transient and continuous waveforms and subsequent processing.

The system was initialiy configured in such a way as to permit time-domain reflectometry studies on a $15 \mathrm{kV}$ distribution cable. The results were significant in that they showed that TDR techniques would have very 1 imited use for detection of incipient faults. The difficulty is that the high frequency attenuation in the extruded polyethylene insulated distribution cable prevents the spatial resolution of the anticipated incipient faults.

Measurements in the future will determine the rf properties of high voltage transmission cables. These results will be important in the design of incipient-fault intrumentation. These measurements will be made in the time doma in requiring mathematical transformation to the desired frequency domain. Extensive software has been written and tested using two different methods. 


\section{References}

1. Certain commercial equipment, instruments, or materials are identified in this report in order to adequately specify the experimental procedure. In no case does such identification imply recommendation or endorsement by the National Bureau of Standards, nor does it imply that the material or equipment identified is necessarily the best available for the purpose.

2. The Tektronix General Purpose Interface Bus (GPIB) is compatible with the Hewlett Packard HP-IB and both are compatible with the IEEE-488-1975 interface specifications.

3. T. P. Lanctoe, J. H. Lawson, W. L. McVey, "Investigation of Insulation Deterioration in $15 \mathrm{kV}$ and $22 \mathrm{kV}$ Polyethylene Cables Removed from Service - III," IEEE Power Engineering Society Summer Meeting, Los Angeles, CA, pp. 759-763 (1978).

4. E. F. Kelley and R. E. Hebner, "The Electric Field Distribution Associated with Prebreakdown Phenomena in Nitrobenzene," Journal of Applied Physics (submitted).

5. H. H. Skilling, "Electric Transmission Lines," First Edition, McGraw-Hi11, pp. 353-355 (1951).

6. J. W. Cooley and J. W. Tukey, "An algorithm for the machine calculation of complex Fourier series," Math. Comput., Vo1. 19, pp. 297-301 (1965). 
7. E. Oran Brigham, The Fast Fourier Transform, Englewood Cliffs, $\mathrm{HJ}$ : Prentice Hall (1974).

8. H. A. Samulon, "Spectrum Analysis of Transient Response Curves," Proc. of I.R.E., Vol. 39, pp. 175-186 (1951).

9. C. Shannon, "Communications in the presence of noise," Proc. I.R.E., Vol. $37, \mathrm{pp} .10-22(1949)$

10. J. Waldmeyer, "Fast Fourier transform for step-like functions: the synethesis of three apparently different methods," IEEE Trans. Inst. Meas. Vol. IM-29, No. 1, pp. 36-39 (1980). 


\section{APPENDIX A}

This software permits the collection of data from the digital processing oscilloscope DPO. The data can first be averaged up to 4096 times by the DPO. The data are plotted on the terminal screen. Portions may be expanded. The data can be filtered (adjacent points averaged). The data can be output to a plotter for quality graphics. 
$\infty$
$\infty$
1
0
1
0

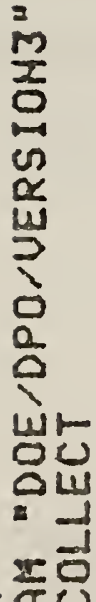

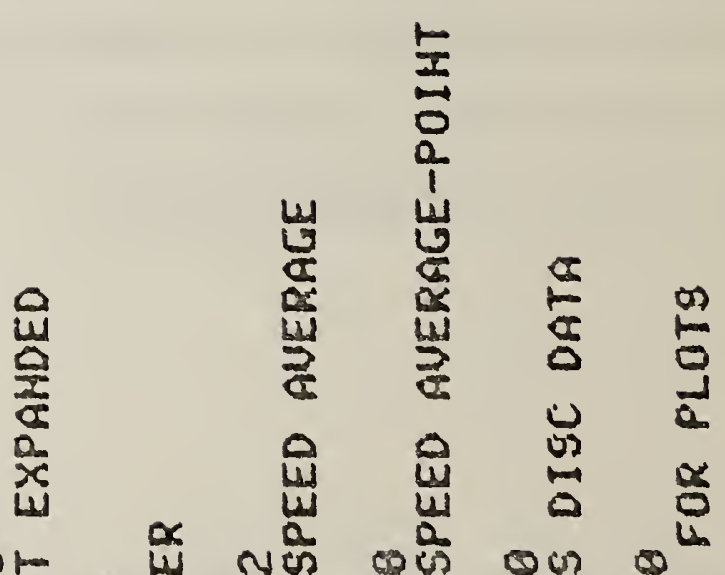

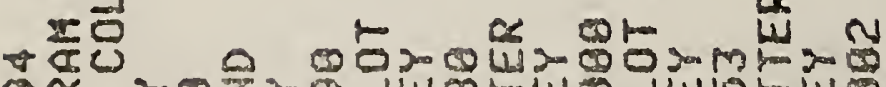

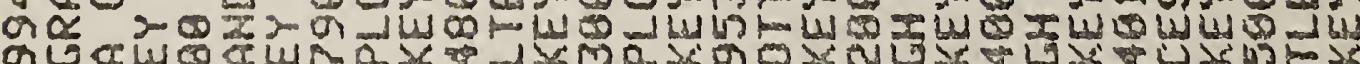

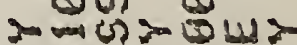

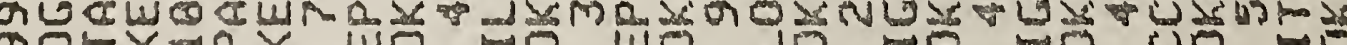

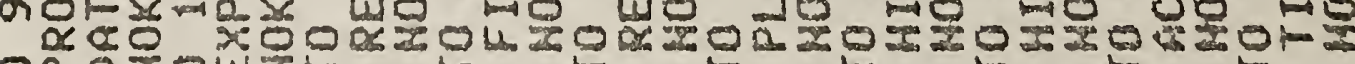
-

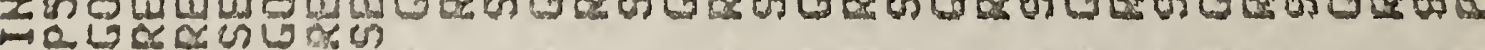
- 


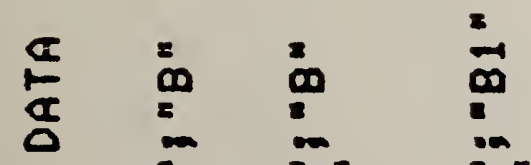

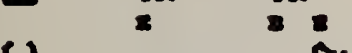

$U_{0}^{0}$

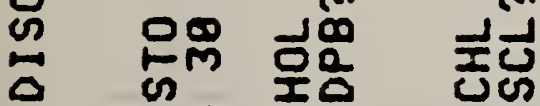

- n

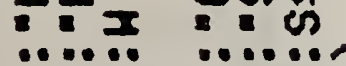

Miñ

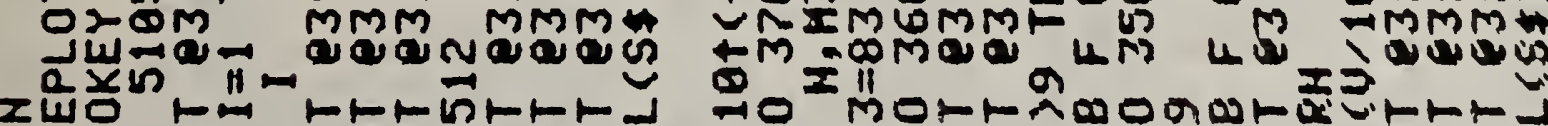

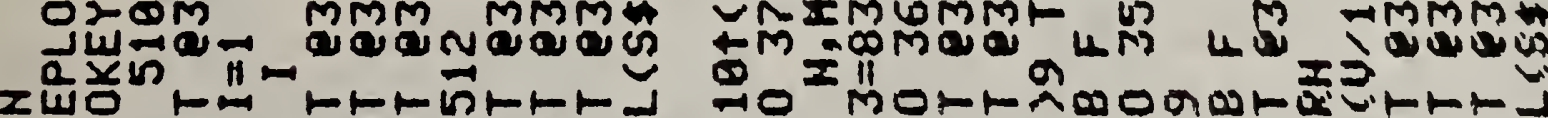

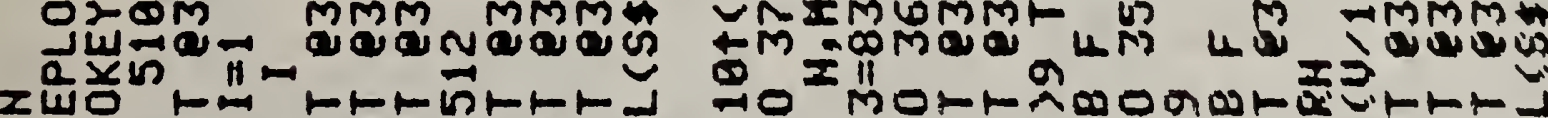

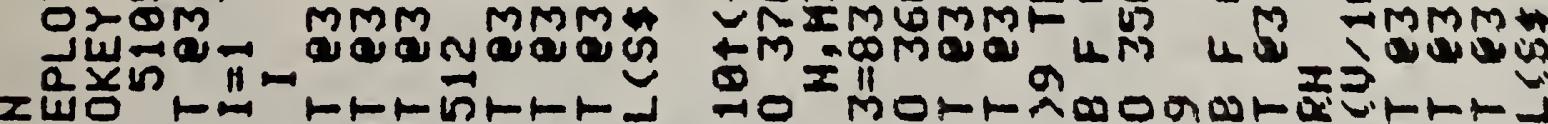

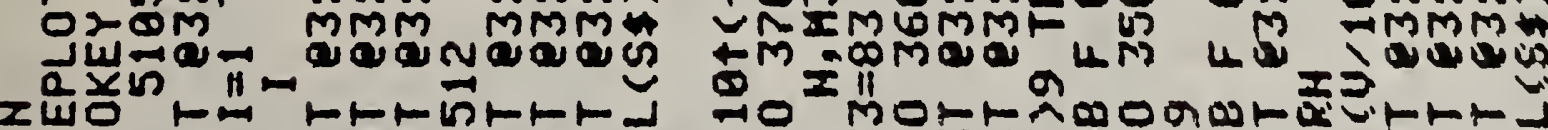

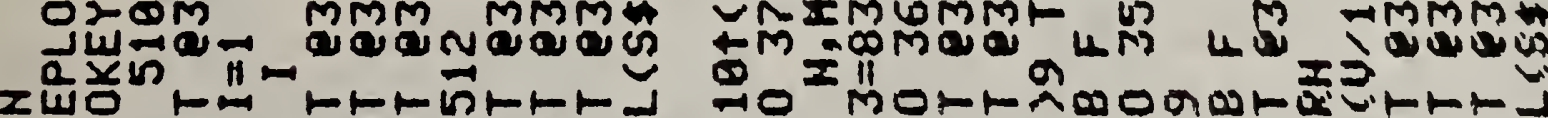

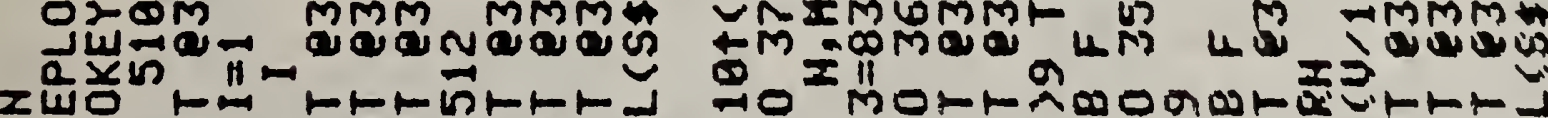

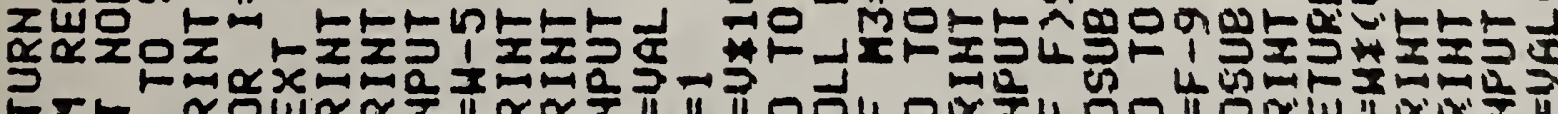

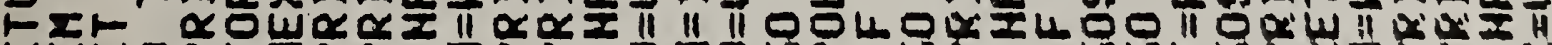

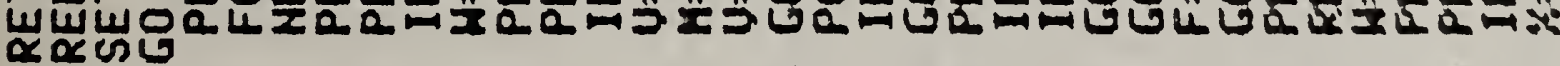

00000000000000000000000000000050

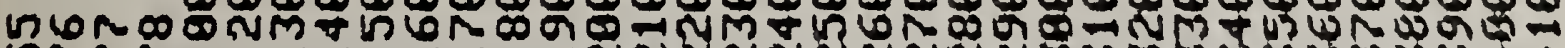

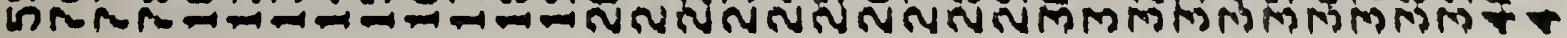




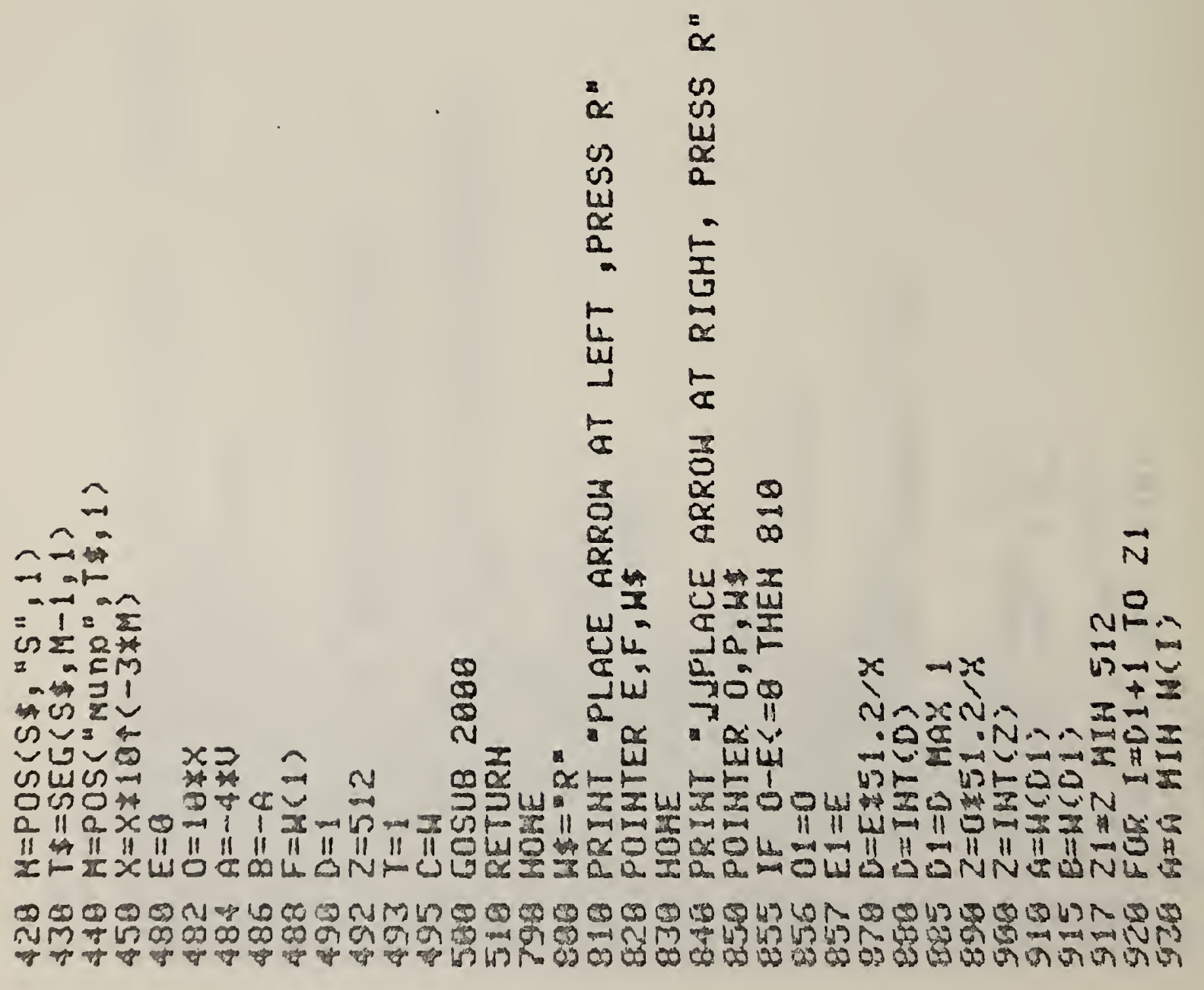




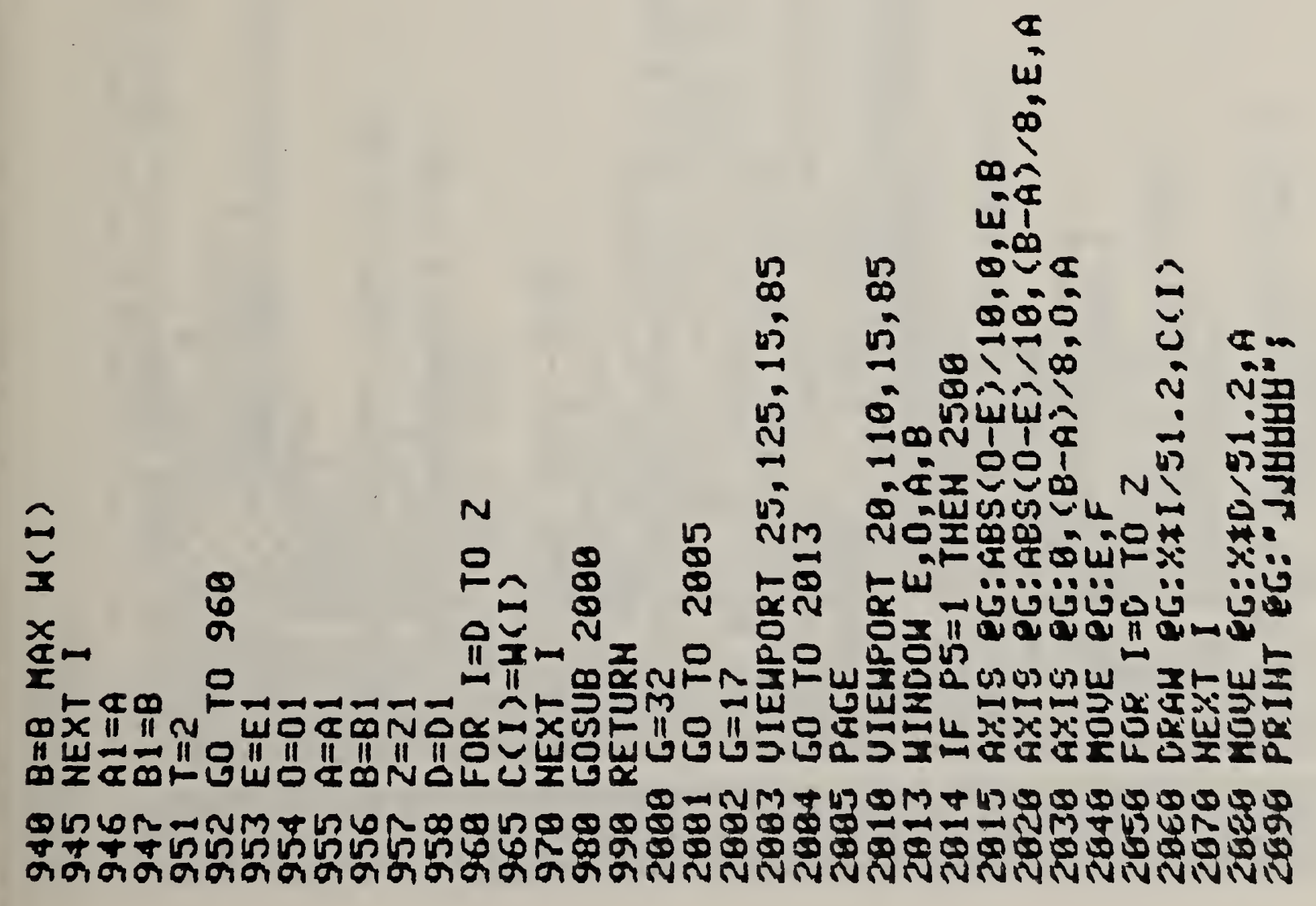




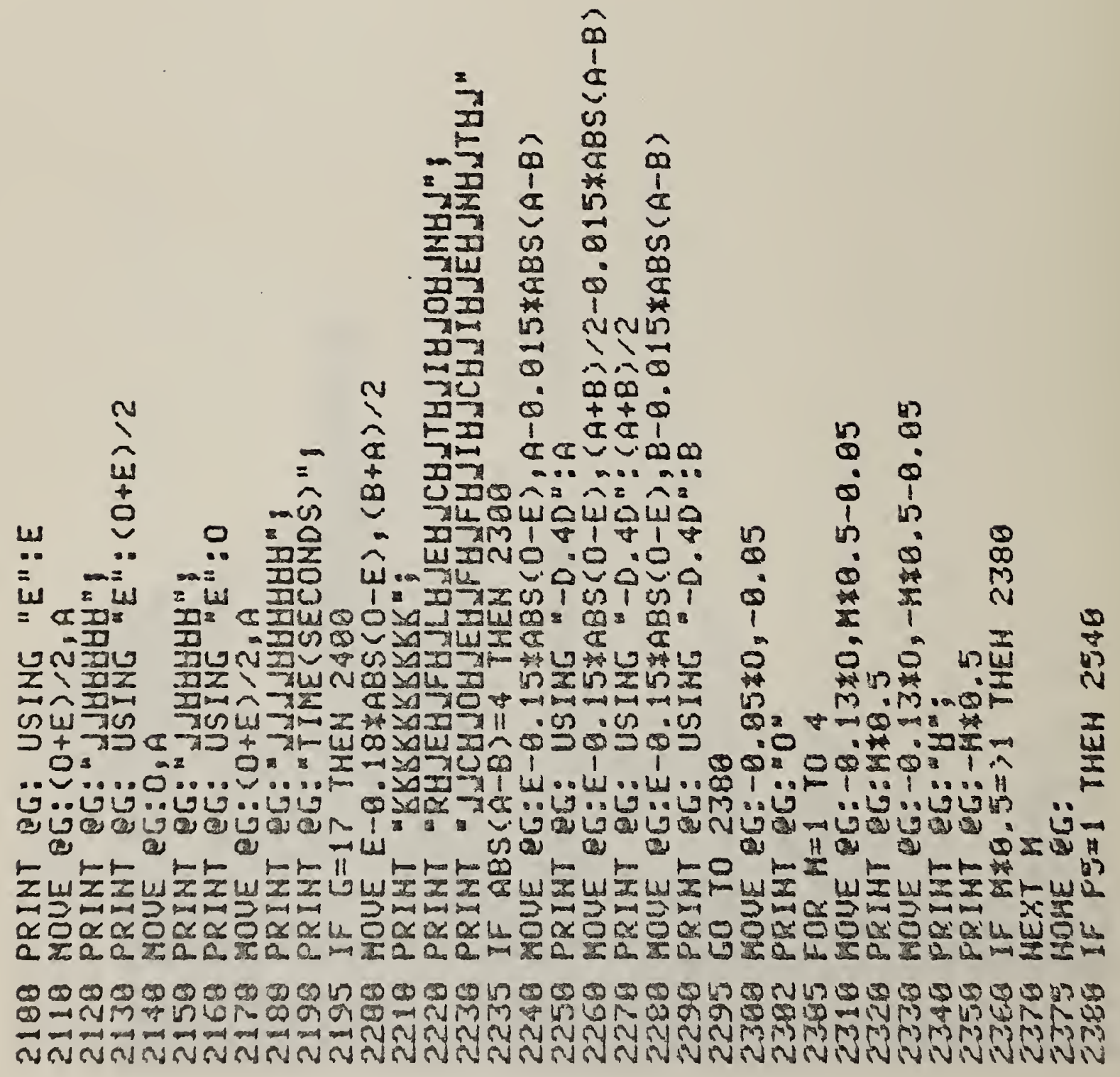




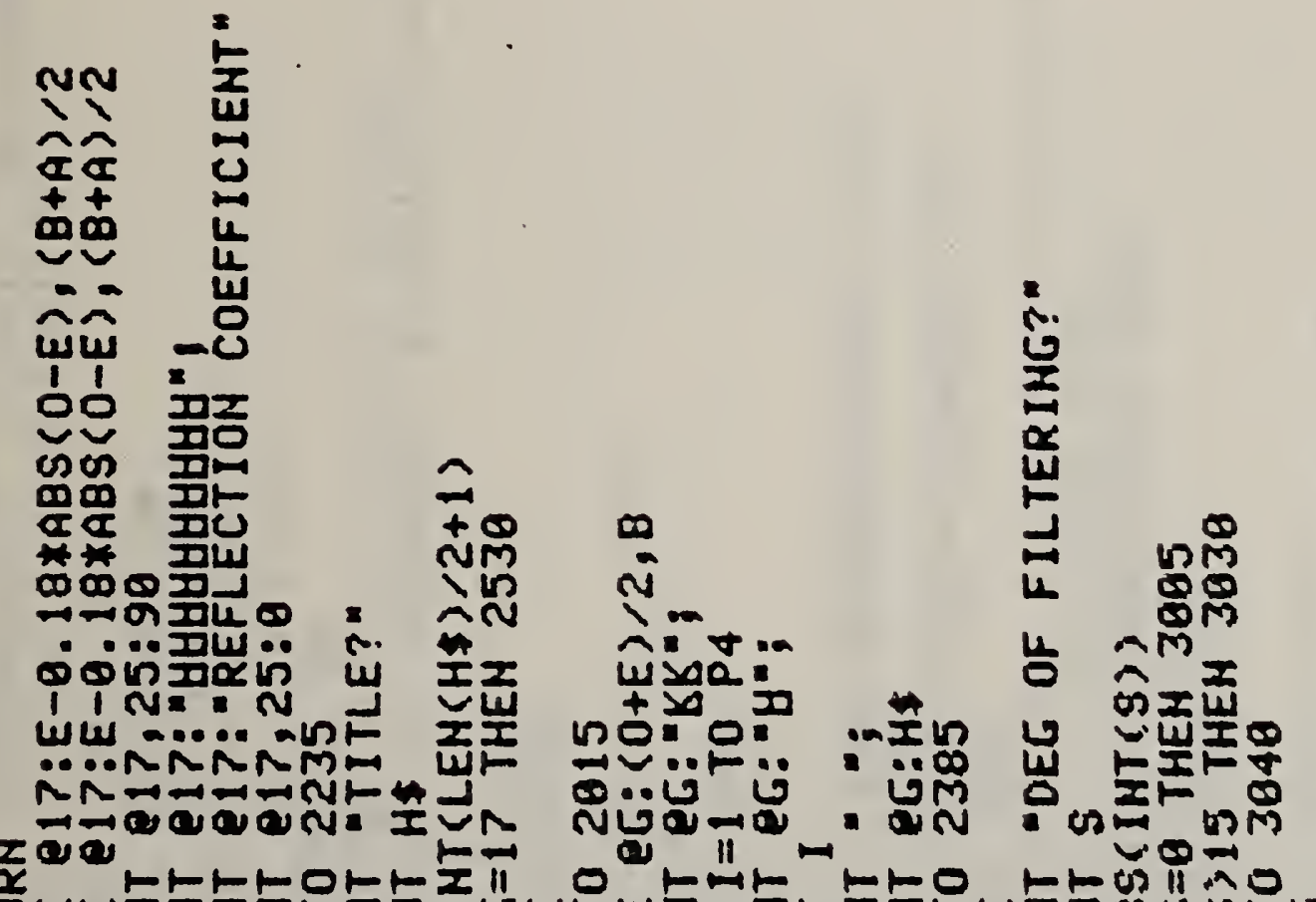

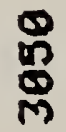

岌

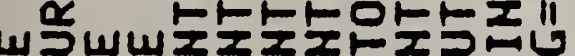

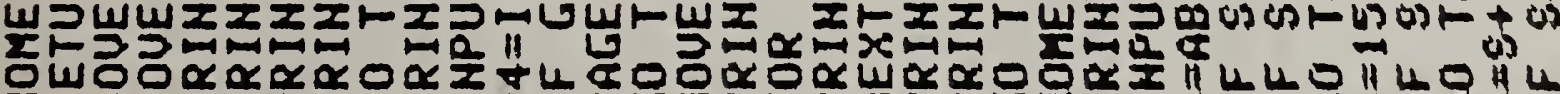

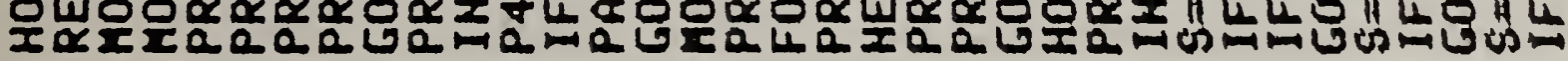

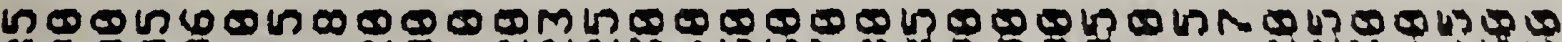

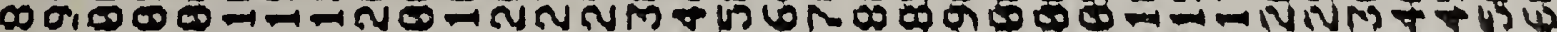

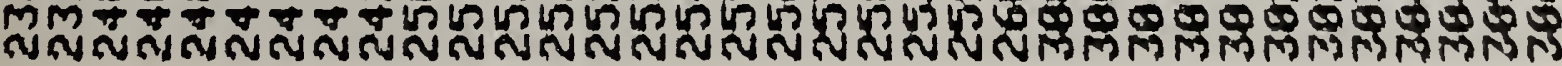




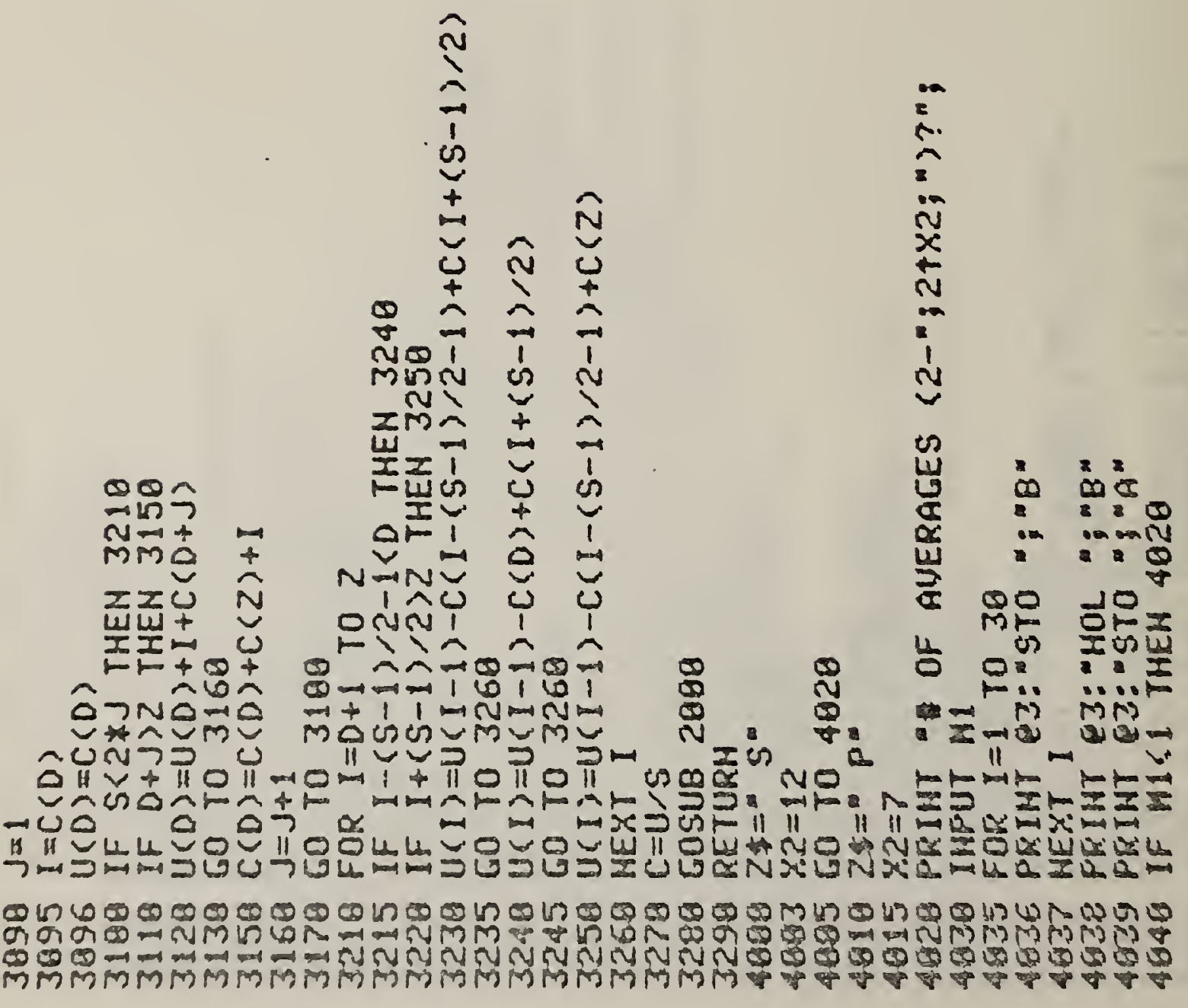




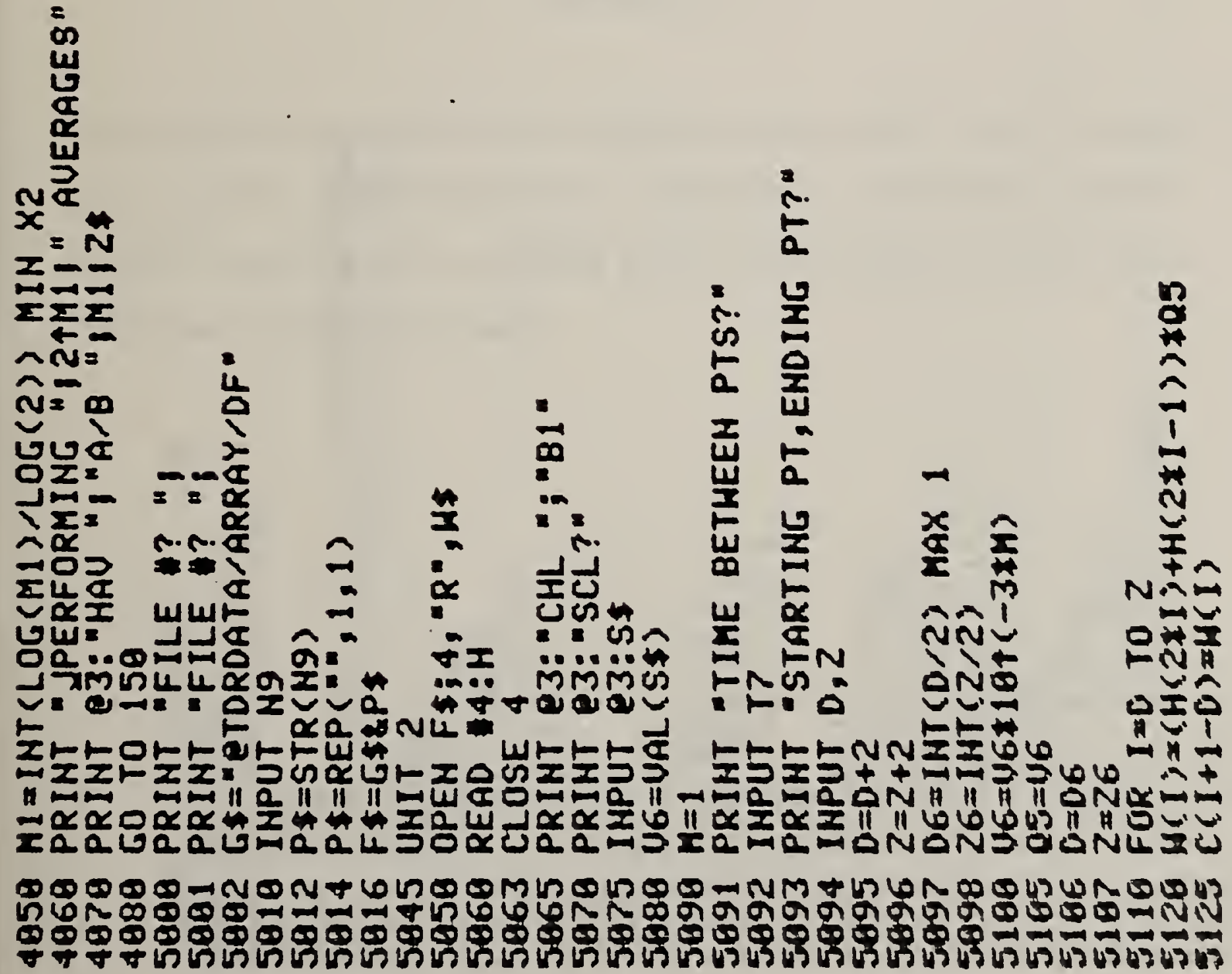




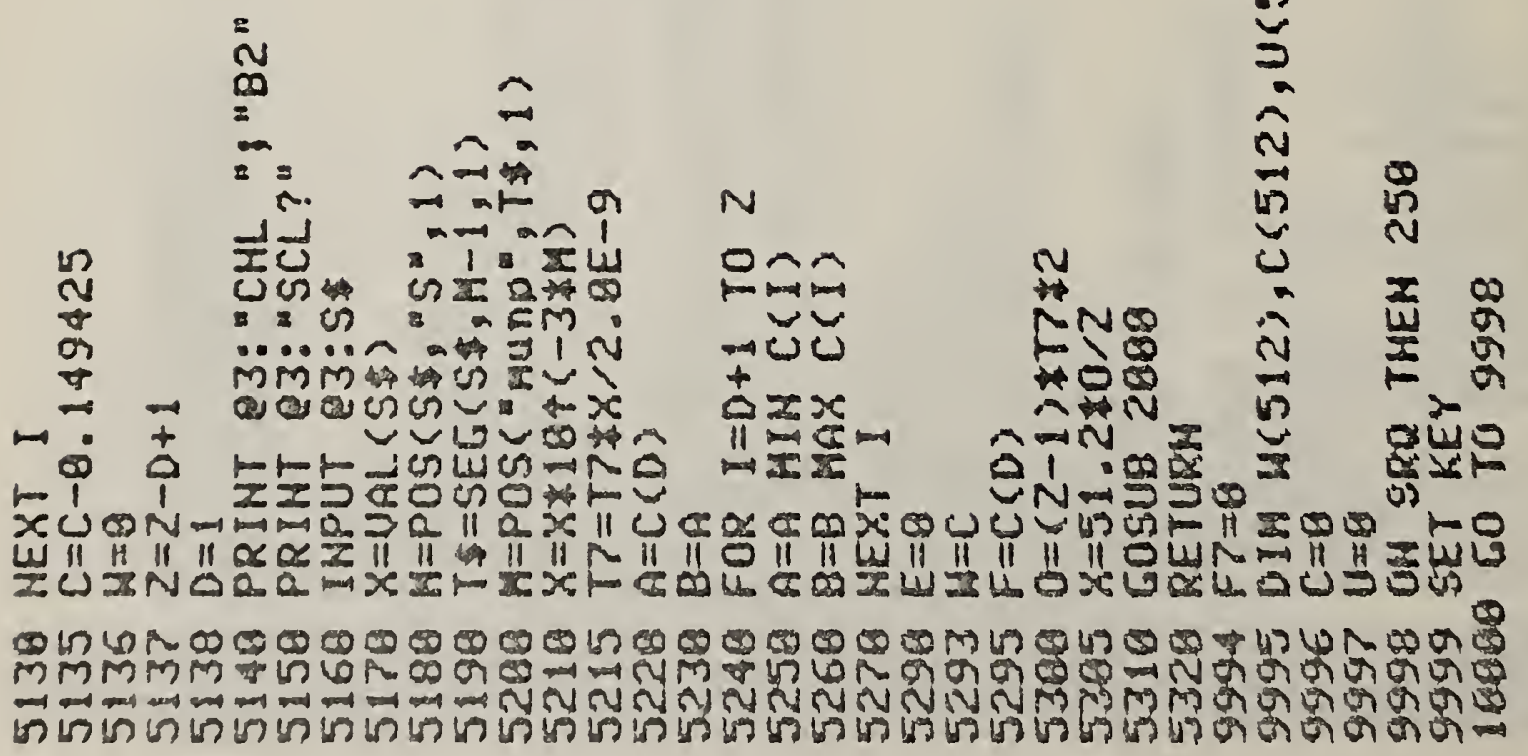




\section{APPENDIX B}

This software, using the $\sin x / x$ approach described in the text, Eq. (9), can be used for a discrete Fourier transform of time-domain results. It is essential that the last digitized point of the waveform equal zero or truncation errors will result. 


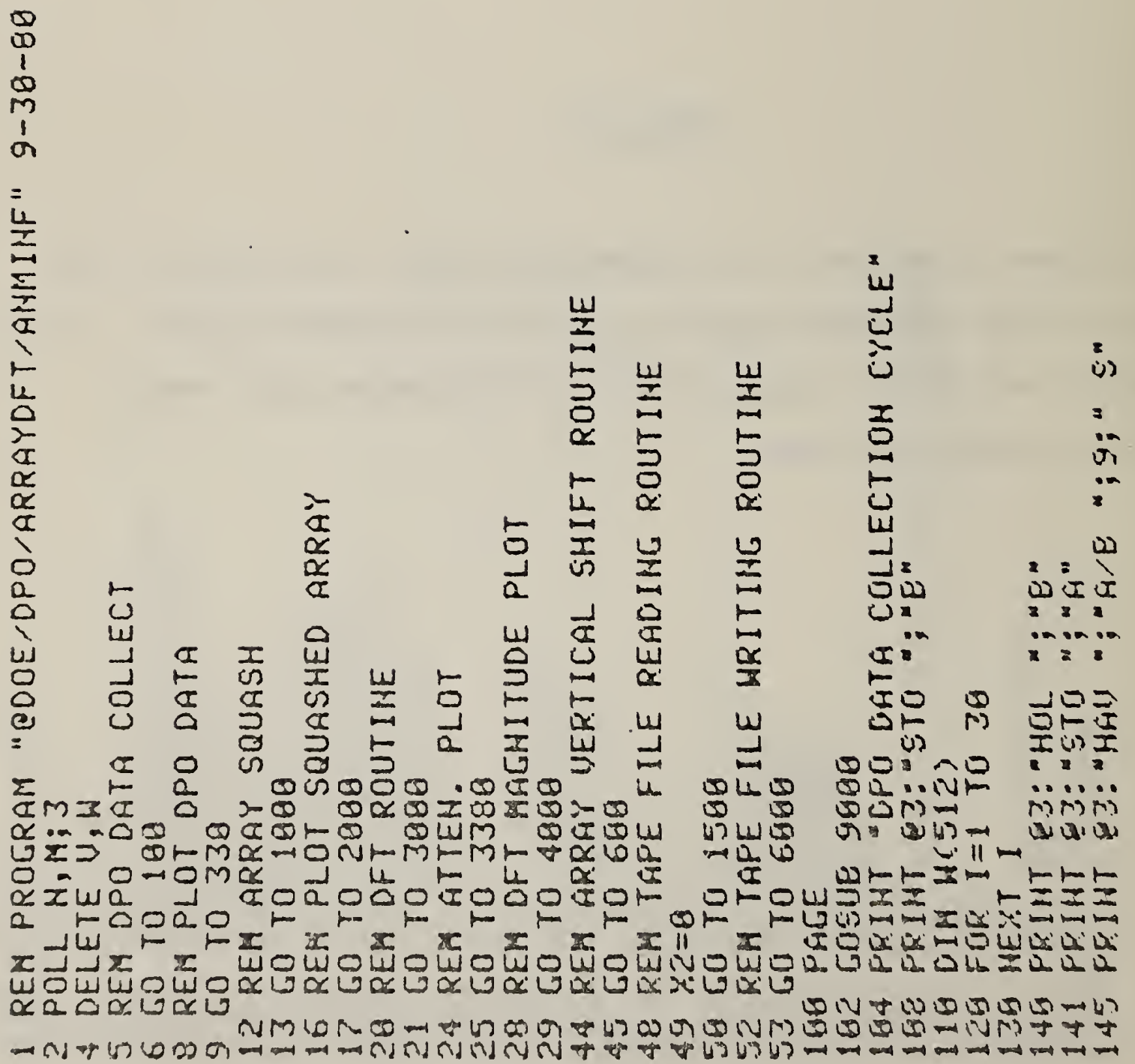




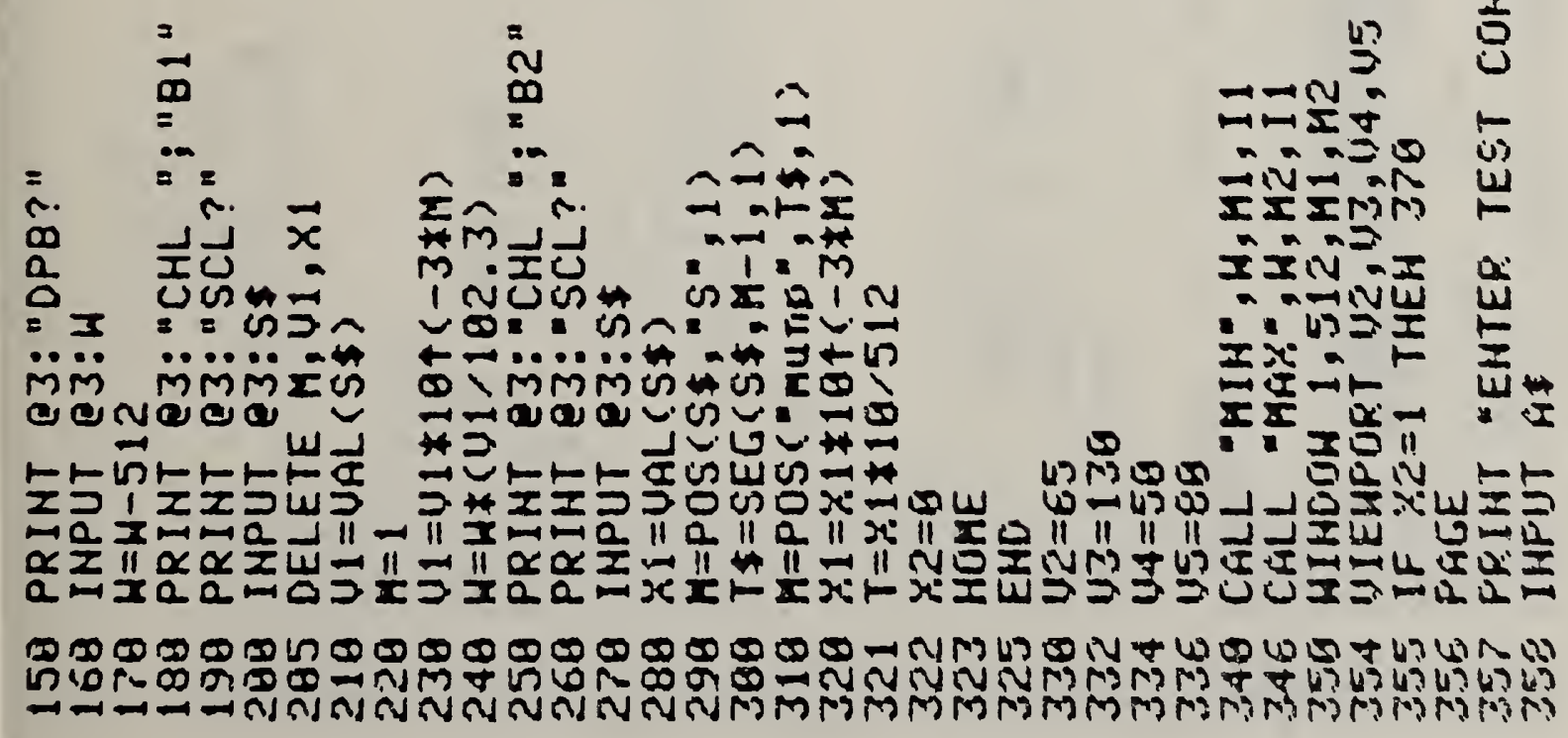




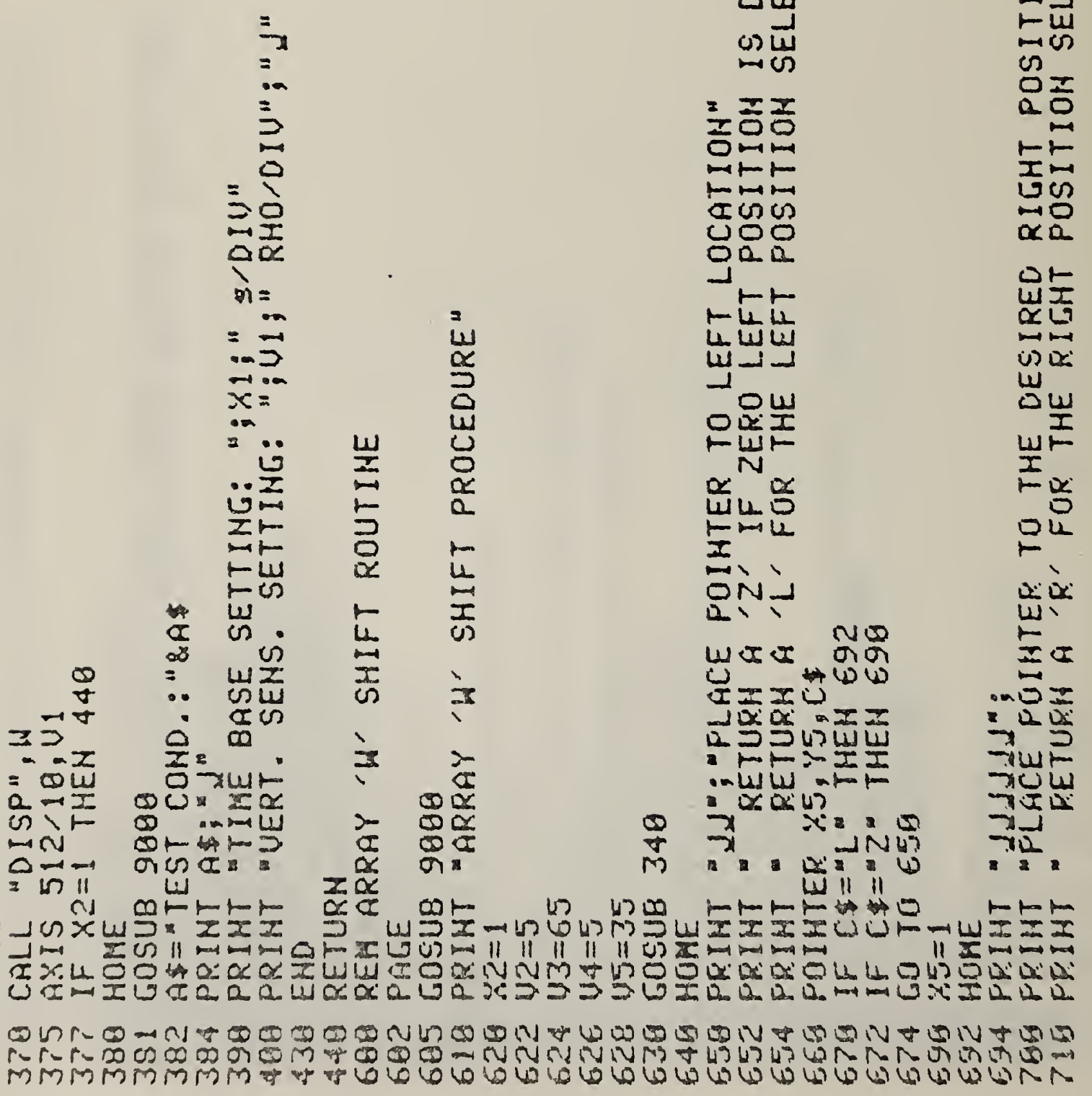




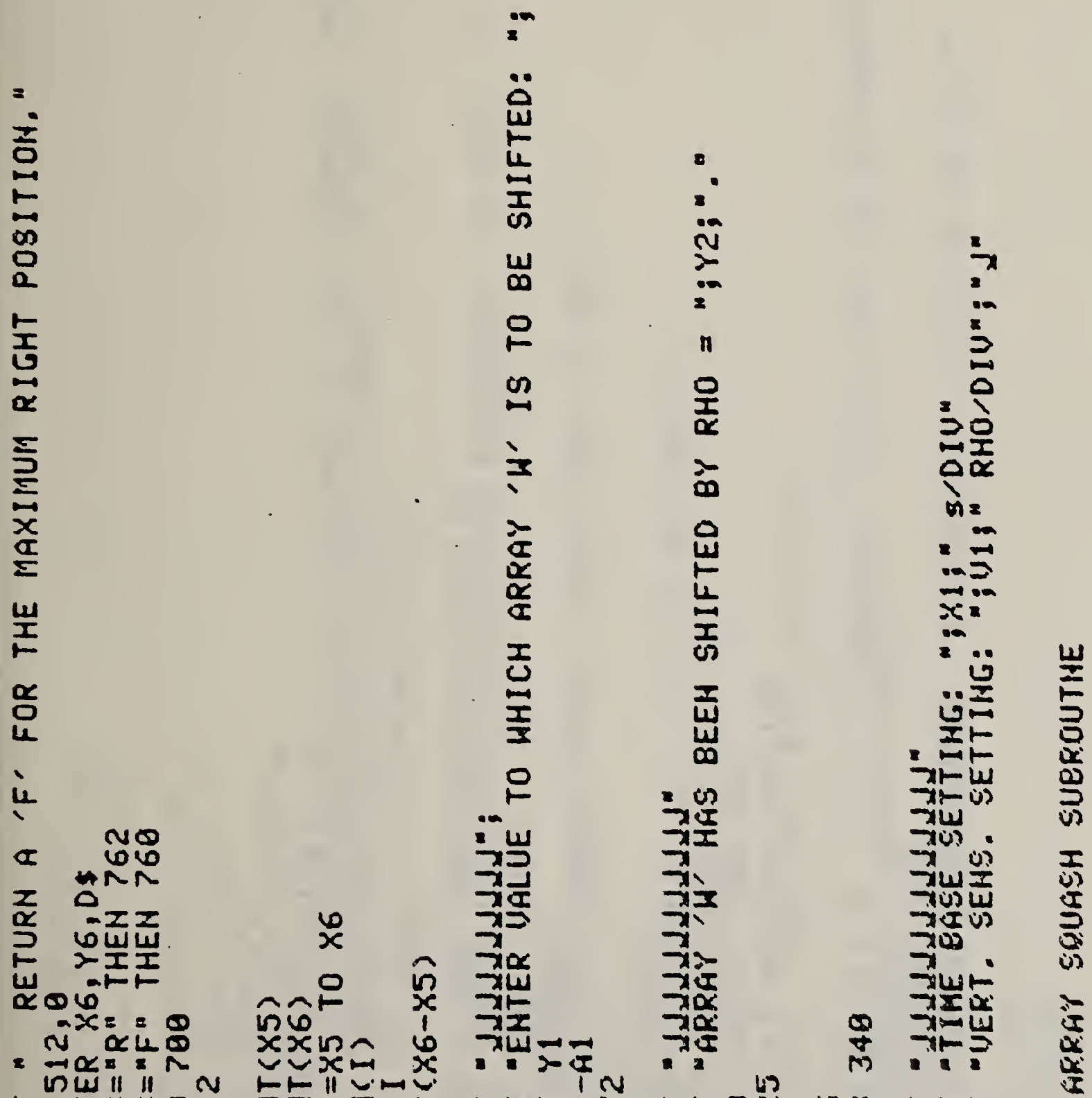

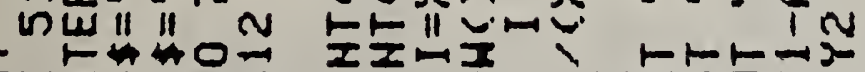

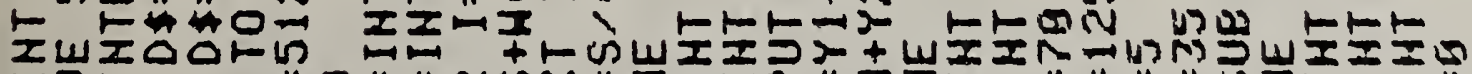

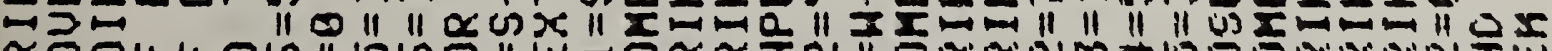

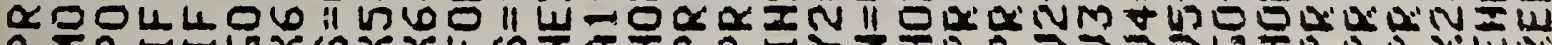

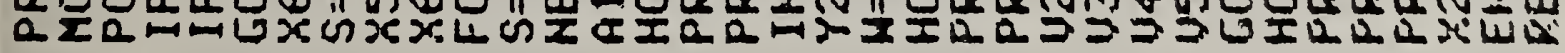

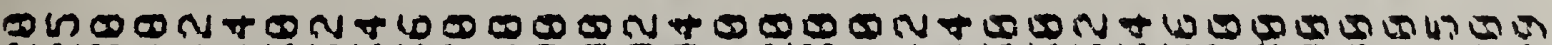

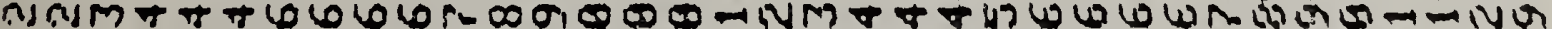

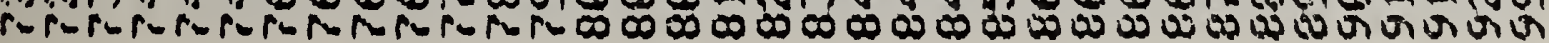



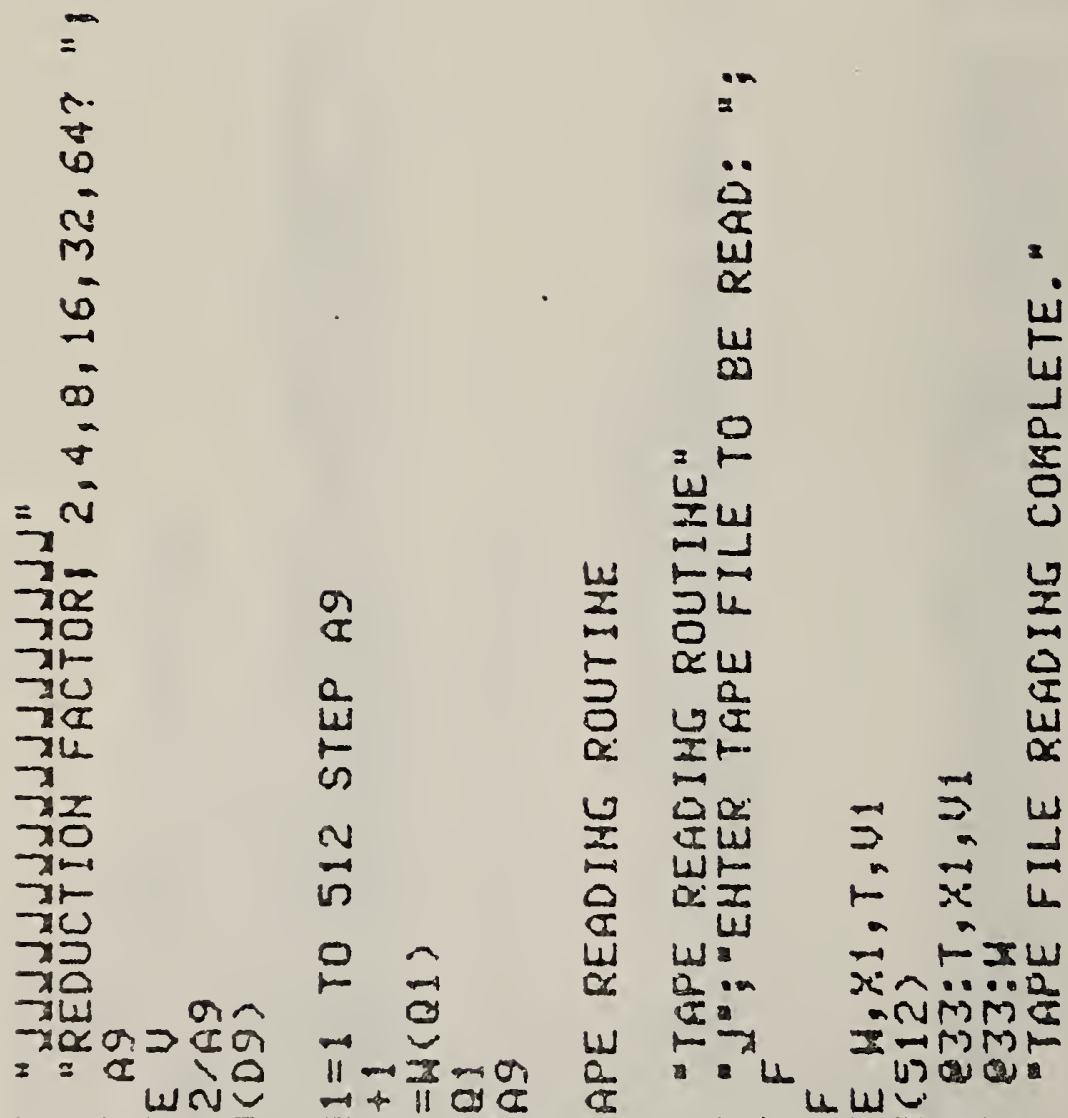

トトトトロつ

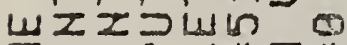
co oñtr

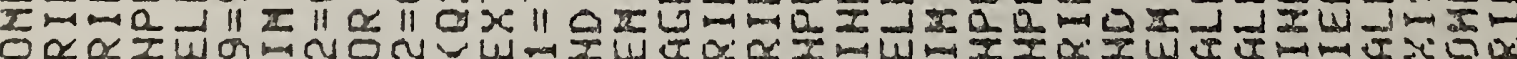

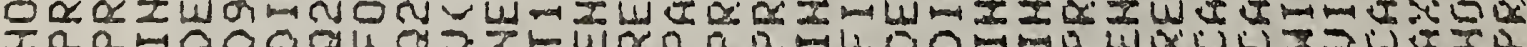

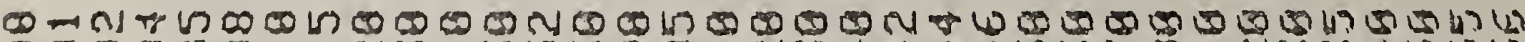

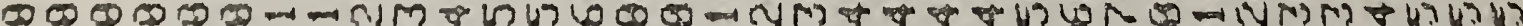
D.

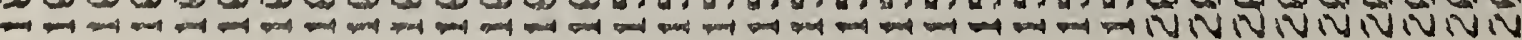




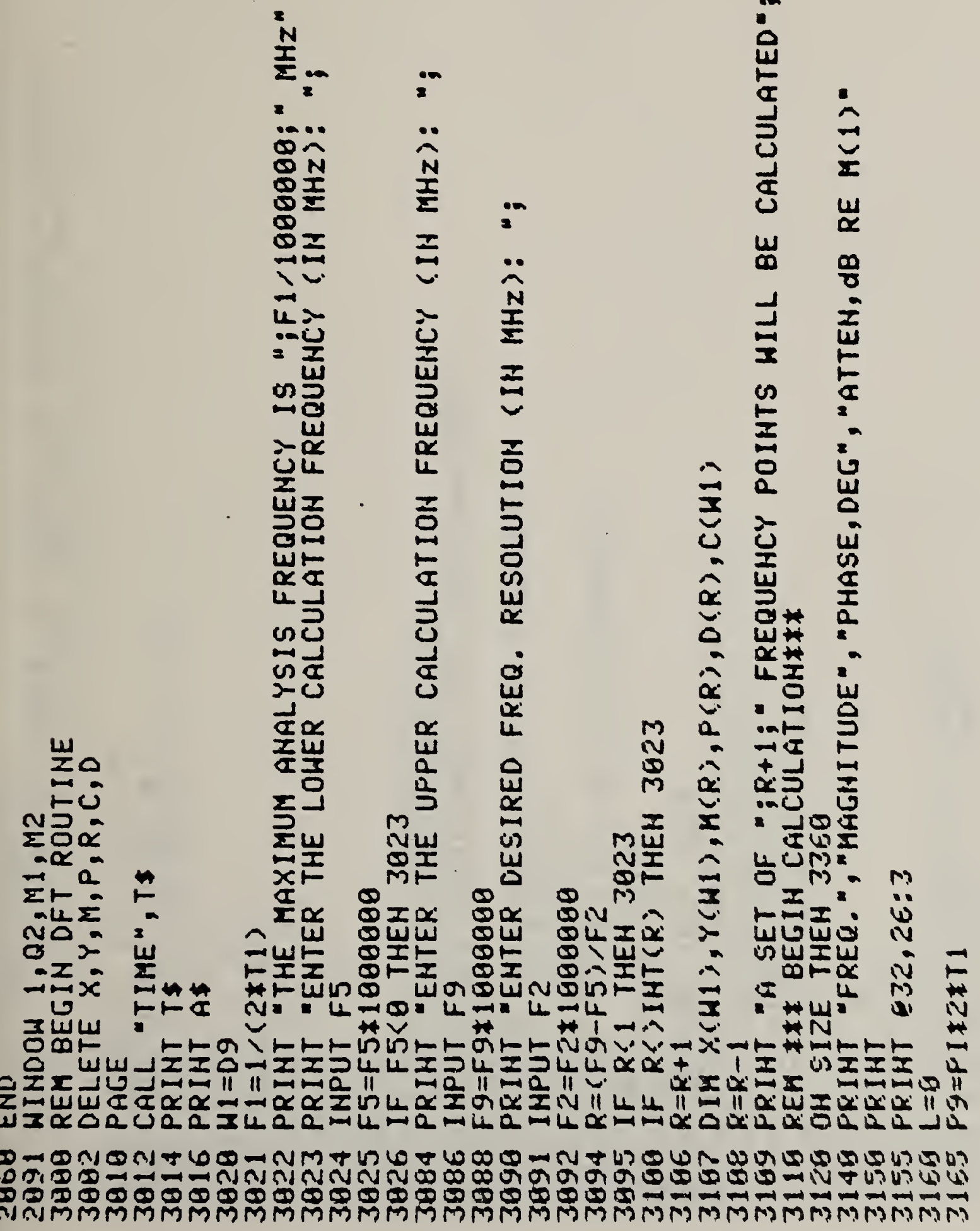



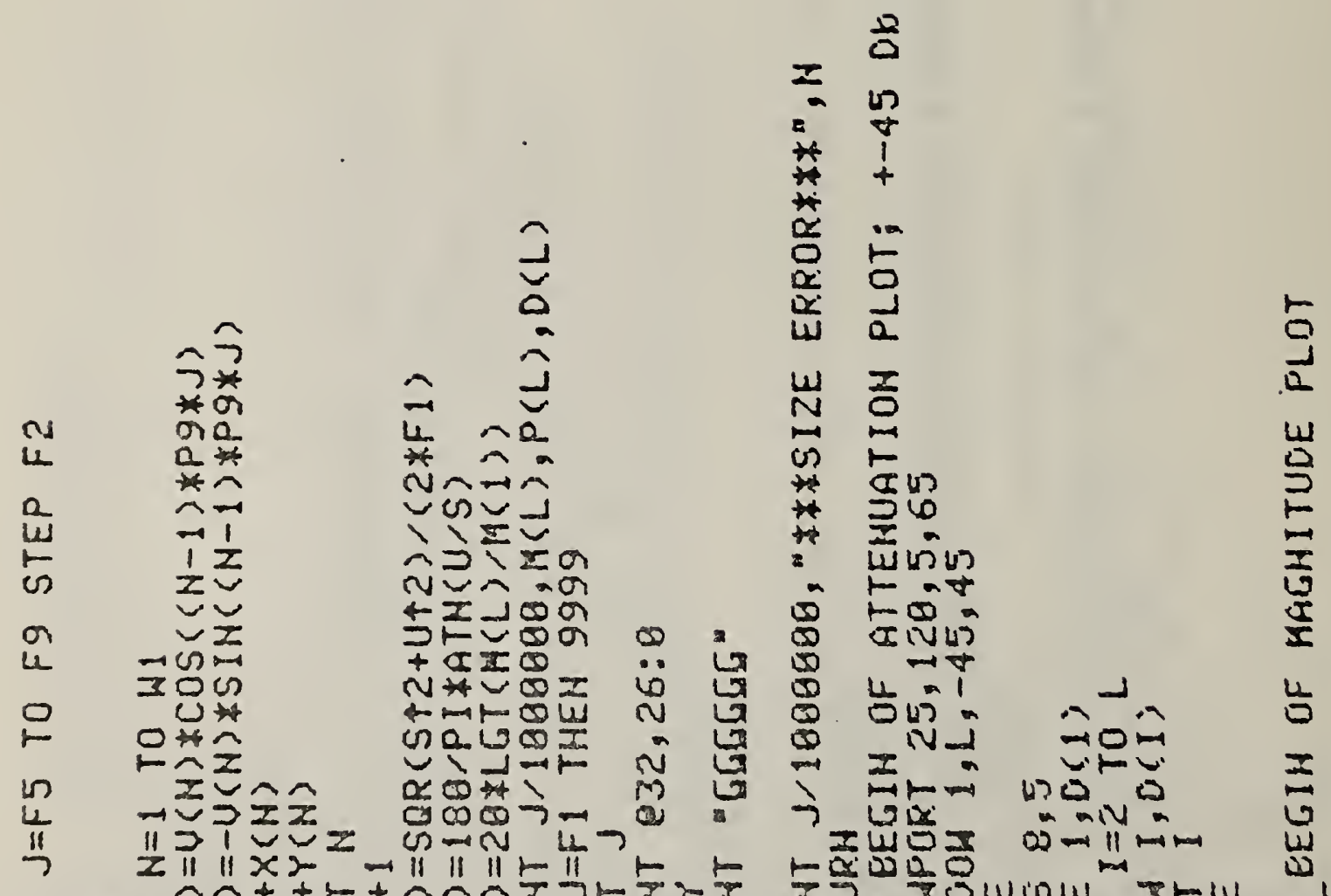

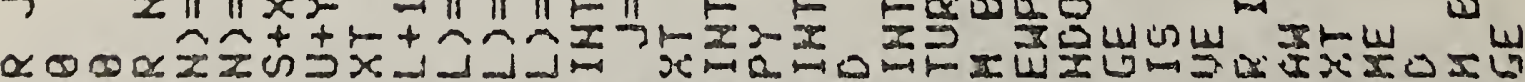

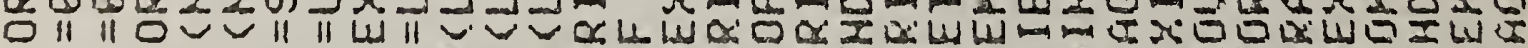

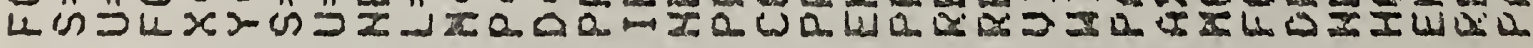

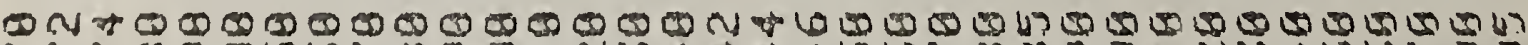

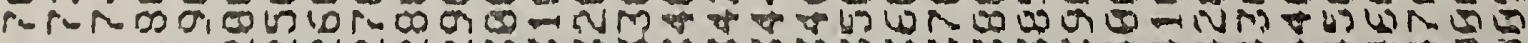

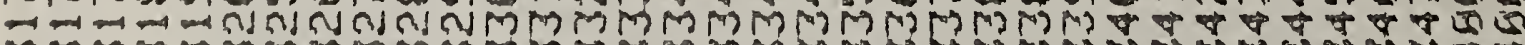

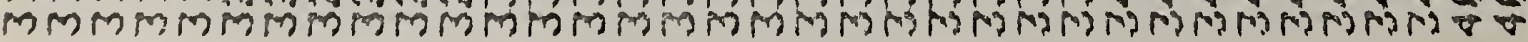




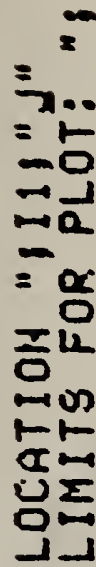

เW

응

$=2$

mas

$\sum \frac{1}{a}$

$=\frac{\Sigma}{\sigma}$

$\cos x$

$\rightarrow \frac{\pi}{\Sigma}$

$m$

$\exists$ 은

$\frac{1}{\alpha} \frac{1}{\alpha}$

$-5$

2 in

$\rightarrow \sum^{2}$

매는

$m \times I$

Er

$=$

$\sum \propto$

20

n

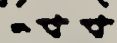

$\infty \pm \pm$

$\infty=$

$\rightarrow m \infty$

- แய

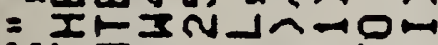

XFZ

I wMた

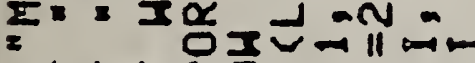

トトトロO ロ

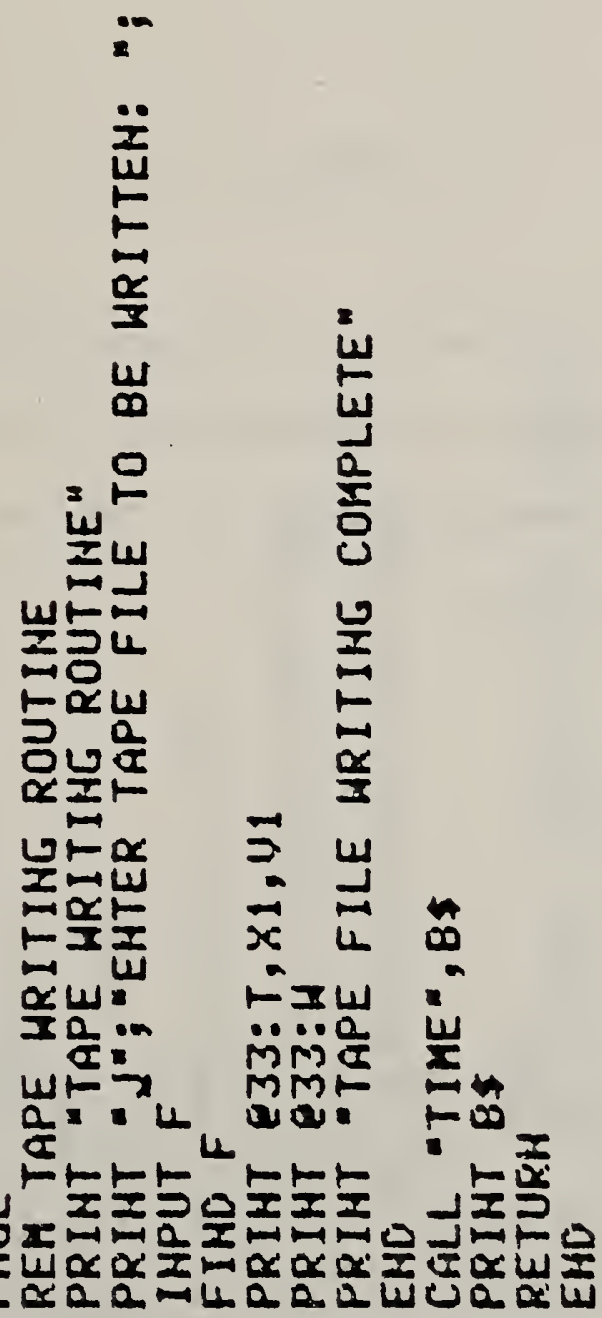

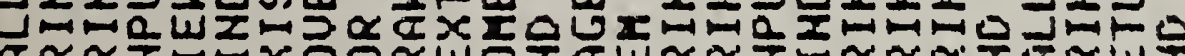

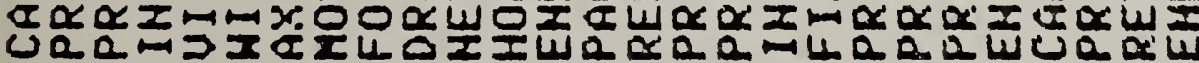

NMOD00000000000-04 -

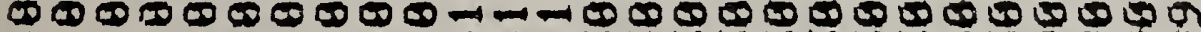

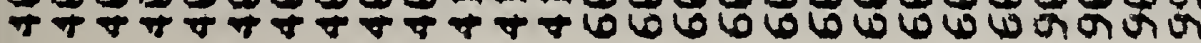




\section{APPENDIX C}

This software using a modified $\sin x / x$ approach, Eq. (19), results in a discrete Fourier transform of time-domain data. The final point of the digitized waveform need not equal zero but the waveform is required to approach some constant value. 


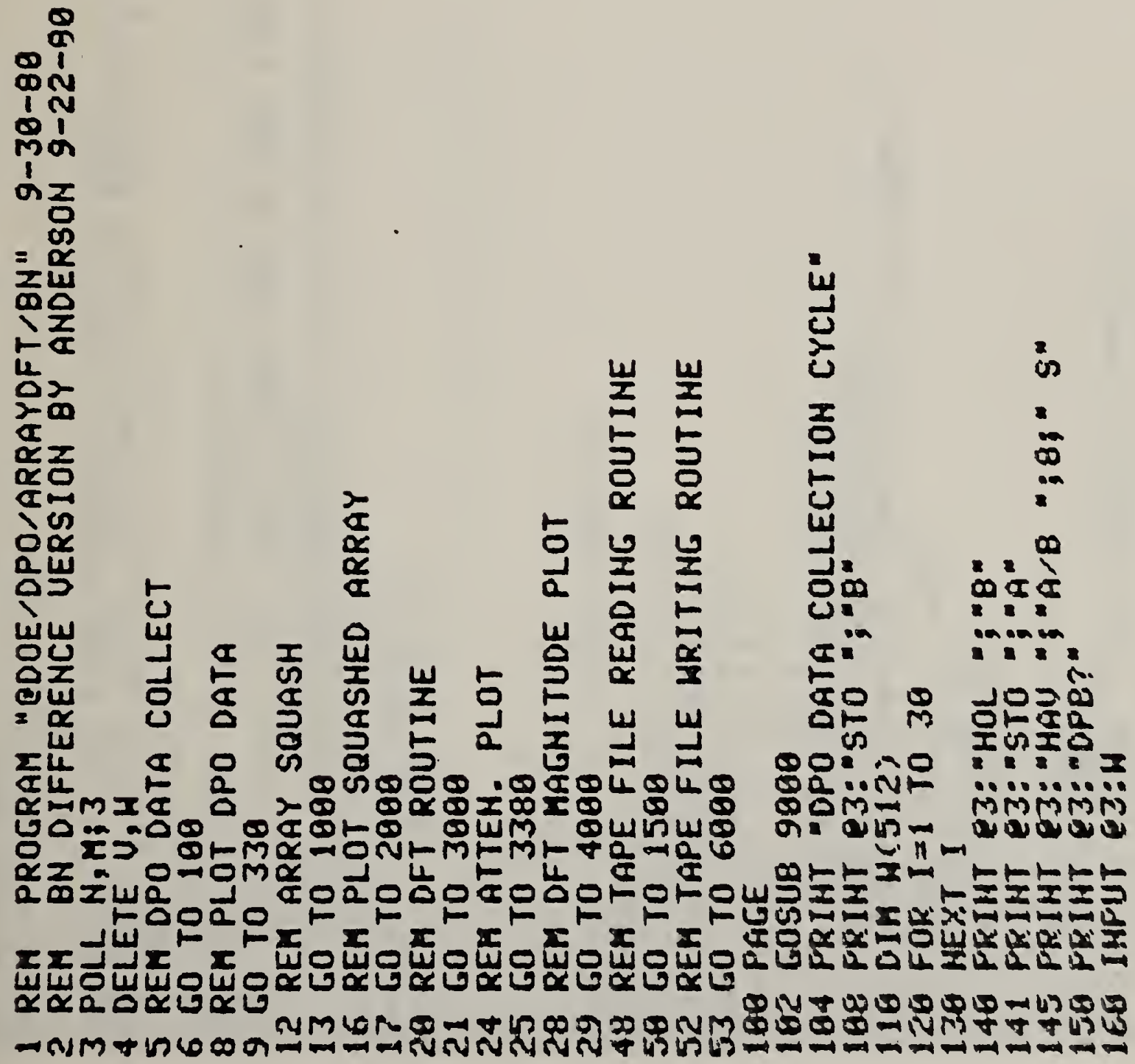




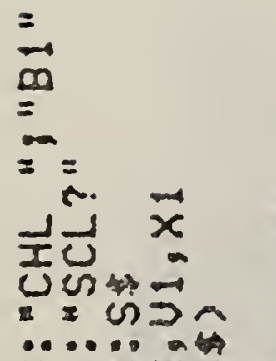

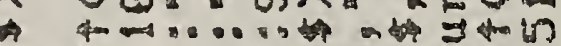
ñrrera -

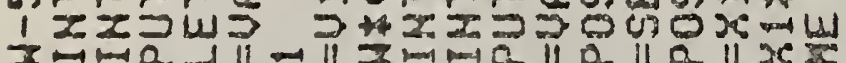

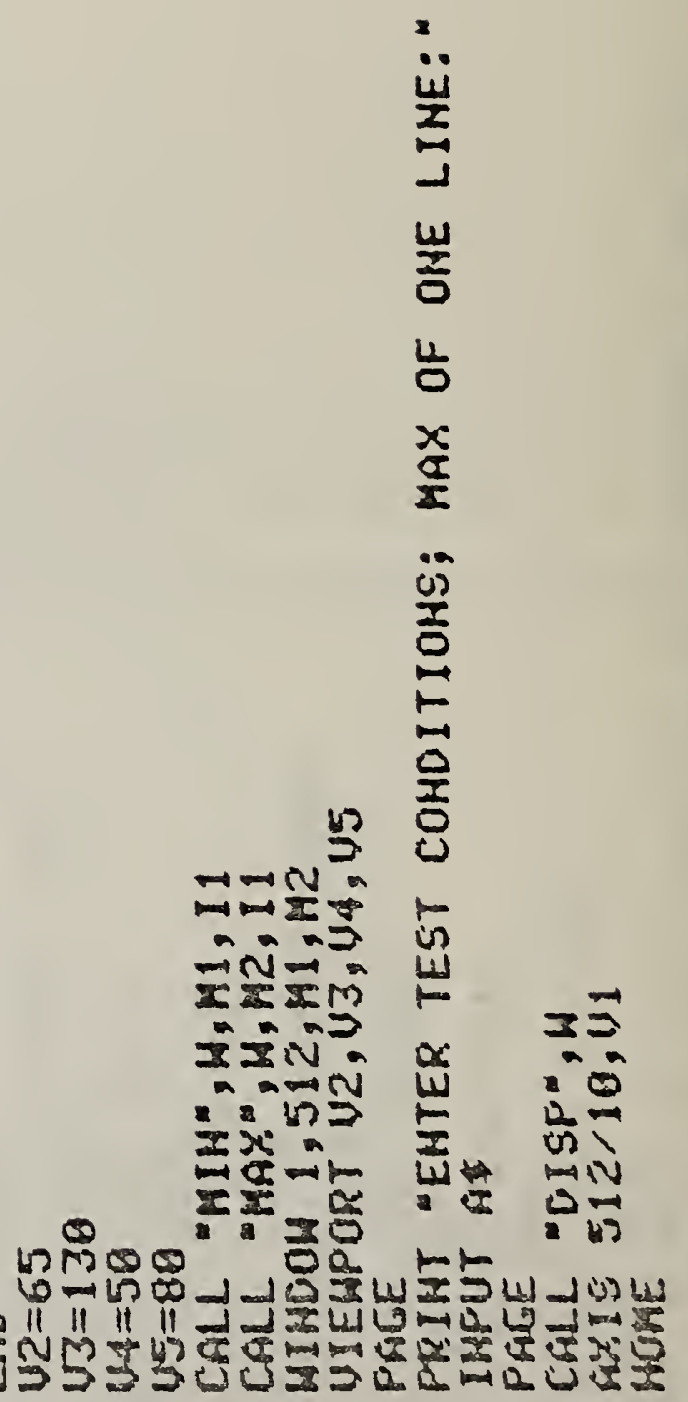

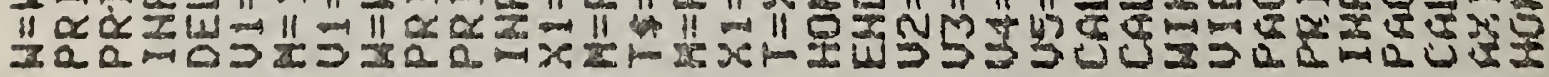

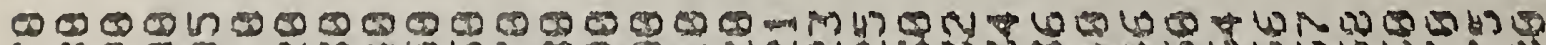

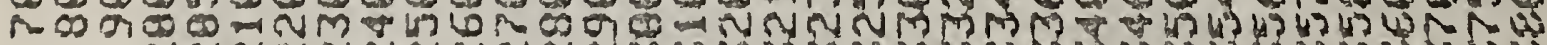
- 


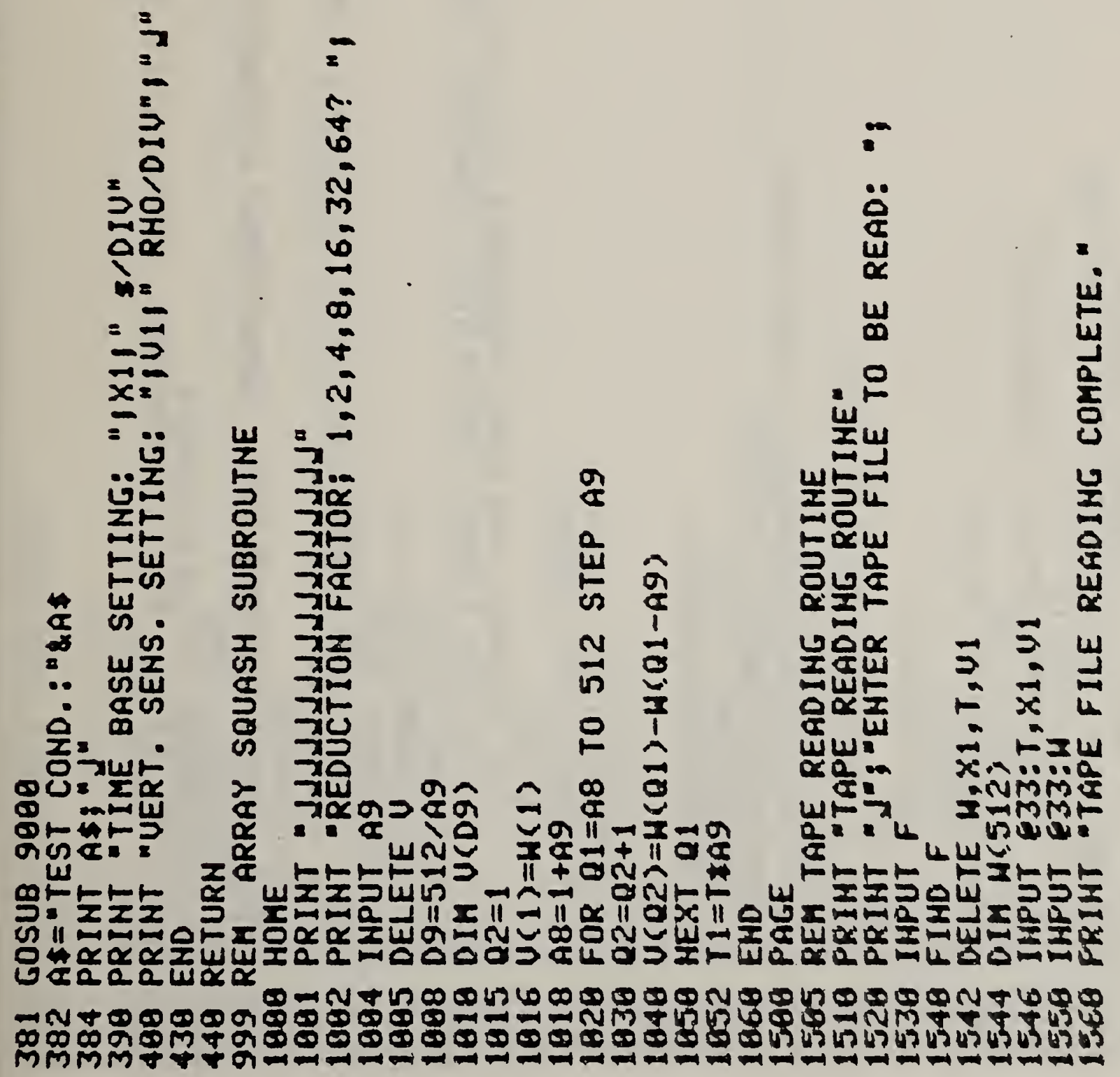


$\frac{\hat{z}}{\frac{2}{\alpha}}$

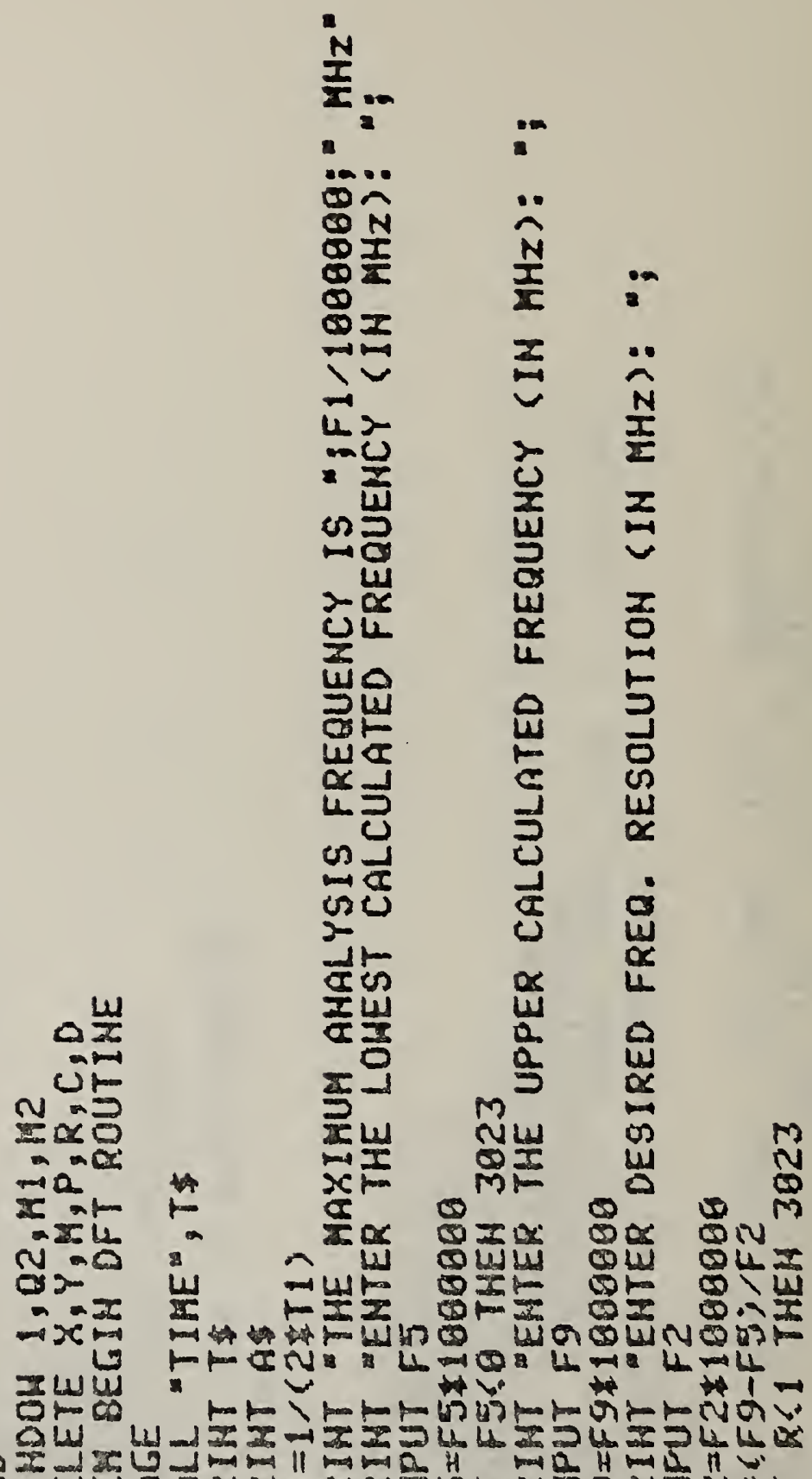

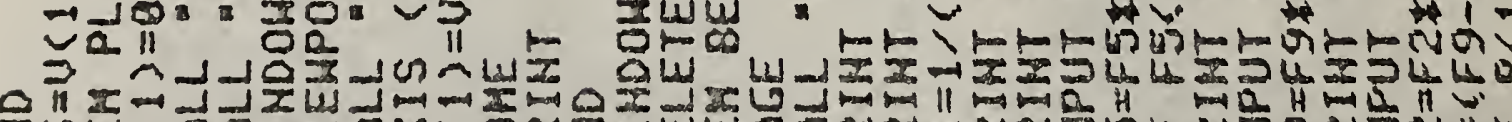

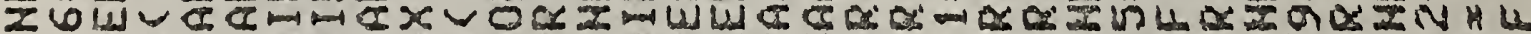

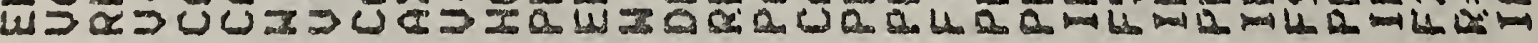

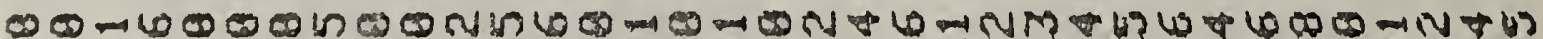
PDO 0 - NMm

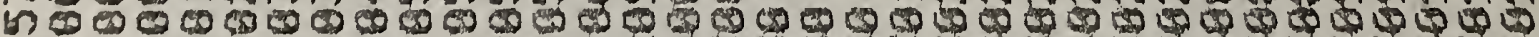

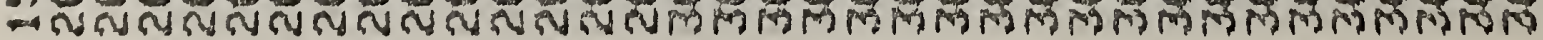




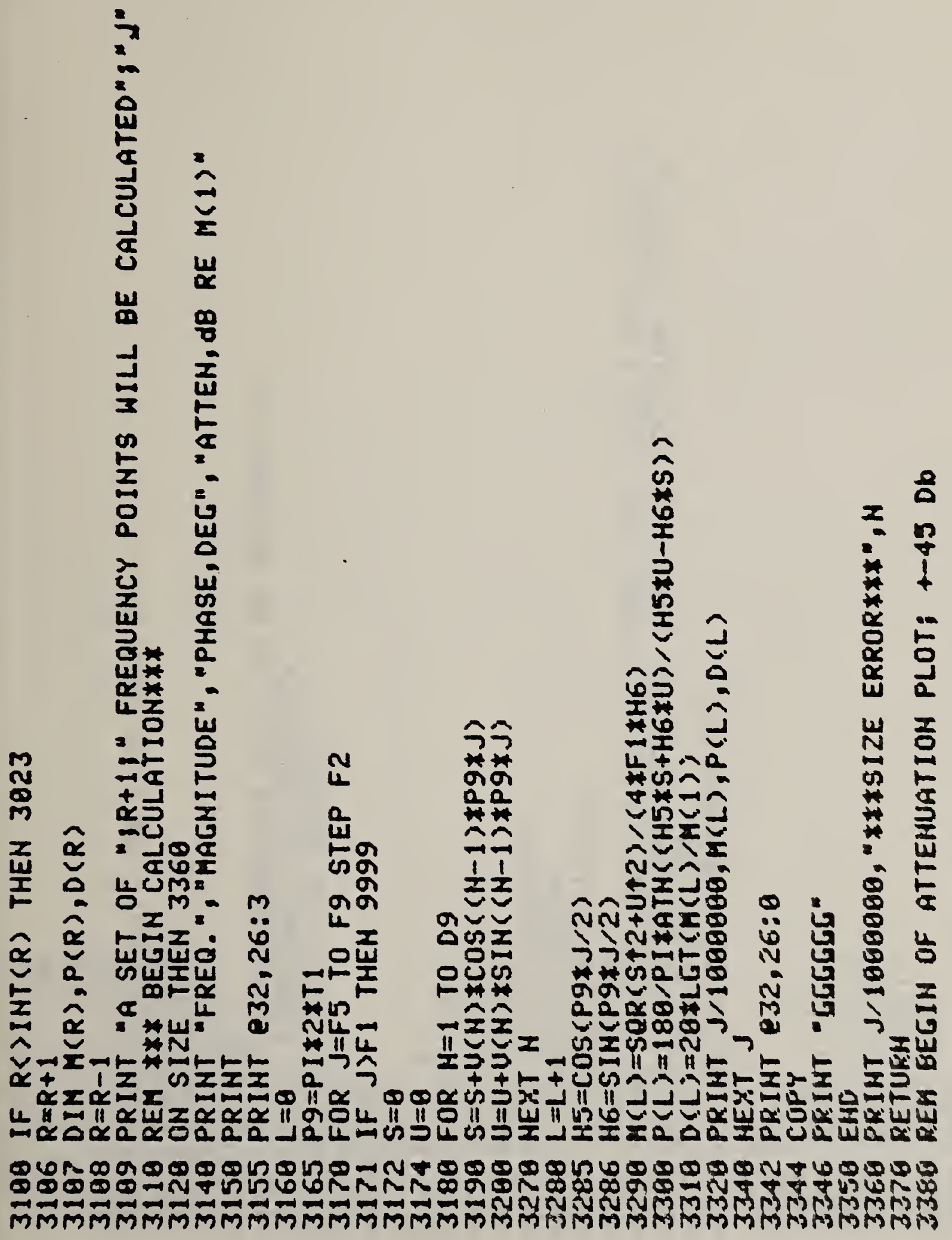


20

tis

$-8$

0

กั

$\rightarrow r$

$n^{-1}$

ñ בon

to no 0

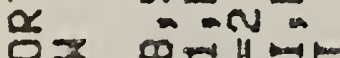
Q

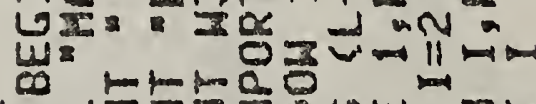

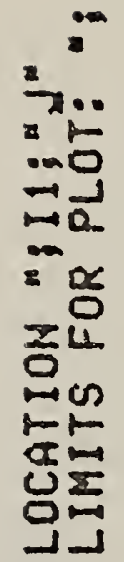

$-w$
$=E$
$m=\frac{1}{a}$

60

in

is $+\frac{1}{2}$

$\cos \frac{1}{3}$

andu

CMxI

u $\Sigma^{m}$ a

तim

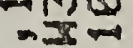

0 -ww $+67^{-1}$

$x x=x$

1

n七七七

a Um $1 x$

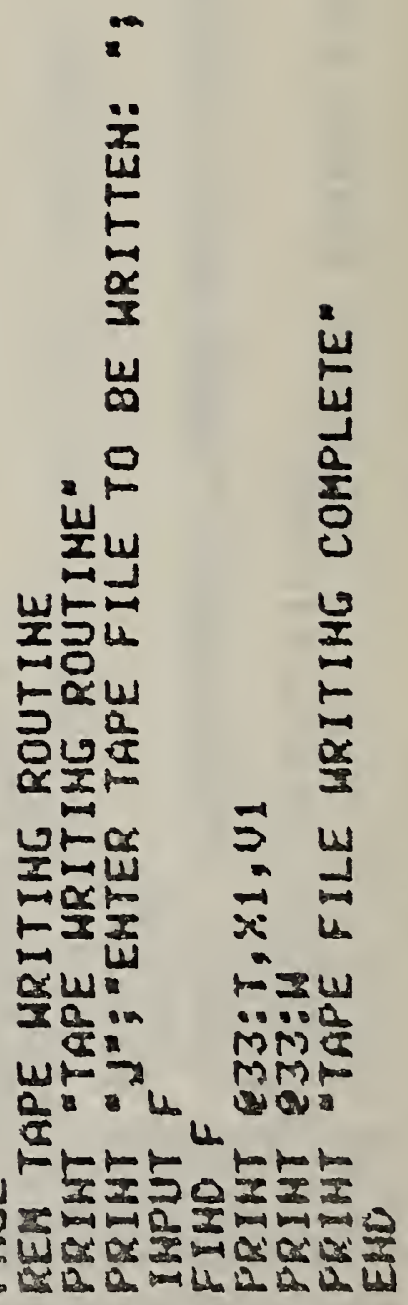

w之.

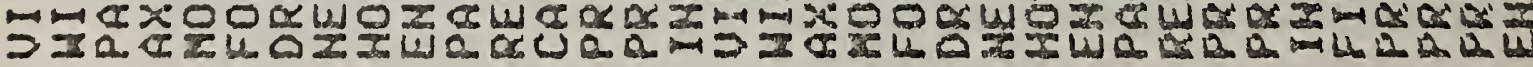

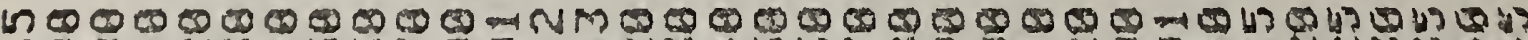
DOE-4NM

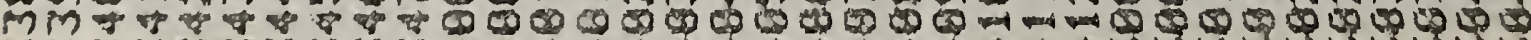

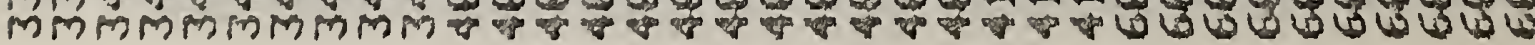


a

$\infty$

in

(o)

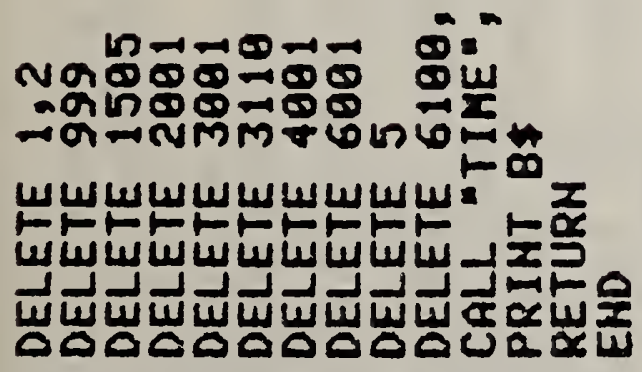

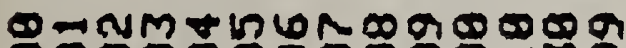
$000000000000 \mathrm{~m}$

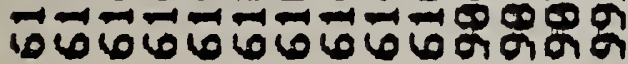




\section{APPENDIX D}

This software performs a fast Fourier transform of time domain data. The technique is a modified Eq. (28) Cooley-Tukey technique that can successfully transform waveforms that do not have the same beginning and ending values. The waveform must begin at an amplitude of zero. 
0
0
1
0
1

o.

No

$=N$

님

ㄴ.

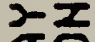

¿心

$\alpha \propto$

때

10

웅

ì

แัฒ

额

影 戛

工远

$\underset{\frac{2}{\alpha}}{\frac{\partial}{\alpha}}$

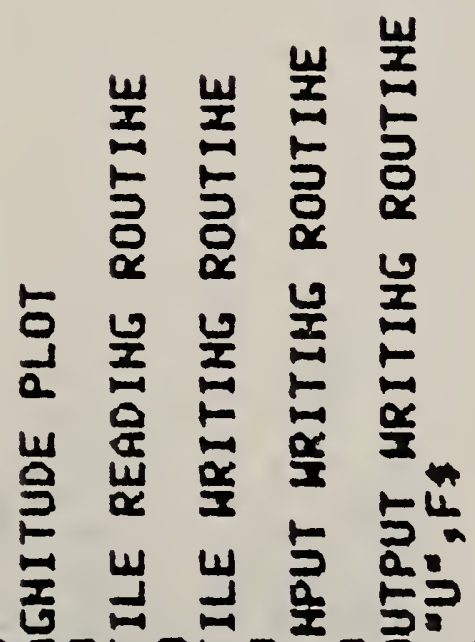

$\frac{1}{0}$

I

E

出

誌

ơ

起昆

꾼..ำㅇำ

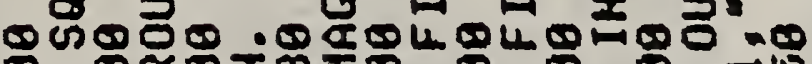

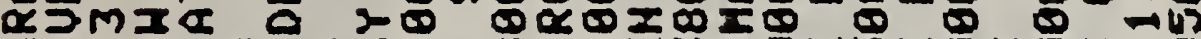

-

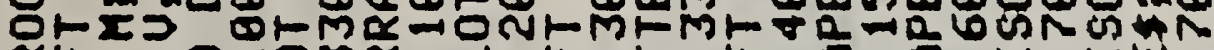

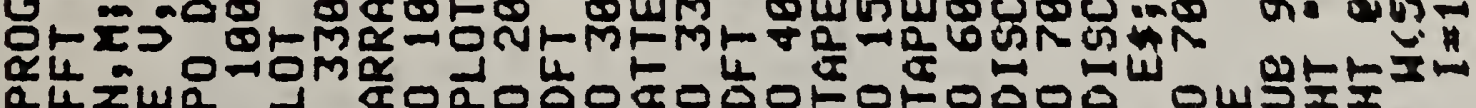

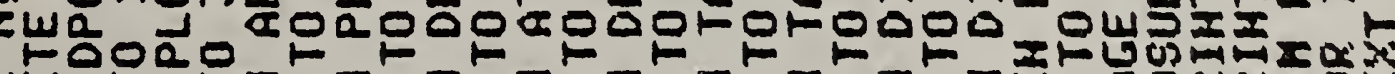
-

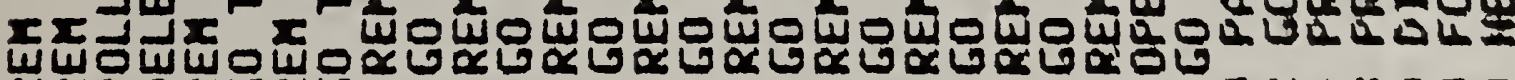

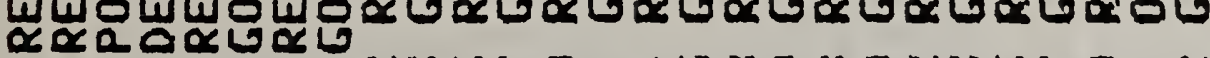

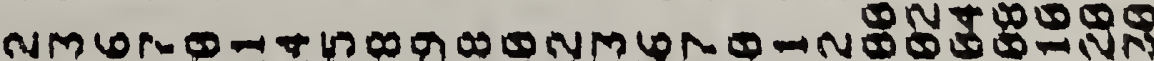
ー MM 


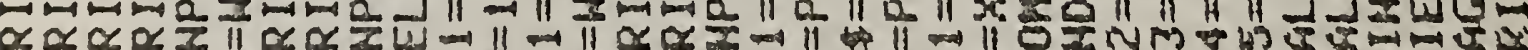

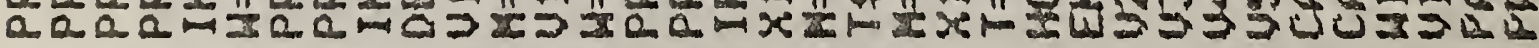




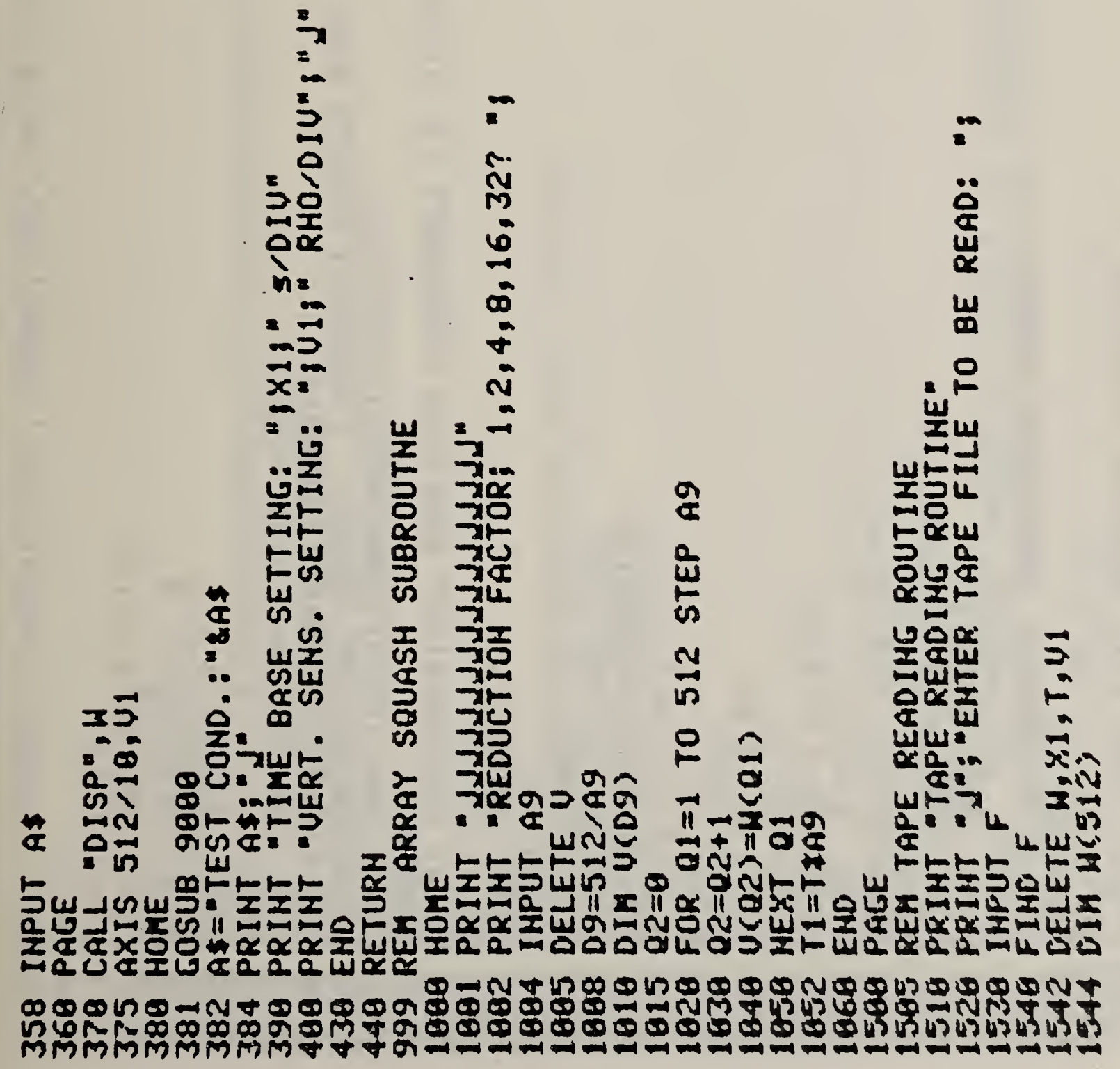



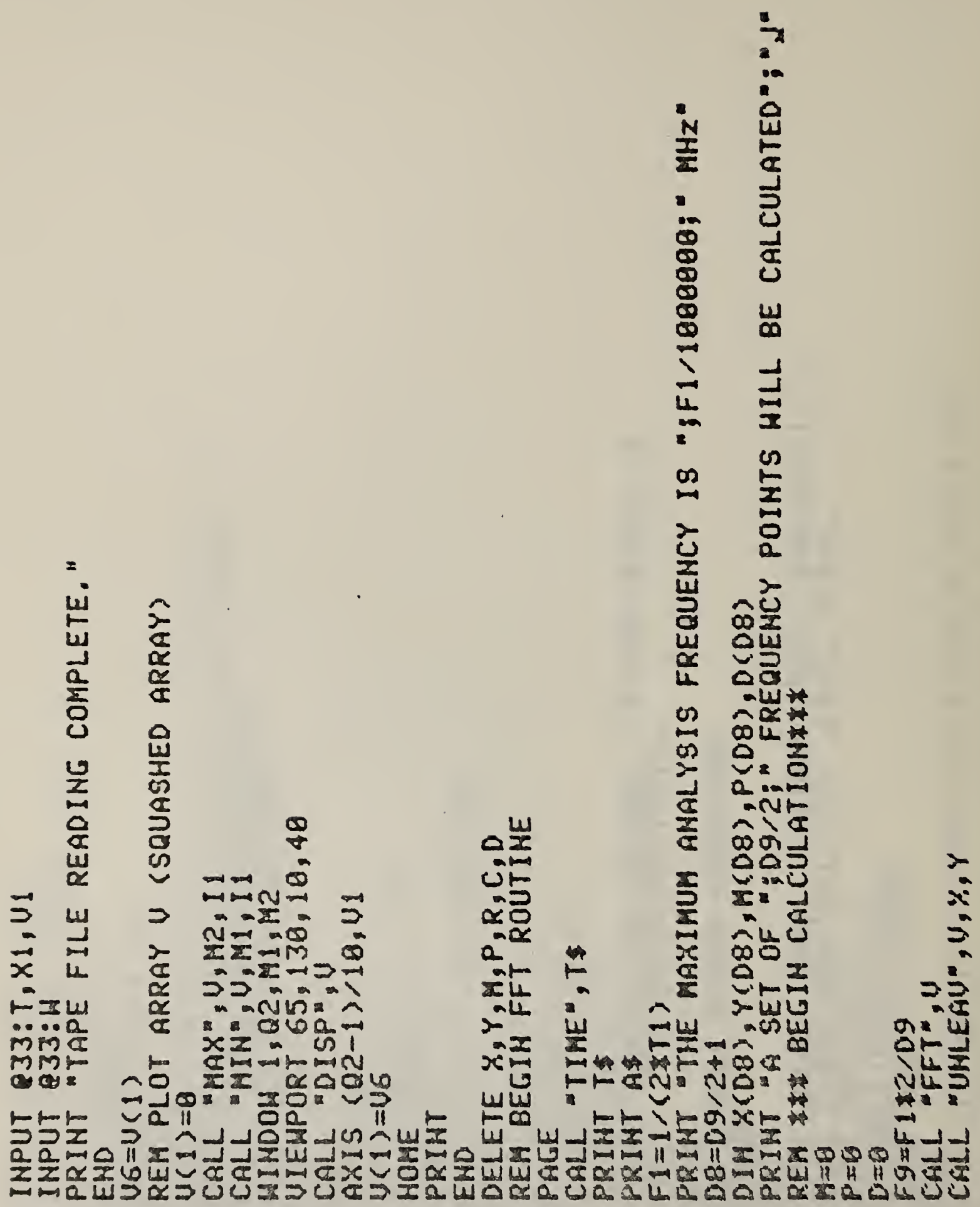

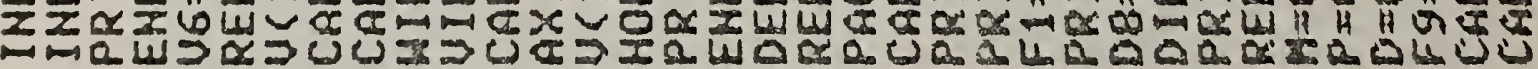

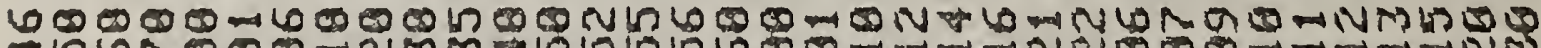
\#In

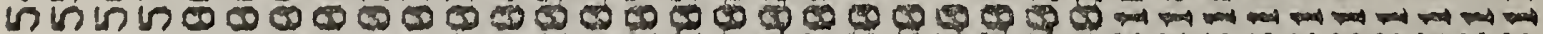

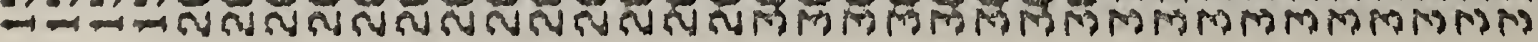



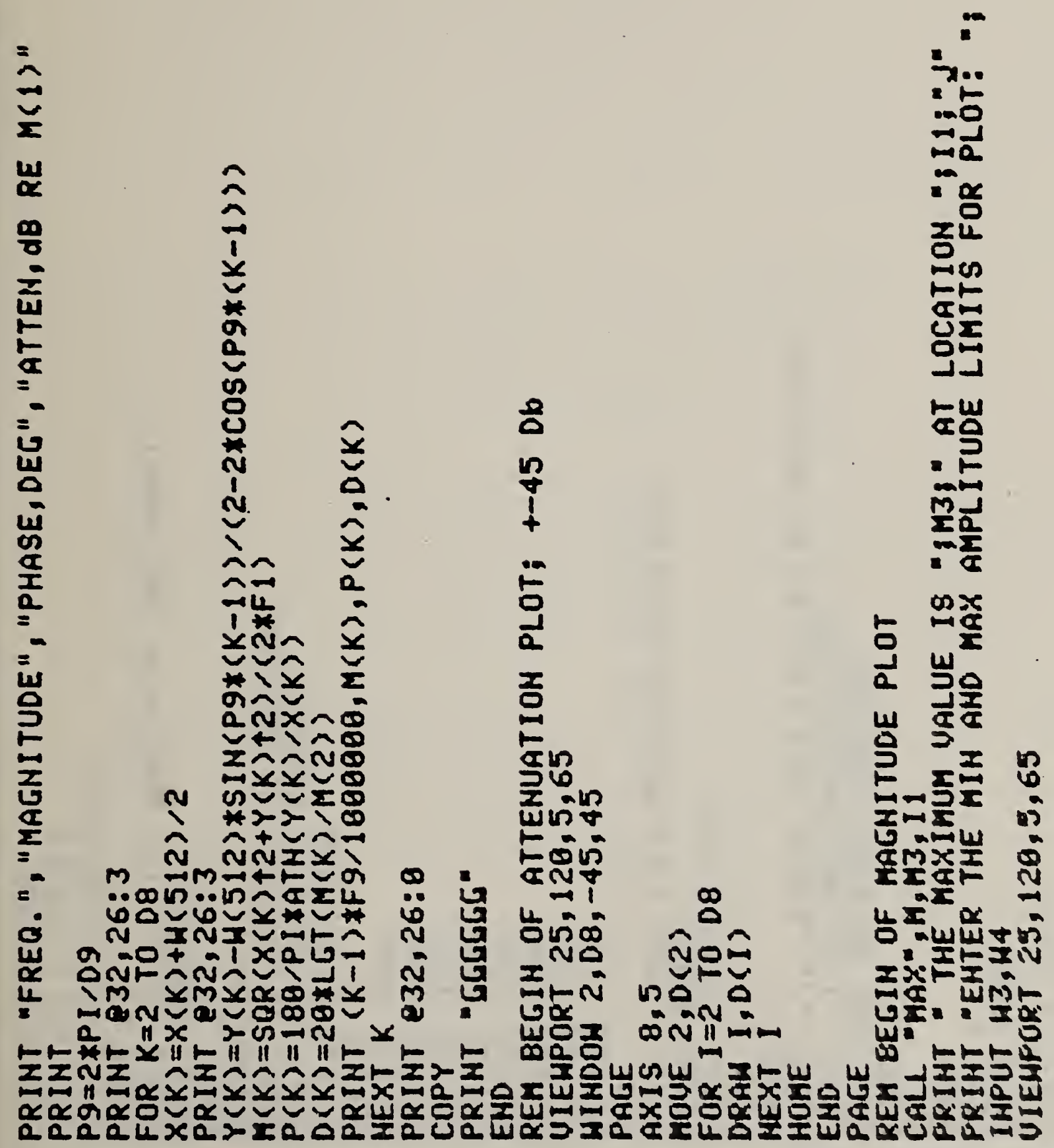

M

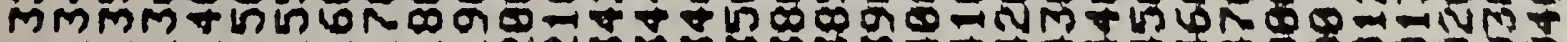

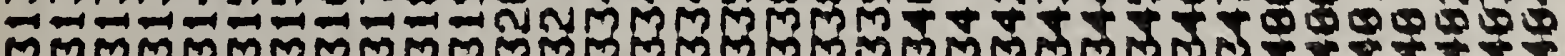




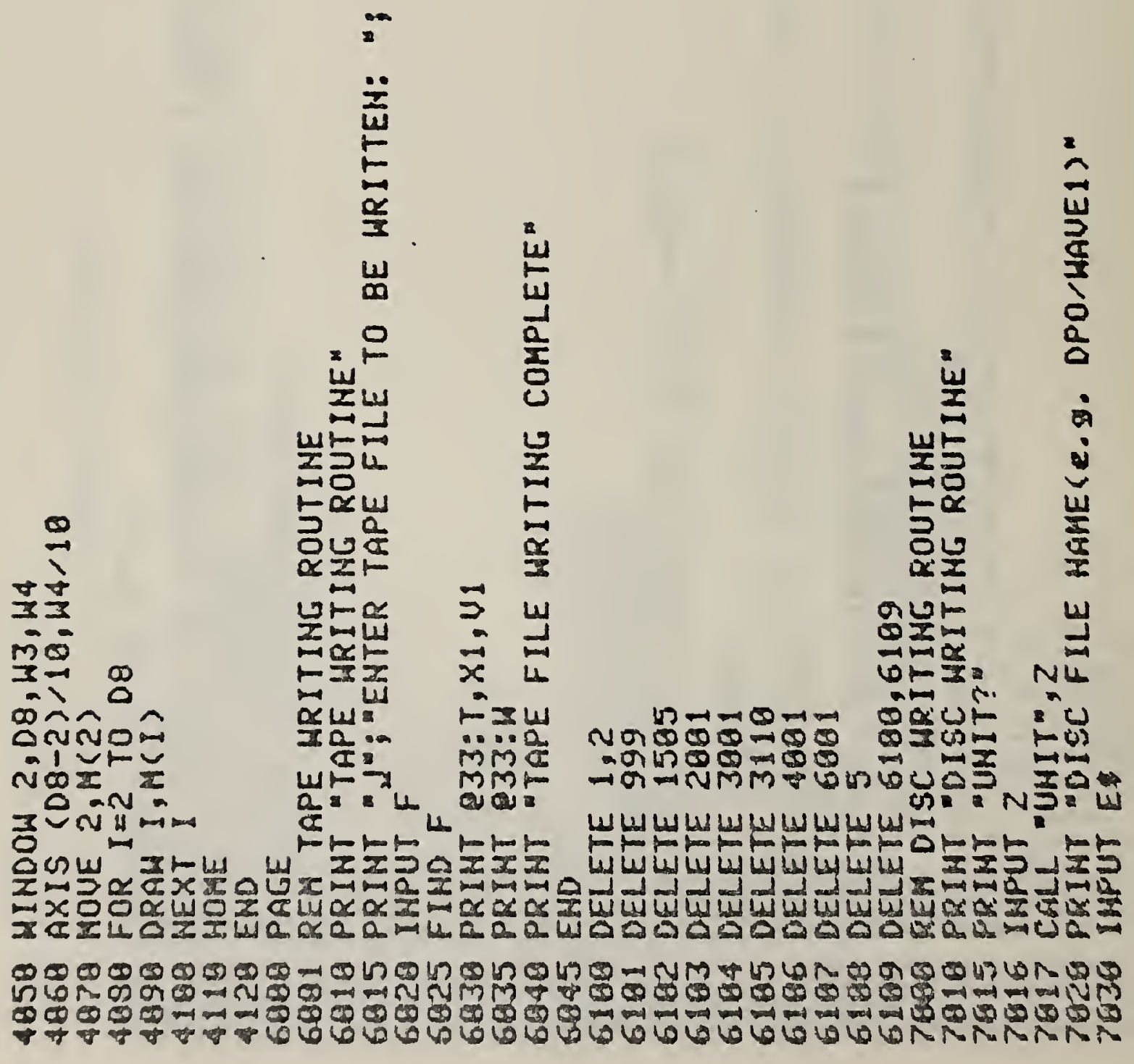




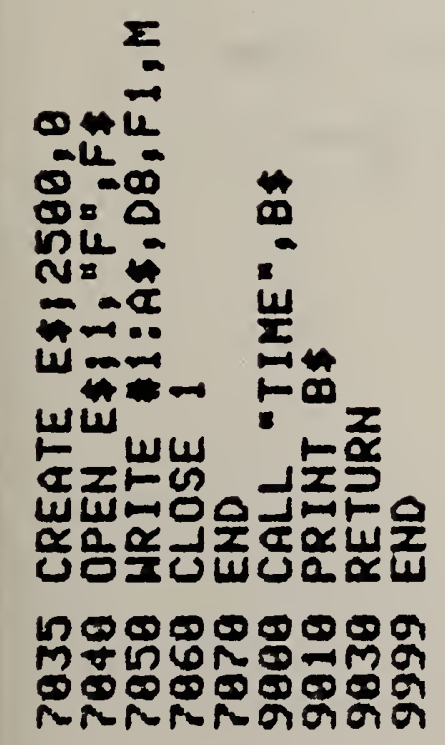




\section{APPENDIX E}

Five different sets of data are included. The first two show the results of using the software contained in Appendices $B$ and $C$ on the same data. The results are identical because the waveform ends at zero amplitude.

The other three sets of data illustrate the performance of the different software approaches, Appendices B, C, and D, to the rising step (starting at zero, ending above zero). Only the software contained in Appendices C and $D$ handle the data correctly. 
The following three pages demonstrate the results of applying the software contained in Appendix $B$ to a step with endpoint equal to zero.

The first page shows the waveform as acquired from the DPO and a reduced form of the waveform which includes only every fourth data point. The $\sin x / x$ software yields the frequency spectrum of the reduced waveform on the second page and a plot of this spectrum is on the third page.

This software correctly transforms waveforms of this type. 

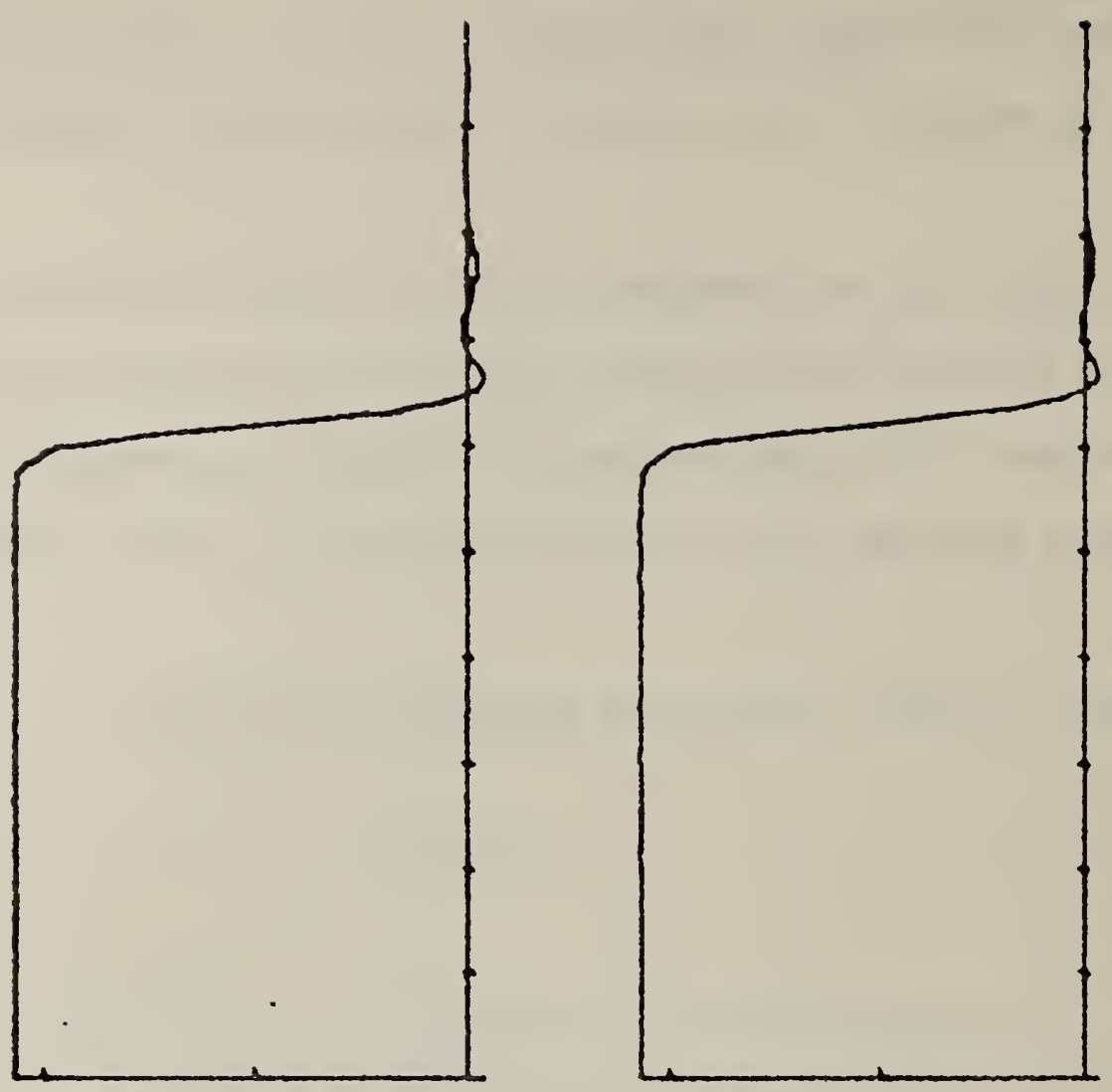

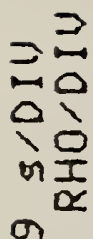

1 in

w。

(

i..

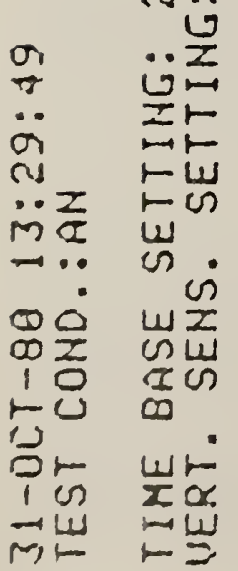

$\forall$

5

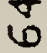

i

$m$

(i)

$\infty$

บे

N

送

落 


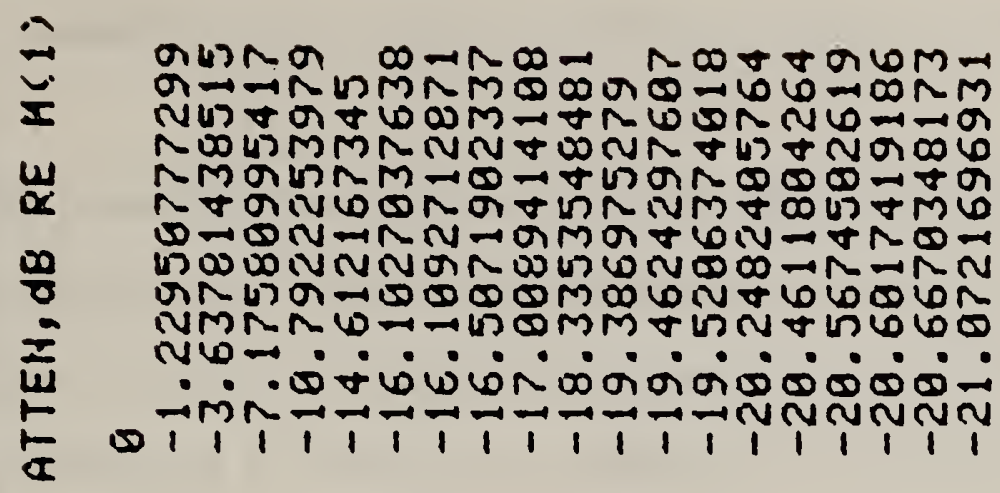

$\infty$

00

$\rightarrow m$

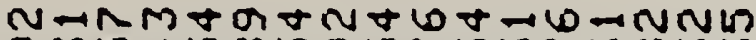
DMw

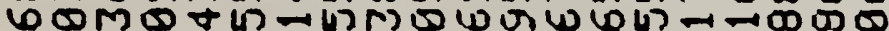

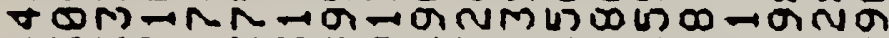

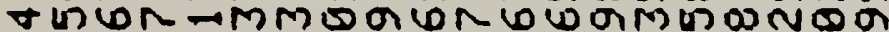

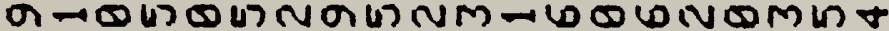

$\therefore \rightarrow$

0
$\omega$
0
$\frac{1}{0}$

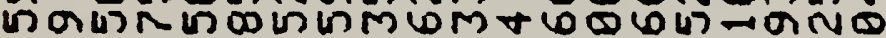

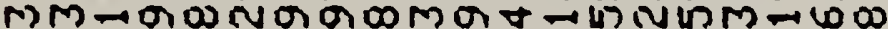
* inncon t

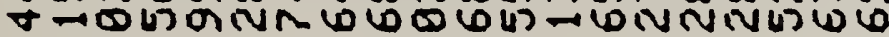

$\frac{N}{I} \tau \stackrel{5}{S}$ I En $\operatorname{En}$ $\because \cdots \frac{1}{a}$ $\infty>>-1$

NUUEU $m \Sigma \pm=\infty$ wuz $\Leftrightarrow \supset 2 m$ $\rightarrow \overrightarrow{0} \widetilde{a}$ uU $>\alpha \alpha \geq=$ uи u 등 U工 2 담 $0 \backsim$ Uト 100 $\alpha \alpha \alpha \cos a$ $4 \perp-1 \omega$ जए $\Leftrightarrow \quad \omega \frac{d}{a} \dot{\frac{\pi}{\alpha}}$ $1 \propto \overline{0}$ $\sigma \alpha \propto \mu u$

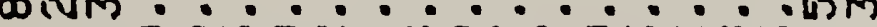

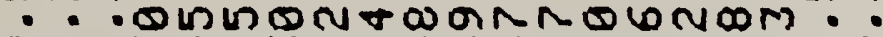

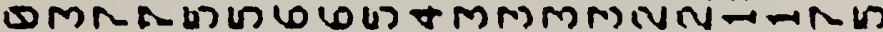
M $0001,1,1,1,1,1,1,1,1$

$000000000000000000-4$ $\rightarrow \rightarrow \rightarrow \rightarrow \rightarrow \rightarrow \rightarrow-\rightarrow-\infty \rightarrow-\infty \rightarrow-\infty \rightarrow-1$ $\begin{array}{llllllllllllllllllll}1 & 1 & 1 & 1 & 1 & 1 & 1 & 1 & 1 & 1 & 1 & 1 & - & 1 & 1 & 1 & 1 & 1 & 1 & 1\end{array}$

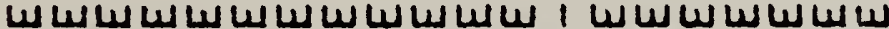

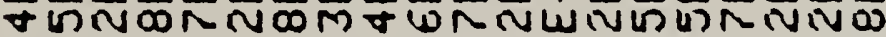

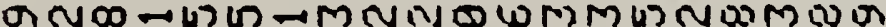

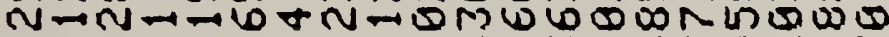

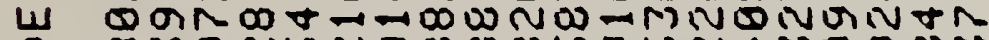

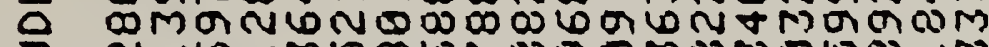

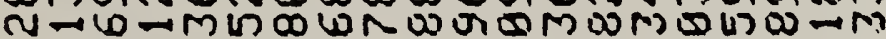

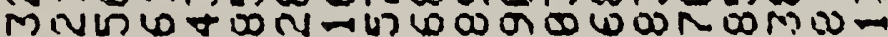

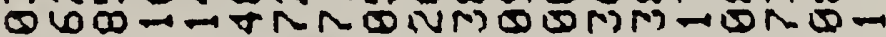

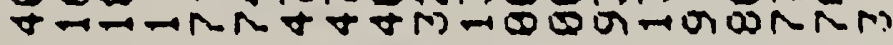

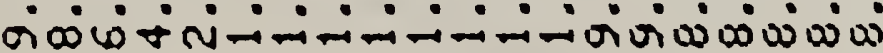
रा山्य $\alpha$ 두중 Mव क्ष

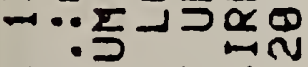
هo

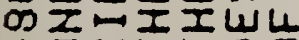

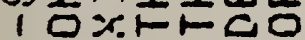
$\mapsto \omega \sigma$

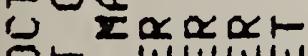
Dト шய山س

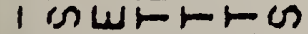
-

MrレயWWI

ת $\frac{\dot{d}}{\frac{u}{u}}$

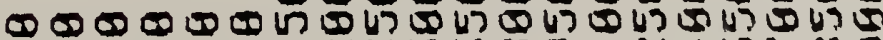

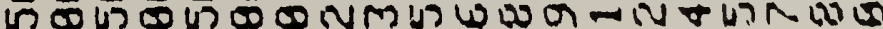

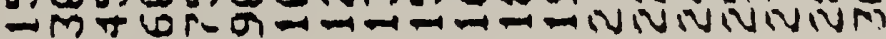



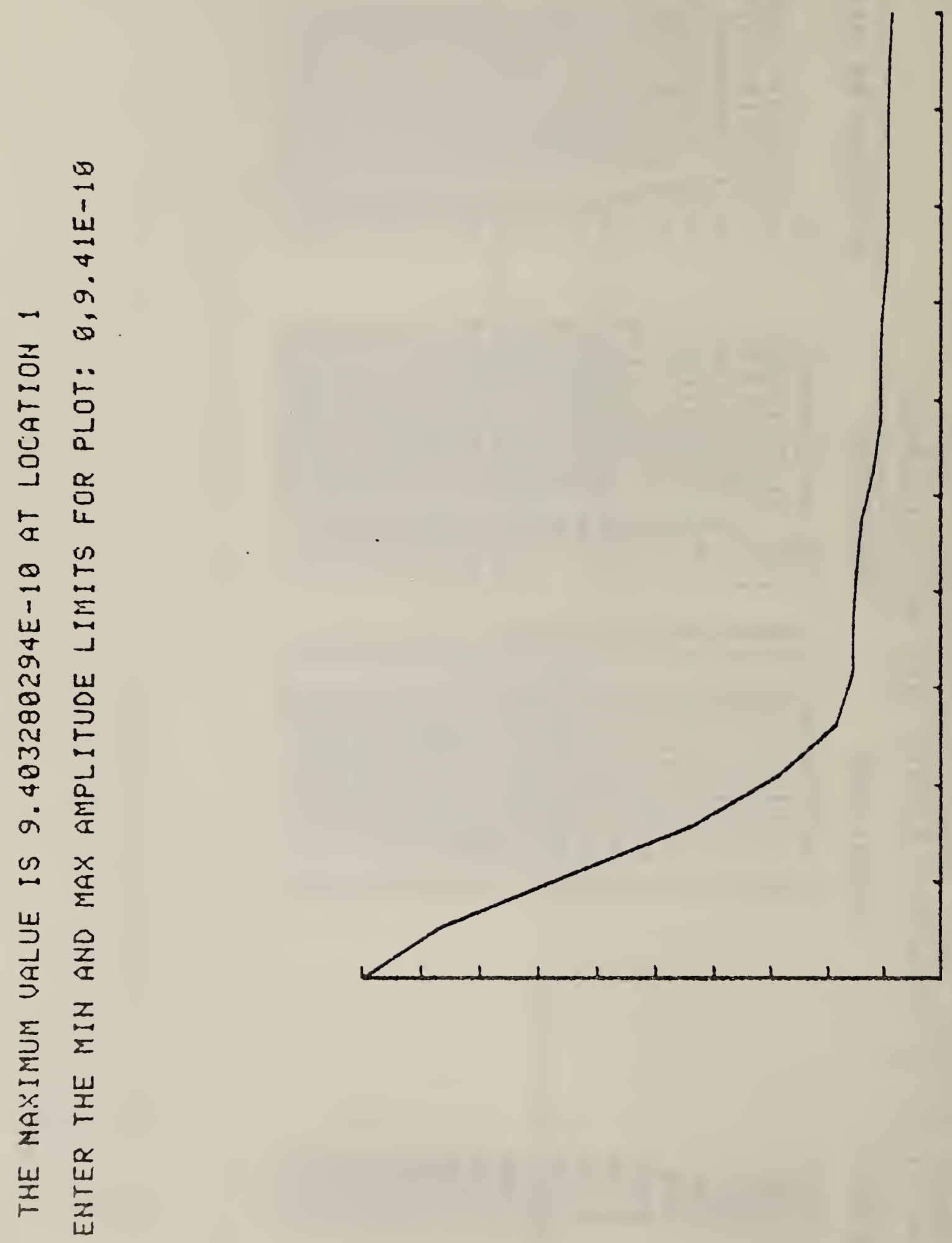
The following three pages demonstrate the results of applying the software contained in Appendix $C$ to a step with endpoint equal to zero.

The first page shows the waveform as acquired from the DPO and a waveform showing the difference between every fourth data point. The modified sin $x / x$ software yields the frequency spectrum of the reduced waveform on the second page and a plot of this spectrum is on the third page.

This software correctly transforms waveforms of this type. 


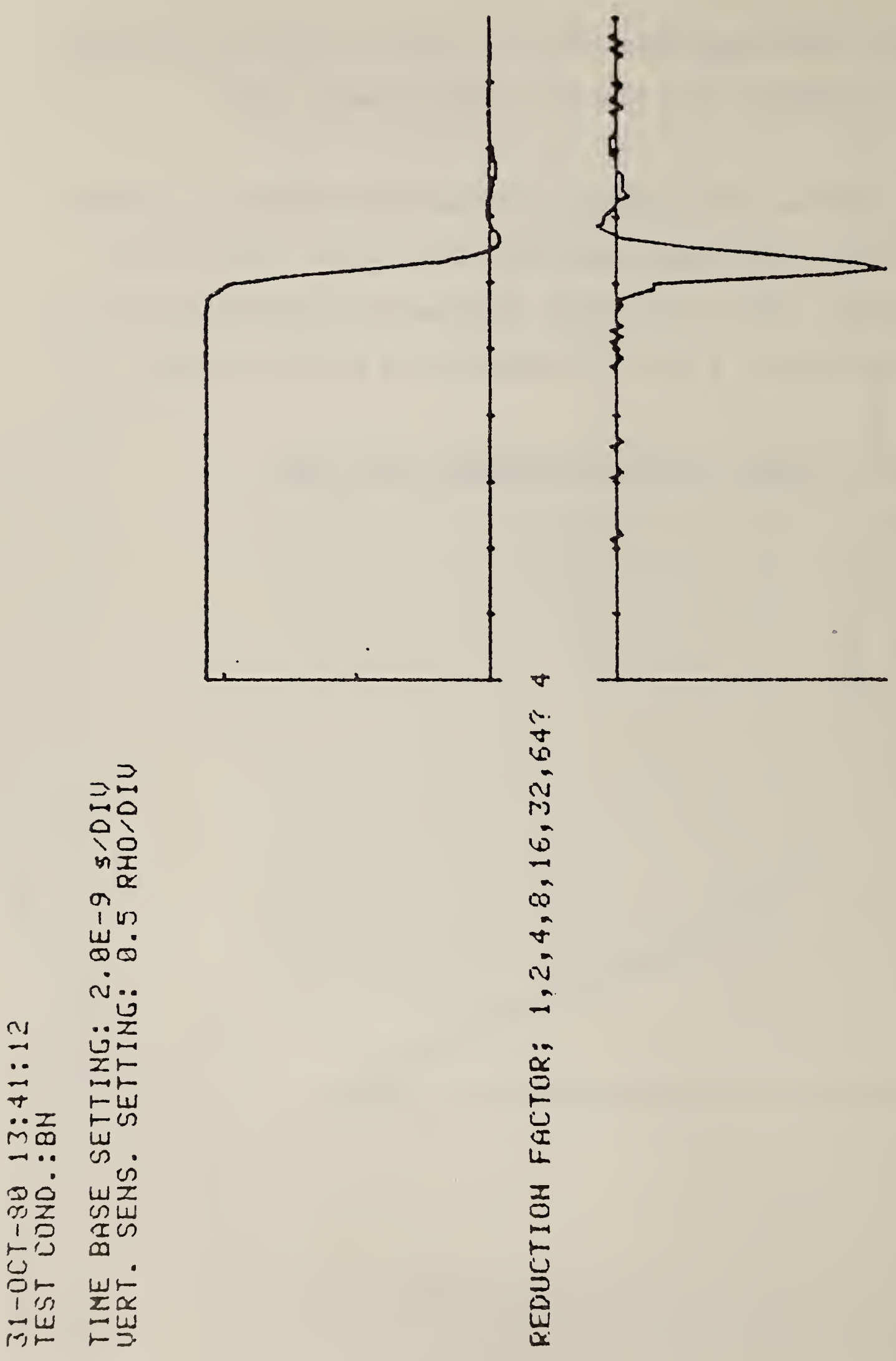


$=$
$=$
$\frac{w}{0}$
$\frac{0}{0}$
$\frac{1}{\sigma}$
$\frac{5}{a}$

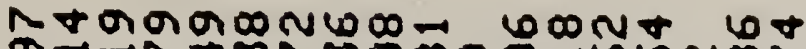

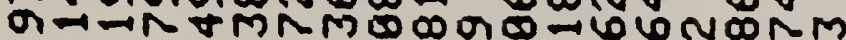

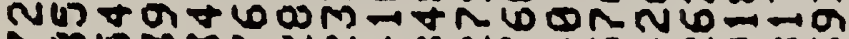
NDUMMNIVIV

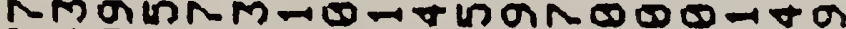
N

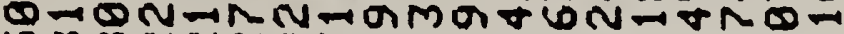

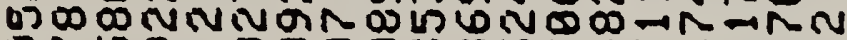

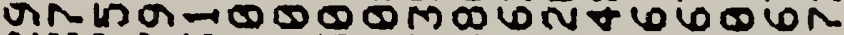

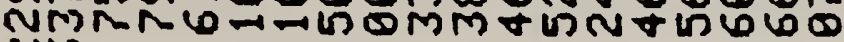

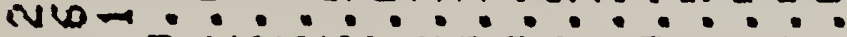

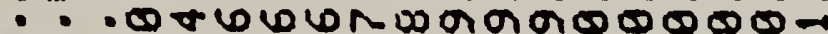

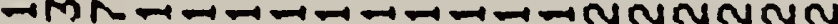

$\infty \infty$

no

$\ddot{n}$

III

NA INOE

$N=\sum=5$

$\pm \geq$

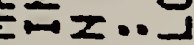

wa

Dr NU

त्रे IU

m른

부지

$\leftrightarrow \supset$ 빅

누의

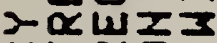

บu转

${ }^{2} u=\omega$

니은

다네교

waroo

$\alpha \perp \alpha \operatorname{so}$

$4 \geqslant \rightarrow \omega$

$\cos \frac{\omega}{2}$

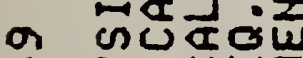

0111111111111111111

$\frac{1}{0}$

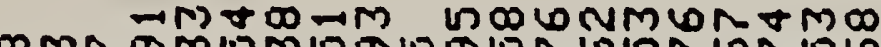

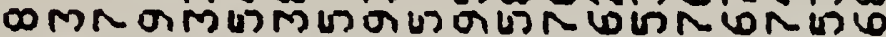

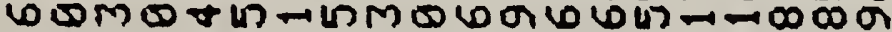
*om-nr-ar-anmus no -

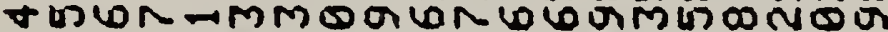

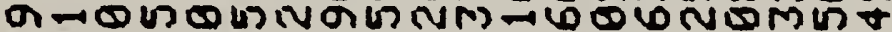

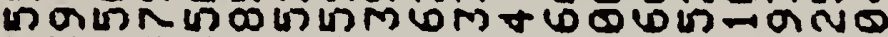
MM- In

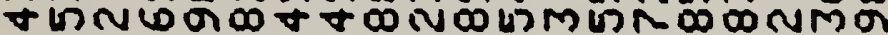

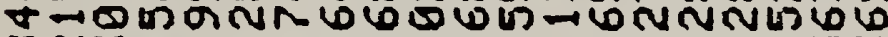

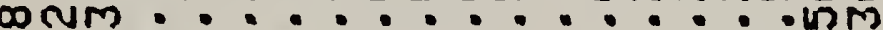

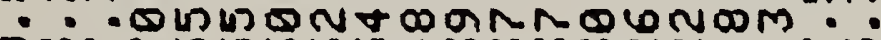
OMNRULW m6001,1,1,1,1,1,1,1,1,

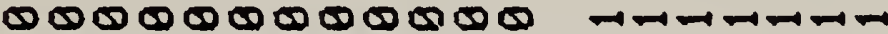

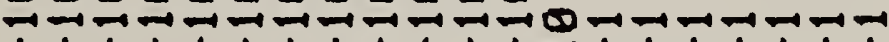

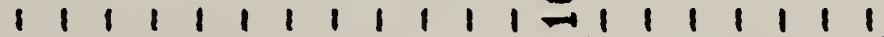

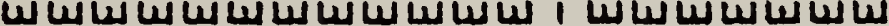

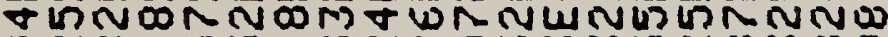

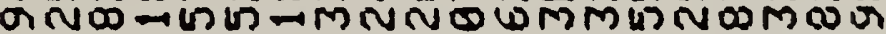
$N=N=-10+N=5 M W 6000470000$

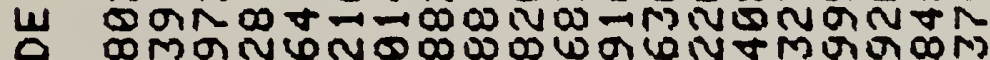

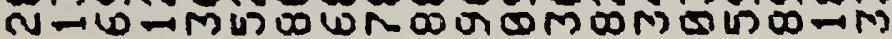

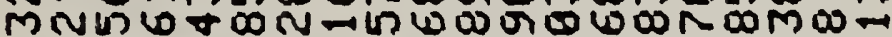

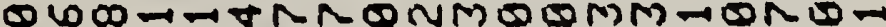

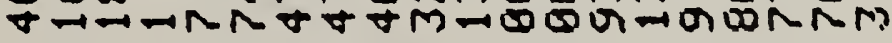

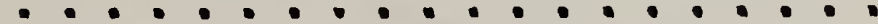

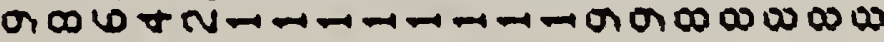

$+\gamma \omega \omega \overrightarrow{0}$

$\rightarrow \pi \cos \alpha u$ $\rightarrow$ zuw $\because z a \equiv a$ ou mo $\overline{0}$ a

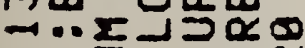
$-2-\infty$ $\infty \subset \geq \omega$ แ

$\infty$ ż工工山U $10 x F=0$ -

$y=\alpha \propto \alpha \infty$ oю แ山шس

i nutrFo $\rightarrow W \geq z z \geq$

MFFU山U

00050500000000 $-0000047045045045045045075$

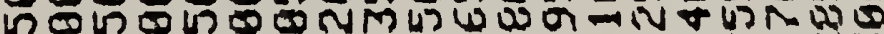

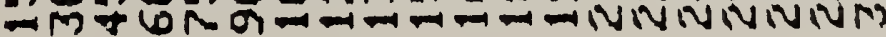



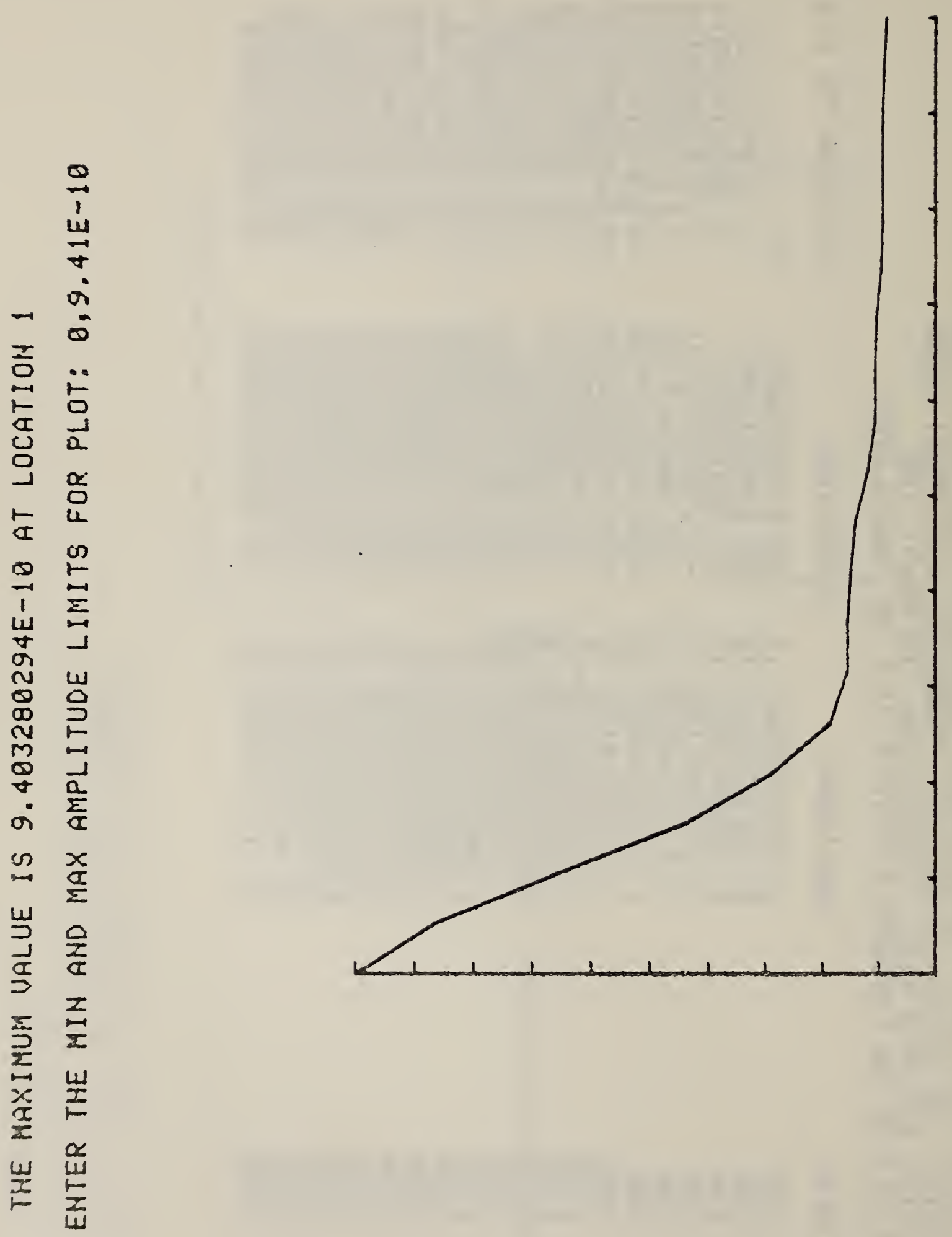
The following ten pages show the results of applying the software contained in Appendix B to a step-like waveform with endpoint not equal to zero.

The waveform, as acquired from the DPO, is on the first page. The transformed spectra is tabulated on the next eight pages and plotted on the last page.

From theoretical considerations in the text and results shown next in this appendix, this software is clearly not applicable to waveforms of this type. 


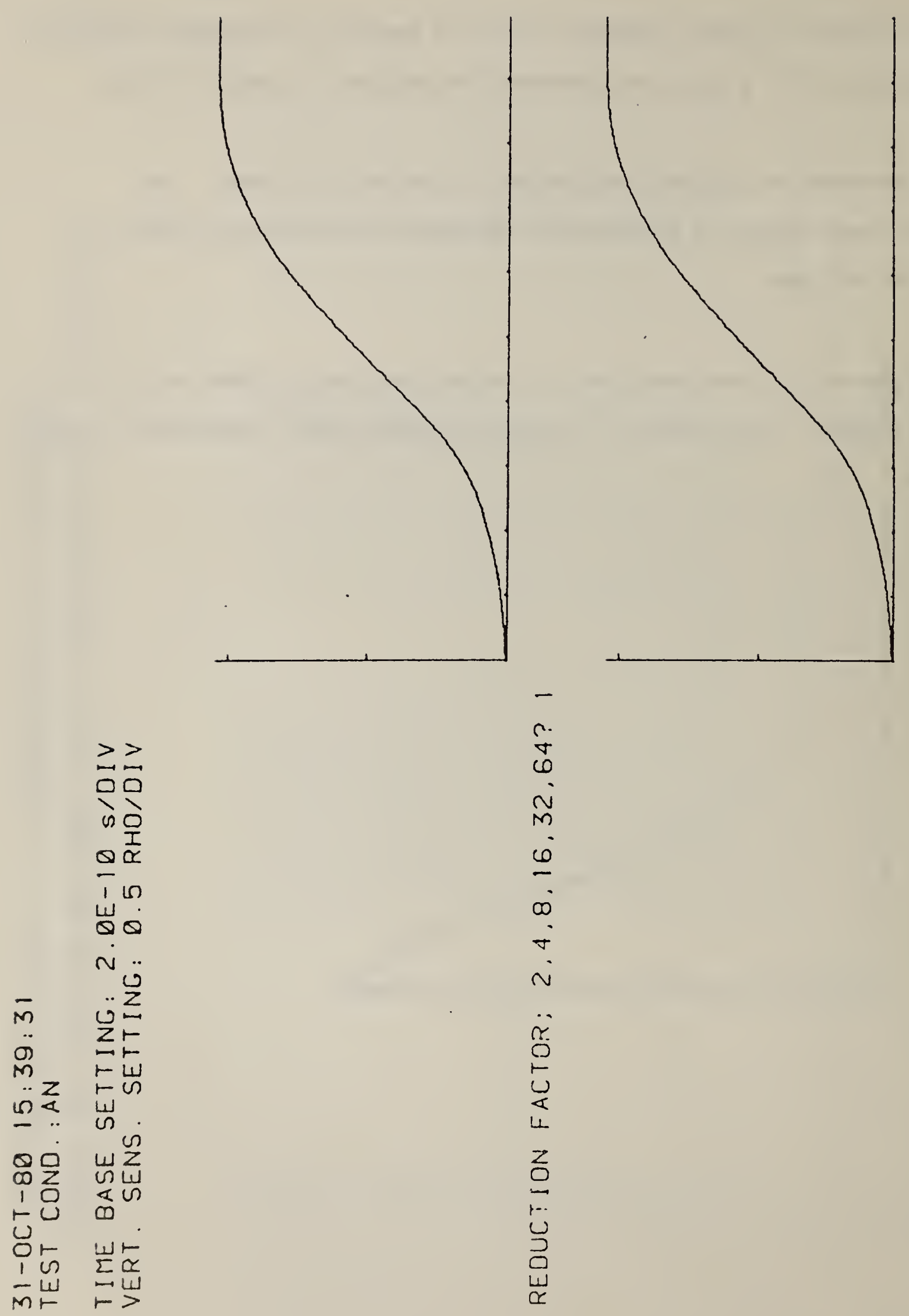




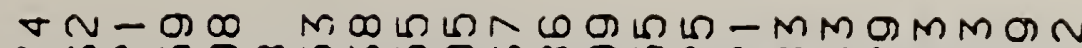
ก - ब $\infty \varnothing-\theta$ व

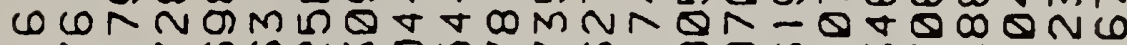

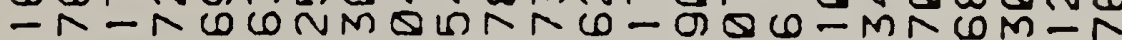
G $M M$ L $\omega \backsim \nabla M M-N \infty Q M L G N N M \omega \infty N M \omega-N \infty 0$ MMLDMWNDN

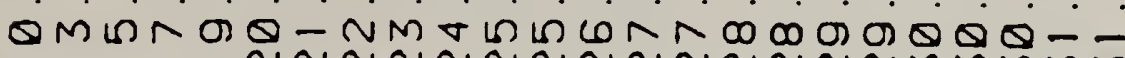
$-\frac{1}{1}-\frac{1}{1} \sim N \sim N N N \sim N N \sim N \sim N M M M M M$

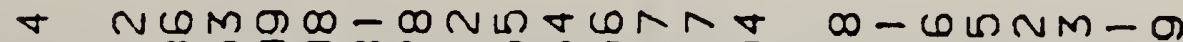

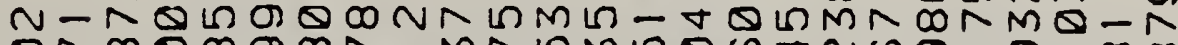
$0 \wedge \infty \theta \infty 0 \infty \Lambda-M N \backsim M L \theta \omega \forall N \omega 0-\theta-\infty \infty$ NMMNDMND CN OMNR $M \infty \nabla \backsim N N \infty-M M \omega-\omega \omega O N M-\wedge \omega M O N M \omega$

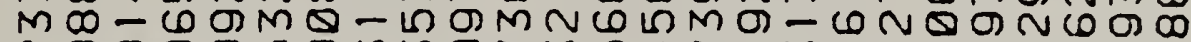
NQQ⿱一⿻丿口⿻上丨 MWQN N N N.

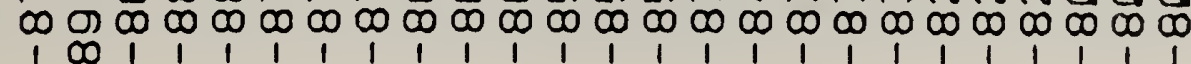

$\infty \succ>I U$

I

NUU之m

$-z z$

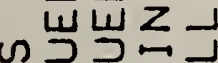
のココこコ 山ل

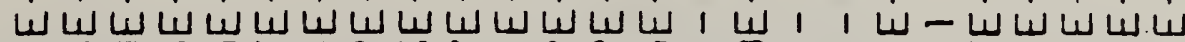
N

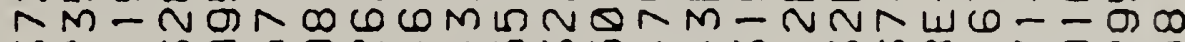

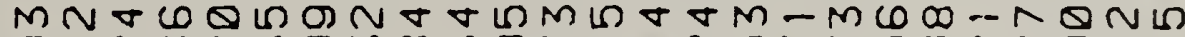
QMNDNEOM⿻ OOR N $\theta N-\theta Q D \infty N \omega L \theta-\theta \omega \nabla \omega-M \nabla \sigma N \sigma \nabla m$

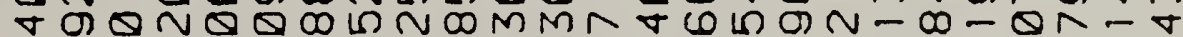
- L - L ம - -

in $>\cup \cup w 0$

..

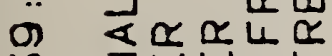

m zw山 $u$ i $2<\geq 0$ ம $<$ व - ㄷ」J织 $1 \omega<$

U) $\Sigma \alpha \propto \alpha \leftarrow$ Or inur - wIZzz MトトU山ய<

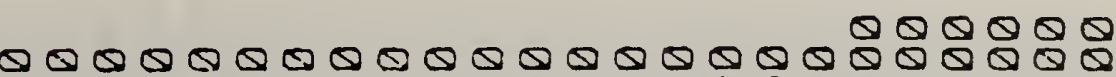

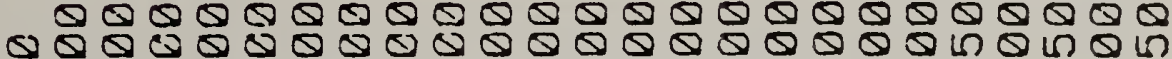
Q

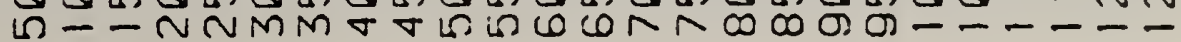


অ

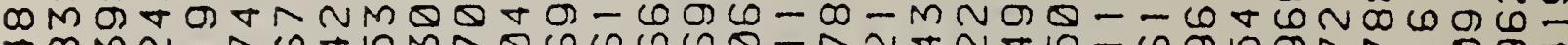
$\infty$ MN -

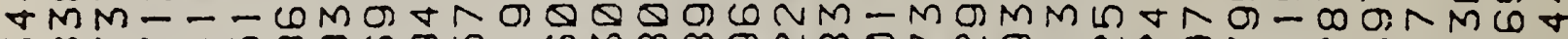
M⿻NR OM L -

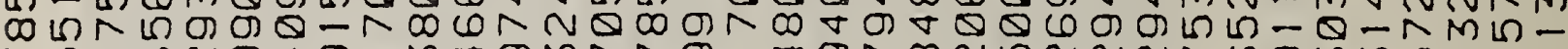
R QN LQQVL- - CNQNM

NNNMNMM

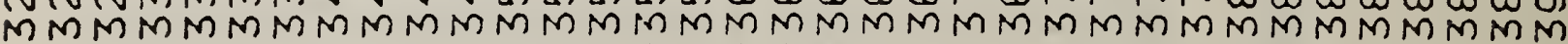

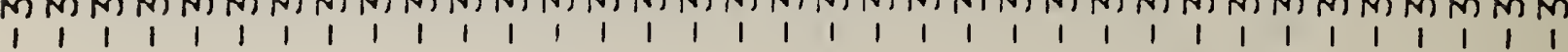

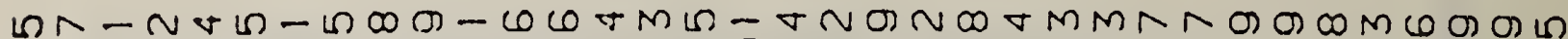

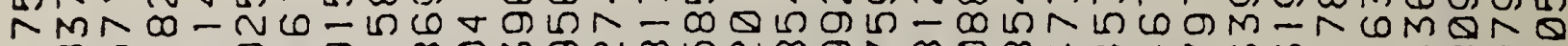

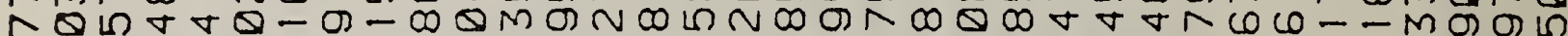

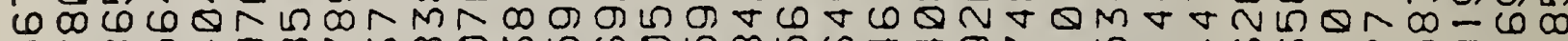

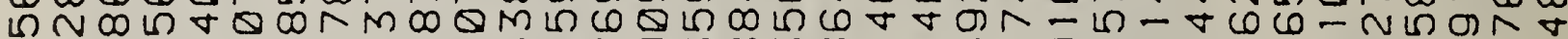

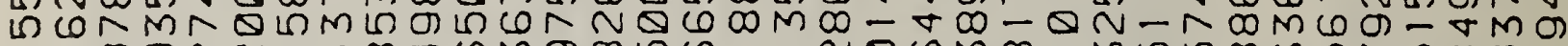

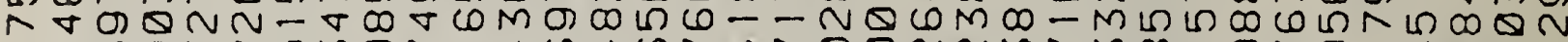
Q

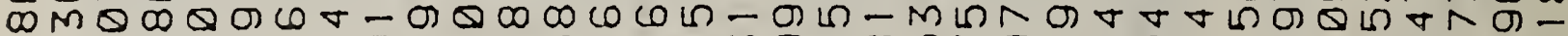

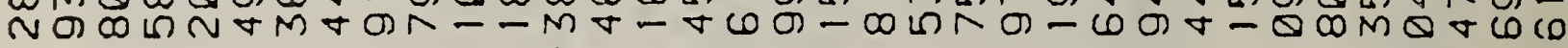

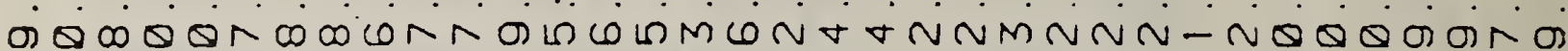
Non

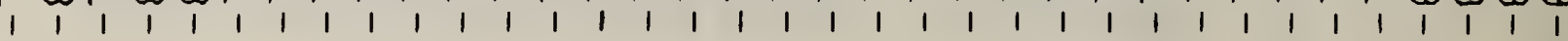

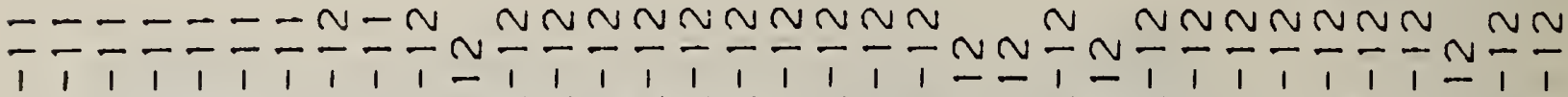
لاسلا N-N M-MOND-.-

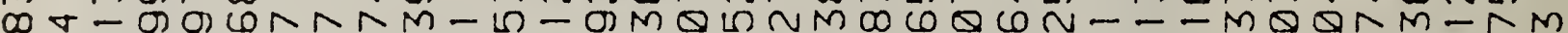
NGNQGNRNWN

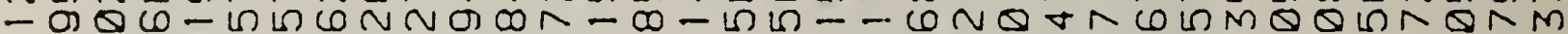
QM-NQORNR- -

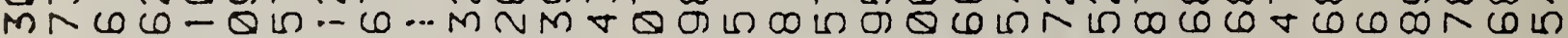

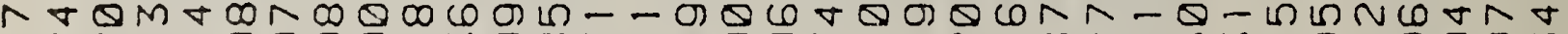

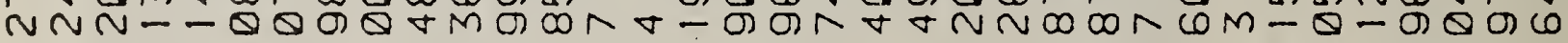

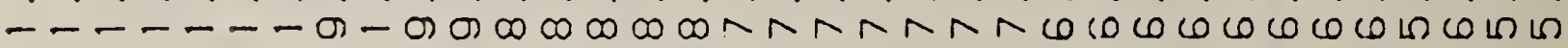

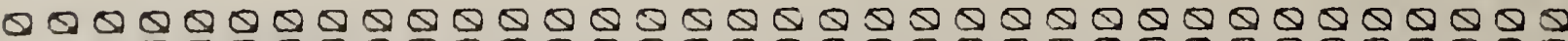

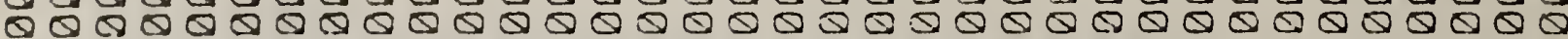

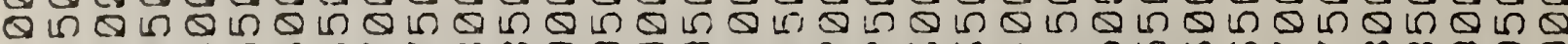

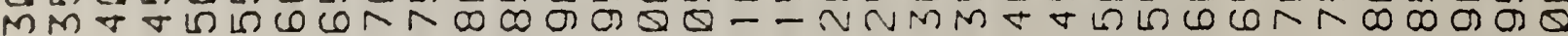

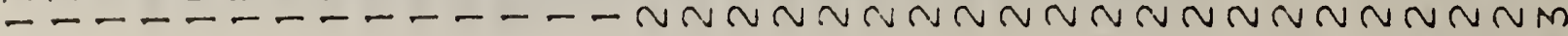




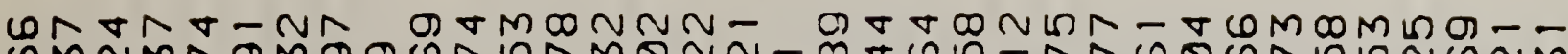

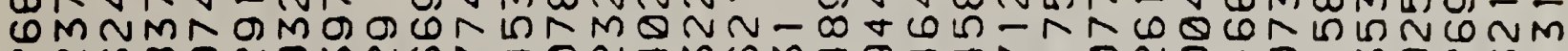
N W ODQNOMNCN -

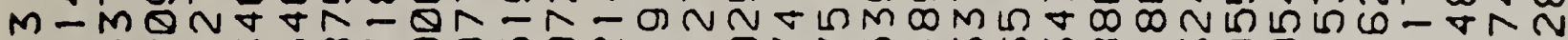

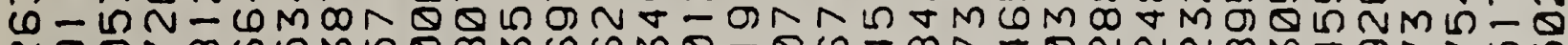
Na ซ

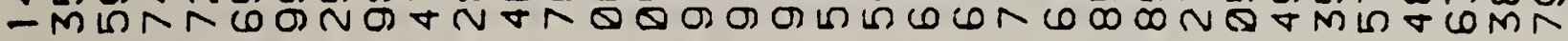

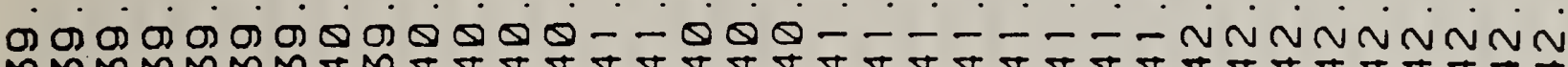
MMMMMMMVMV

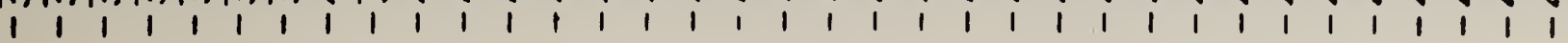

mIMNM⿻ ก TMD m MNN-NMWL

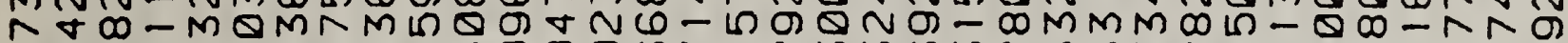
D

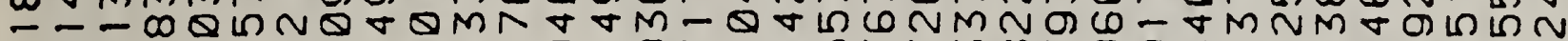
ก ம

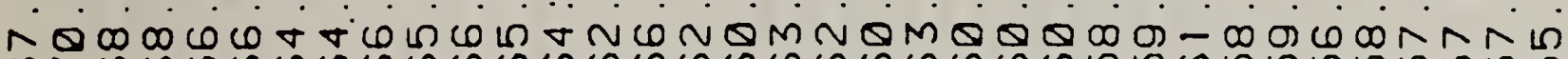
c $\begin{array}{llllllllllllllllllllllllllllllllll}1 & 1 & 1 & 1 & 1 & 1 & 1 & 1 & 1 & 1 & 1 & 1 & 1 & 1 & 1 & 1 & 1 & 1 & 1 & 1 & 1 & 1 & 1 & 1 & 1 & 1 & 1 & 1 & 1 & 1 & 1 & 1 & 1 & 1\end{array}$

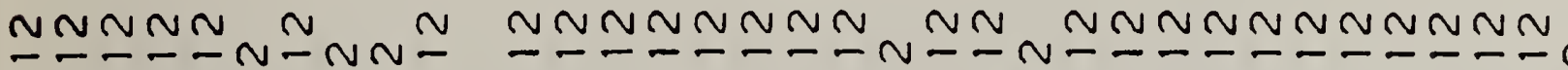
$-\frac{1}{1}-\frac{N}{1}-1 \leq-1 \times 1-\frac{1}{1}-\frac{1}{1}-\frac{1}{1}-\frac{1}{1}-\frac{1}{1}-\frac{1}{1}-\frac{1}{1}-\frac{1}{1}-\frac{1}{1}-\frac{N}{1}$

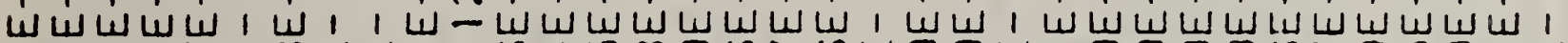
ณर অQ

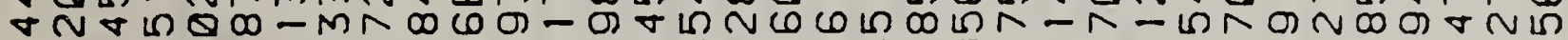
Q N NR U * $\forall Q \omega \omega N N-\omega N \omega \nabla \infty-N N Q \omega \infty \omega Q N M \infty-M-\backsim M M \sigma Q \forall N \infty \infty$

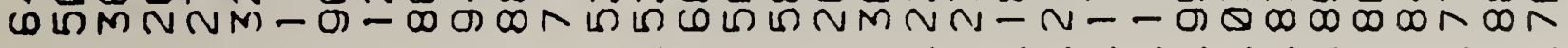
ம

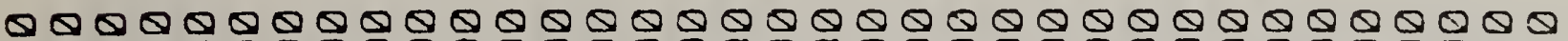

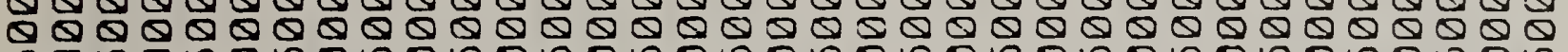

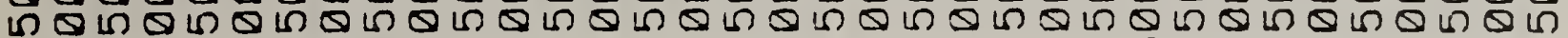

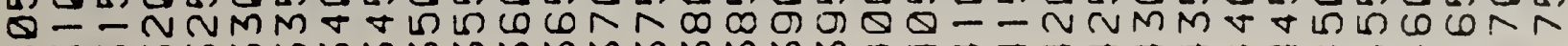
$M M M M M M M M M M M M M M M M M M M \sigma \nabla \nabla \nabla \nabla \nabla \nabla \nabla \nabla \nabla \nabla \nabla \nabla \nabla \nabla \nabla$ 


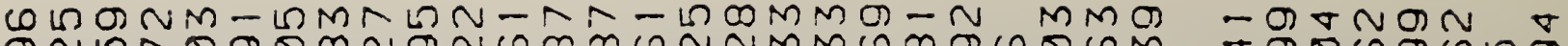
Q N

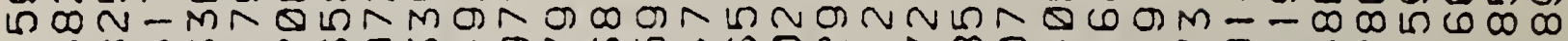
-

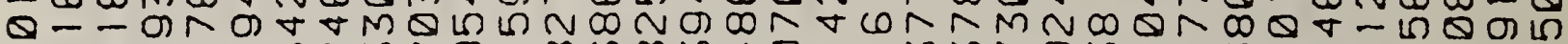

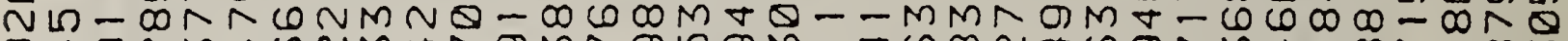
Q

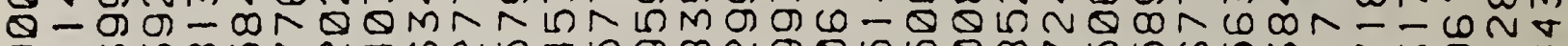
OQMQDR NMLR

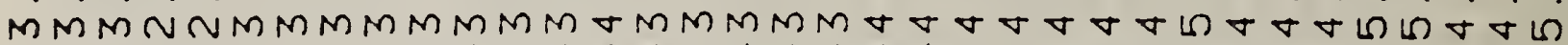
1
$\theta$

- LMMNDT N NDMQ IOQQQD MOWM

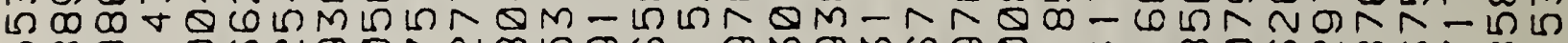

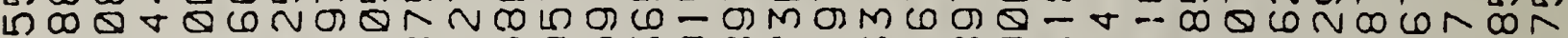

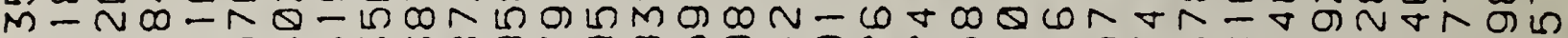

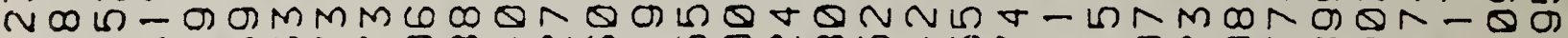
a - - -

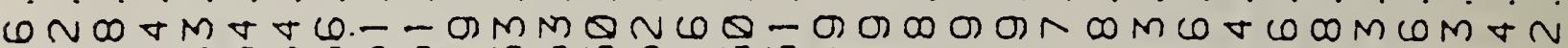
مأ

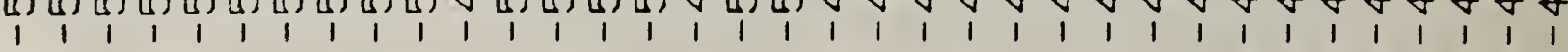

NNNNNNN NNNNNN NNNNNNNNNNNNNN NNNN

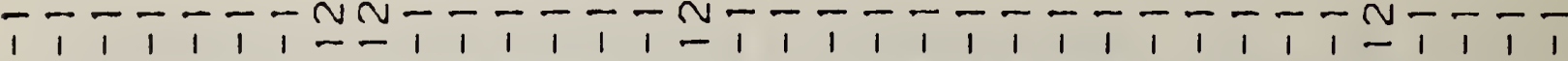

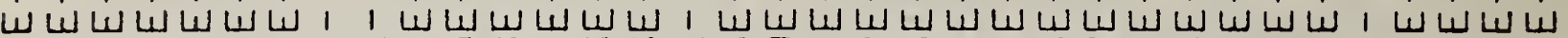
ถО

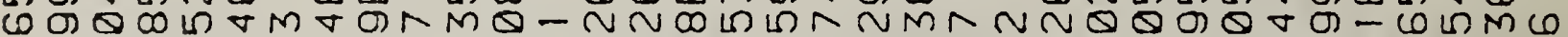

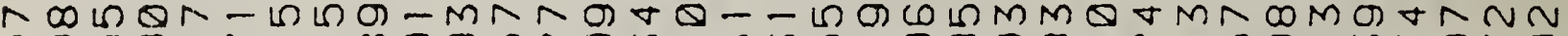

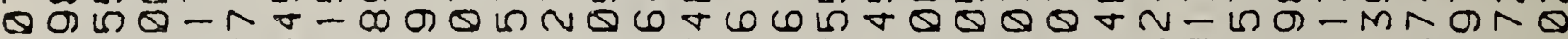
NNNGMGQVT-N - OtQRN寸G

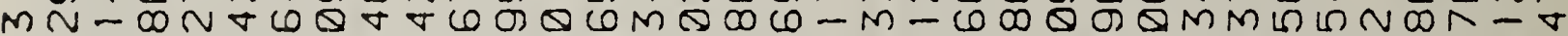

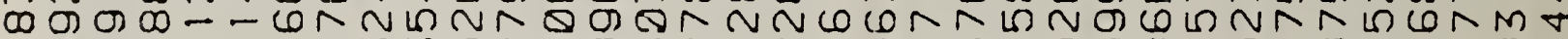
ద

MMMMMMMMMMMMMMMMMMMMMNMMMMNNMMNNNMN

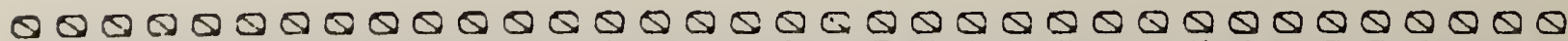
O 0 L

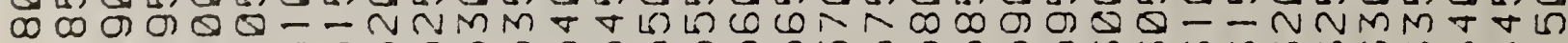
प प प 
ИD

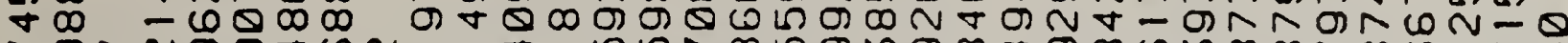
ヘ

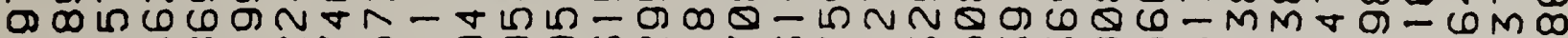
N-N

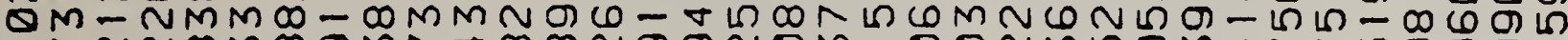
- NNNDMDOMN ब क NMVNQ- ONNR ம $\begin{array}{llllll}1 & 1\end{array}$ $\begin{array}{llllllllllllllllllllllllllllllllll}1 & 1 & 1 & 1 & 1 & 1 & 1 & 1 & 1 & 1 & 1 & 1 & 1 & 1 & 1 & 1 & 1 & 1 & 1 & 1 & 1 & 1 & 1 & 1 & 1 & 1 & 1 & 1 & 1 & 1 & 1 & 1 & 1 & 1\end{array}$

นก Oव NCVN Q NMQN-

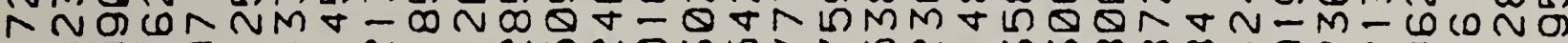

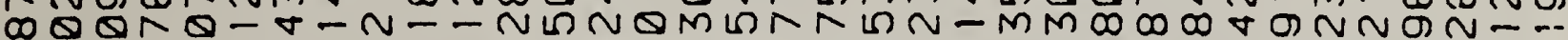
Q

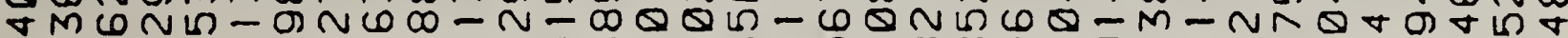
ம - NMM-N$\forall \nabla \nabla \nabla \nabla \nabla \nabla M \nabla \nabla \nabla M M M \nabla M M M M M M M M M M M M M M M M M N M M$ $\begin{array}{llllllllllllllllllllllllllllllllll}1 & 1 & 1 & 1 & 1 & 1 & 1 & 1 & 1 & 1 & 1 & 1 & 1 & 1 & 1 & 1 & 1 & 1 & 1 & 1 & 1 & 1 & 1 & 1 & 1 & 1 & 1 & 1 & 1 & 1 & 1 & 1 & 1 & 1\end{array}$

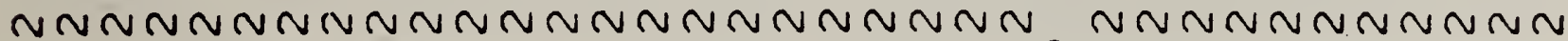

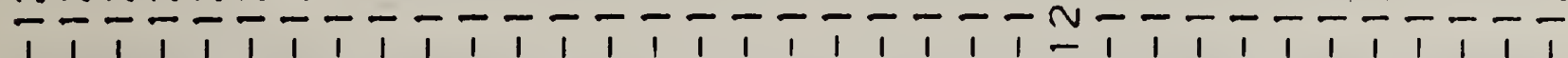

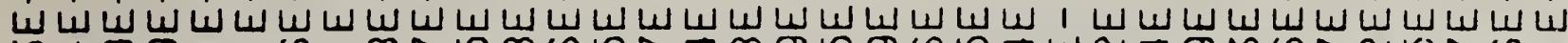
M TR ONM

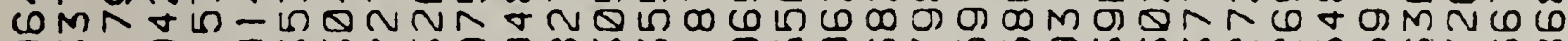

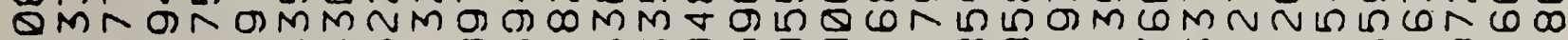

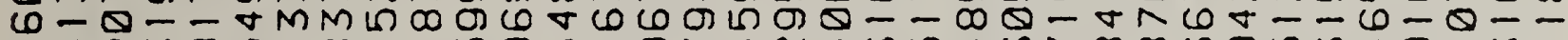

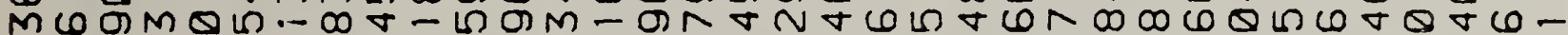
-

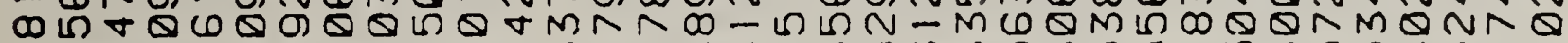
NRQ

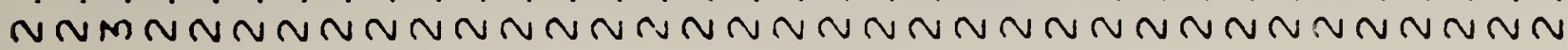

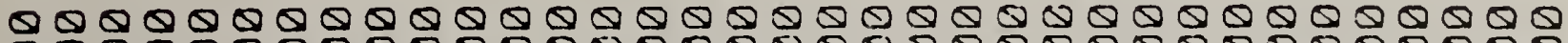

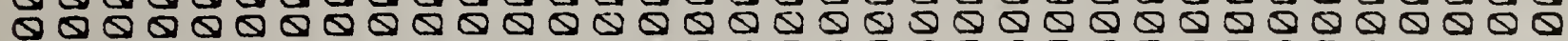
L ए ம 


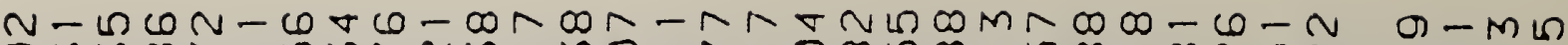
Q $\forall \forall$ V

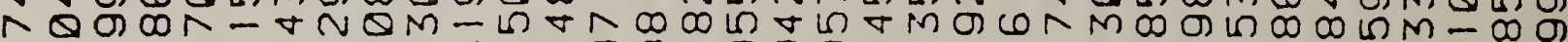
ИNDO NONODOMM

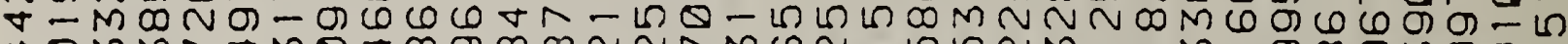
४QMMN W M बO ம

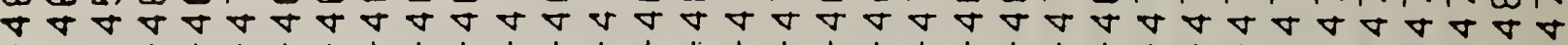

DNMALNNM mA

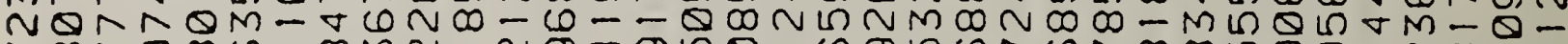
N Q NON

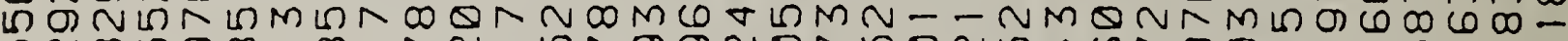

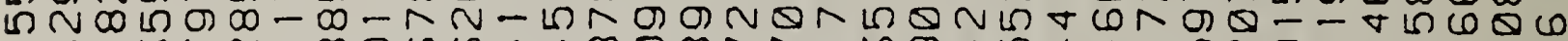
CO NR OD

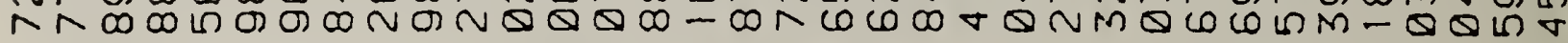

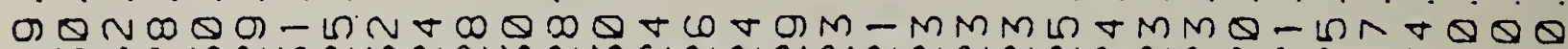

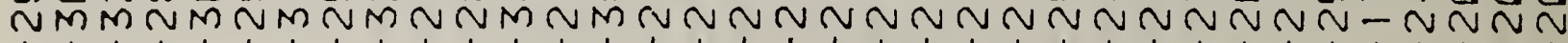

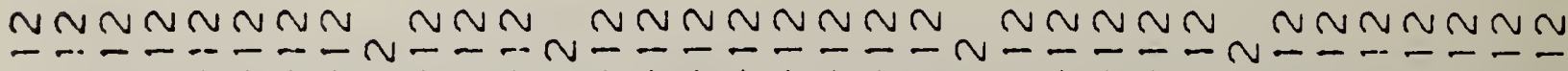
$\begin{array}{lllllllllllllllllllllllllllllllllll}1 & 1 & 1 & 1 & 1 & 1 & 1 & 1 & - & 1 & 1 & 1 & - & 1 & 1 & 1 & 1 & 1 & 1 & 1 & 1 & - & 1 & 1 & 1 & 1 & 1 & - & 1 & 1 & 1 & 1 & 1 & 1 & 1\end{array}$

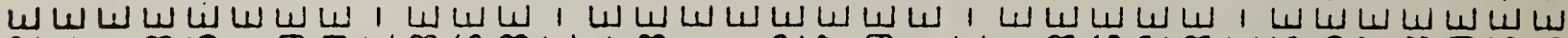

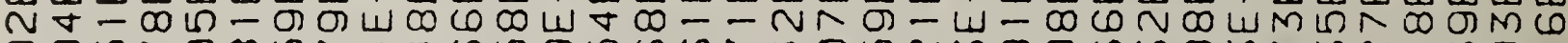

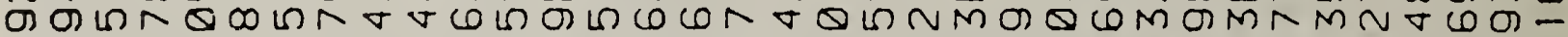
UDQ O

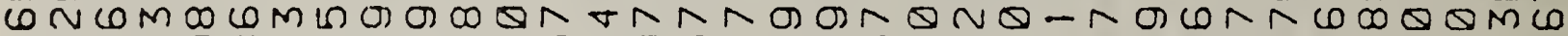
NoD N in $\forall N L L N \cap \nabla M \nabla M \nabla-M N M M N-M N Q M M N M Q N N--N D-$

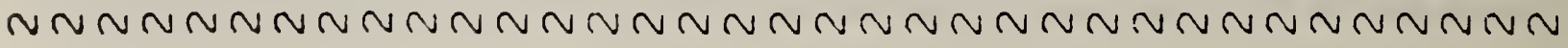

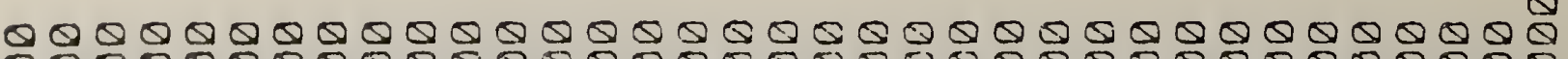

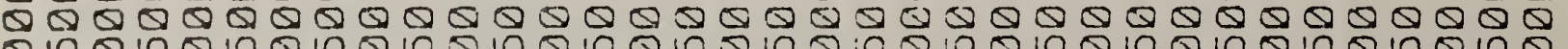
MMt

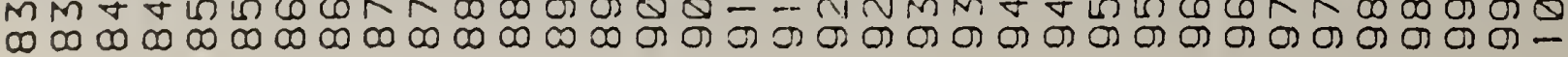


NR N -

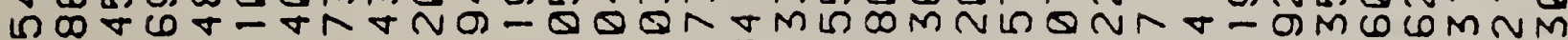
மNL И MVOD ANNM LO-

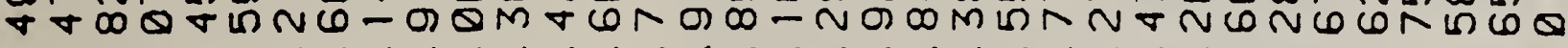

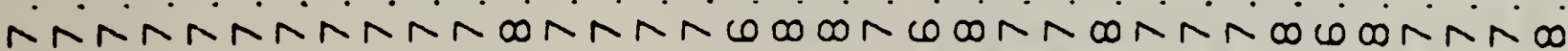

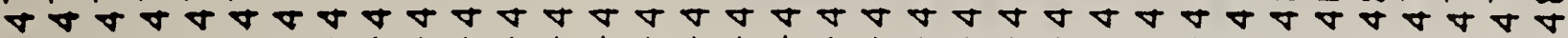

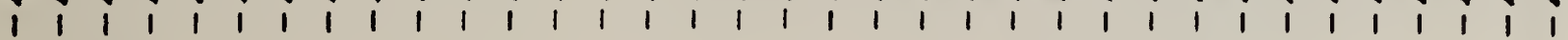

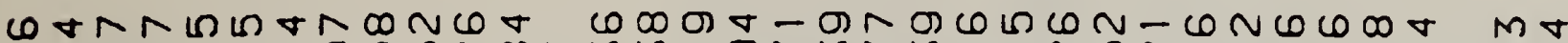

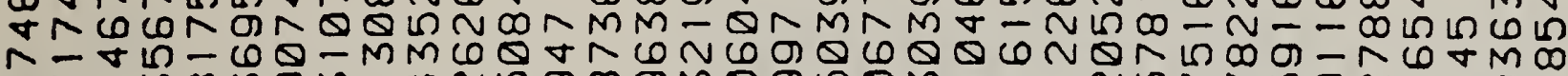

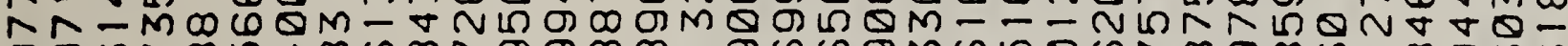

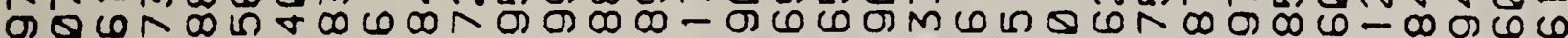
ద O) ब

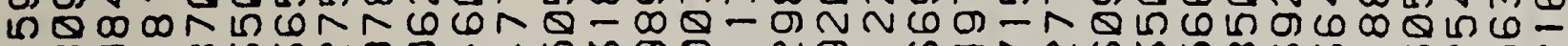

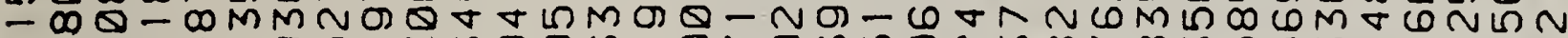
os - 0 Q

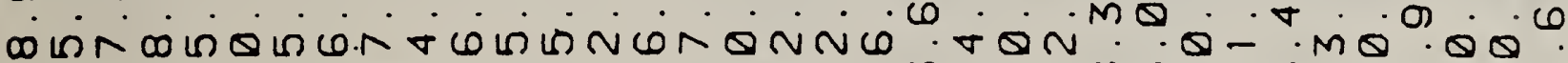

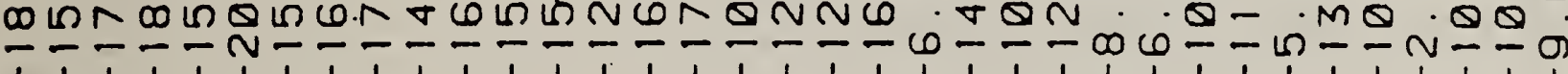

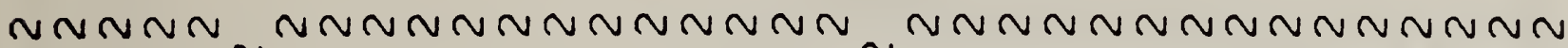

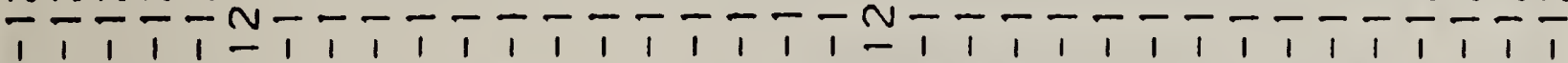

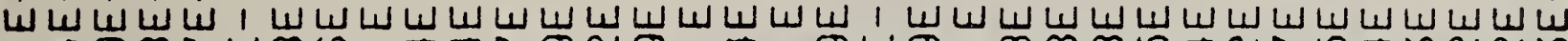
-

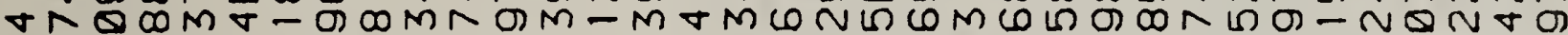
NMMOSQN ИQ NNN

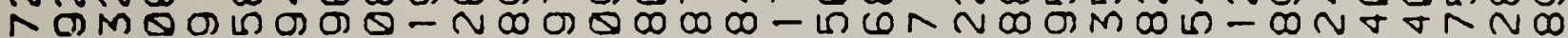
ம-N Иம

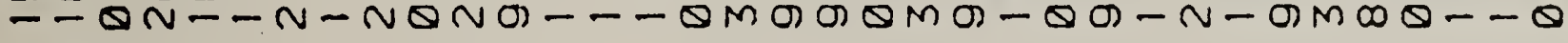

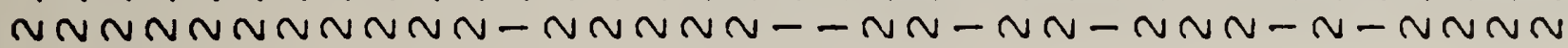

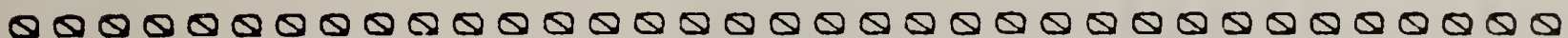

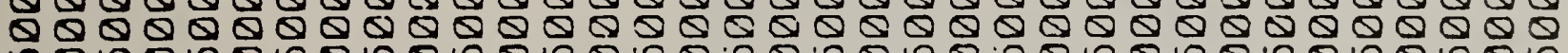
in Q- - NNMM $\forall$ H

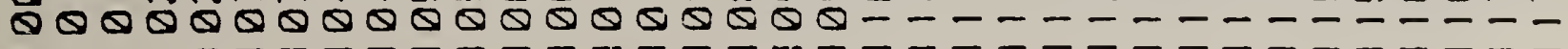


$\omega \square \pi \wedge M \infty N \infty-N L \omega M-\nabla N G \square+N$ O

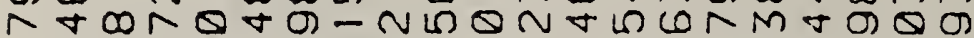
QN NO

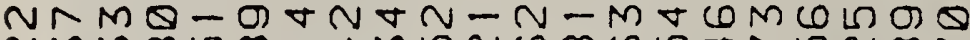
NMMD - DNMNR DOMN N

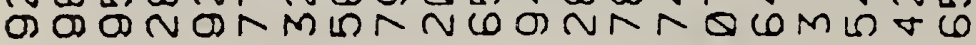

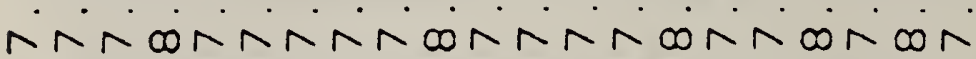

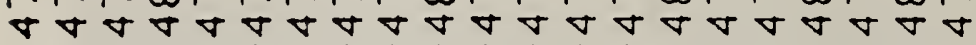
$\begin{array}{llllllllllllllllllll}1 & 1 & 1 & 1 & 1 & 1 & 1 & 1 & 1 & 1 & 1 & 1 & 1 & 1 & 1 & 1 & 1 & 1 & 1 & 1\end{array}$

ancont $Q 00 M N N M-0 \omega 0-6 N-10-0001$

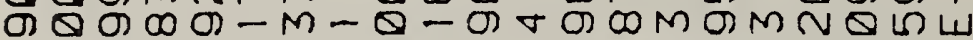
O $\infty M N N N+M M N-06 \nabla \omega N \otimes M \omega R$ L

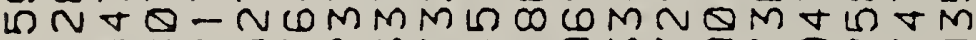
DMOCNINNCN NLN MNIONMN CN NNQ-NMNM⿻

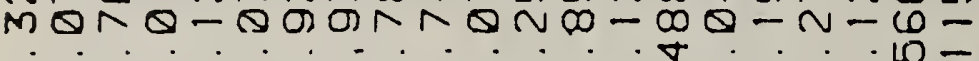
Nं $1,1,1,1,1,1,1,1,0,1,1, M$

NNN NNNN NNNNNNNNN

$N-\frac{N}{1}-\frac{N}{1}-\frac{N}{1}-\frac{1}{1}-\frac{1}{1}-\frac{1}{1}-N N$

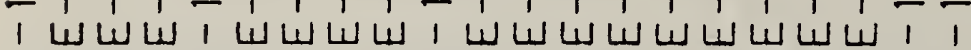

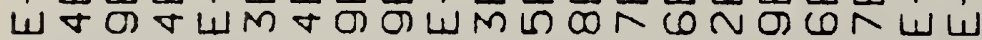

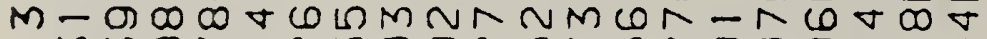
- MMQN-NLQ ONLNLNOQ

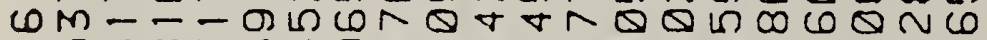

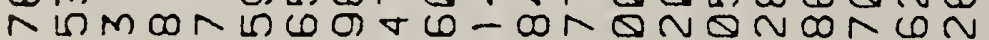

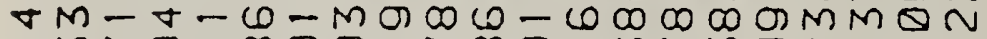

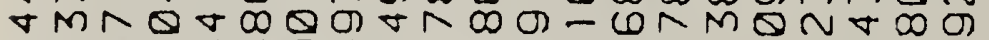

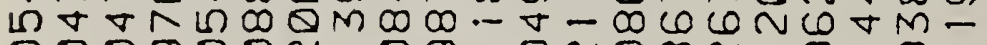
$\theta 00000 N-\theta \sigma-\theta N \theta \infty N-\sigma-\sigma-$ $N N N-N N N N N-N N N \vec{N}-\dot{N}-\dot{N}$

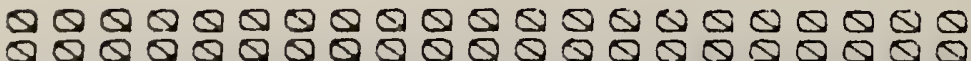

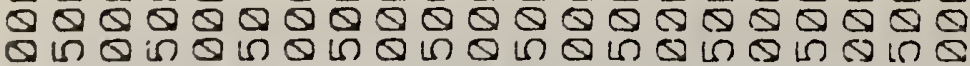

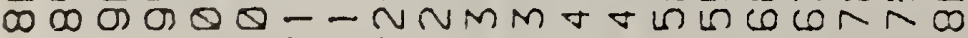
- -. - NNNNNNNNNNNNNNNNN 


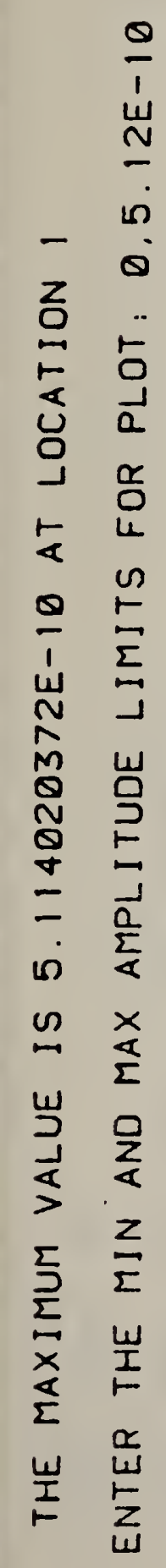


The following ten pages show the results of applying the software contained in Appendix $C$ to a step-like waveform with endpoint not equal to zero.

The first page shows the waveform as acquired from the DPO and the difference waveform obtained by subtracting successive points of the original waveform. The frequency spectrum of this difference waveform is tabulated on the next eight pages and plotted on the last.

This software correctly transforms waveforms of this type. 

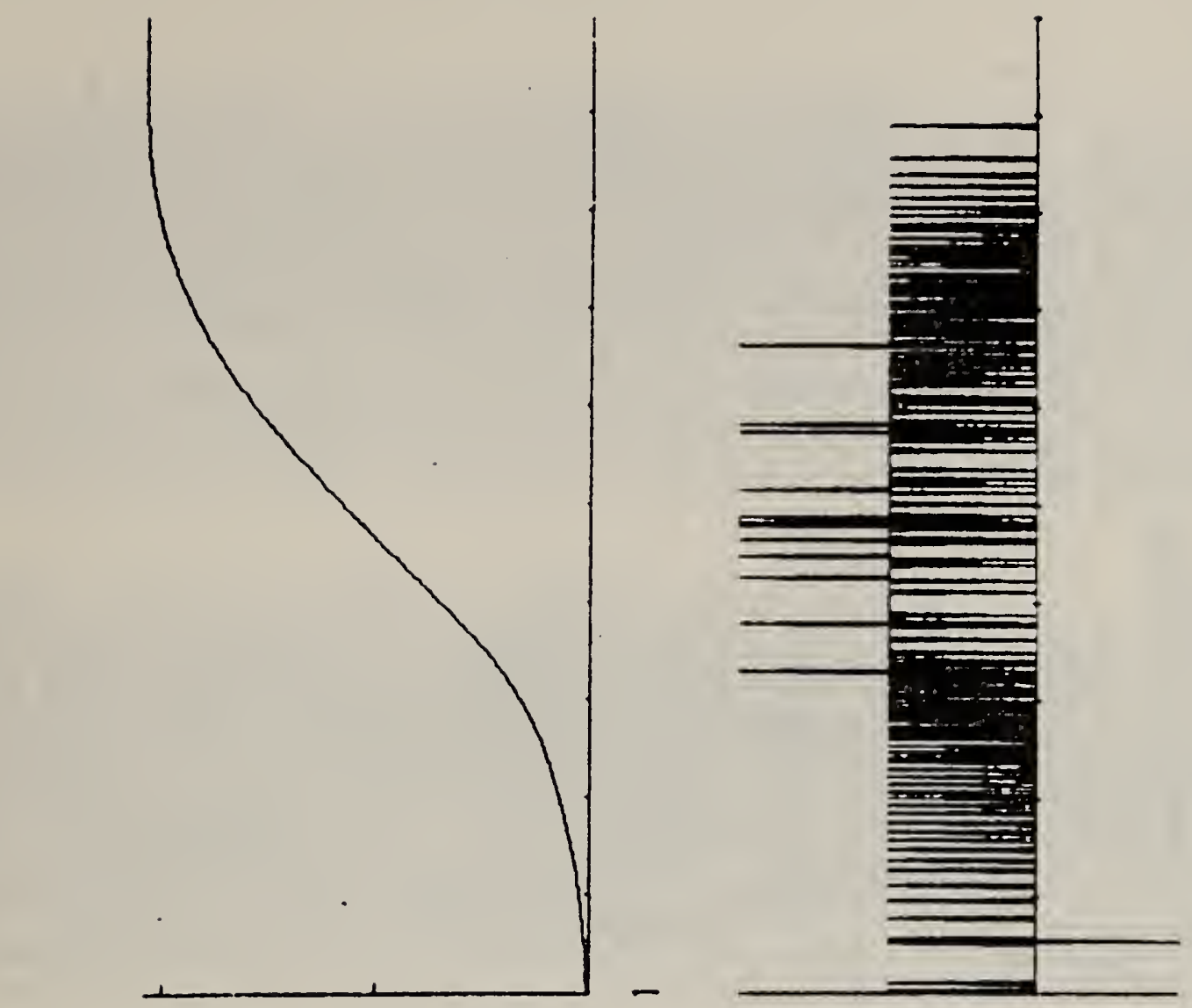

$>>$
믐
in $\frac{0}{\frac{1}{\alpha}}$
ब

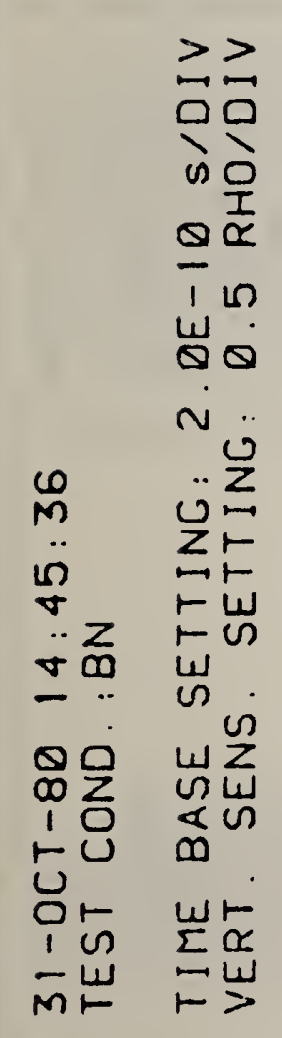

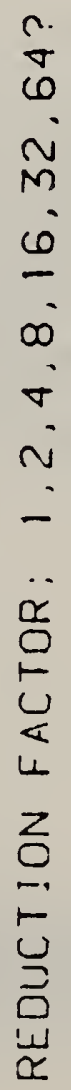


$=$
$\Sigma$
$w$
$\propto$
0
0
$z$
5
5
$\leftarrow$

$\theta$
$\theta$
0
0
10

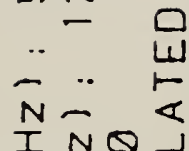
NIN NQ⿻ IEIQ⿱一兀)

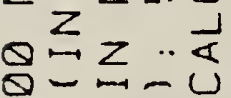
$\theta-m-\omega$ $\infty>I U$ NU> $-Z \omega$ w $Z Z$ -

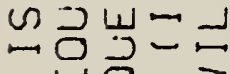
प० 3 $>\approx w z$ Uயव $\simeq$ $z$ L w口乞z ว以ดつセ Oトய- 10 w $<100$ $\propto-j<\omega$

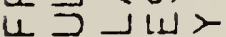
Uवษ 我岁 $>0<03$

ம बir

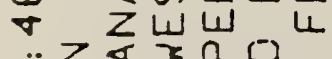
ஏ

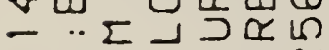

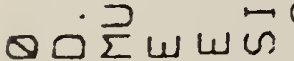
$\infty z=I I \omega u$ $10 x$

บ $匚 \alpha \propto \alpha-$ 0ю山山山山 ஸ山トレトの - wIZZZ MトレU山山く
ט

岁

u

in

I

$\frac{1}{a}$

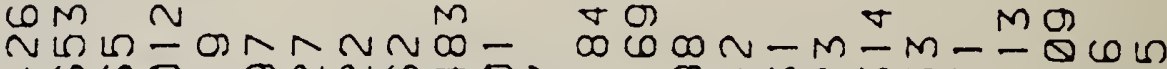

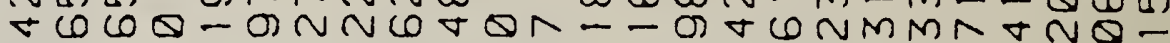

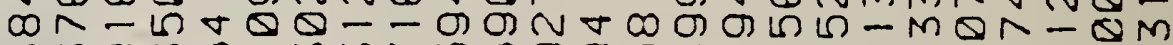
M⿻ - LC $\wedge \omega$ เ

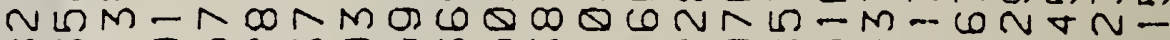

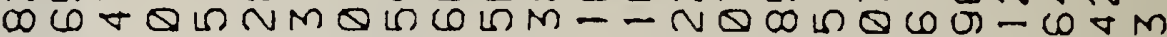

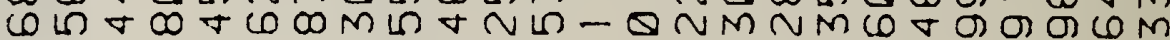

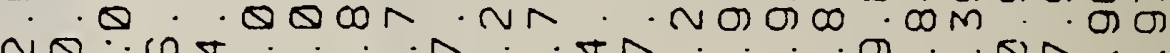
क N

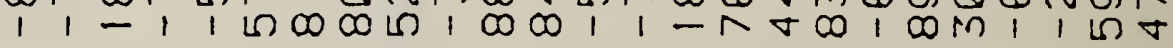

Q-NNNMNMNMMN Q - - - - - - - - $M-\ldots-\cdots M-m M$

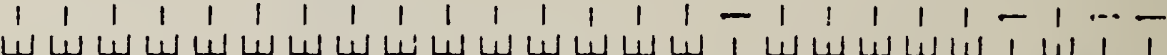

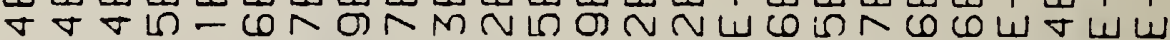

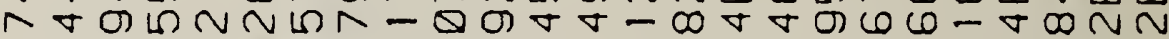
त $\sigma \infty m-\theta m \sim N \nabla N$ G L

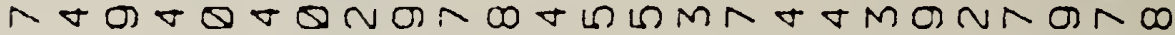
$\omega N \omega N \nabla \nabla N M-\infty \nabla N O M M O \infty-\theta Q N Q M \infty L$

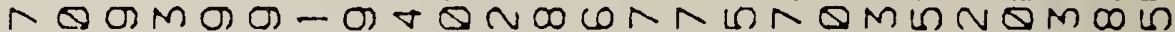

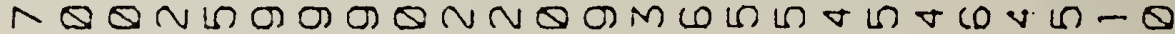

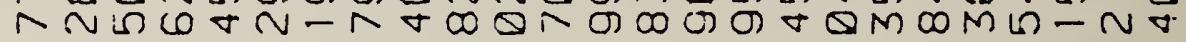
$--\Pi--\nabla-M N-G N N-N N-N--M N-$

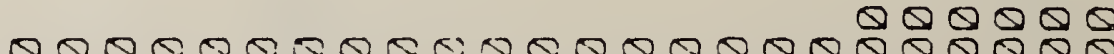

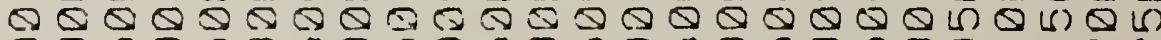
$\theta 0$ Q

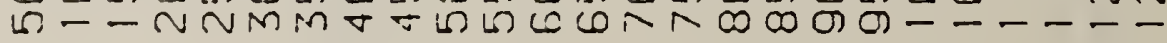


N

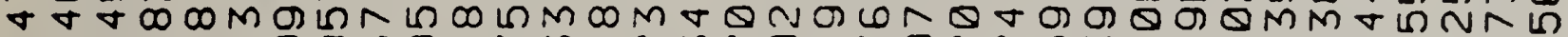
Q -

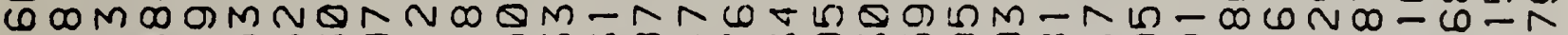
எ M 0 M I U - I MMM J

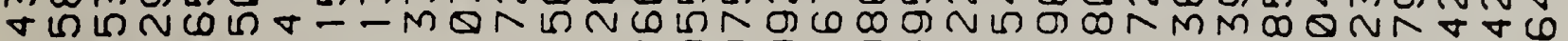

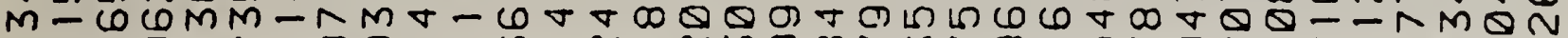
QNRE-N-OQ

Nuा L i

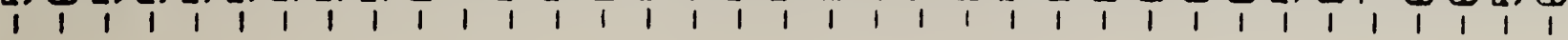

N

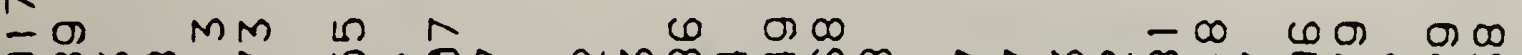

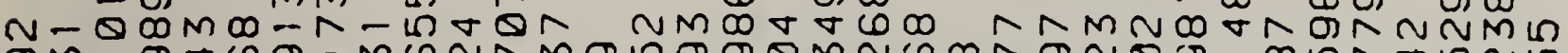

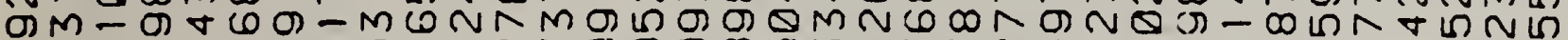

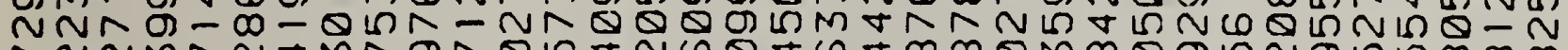
NNNMNN Q-NNDMUDNRN NCONMMDN Иब

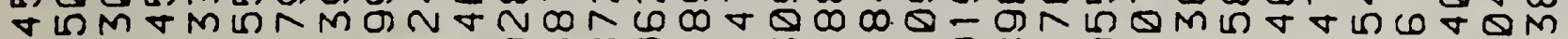
- M

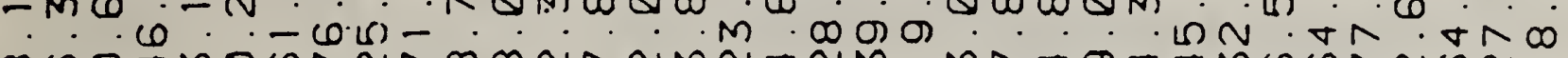
D

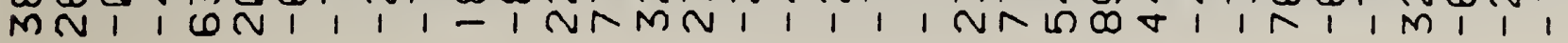

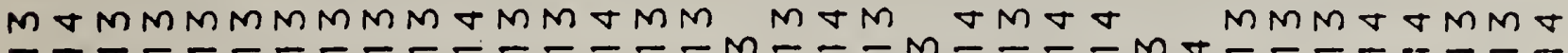

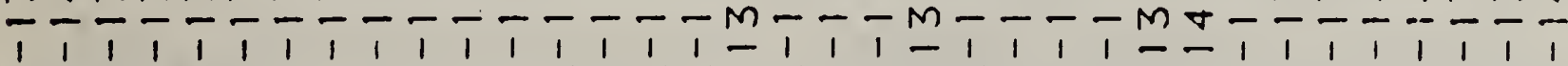

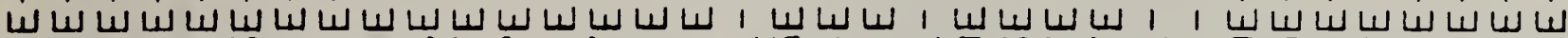

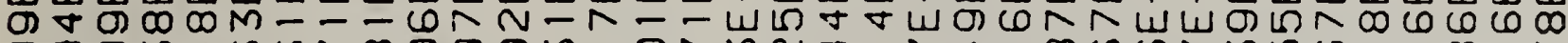

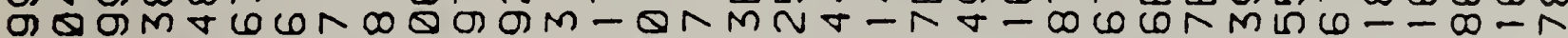

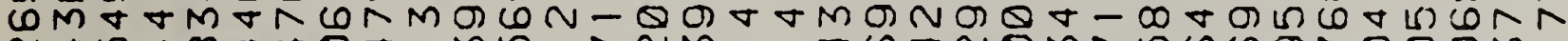
N GN

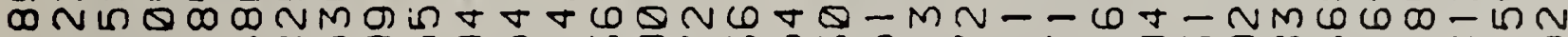

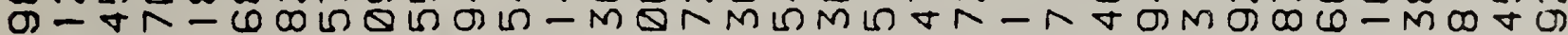
QLOTRNR

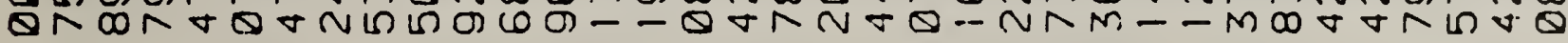

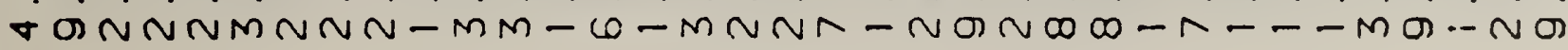

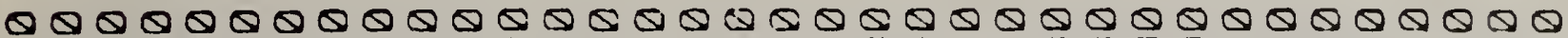

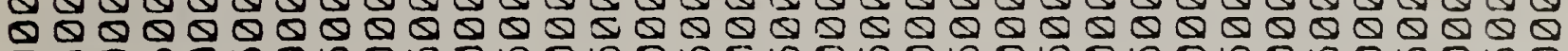
Q MM

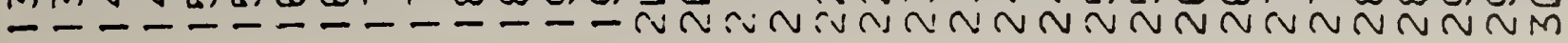


४⿻ L

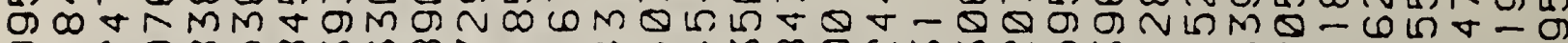

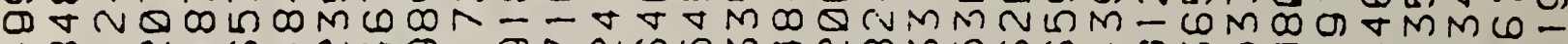

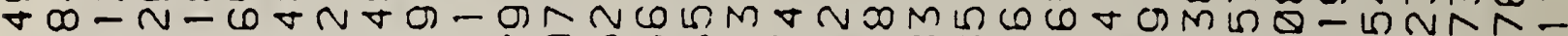

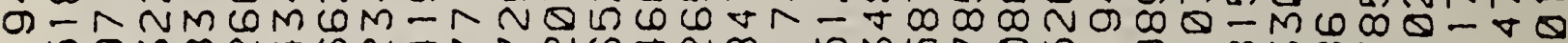
-

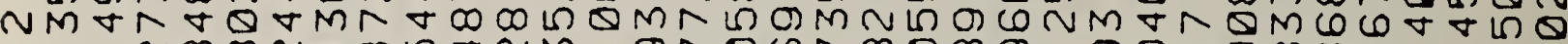

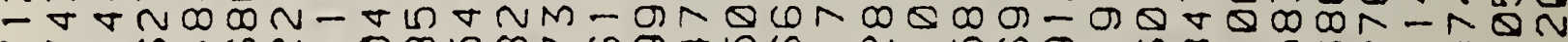

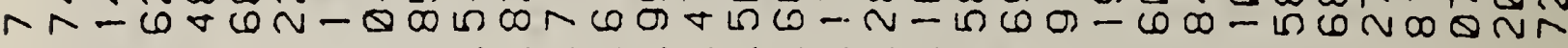

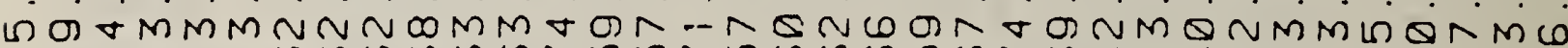
ம

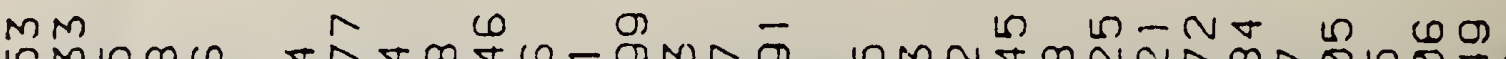

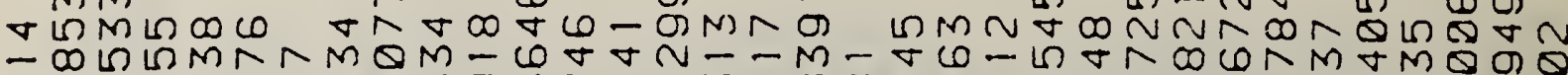

N $\infty M M N N N$ N

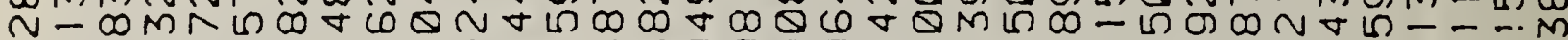
แ $\theta$ ம N N $\infty \omega \infty \theta N \infty M L \omega R \nabla-\lambda \omega L M M N R-\infty \sigma \nabla \nabla \nabla \omega 6 \nabla \omega-0 N \infty-10$

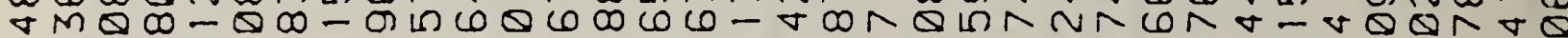

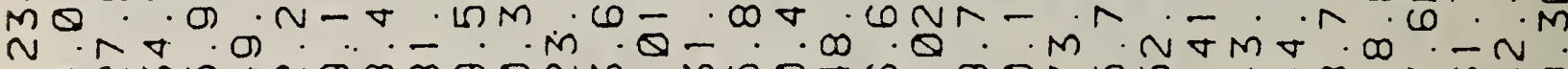

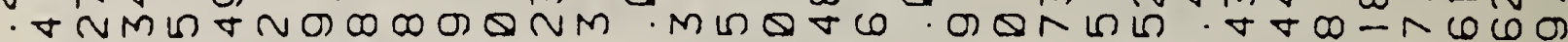

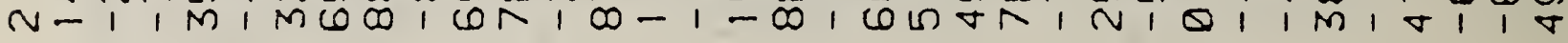

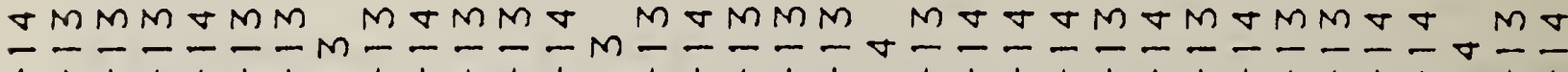

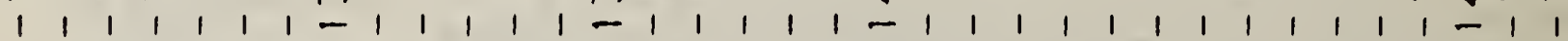

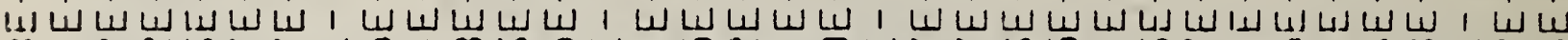

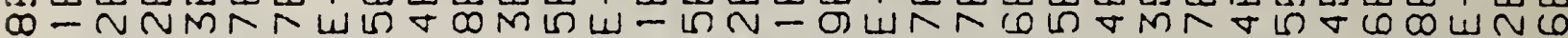

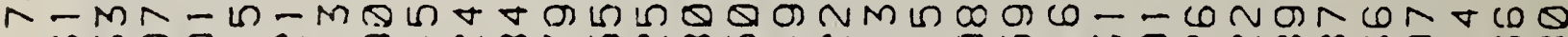

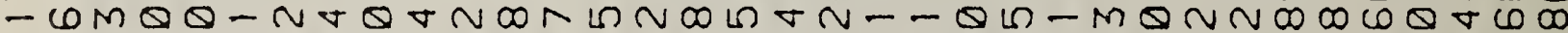

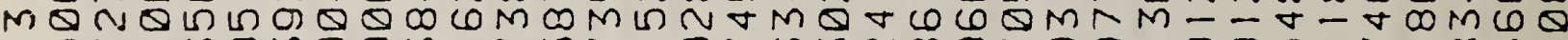

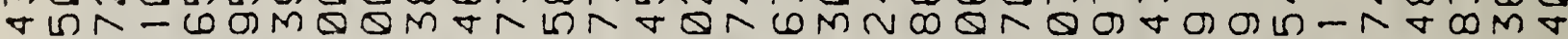
W

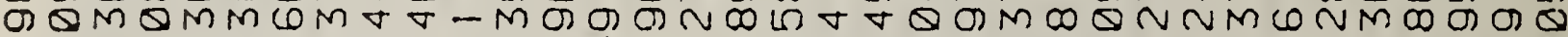
QN QN $N \infty-\cdots N-M M \nabla \nabla--N \infty N N M \omega M \log \nabla N \omega M N \omega \nabla--\omega \omega \nabla N N$ $a-\cdots-m-\cdots-\omega-N-N-N-N-\infty-\infty-N-\infty$

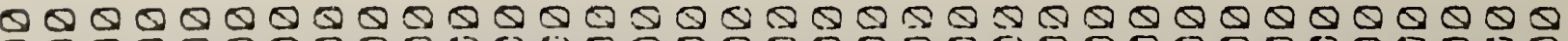

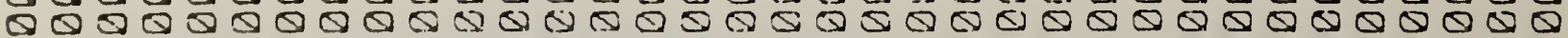

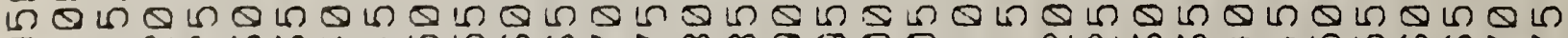

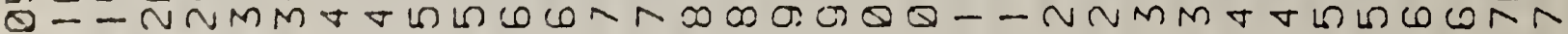
MMMMMMMMMMNMMMMMNMM 
ИM⿻ NNGD N N Q NM⿻ M

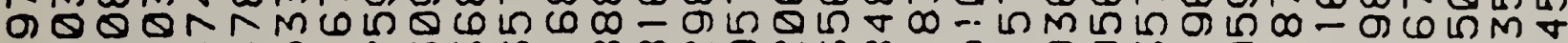
-

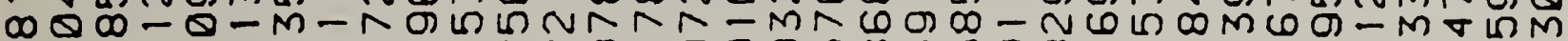

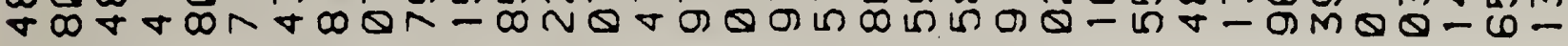
M ம

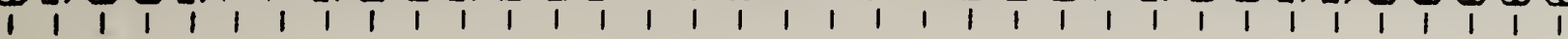

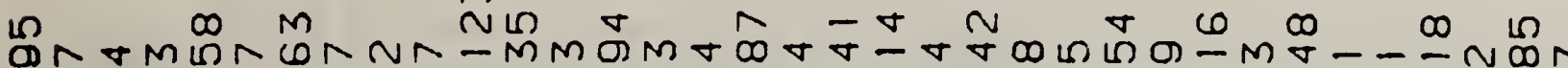
- OUMN

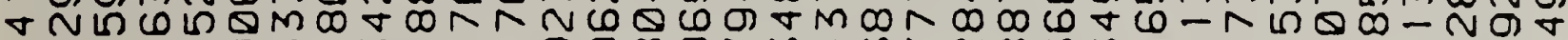

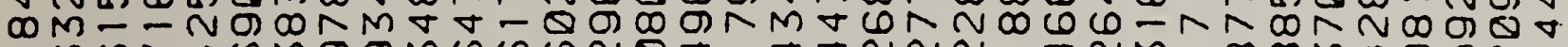
-

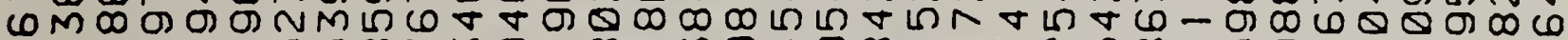
QN M- - LMNQQD-

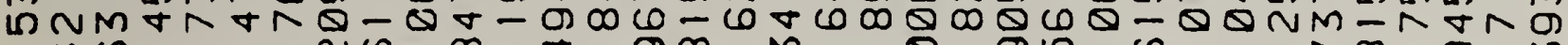

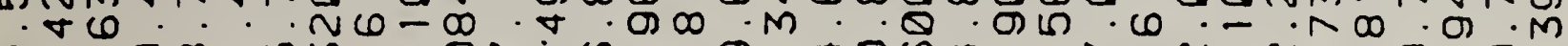

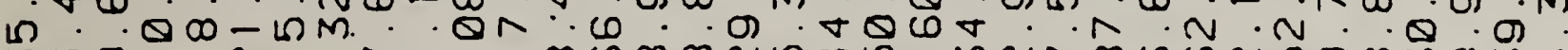
MLQ

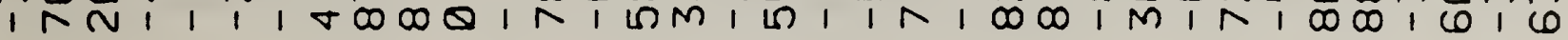

$M M M V M \quad \forall M M \nabla M M \nabla M \nabla M \nabla \nabla \nabla M \nabla M \nabla \nabla \nabla M M M M M M M V M$

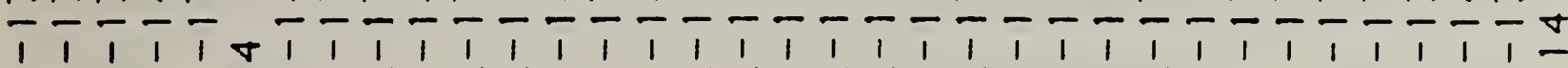

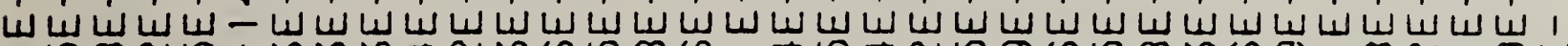

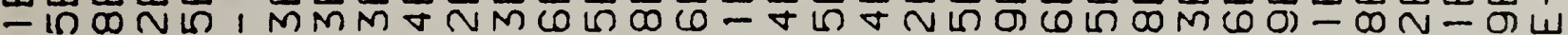
U⿴NQ

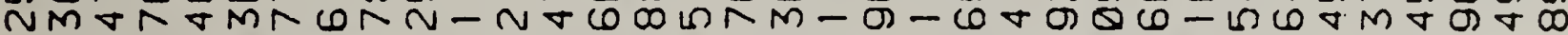

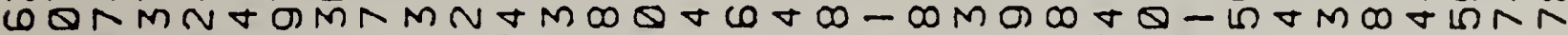

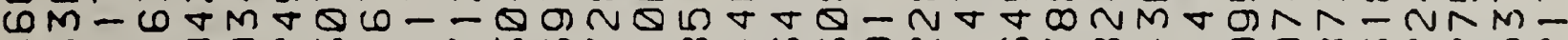

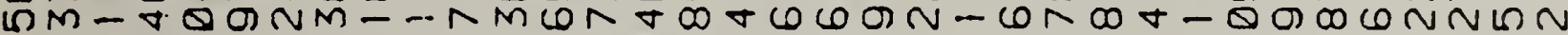

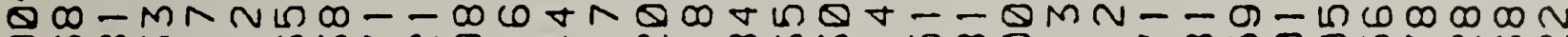

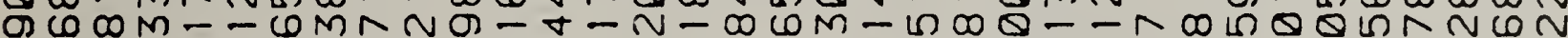
- I

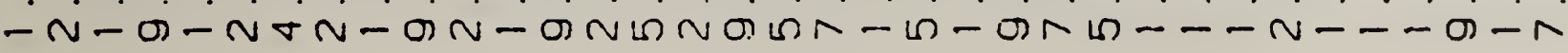

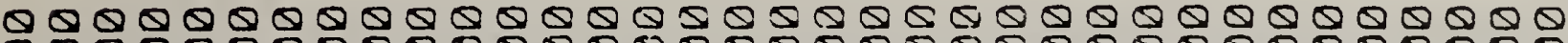

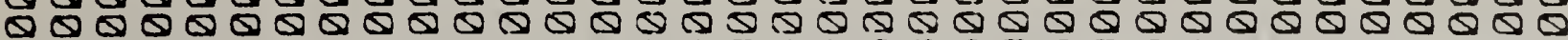
Q

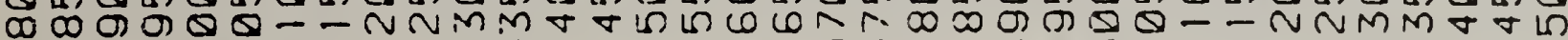

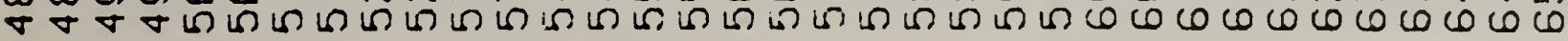




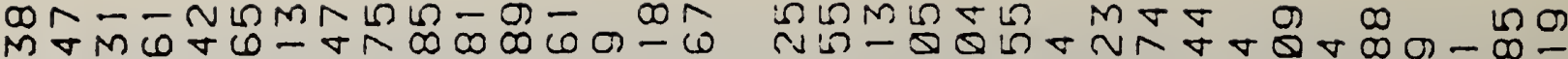
M L - MDNND-

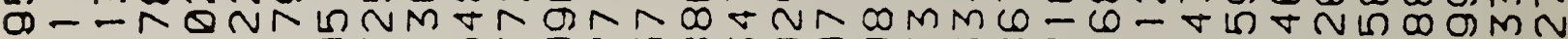
बの G GM⿻MOMN mष ம N ம

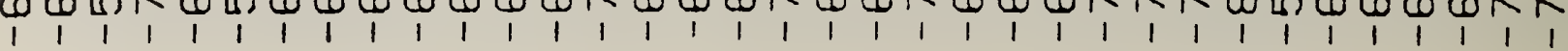

$\omega$ NGN NLMN बM-

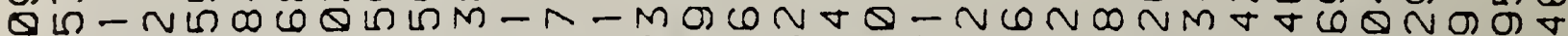

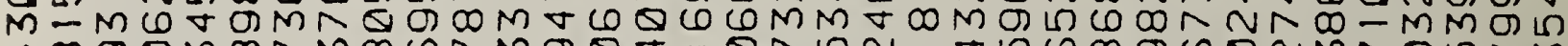

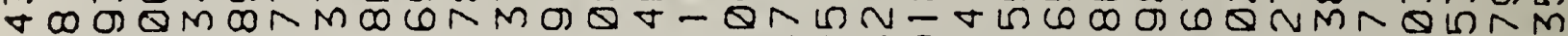
NMNM⿻ MNQN

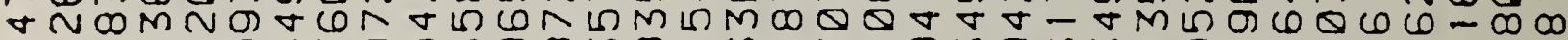

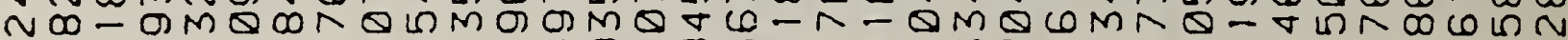

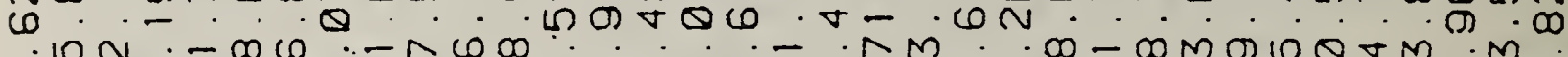

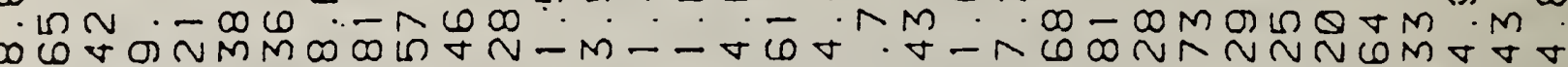
$\begin{array}{llll}1 & 1 \\ 0 & 1 & 1\end{array}$

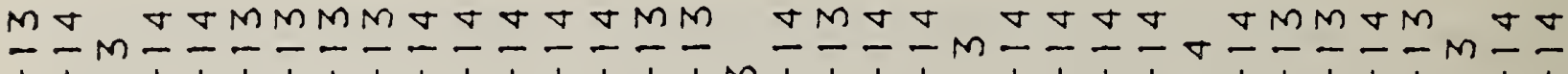

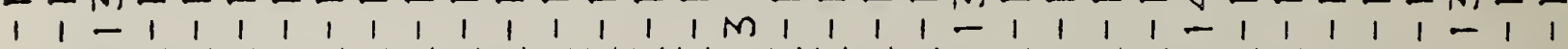

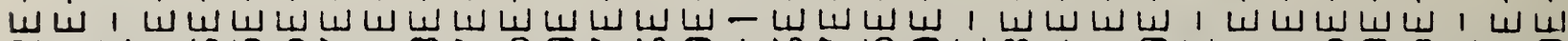
ก-山W - LR

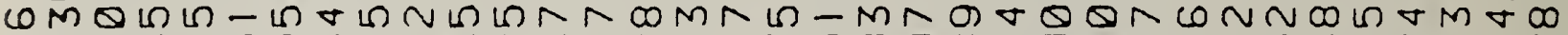
$\omega-$ -

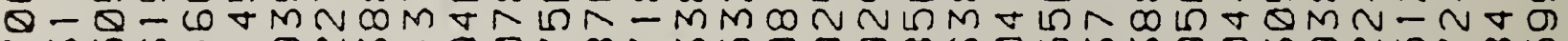
NMLமVN

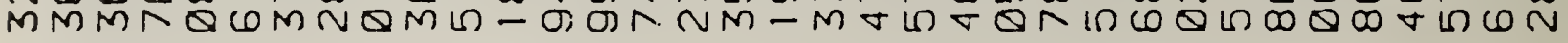

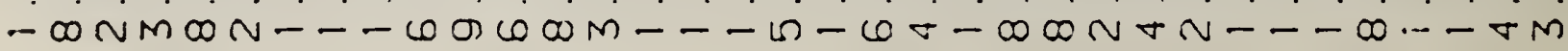

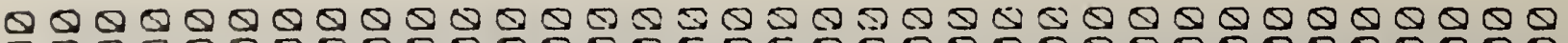

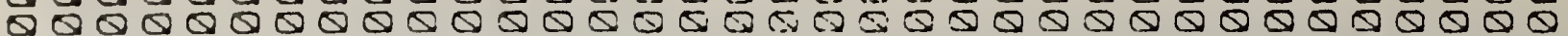
L ए ம 


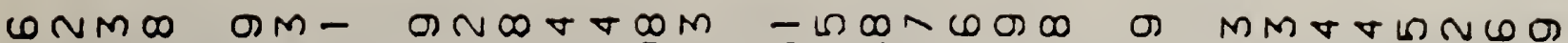
NQNNONR-MUNDM Q ब の

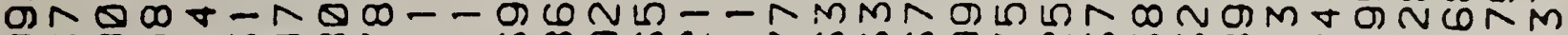

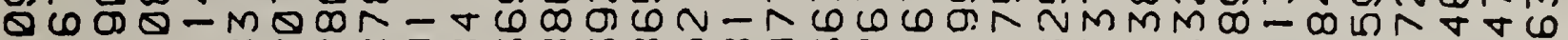
* U

I C

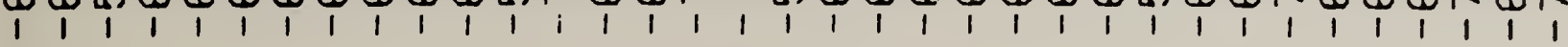

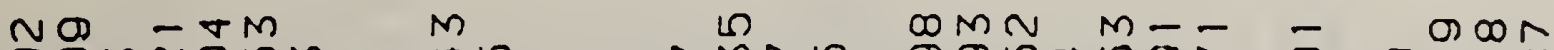

MOI L ४ - MN

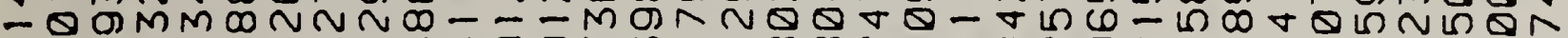
Q NQ

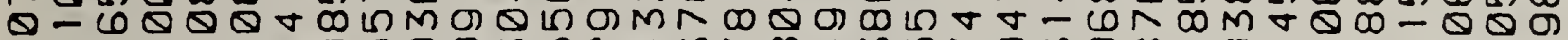
NGMENGDMMQ

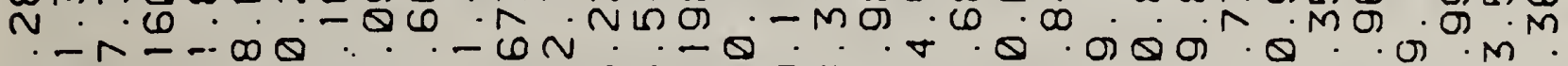
O)

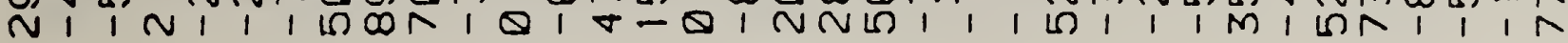

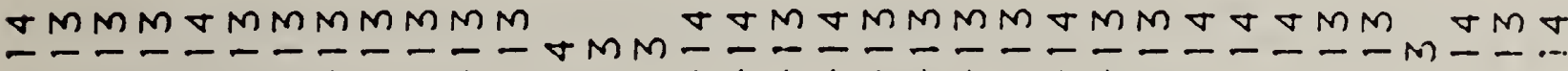

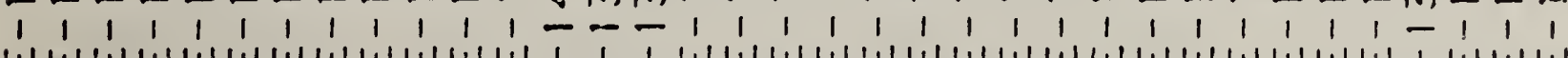

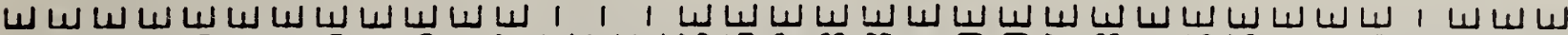
-

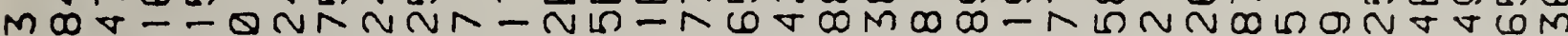
Nл

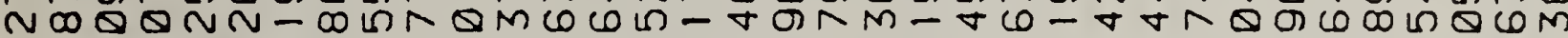

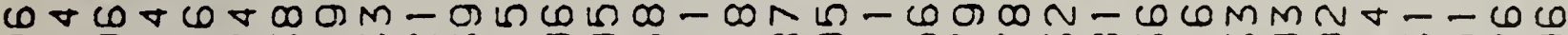
O⿻

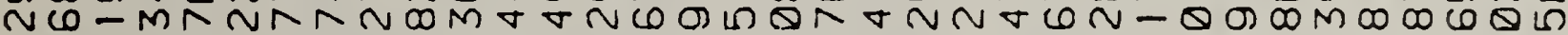
क

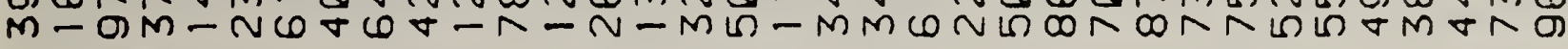

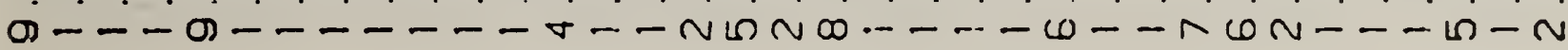

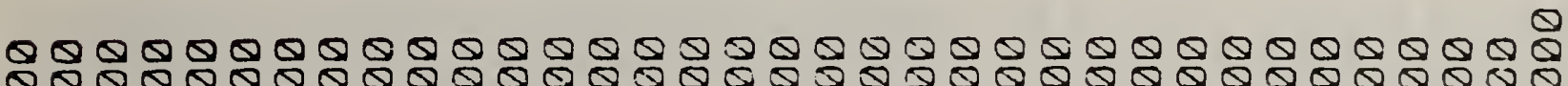

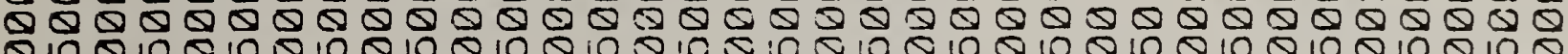
MMV

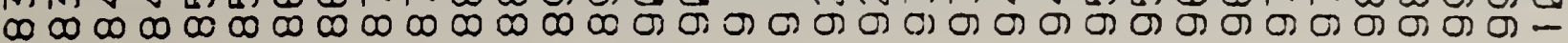


OMMV $\infty N$ O

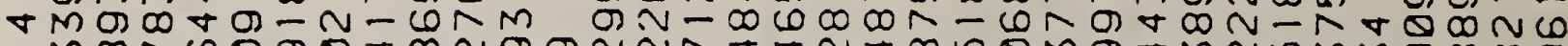
- MDN NQL-NM

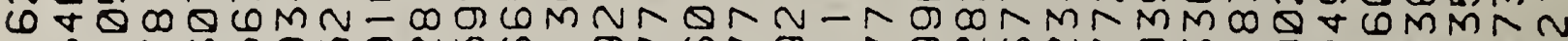
ம

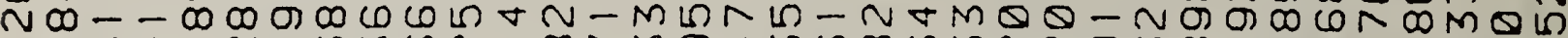
ONW N

NA

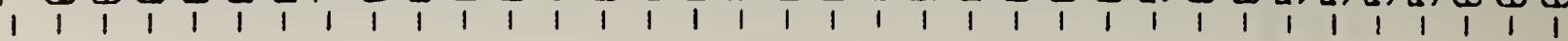

DNOAO

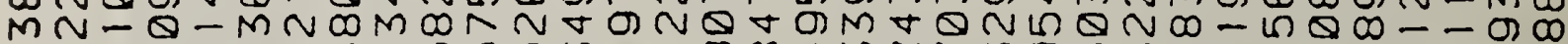

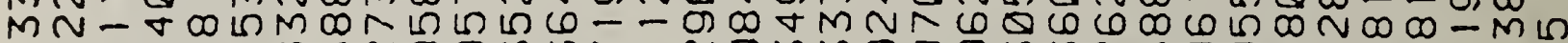
$\infty$ I N-

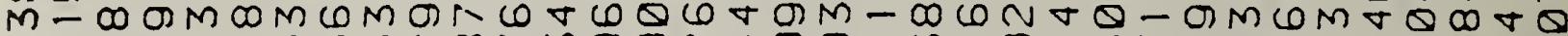

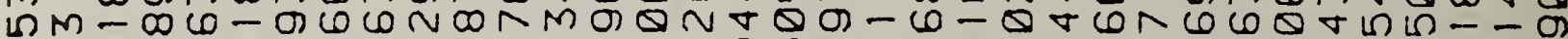

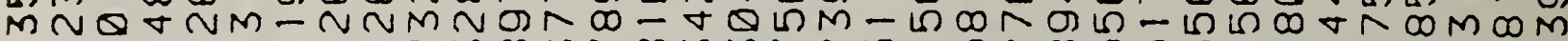

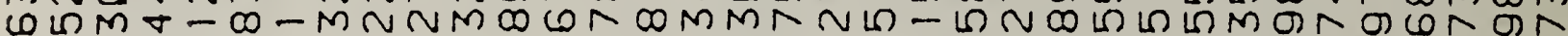
G- NLNL

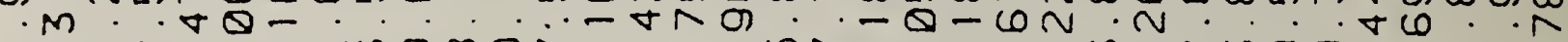

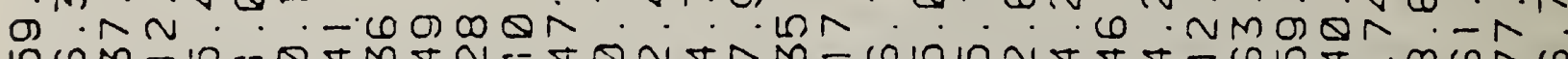
L IN 1 1

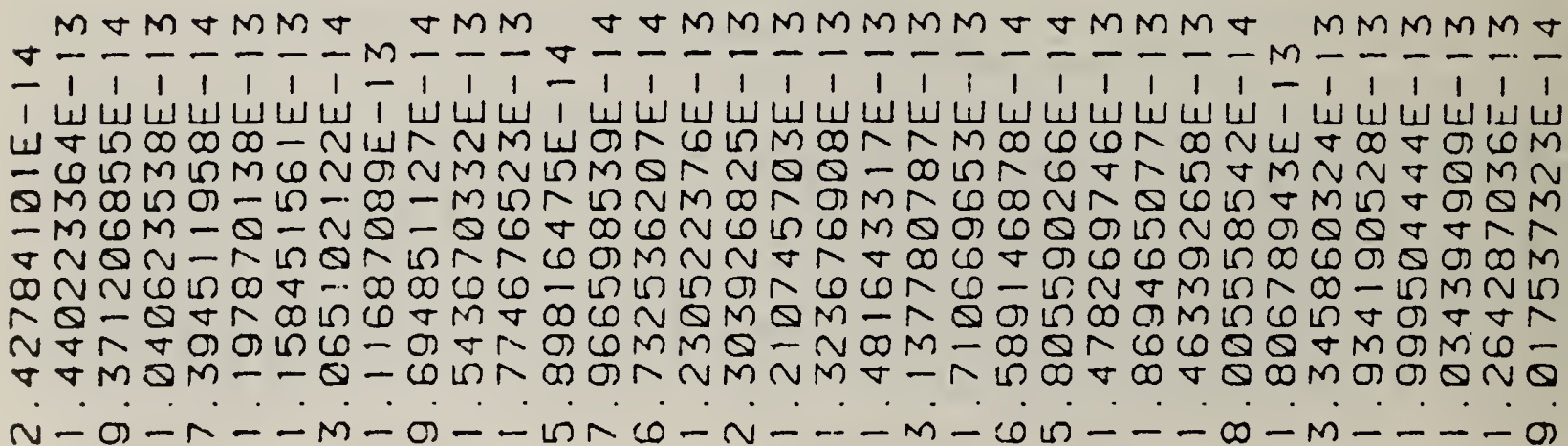

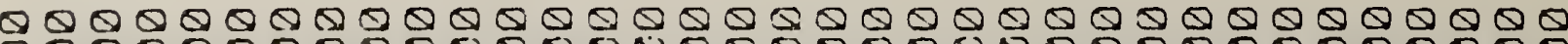

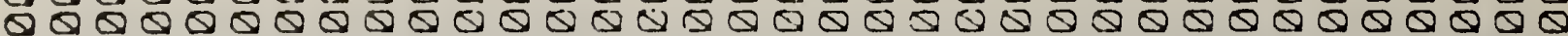
L ब Q- - NNMM $00000000000000000000-\ldots \ldots \ldots$ 
N

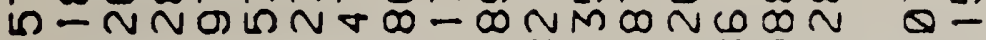
MMOMONNFF- - $\infty$ ON $N \infty Q M-\nabla \infty$ $m-\infty \forall \theta \infty \forall \forall \theta \sigma N \nabla L \infty \omega \nabla L \nabla-N \theta$ QN

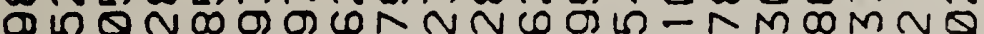
ONNMOOONND- ONRMOQN

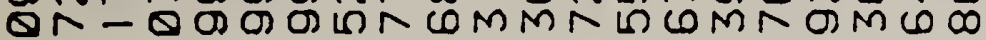
$\theta \omega \omega N \infty \wedge \infty \omega \nabla N \omega M N \infty-\omega N \omega N \backsim \sigma$

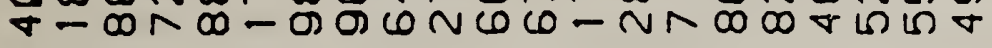

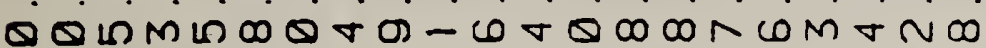

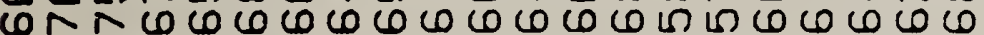

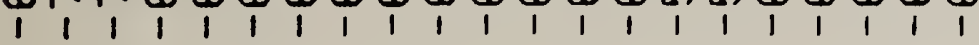

m

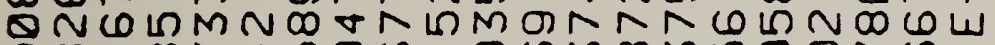
Q $-\infty \pi \forall$ -

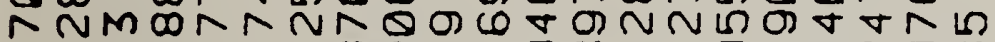

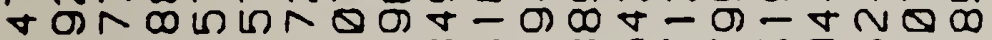
$N N-Q \infty \omega N-\infty \infty \omega-\infty \Pi N N M Q M N-$

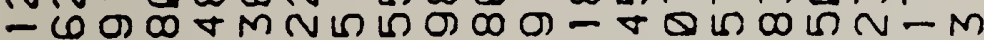

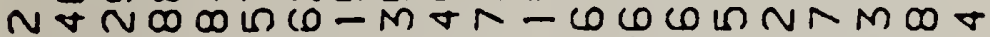
N

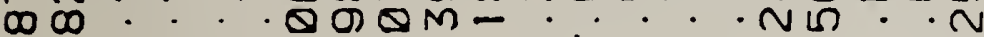

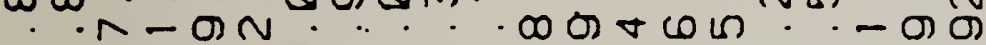
an I

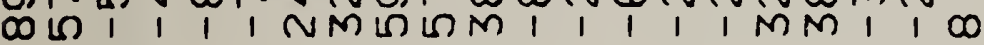

$M \nabla \nabla M \nabla \nabla M M \nabla M \nabla M M \sigma M M \nabla M M \sigma$

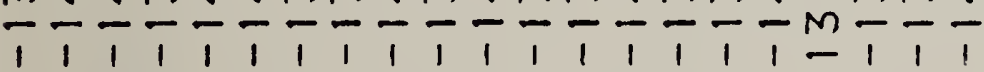

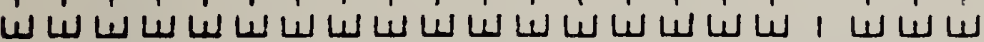
ब

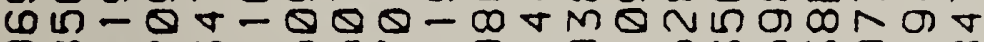

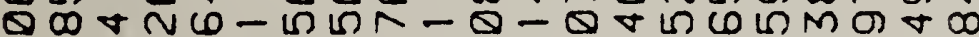

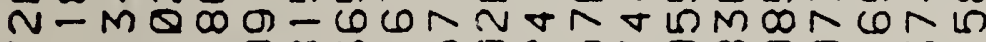

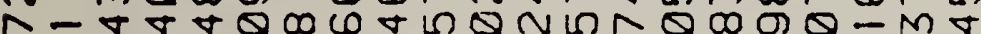
$\checkmark \omega \omega M Q \sigma-\omega-\omega \omega N R-\infty N N M Q \nabla N$ $N-N \infty M-\omega M \sigma \nabla-N-\infty \theta m \theta N \omega \forall N$

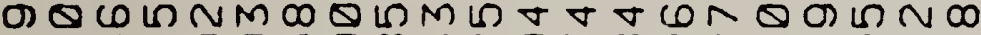

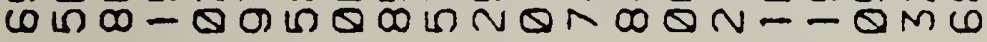

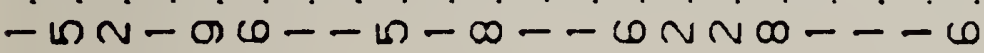

O

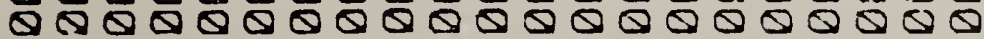
Q

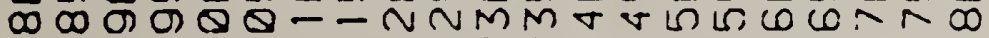
- - - $N N \sim N \sim N \sim N \sim N \sim N N \sim N N N$ 


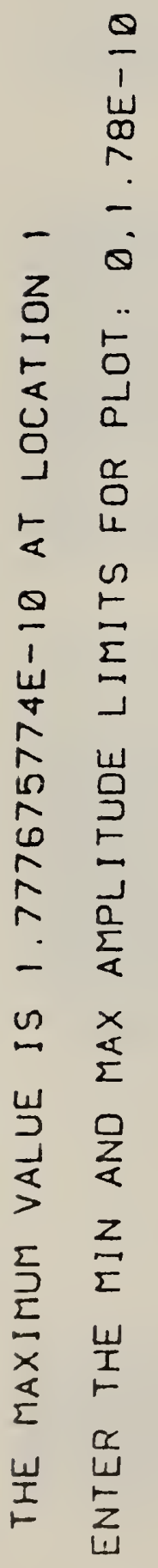


The following ten pages show the results of applying the software contained in Appendix $D$ to a step-like waveform that begins at zero and ends at some nonzero value.

The waveform, as acquired by the DPO, is shown on the first page. The transformed spectrum is tabulated on the next eight pages and plotted on the last.

This software correctly transforms waveforms of this type. 

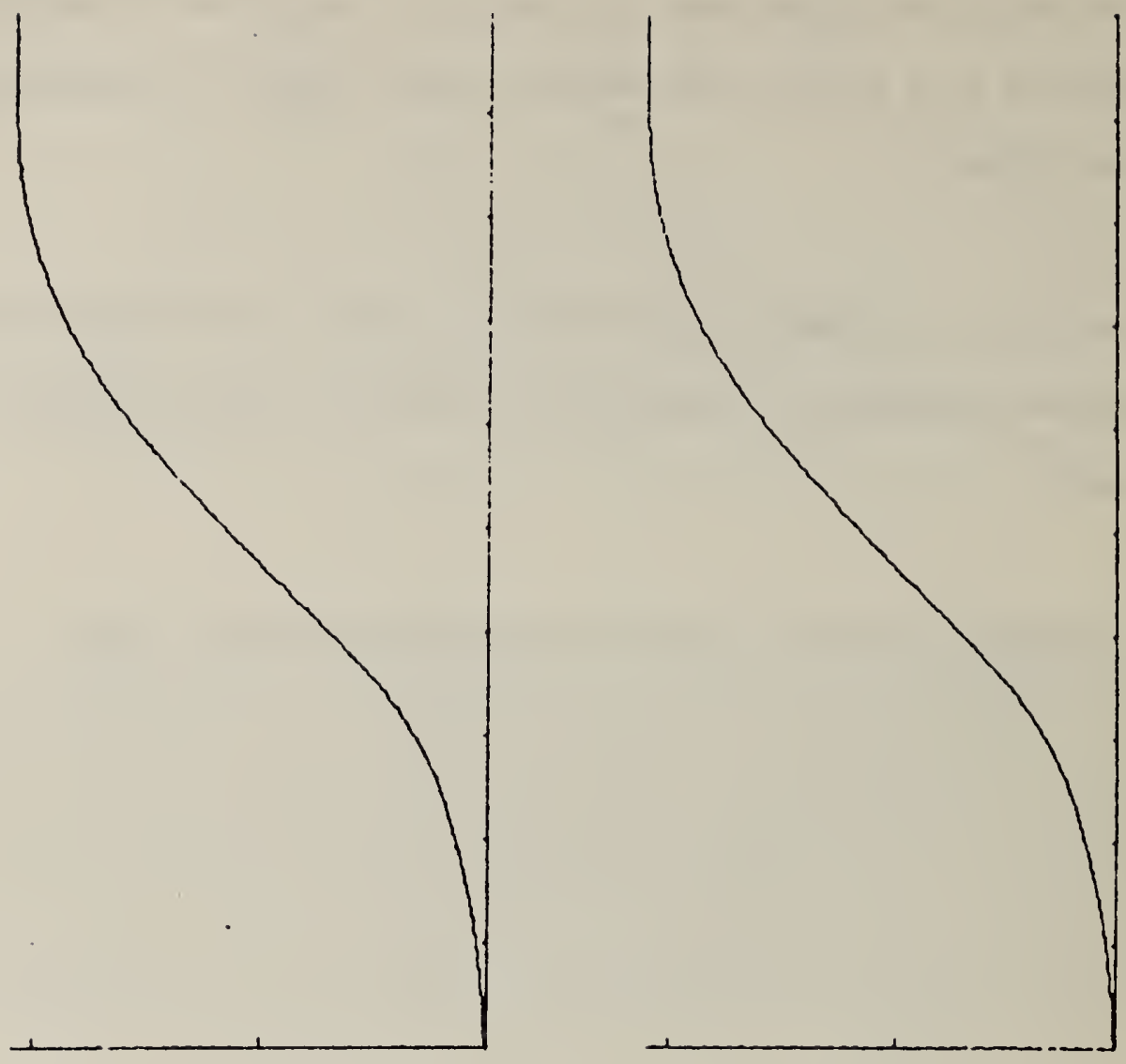

$\geq \geq$
00
के $\frac{\partial}{x}$
$0 \frac{1}{x}$

in

I $\theta 0$

u N.

- $0 \quad$ 品

. E Z

(n) $\leq r$

난

¿4. W.

@品

10 बin

U $\infty$

它 $=$

m出

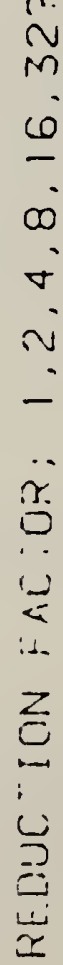


$=$

m⿻

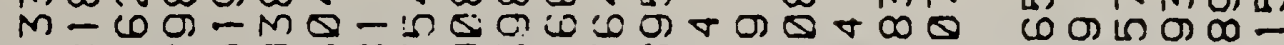
-

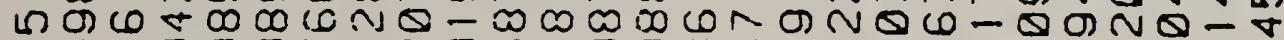
$\infty \Lambda V Q Q E N$ T NOळ

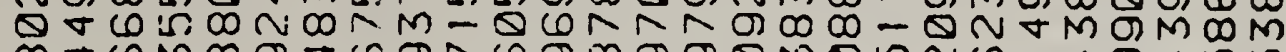

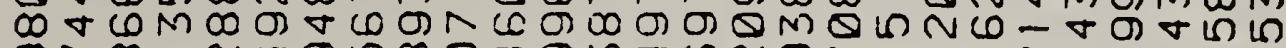

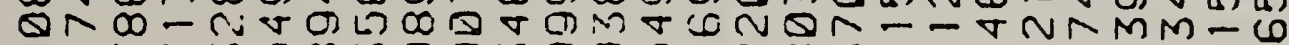

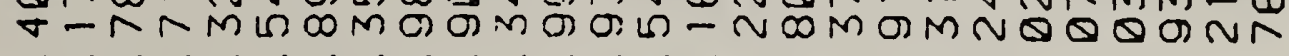

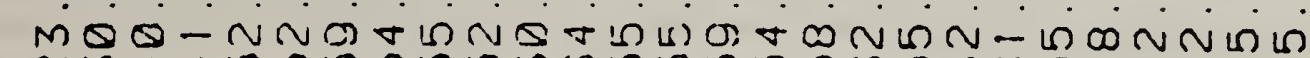

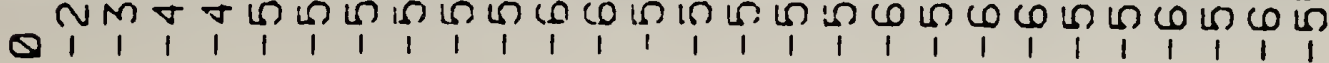

D

L N马

岂

U

$I$

Q

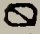

$\infty \omega$

$\sim \infty$

-

$\Omega$

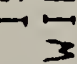

$>$

Un

z

w

$2=$

0

무

Wu>

uथ

๒セ4

ํำ

$\ddot{\infty}^{\Sigma} \frac{1}{\alpha} \frac{\omega}{\alpha}$

$m \vdash z u$

. $4<$

$\nabla L \omega$

- . $\sum \stackrel{2}{2}$

Q미

क

r

U上坛

1 जแ

..WI

$M F F \ll$

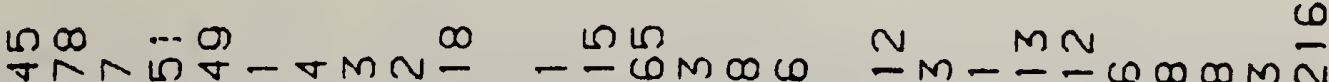

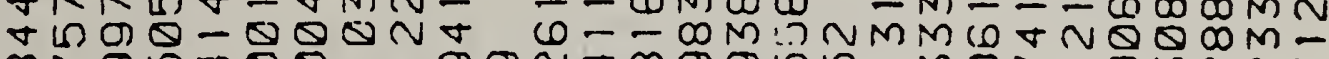

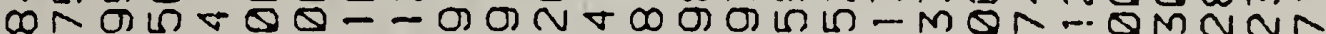
M م N $\infty \omega \nabla \theta L N M Q L \omega L M-N Q \infty L \theta \omega 0-\omega \nabla M L \theta Q$

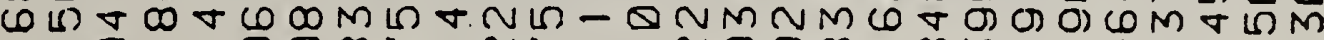

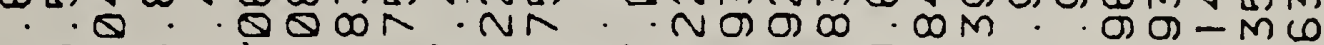
NQ 1

Q-NN $M M M M M M M \sigma M M \quad M M M M M \quad M \quad M \sigma M$ - $-\frac{1}{1}-\frac{1}{1}-\frac{1}{1}-\frac{1}{1}-\frac{1}{1}-\frac{1}{1}-m M-\frac{1}{1}$

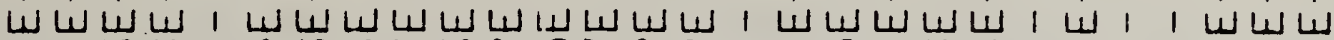
v ก

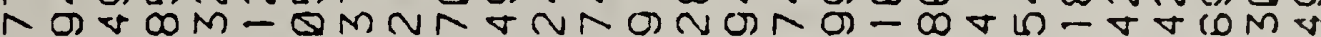
ИL R $\omega N \operatorname{loN} \forall \forall N M-\infty \nabla N G M M \sigma \infty-\theta \otimes N Q M \infty \Pi \infty N L$

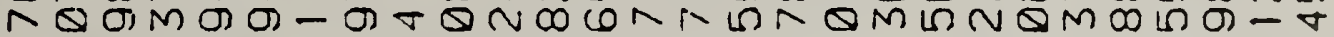

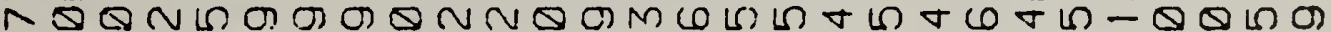
N N

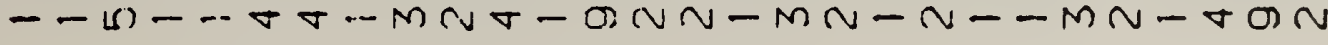

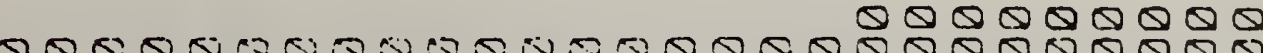

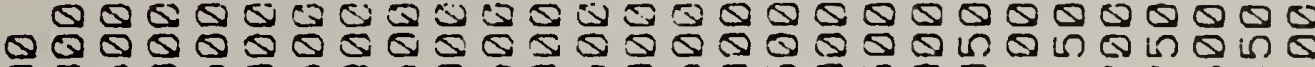

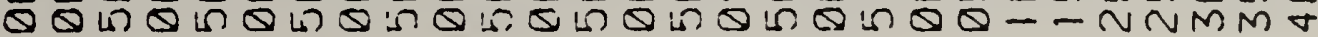

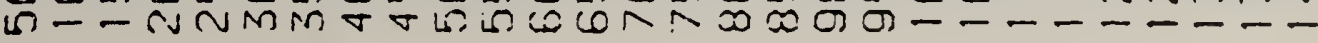




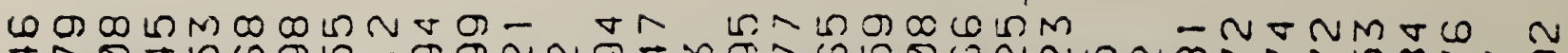

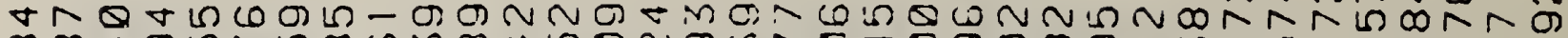

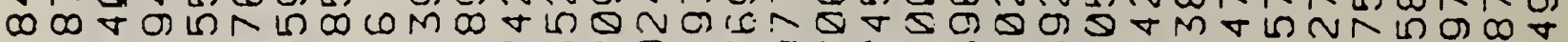
$\forall \forall-\theta 0 \omega 0$ -

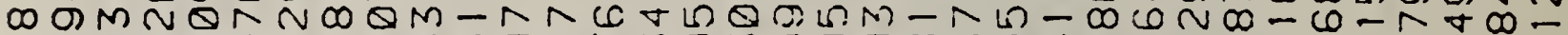
Q 1 I

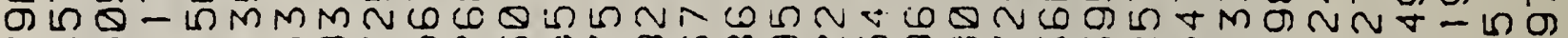
NG

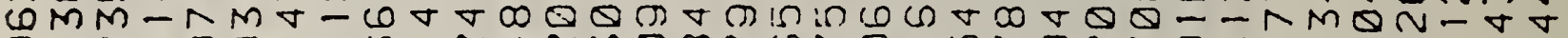

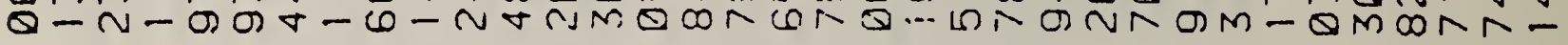
cN ا

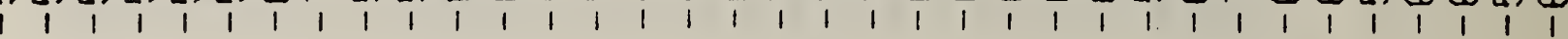

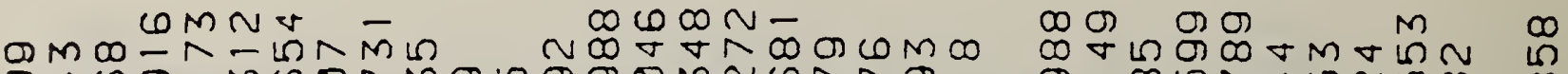
G

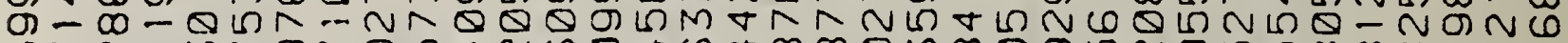
MNN NDM NMONLN A MMDNQ LMLO OJ D

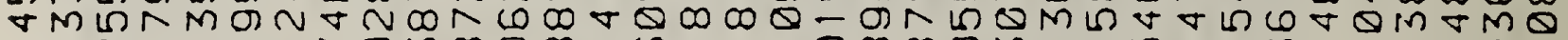

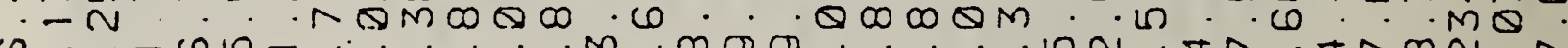

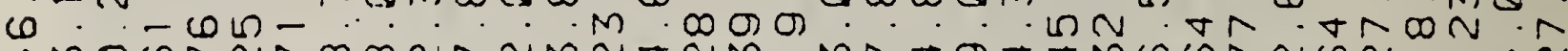
VMQ

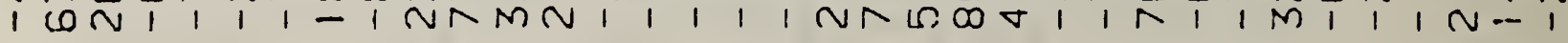

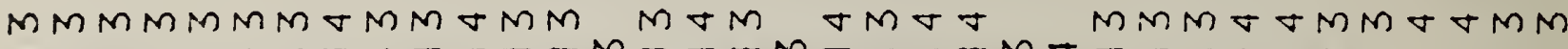

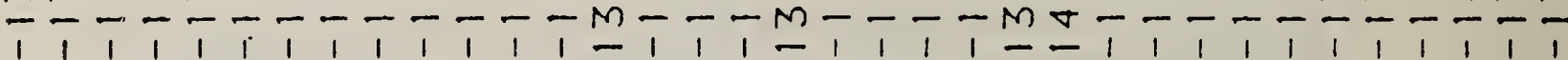

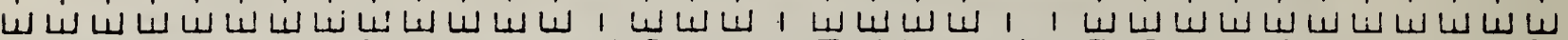

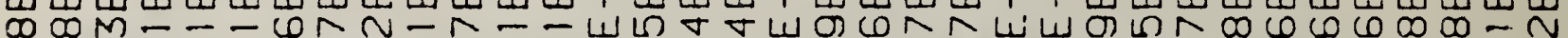

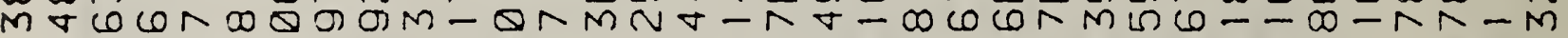
-

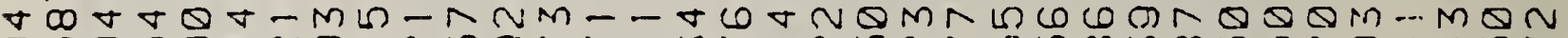
D

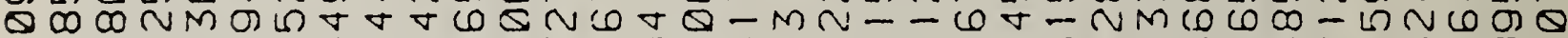
$\Lambda$ -

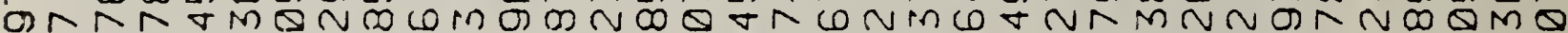

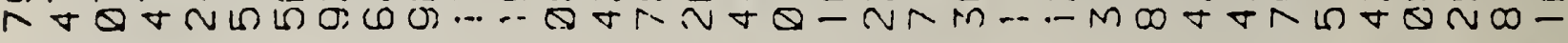
NNMNNN-MM-

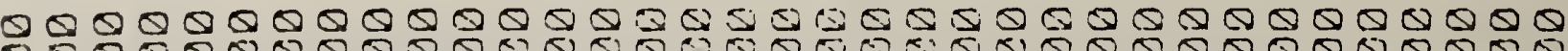

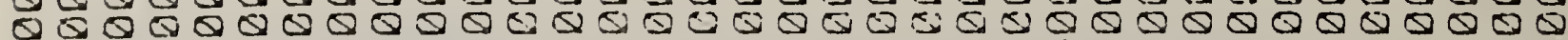
nQ *

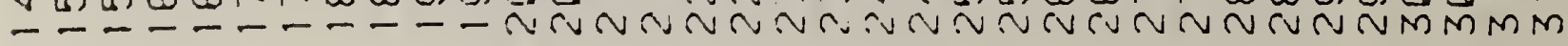




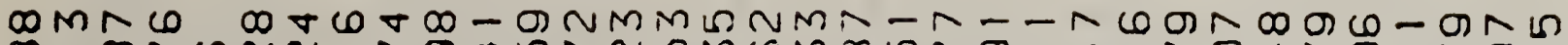

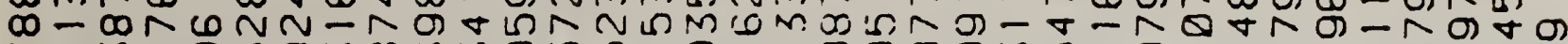

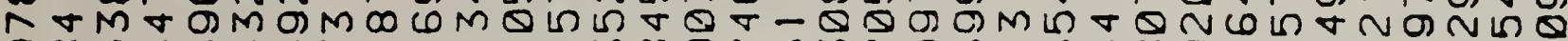
Q

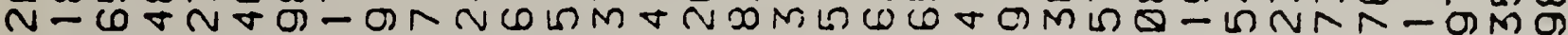
NMEM

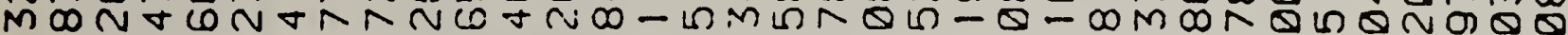
N $\forall \theta \nabla M N \nabla \infty \infty$ L

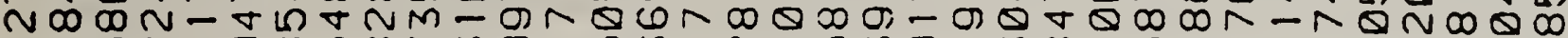

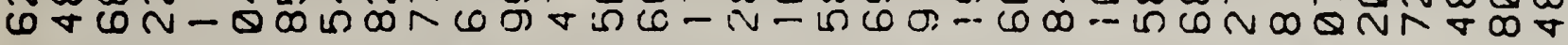

MMNN WN

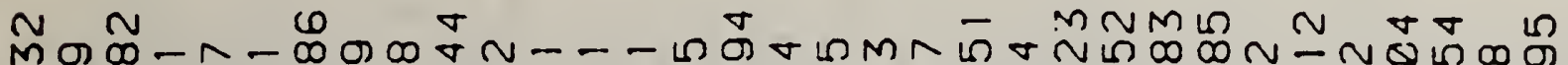

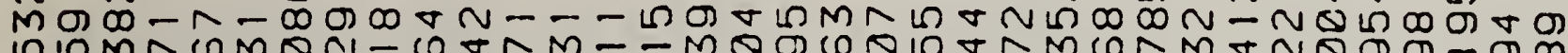
И

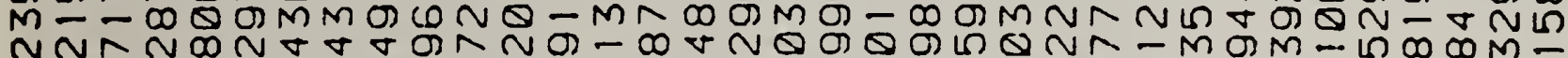
MN I D

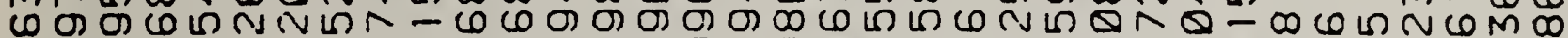
-

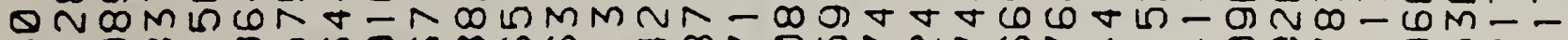

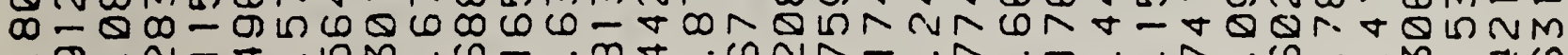

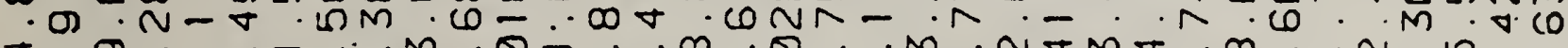

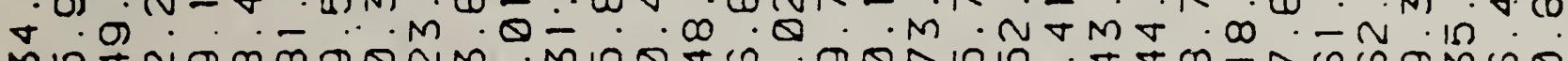
MI IMI MW

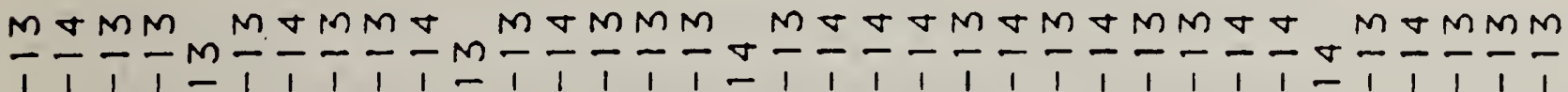

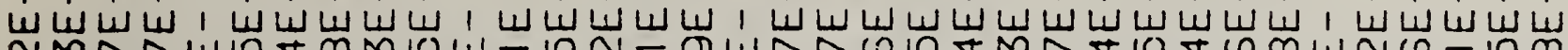
NMNNULU

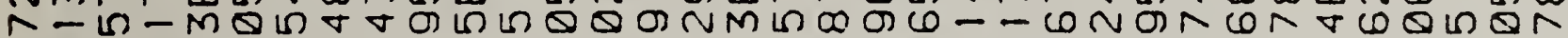

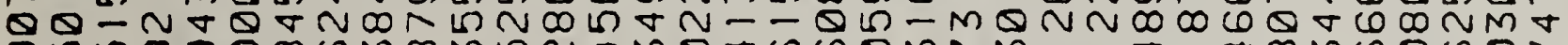
$\theta$ Q -

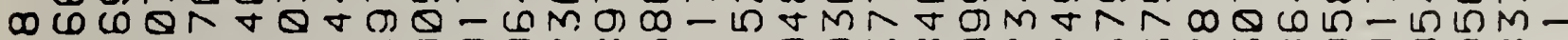

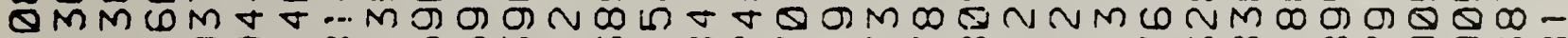
R

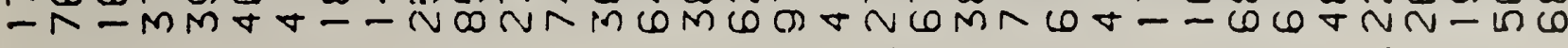

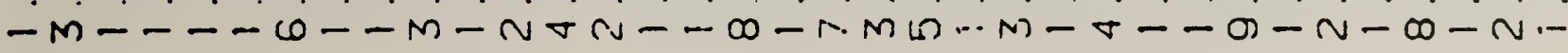

D

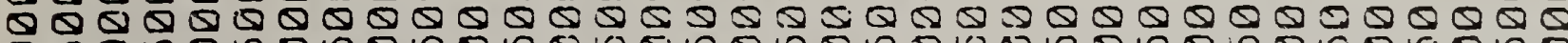

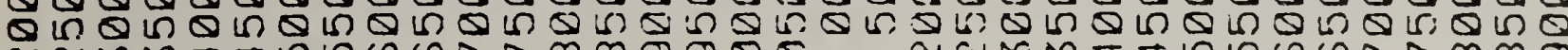
NUMM

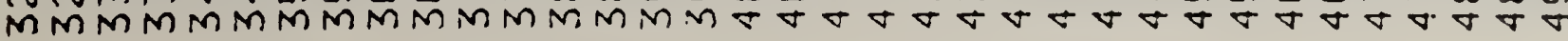


- N - GN-N $-N M N N G L M \nabla N N$ N MM

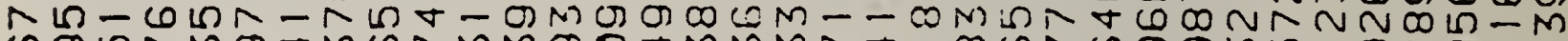
COLNMOJ M J QR NM⿻上丨 NOML-NGM O- Q - M-N

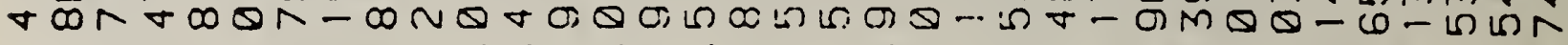
ம win MUN

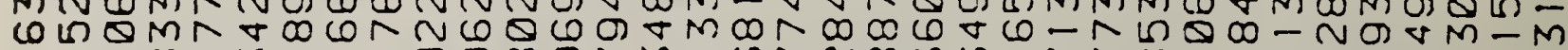

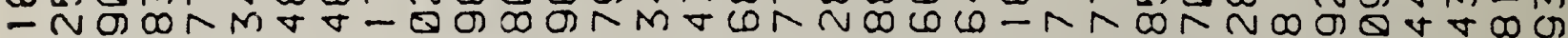
N OI IN NML

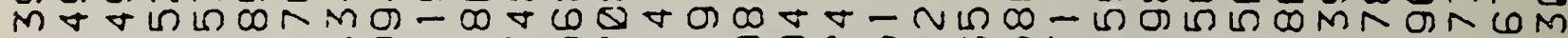
ИMNQ⿴囗⿰丿㇄口阝

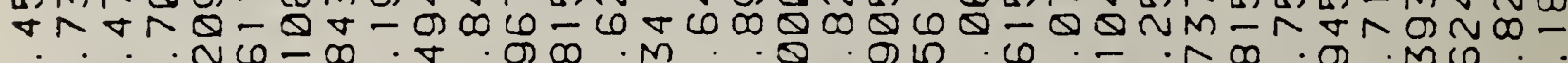

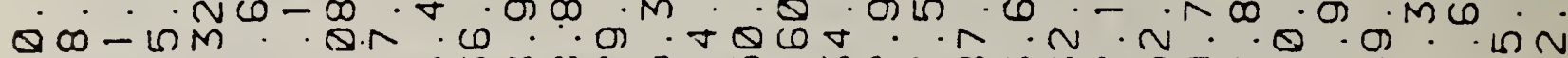
- - N- N - - -

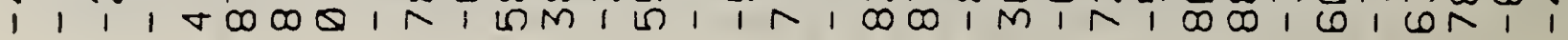

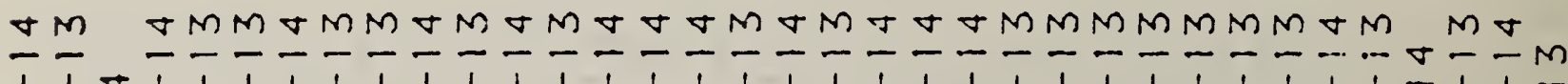

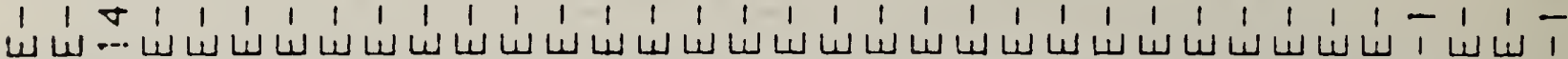
NL I MMN Q N MN

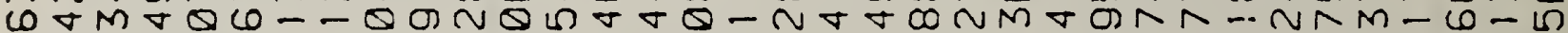
T 0 ONM- - NMWN

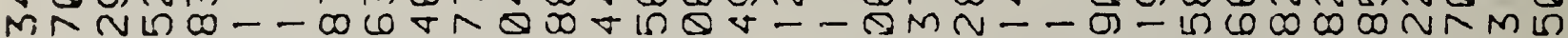

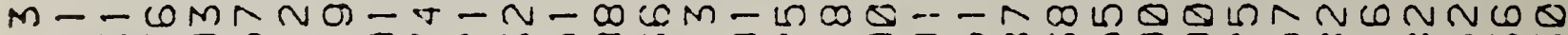

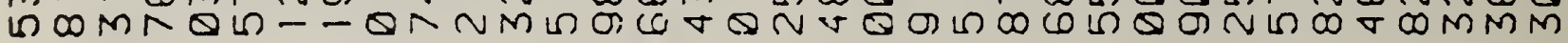

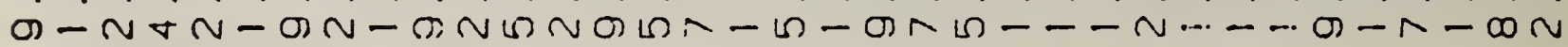

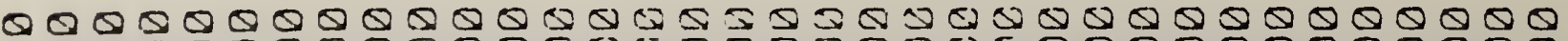

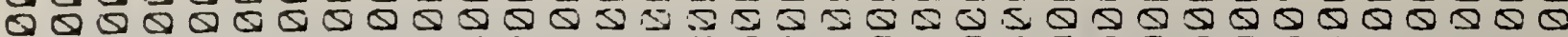
L

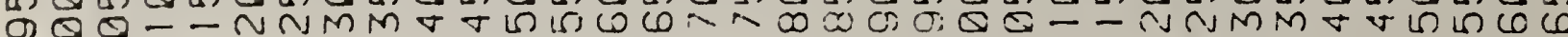
$\forall$ v 
M

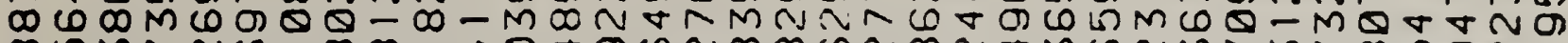

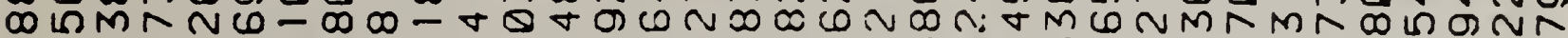

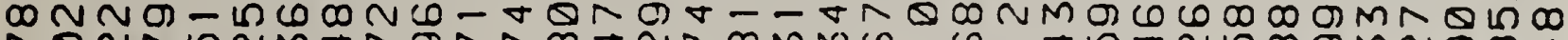
NQNR ה - -

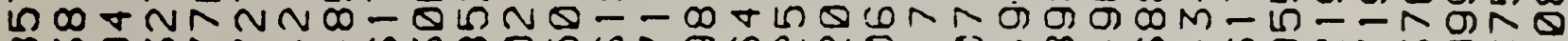
DMOMNR -

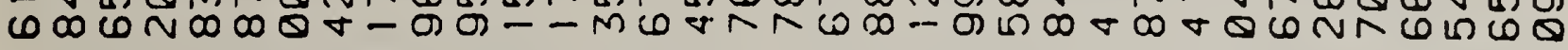
Mம त

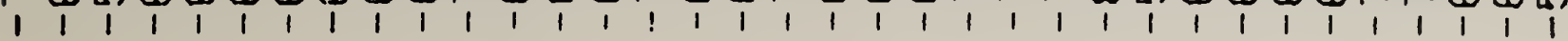

ம ம QM⿻上丨冂⿻上丨

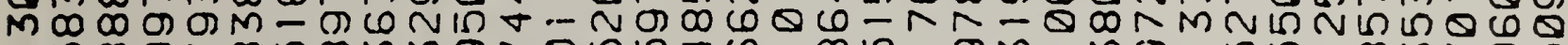
- In a

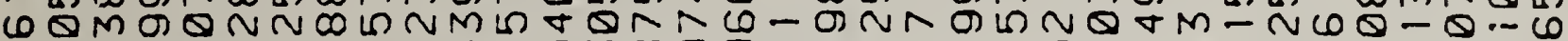
MNOJ

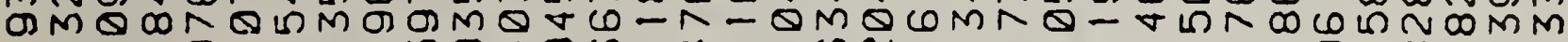

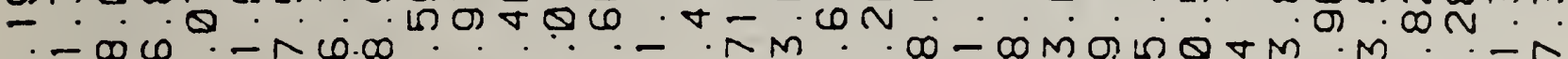

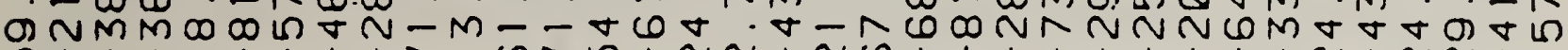

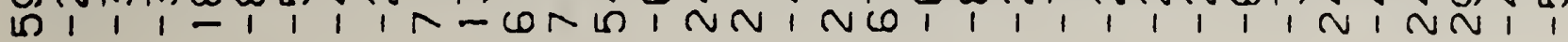

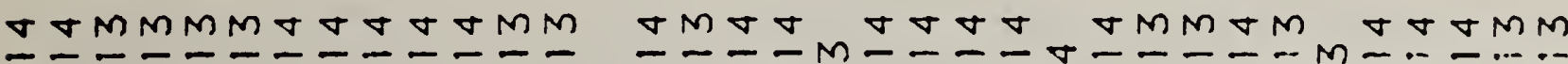

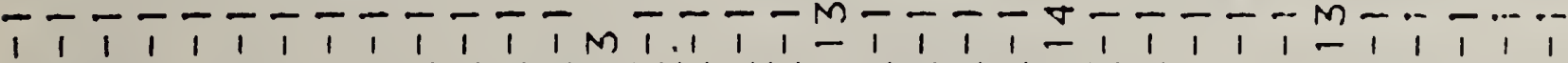

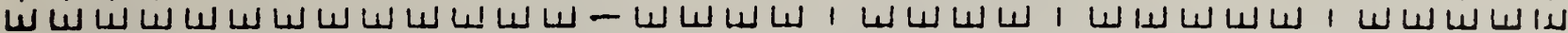
- ம ON CNMQQLEИเ L

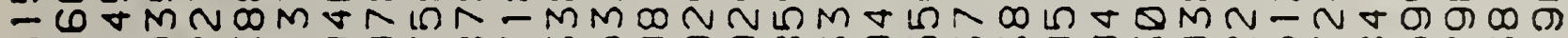
ம

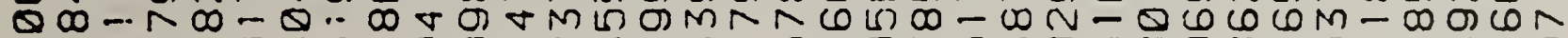
NQ

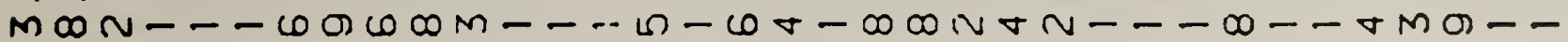

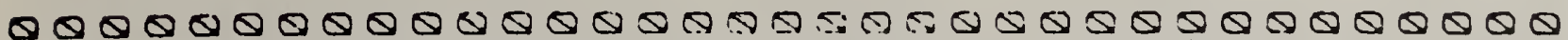

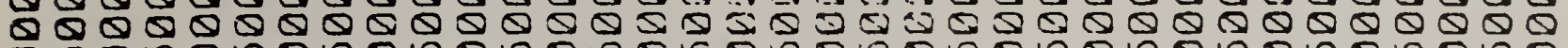
Q NR⿻ ம6 


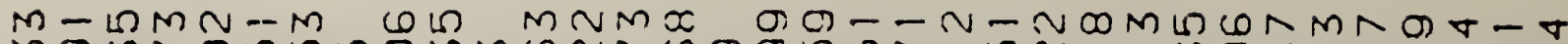
LMOCN OLLLLQ - MOINDMOMNND

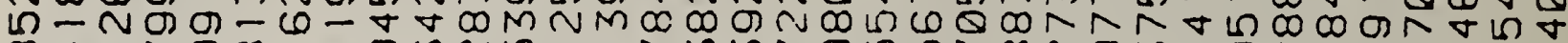

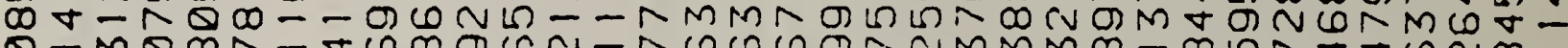
Q - MQ

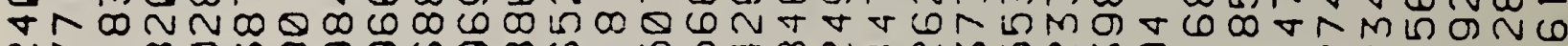
NA - $\infty$ Q

N W ब - M-MDND $N \forall \infty \omega N$ U MNDNNND - - M MNNQ⿻日禸

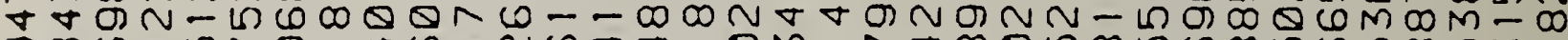
Q

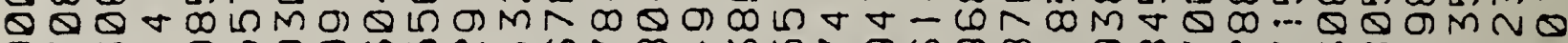
Q Q

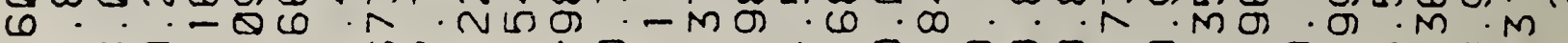

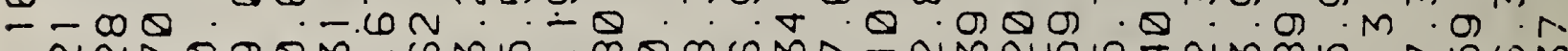
- NNRQOQMM.

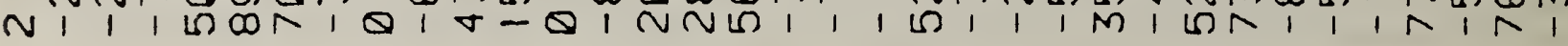

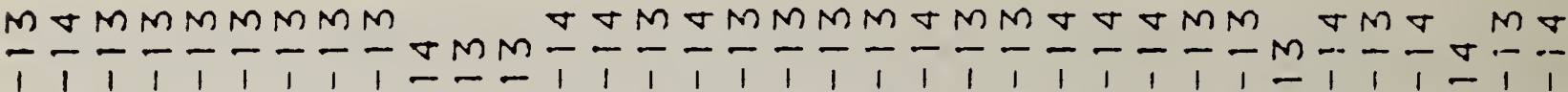

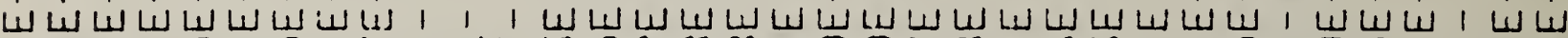

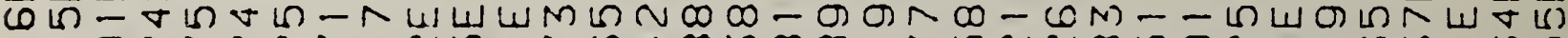
- - QNRNNR...NI - N N

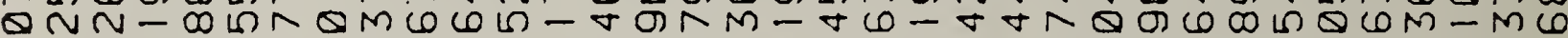
*

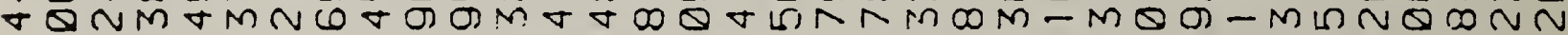
MNMRNNDM

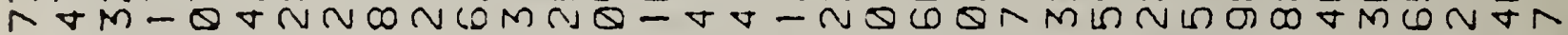

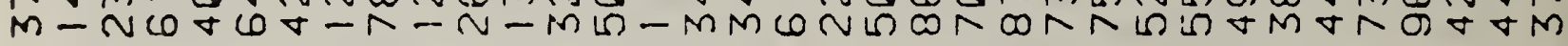

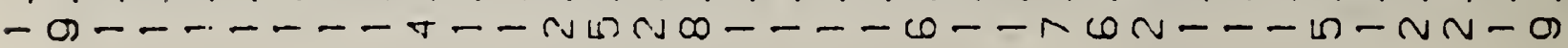

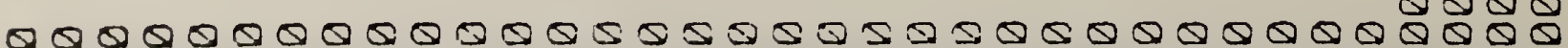
O

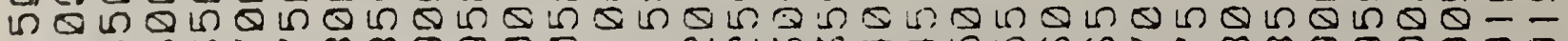
v

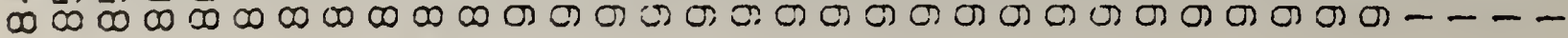




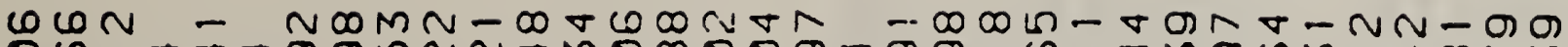
Q

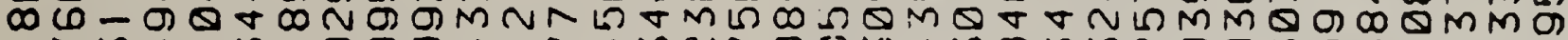

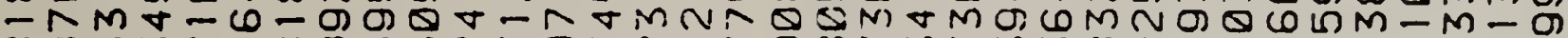

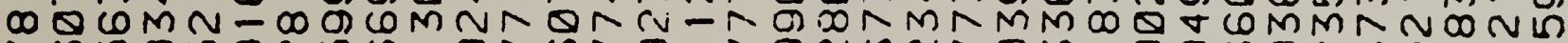
N - $\infty$ -

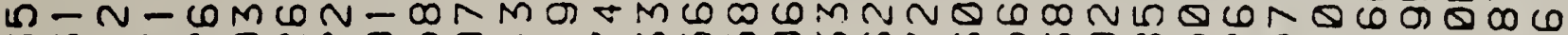
ம -NMML ம

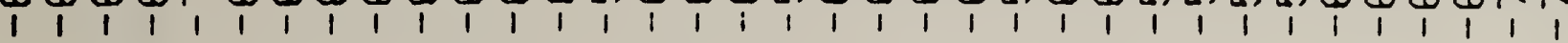

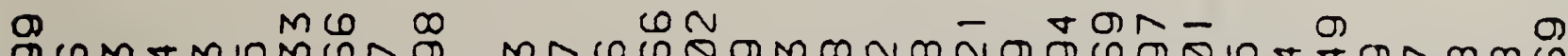
D

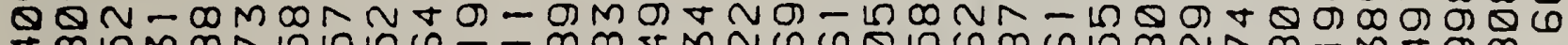
ช бM Ф

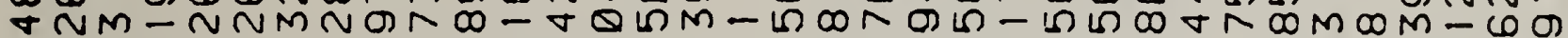

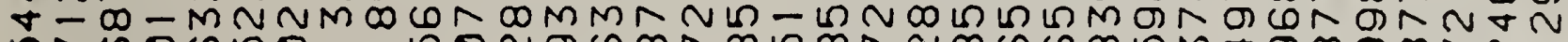
แN N N

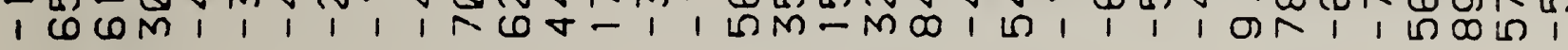

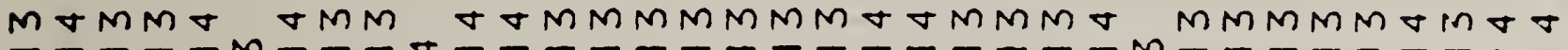
-

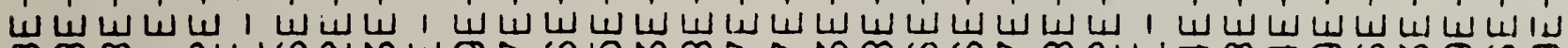

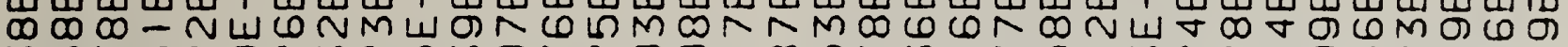

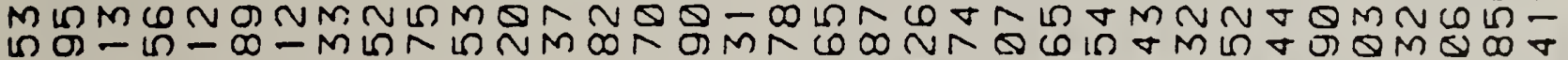

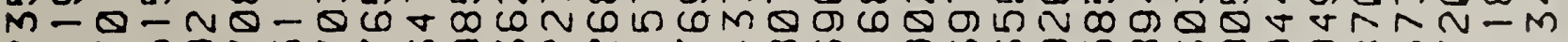
N-N I R R R

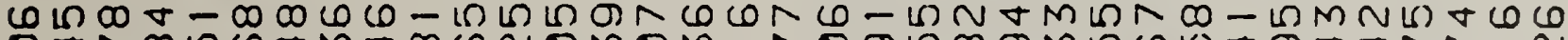

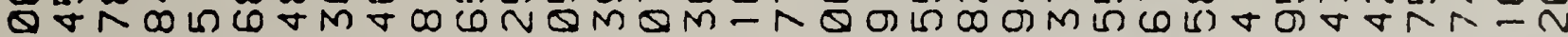
* 0 क

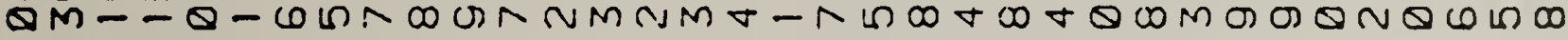

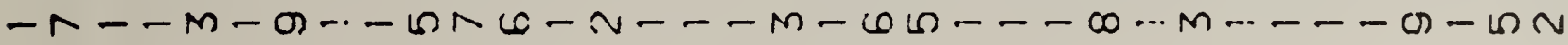

D.

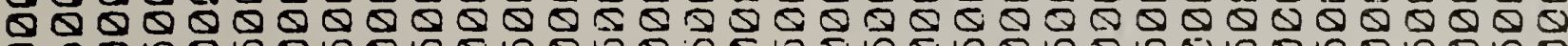
ద

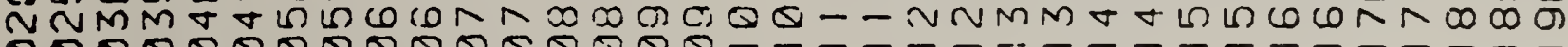

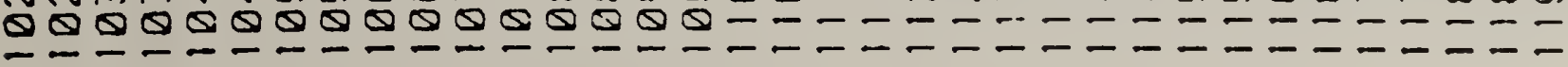




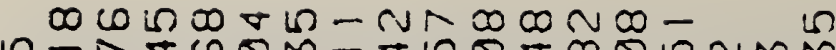
n一 $m \otimes N \sim \nabla \omega-N \infty O M \omega \infty-M-\nabla \infty$

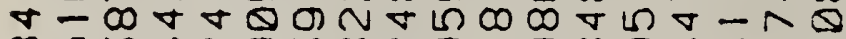
DLMMNOMDNOTQDQ No a d R N MOOONND- $O N L M O Q N \omega \nabla \omega$ Q ODO UN $\sim \infty N \infty \omega \nabla N \omega M \cap \infty-\omega N \omega \sim \omega C$

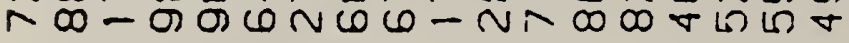
M ம $1,1,1,1,1,1,1,1111$

on

Non $\sin$ nN $N M \forall-a \forall-\omega N \forall N \omega-\omega n--1$ ПMNDMCVNONNN

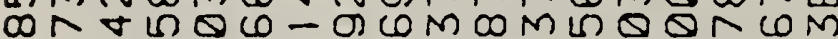
कก $\infty$ 几 $Q \infty \omega N-10 \omega-\infty L N R M Q M N$

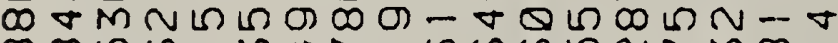
$\infty \infty \omega \omega-M \nabla N-\omega \omega \omega L N R M \infty-$ . . ब OQ - ON. - $\infty \pi \forall N O N \infty \infty N C N N N \infty M N$. 1 1 NMLINM1 1 1 1 I MM। 1-

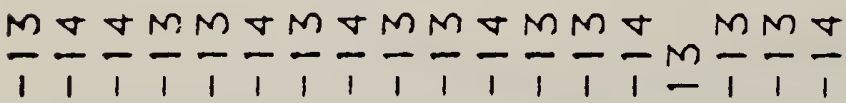

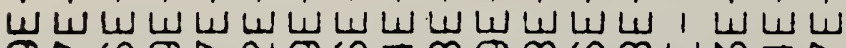
कर

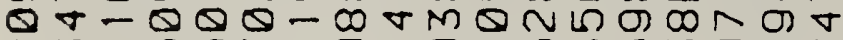
NGQ $0-\omega \omega N N \nabla N+\omega M \infty N \omega N$

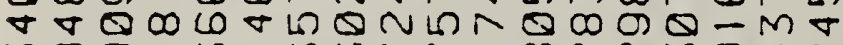
$M \otimes 0-\omega-\omega \omega N R-\infty N N M Q \nabla N$ $\infty M-\omega M \sigma V V N-\infty Q M Q N \omega \nabla N$ LNM⿻日乚MLV

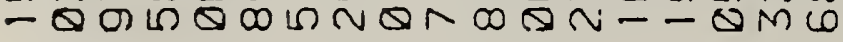

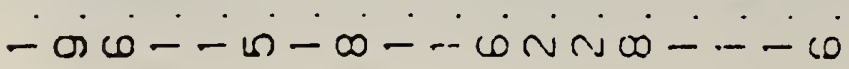

0
0.00

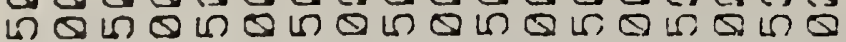

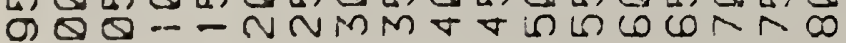
- NNRNRNNNNNNNNRNNN 
0

虜

$\sim \overline{0}$

남

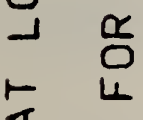

感

N

กิ

$\stackrel{N}{N}$

ก

$\therefore \sum_{\alpha}^{a}$

$\sim \times$

岁昌

$\xi \frac{z}{\Sigma}$

岌

$\Sigma \alpha$

I $\frac{\alpha}{\square}$ 

BIBLIOGRAPHIC DATA

SHEET (See instructions)

1. PUBLIICATION OR
REPORT NO.
$81-2235$

2. Performing Organ. Report No 3. Publication Date

4. TITLE AND SUBTITLE

1980 Annual Report: Technical Contributions to the Development of Incipient

Fault Detection/Location Instrumentation

5. $A U T H O R(S)$

W. E. Anderson and J. D. Ramboz

6. PERFORMING ORGANIZATION (If joint or other than NBS, see instructions)

NATIONAL BUREAU OF STANDARDS

DEPARTMENT OF COMMERCE

WASHINGTON, D.C. 20234

7 EoguacefGranc No.

AO63-EES

8. Type of Report \& Period Covered

Oct. 1, 1979-

September 30,1980

9. SPONSORING ORGANIZATION NAME AND COMPLETE ADDRESS (Street, City, Stote, ZIP)

Department of Energy

Office of Electric Energy Systems

Washington, D.C. 20461

10. SUPPLEMENTARY NOTES

Document describes a computer program; SF-185, FIPS Software Summary, is attached.

11. ABSTRACT (A 200-word or less factual summary of most significant information. If document includes a significant bibliography or literature survey, mention it here)

Technical barriers exist in the development of instrumentation to detect and locate incipient faults in underground transmission cables. Knowledge is required of the physical, chemical, and electromagnetic properties of cables which precede breakdown, of the manner in which characteristic rf signals propagate in cables, and of appropriate methods of coupling detection systems to operating transmission cables.

A measurement program has been initiated that will provide data on the rf properties of cables and on the characteristics of some forms of incipient faults. Preliminary measurements demonstrate the 1 imitations of frequency- or time-domainreflectometry techniques in the detection of incipient faults. Software is presented which permits the Fourier transform of step-like waveforms.

12. KEY WORDS (Six to twelve entries; alphabetical order: capitalize only proper names; and seporote key words by semicolons) aging; cables; dielectrics; electric insulation fault location; time-domainreflectometry; underground transmission.

13. AVAILABILITY

Unlimited

For Official Distribution. Do Not Release to NTIS

Order From Superintendent of Documents, U.S. Government Printing Office, Washington, D.C. 20402.

14. NO. OF PRINTED PAGES

130

15. Price

Order From National Technical Information Service (NTIS), Springfield, VA. 22161 


\begin{tabular}{|c|c|c|}
\hline $\begin{array}{l}\text { U.S. OEPT. OF COMM. } \\
\text { BIBLIOGRAPHIC DATA } \\
\text { SHEET (See instructions) }\end{array}$ & $\begin{array}{l}\text { 1. PUBLICATION OR } \\
\text { REPORT NO. } \\
81-2235\end{array}$ & 2. Performing Organ. Report Nof 3. Publication Date \\
\hline
\end{tabular}

4. TITLE AND SUBTITLE

1980 Annual Report: Technical Contributions to the Development of Incipient

Fault Detection/Location Instrumentation

5. $\operatorname{AUTHOR}(S)$

W. E. Anderson and J. D. Ramboz

6. PERFORMING ORGANIZATION (If joint or other than NBS, see instructions)

NATIONAL BUREAU OF STANDARDS

DEPARTMENT OF COMMERCE

WASHINGTON, D.C. 20234

9. SPONSORING ORGANIZATION NAME ANO COMPLETE ADDRESS (Street. City. Stute, ZIP)

Department of Energy

Office of Electric Energy Systems

Washington, D.C. 20461

10. SUPPLEMENTARY NOTES

$\square$ Document describes a computer program; SF-185, FIPS Software Summary, is attached.

11. ABSTRACT (A 200-word or less foctua) summary of most significant information. If document includes o significant bibliography or literature survey. mention it here)

Technical barriers exist in the development of instrumentation to detect and locate incipient faults in underground transmission cables. Knowledge is required of the physical, chemical, and electromagnetic properties of cables which precede breakdown, of the manner in which characteristic rf signals propagate in cables, and of appropriate methods of coupling detection systems to operating transmission cables. A measurement program has been initiated that will provide data on the rf properties of cables and on the characteristics of some forms of incipient faults. Preliminary measurements demonstrate the limitations of frequency- or time-domainreflectometry techniques in the detection of incipient faults. Software is presented which permits the Fourier transform of step-like waveforms.

12. KEY WORDS (Six to twelve entries; alphabetical order: copitalize only proper names; and separote key words by semicolons) aging; cables; dielectrics; electric insulation fault location; time-domainreflectometry; underground transmission:

13. AVAILABILITY

Unlimited

For Official Distribution. Do Not Release to NTIS

Order From Superintendent of Documents, U.S. Government Printing Office, Washington, D.C. 20402.

14. NO. OF

PRINTED PAGES

130

- Order From National Technical Information Service (NTIS), Springfield, VA. 22161

15. Price

$\$ 12.50$ 
